\title{
PREVENÇÃo DA MORTALIDAdE INFANTIL \\ NO PARANÁ: \\ AVALIAÇÃO E REPRESENTAÇÃO SOCIAL
}

\section{Márcia Helena Freire Orlandi}

Tese apresentada ao Programa de PósGraduação em Saúde Pública da Faculdade de Saúde Pública da Universidade de São Paulo para obtenção do título de Doutor em Saúde Pública.

Área de Concentração: Epidemiologia

Orientador: Prof. Dr. Ruy Laurenti

São Paulo

2007

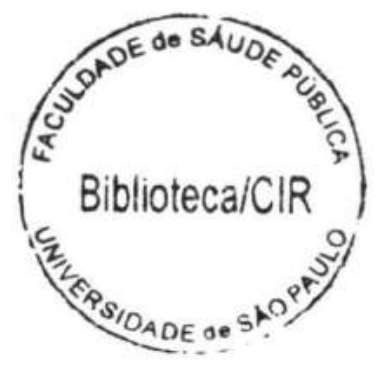


É expressamente proibida a comercialização deste documento tanto na sua forma impressa como eletrônica. Sua reprodução total ou parcial é permitida exclusivamente para fins acadêmicos e científicos, desde que na reprodução figure a identificação do autor, título, instituição e ano da tese.

$$
49030 / 2007 \text { doc }
$$


Dedico esta produção aos meus jovens filhos $e$ amigos Filipe, Ezequiel e Larissa Helena e d minha mãe e amiga Wilma. Pessoas que me motivaram, apoiaram e entenderam os momentos de ausência. Obrigada! 


\section{Agradeço a...}

\section{Agradecimentos}

Deus soberano, onipotente e onipresente por seu imenso amor para comigo.

Ao Prof ${ }^{\circ}$ Dr Ruy Laurenti por ter me oportunizado sua orientação, apoio e conhecimento.

Ao Prof ${ }^{\circ}$ Fernando Lefèvre e Prof ${ }^{a}$ Ana Maria Cavacalcanti Lefèvre pelo incentivo, acolhimento no IPDSC e profícua discussão sobre o Discurso do Sujeito Coletivo.

À Prof ${ }^{a}$ Márcia Furquim de Almeida pela colaboração bibliográfica e sugestões.

À Prof ${ }^{a}$ Tâmara Iwanow Cianciarullo por ter aceitado participar da banca e pela apreciação do trabalho.

À Sonio Isoyama Venâncio pelas considerações e compartilhamento do trabalho preventivo do óbito infantil.

À coordenação estadual dos Comitês de Prevenção da Mortalidade Infantil do Paraná pelos dados e informações fornecidas.

À amiga Luzia Marta Bellini por ter me permitido conhecer sua generosidade e conhecimento. Também pela revisão textual e incentivo para a conclusc̃o da tese.

Aos colegas e amigos Marieta, Herbert, Marinaldo agradecimento especial pelo carinho, contribuições e credibilidade.

À ex-aluna Cristina Yurie Sekine pelo apoio e participação na elaboração do trabalho.

Aos colegas do Departamento de Enfermagem da UEM por terem propiciado meu afastamento para a pós-graduação.

Aos professores e técnicos administrativos da FSP/USP pelo apoio, ao CBCD em especial à Mirian.

À CAPES pela bolsa de estudo concedida.

A todos os sujeitos sociais $e$ instituições que me receberam, com atenção $e$ respeito, pela valiosa contribuição com a pesquisa.

Aos meus queridos tios Reinaldo, Maria José e Ruth que me acolheram em suas casas para 0 curso da pós-graduação.

A todos que estiveram nos bastidores, mesmo que distantes dessa empreitada orando $e$ incentivando esta etapa de minha vida.

MEUS AGRADECIMENTOS DE CORAÇÃO À TODOS VOCÊS! 


\section{RESUMO}

ORLANDI, M.H.F. Prevenção da mortalidade infantil no Paraná: avaliação e representação social. 2007. 250p. Tese (Doutorado em Saúde Pública) - Faculdade de Saúde Pública, Universidade de São Paulo, São Paulo, 2007.

Introdução - Pesquisou-se o contexto da Prevenção do Óbito Infantil para avaliação do impacto do trabalho de vigilância e investigação dos Comitês e sua Representação Social no estado do Paraná. O óbito infantil é considerado como um evento sentinela das condições de saúde da população e da qualidade da assistência, base para o estabelecimento e continuidade da vigilância com proposição de ações para reduzílo. Objetivos - Avaliar o impacto do trabalho preventivo do Óbito Infantil desenvolvido no estado do Paraná e sua Representação Social para os profissionais da saúde. Método - Adotou-se a investigação avaliativa por triangulação de métodos qualiquantitativos devido à complexidade e dialética das informações do óbito infantil e de sua prevenção. $O$ trabalho quantitativo foi realizado com os dados secundários de óbitos infantis de mães residentes no Paraná, para o período de 1997 a 2005 e foram extraídos do Sistema de Informação de Mortalidade e Sistema de Nascido Vivo do Ministério da Saúde. O período foi dividido em três Triênios. Foi verificado o perfil das Taxas de Mortalidade Infantil do Paraná segundo as Regionais de Saúde do Estado. As variáveis trabalhadas em número absoluto e proporcional foram: sexo, idade, duração da gestação, peso ao nascer, idade e escolaridade da mãe. Do Sistema de Informação de Mortalidade Infantil do Paraná, foram trabalhadas as variáveis: sexo, idade, evitabilidade, qualidade dos dados da Ficha de Investigação, determinante causal, medidas de prevenção e intervenção na mortalidade infantil. Foi utilizada investigação a documentos: sobre implantação, operacionalização dos Comitês de Prevenção da Mortalidade Infantil e Manual dos Comitês de Prevenção do óbito Infantil e Fetal do Ministério da Saúde. Para a representação social optou-se pelo Método do Discurso do Sujeito Coletivo. Foram entrevistados 80 sujeitos sociais envolvidos em instâncias de gestão ou da assistência à criança. As entrevistas foram gravadas e transcritas, e as respostas trabalhadas no software Qualiquantisoft ${ }^{\circledR}$. Resultados - A Taxa de Mortalidade Infantil decresceu para todo o estado do Paraná no período do estudo. Esse decréscimo ocorreu de maneira distinta nas 22 Regionais de Saúde do Estado. Os óbitos infantis aconteceram com predomínio em crianças do sexo masculino e com até 06 dias completos de vida. Houve melhoria das informações registradas nas Declarações de Óbitos em relação a todas as variáveis estudadas, percebida pela grande redução das categorias ignoradas. Houve variação do percentual de investigação entre o $2^{\circ}$ Triênio com $59,03 \%$ dos óbitos infantis ocorridos e no $3^{\circ}$ Triênio ocorreu investigação de $77,21 \%$ dos óbitos infantis ocorridos no Paraná, com diferenças entre as Regionais de Saúde. A proporção de óbitos considerados evitáveis pela investigação e análise, no $2^{\circ}$ Triênio foi de $73,70 \%$ e, no $3^{\circ}$ Triênio, de $71,71 \%$. A qualidade das informações contidas nas Fichas Confidenciais de Investigação foi considerada satisfatória. Das categorias de determinantes causais apontadas na investigação quase $50 \%$ foram atribuídas a uma das áreas de assistência à saúde (médica, hospitalar ou ambulatorial); em torno de 19\% dos determinantes foram de 
responsabilidade social; e a responsabilidade da família mostrou-se ascendente entre os Triênios (18,81\% e $20,13 \%)$. As medidas de atenção ambulatorial foram as mais freqüentes nos dois Triênios $(31,46 \%$ e $33,31 \%)$, com ênfase ao acesso e à qualidade do pré-natal. Na seqüência, apareceram as medidas de atenção hospitalar e as medidas de suporte social, com cerca de $25 \%$ nos Triênios. Os Discursos construídos com a categorização das respostas a três questões revelaram a representação social de valorização e preocupação com o trabalho preventivo do óbito infantil e com a operacionalização de Programas governamentais e locorregionais. As expressões de dificuldades no trabalho preventivo e sugestões para minimizá-las foram mais compartilhadas em relação à gerência, política e área financeira. Detectou-se que o trabalho dos Comitês no estado do Paraná é pouco conhecido pelos profissionais dos serviços, no entanto expressam perceber seu impacto operacional e alguma melhoria na assistência. Os profissionais que trabalham com os Comitês enfatizam a necessidade de redirecionamento estrutural e operacional. Conclusões - Esta investigação subsidia um processo de avaliação dos Comitês e contribui para o conhecimento da história da implantação e das atividades dos Comitês de Prevenção da Mortalidade Infantil no estado do Paraná e no Brasil, proporcionando, desse modo, abertura para maior visibilidade, vigilância e redução dos óbitos infantis.

Descritores: mortalidade infantil; avaliação de programas e projetos de saúde; avaliação de serviços de saúde; políticas públicas; prevenção primária. 


\begin{abstract}
ORLANDI, M.H.F. Prevention of child mortality in Paraná, Brazil: evaluation and social representation. 2007. 250 pages. Doctoral Thesis in Public Health Faculty of Public Health, Universidade de São Paulo, São Paulo SP Brazil, 2007.
\end{abstract}

Introduction - Report on child mortality prevention is provided to evaluate impact of monitoring and investigation undertaken by Committees and their social representation in the state of Paraná, Brazil. Child mortality is a warning event on the health conditions in a given population and on health assistance quality. They actually foreground the establishment and continuation of monitoring so that child mortality may be in constant decrease. Aims - Current research evaluates the impact of child mortality prevention policy in the state of Paraná and its social representation for the benefit of health professionals. Method - An investigatory evaluation has been undertaken by qualitative and quantitative methods, owing to the complexity and the dialectics of information on child mortality and its prevention. Quantitative research consisted of secondary data on child mortality which occurred to mothers living in Paraná from 1997 to 2005, divided into three three-year periods, which was obtained from the Information System on Mortality and from the Liveborn Babies System of the Brazilian Health Ministry. Child Mortality rates of the state of Paraná, hailing from the Regional Health Offices in Paraná, were also consulted. Sex, age, pregnancy duration, weight at birth, mother's age and schooling were the variables taken absolutely and proportionally. Sex, age, avoidance, quality of data in the Investigation File, determining cause, prevention measures and intervention in child mortality were variables taken from the Information System on Child Mortality in Paraná. Documents on establishment and on the policy of the Committees for the prevention of Child Mortality and the Handbook for Committees for the prevention of Child and Fetal Mortality published by the Health Ministry were analyzed. The Discourse Method of the Collective Subject was selected for social representation. Eighty subjects involved in the administration and child assistance were interviewed. Interviews were recorded, transcribed and processed by

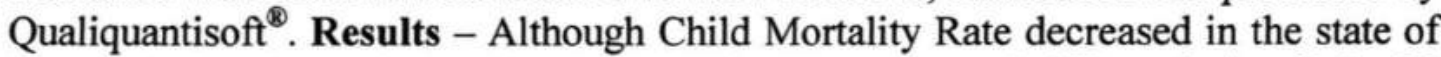
Paraná during the period under analysis, decrease occurred differently in all the 22 Health Sectors in Paraná. Child mortality was predominant in males, up to 6 full days of life. Improvement in information on death declarations may be registered in all variables under analysis. In fact, a great decrease in alleged unknown causes has be reported. Percentage investigation varied between the second three-year period, with $59.03 \%$ child mortality and the third three-year period, with $77.21 \%$ child mortality in the state of Paraná, with differences among the Regional Health Sectors. Percentages of avoidable death reports by investigation and analysis were $73.70 \%$ and $71.71 \%$ respectively for the $2^{\text {nd }}$ and $3^{\text {rd }}$ three-year period. Quality of information in Classified Investigation Files was satisfactory. Almost $50 \%$ of determining causes mentioned in the investigation accounted for one of the health assistance areas, either medical, hospital or clinical. Whereas approximately $19 \%$ of the above causes were accountable to the social sector, families' responsibility was on the increase between 
the three-year periods $(18.81 \%$ and $20.13 \%)$. Clinic procedures were the most frequent during two three-year periods, reaching $31.46 \%$ and $33.31 \%$, with emphasis on access and quality of prenatal procedures. Hospital and social support procedures came next with approximately $25 \%$ during the three-year periods. Constructed discourses with answers to three issues showed social representation comprising value and concern in the context of preventive work on child mortality and the efficiency of governmental, regional and local programs. Difficulties in preventive assignments and recommendations to lessen difficulties within the administration, political and financial sectors were specially mentioned. The work of the Committees in the state of Paraná is only slightly acknowledged by professionals, even though they perceive their operational impacts and slight improvement in assistance. Professional assignment with the Committees pinpoints the need for structural and operational re-directions. Conclusions - Current investigation may subsidize the Committees' evaluation process and contribute towards the history of the establishment and the activities of the Committees for the Prevention of Child Mortality in the state of Parana and in Brazil. It may also be a contribution towards higher transparency, monitoring and reduction of child mortality.

Key words: child mortality; evaluation of health programs and projects; evaluation of health services; public policies; primary prevention. 


\section{ÍNDICE}

\section{INTRODUÇão}

1.1. A OPÇÃo PELO TEMA

1.2. CoNTEXTUALIZAÇão Da MoRTALIDAde INFANTIL 22

1.3. O Sistema Único de SAÚde \& Promoção da SAÚde \& 35 Políticas Públicas

1.4. A AVALIAÇÃo: um caminho para a melhoria das ações em saúde

1.5. O EsTADO DO PARANÁ

1.5.1. CARACTERÍSTICAS Geográficas E PopUlacionais

52

1.5.2. Divisão AdMINISTRATIVA dA SAÚdE

\section{OS OBJETIVos}

2.1. Objetivo Geral

\section{A Metodologia}

3.1. A FUNDAMENTAÇÃo TEÓRICA ACERCA dO MÉTOdO

3.1.1. ABORDAGEM QUANTITATIVA

\subsubsection{ABORDAGEM QUALITATIVA}

3.1.2.1. O DiscurSo do SUJeITo Coletivo

3.2.1. A Mortalidade Infantil No Paraná: dados secundários

3.2.2. OS ÓBITOS INFANTIS INVESTIGADOS 
3.2.3.1. DEFINIÇÃO DA POPULAÇO PARA ENTREVISTA

3.2.3.2. ELEIÇÃO DOS ATORES SOCIAIS 96

3.2.3.3. INSTRUMENTO DE PESQUISA $\quad 99$

\section{Os Resultados e Discussão}

\subsection{A MortaldDade INFantil no Paraná}

4.1.1. OS ÓBITOS INFANTIS OCORRIDOS: contextualização

4.1.2. PIONEIRISMO NA INVESTIGAÇÃo DOS ÓbITOS INFANTIS: Os Comitês de Prevenção da Mortalidade Infantil

4.1.3. OS ÓBITOS INFANTIS INVESTIGADOS

4.2. AS RePRESENTAÇÕES SoCIAIS sobre a Prevenção da Mortalidade Infantil e sobre os Comitês de Prevenção da Mortalidade Infantil do Estado do Paraná.

\subsubsection{CARACTERIZAÇÃO DOS ATORES SOCIAIS}

4.2.3. ConHecimentos dos Programas, EstratégIas E AÇõES DE PREVENÇÃo DA MORTALIDADE INFANTIL

4.2.4. DIFICULDADES ENCONTRADAS PARA A PREVENÇÃO DA MORTALIDADE INFANTIL \& SUGESTÕES PARA MINIMIZAR AS DIFICULDADES

4.2.5. DSC E A PREVENÇÃo DA MORTALIDADE INFANTIL NO PARANÁ: considerações

VI. ConsideraÇões FinaIs 
$\begin{array}{lr}\text { ANEXOS } & \text { i } \\ \text { Anexo 1 - Ficha Confidencial de Investigação de Óbito Infantil } & \\ \text { Neonatal } & \text { ii } \\ \text { Anexo 2 - Ficha Confidencial de Investigação de Óbito Infantil } & \text { iii } \\ \text { Tardio } & \text { iv } \\ \text { Anexo 3 - Ficha de Análise Final do Óbito } & \mathbf{v} \\ \text { Anexo 4 - Critérios de Redutibilidade para o Óbito Infantil } & \\ \text { Anexo 5 - Medidas de Prevenção e Intervenção na Mortalidade } & \text { vi } \\ \text { Infantil } & \text { vii } \\ \text { Anexo 6-Instrumento de Pesquisa } & \text { viii } \\ \text { Anexo 7-Aprovação da pesquisa pelo Comitê de Ética } & \text { Anexo 8-Regionais de Saúde do estado do Paraná }\end{array}$

\section{APÊNDICES}

Apêndice 1 - Distribuição da População $\left(\mathrm{n}^{\circ}\right.$ ) do Brasil e Regiões, 1997 a 2005.

Apêndice 2 - Distribuição da População $\left(\mathrm{n}^{\circ}\right)$ menor de um ano do Brasil e Regiões, 1997 a 2005.

Apêndice 3 - Distribuição dos óbitos infantis ( ${ }^{\circ} \mathrm{e} \%$ ) com idade ignorada, Brasil, Regiões e estado do Paraná, 1997 a 2004.

Apêndice 4 - Taxa de Mortalidade Infantil (\% NV) segundo

Regional de Saúde e Triênios, estado do Paraná, 1997 a 2005.

Ap-5

Apêndice 5 - Distribuição dos Nascidos Vivos ( $\mathrm{n}^{\circ}$ ) segundo Regional de Saúde e ano de ocorrência, estado do Paraná, 1997 a 2005. 


\section{LISTA DE GRÁFICOS}

Gráfico 1: Taxa de Mortalidade Infantil (\%o NV) scgundo continentes e países do mundo, 1990 - 2004.

Gráfico 2: Taxa de Mortalidade Infantil (\% NV), Brasil e Regiões, Brasil, 1997 a 2004.

Gráfico 3: Taxa de Mortalidade Infantil (\%o NV) segundo Regional de Saúde e Triênios, Paraná, 1997 a 2005.

Gráfico 4: Distribuição das categorizações construídas (A2 - F2) em relação à pergunta 2 (Fale sobre as dificuldades de implantaçäo do Comite e/ou de execução do trabalho preventivo do óbito infantil nesta regıonal / municipio / serviço) segundo a força de compartilhamento das idéias (\%) apresentadas nos discursos coletivos, Paraná, 2007.

Gráfico 5: Distribuição das categorizações construídas (A3 - F3) em relação à pergunta 3 (Que sugestões você faz para que as dificuldades que mencionou sejam resolvidas ou minimizadas) segundo a força de compartilhamento das idéias (\%) apresentadas nos discursos coletivos, Paraná, 2007. 


\section{LISTA DE TABELAS}

Tabela 1: Distribuição ( $n^{\circ}$ e \%) da população do Brasil segundo Regiőes e trimestres, Brasil, 1997 a 2005.

Tabela 2: Distribuição ( $n^{\circ}$ e \%) da população de menor de um ano do Brasil segundo Regiões e trimestres, Brasil, 1997 a 2005.

Tabela 3: Macrorregionais do Estado do Paraná segundo Taxa Média de Mortalidade Infantil (\%o NV) e sua classificação na pesquisa (maior, médio e menor), 1997 - 2004.

Tabela 4: Distribuição (frequêencia e \%) dos óbitos infantis nos Triênios segundo sexo e faixa etária, estado do Paraná, 1997 a 2005.

Tabela 5: Distribuição (freqüência e \%) dos óbitos infantis nos 109 Triênios segundo duração da gestação e peso ao nascer, estado do Paraná, 1997 a 2005.

Tabela 6: Caracterização das mães das crianças menores de um ano que foram a óbito nos Triênios segundo idade e escolaridade, estado do Paraná, 1997 a 2005.

Tabela 7: Distribuição (frequêencia e \%) dos óbitos investigados nos Triênios segundo Regional de Saúde e proporção investigada (em relação ao SIM), estado do Paraná, 2000 a 2005.

Tabela 8: Caracterização do óbito infantil investigado (frequeência e

\%) nos Triênios segundo sexo e faixa etária, estado do Paraná, 2000 a 2005.

Tabela 9: Cáracterização do óbito infantil investigado (frequêencia e

\%) nos Triênios, segundo qualidade das informações da Ficha Confidencial, estado do Paraná, 2000 a 2005.

Tabela 10: Caracterização do óbito infantil investigado (frequêencia e

\%) nos Triênios segundo evitabilidade e determinantes causais* do óbito, estado do Paraná, 2000 a 2005.

Tabela 11: Caracterização do óbito infantil investigado (frequência e \%) nos Triênios segundo as medidas de prevenção $e$ intervenção na mortalidade infantil, estado do Paraná, 2000 a 2005. 
Tabela 12: Caracterização do óbito infantil investigado (frequêencia e 151 \%) nos Triênios segundo medidas de atenção ambulatorial, estado do Paraná, 2000 a 2005.

Tabela 13: Caracterização do óbito infantil investigado (freqüência e \%) nos Triênios segundo medidas de atenção hospitalar, estado do Paraná, 2000 a 2005.

Tabela 14: Caracterização do óbito infantil investigado (freqüência e $\%)$ nos Triênios segundo as medidas de prevenção direcionadas às gestantes, estado do Paraná, 2000 a 2005.

Tabela 15: Distribuição ( ${ }^{\circ} \mathrm{e} \%$ ) dos leitos de Unidades Intensivas e de Cuidados Intermediários Pediátricos (Neonatal e Infantil), segundo habilitação pelo SUS, estado do Paraná, 2007.

Tabela 16: Caracterização do óbito infantil investigado (freqüência e \%) nos Triênios segundo medidas de suporte social, estado do Paraná, 2000 a 2005.

Tabela 17: Distribuição dos entrevistados (freqüência e \%) de acordo com a categorização e identificação no Qualiquantisoft, Paraná, 2007.

Tabela 18: Distribuição dos entrevistados (freqüência e \%) segundo sexo, faixa etária e grau de escolaridade, Paraná, 2007.

Tabela 19: Distribuição das categorizações construídas (A1 - F1) das 165 respostas à questão 1 (Quais ações, estratégias ou programas tem sido desenvolvidas para se prevenir o óbito infantil nesta regional / municipio / serviço?) segundo freqüência $\left(n^{\circ}\right)$ e força de compartilhamento das idéias (\%) apresentadas nos discursos individuais e coletivo, Paraná, 2007.

Tabela 20: Distribuição das categorizações construídas (A2 - F2) em relação à pergunta 2 (Fale sobre as dificuldades de implantação do Comitê e/ou de execução do trabalho preventivo do óbito infantil nesta regional / municipio / serviço) segundo frequeência $\left(\mathrm{n}^{\circ}\right)$ e força de compartilhamento das idéias (\%) apresentadas nos discursos individuais e coletivo, Paraná, 2007.

Tabela 21: Distribuição das categorizações construídas (A3 - F3) em relação à pergunta 3 (Que sugestões você faz para que as dificuldades que mencionou sejam resolvidas ou minimizadas) segundo freqüência $\left(\mathrm{n}^{\circ}\right)$ e força de compartilhamento das idéias (\%) apresentadas nos discursos individuais e coletivo, Paraná, 2007. 


\section{LISTA DE QUADROS}

Quadro 1: Oposições complementares entre a pesquisa acadêmica de avaliação e a investigação avaliativa.

Quadro 2: Grupos de Critérios de Redutibilidade do Óbito Infantil, Comitês de Prevenção da Mortalidade Infantil, SESA, Paraná, 2007.

Quadro 3: Grupos de Medidas de Prevenção e Intervenção da Mortalidade Infantil, Comitês de Prevenção da Mortalidade Infantil, SESA, Paraná, 2007.

Quadro 4: Macrorregionais e Regionais de Saúde segundo municípios-sede, número de municípios adstritos, população total e menor de um ano, Paraná, 2007.

Quadro 5: Regionais de Saúde do Estado do Paraná segundo Taxa de Mortalidade Infantil (\%o NV) no $1^{\circ}$ Triênio (1997/99) e $3^{\circ}$ Triênio (2002/05) e percentual de redução da mortalidade infantil no período e ano a ano, Paraná, 1997 - 2005.

Quadro 6: Atribuições do Comitê de Prevenção do Óbito Infantil e Fetal segundo ações que as compõem, MS, 2004. 


\section{LISTA DE ABREVIATURAS, SIGLAS E SÍMBOLOS}

AAP - Academia Americana de Pediatria

AC - Ancoragens

ACS - Agente Comunitário de Saúde

AIDS - Síndrome da Imunodeficiência Adquirida

AIH - Autorização de Internação Hospitalar

AMA - Associação Médica Americana

BR - Brasil

BRM - Brechas Redutíveis de Mortalidade

CBCD - Centro Brasileiro de Classificação de Doenças em Português

CEPMI - Comitê Estadual de Prevenção do Óbito Infantil

CH - Comitê Hospitalar de Prevenção da Mortalidade Infantil

CIDS - Centro de informações e diagnósticos de Saúde

CIH - Comitê Intra-hospitalar

CM-Comitê Municipal

CMI - Coeficiente de Mortalidade Infantil

CMPMI - Comitê Municipal de Prevenção da Mortalidade Infantil

CNES - Cadastro Nacional de Estabelecimentos de Saúde

CNS - Conselho Nacional de Saúde

CO-Centro-Oeste

COEP - Comitê de Ética e Pesquisa

CONASEMS - Conselho Nacional de Secretários Municipais de Saúde

CONASS - Conselho Nacional de Secretários de Saúde

COREN - Conselho Regional de Enfermagem

CORESS - Conselho Regional de Serviço Social

CPMI - Comitê de Prevenção da Mortalidade Infantil

CR - Comitê Regional

CRM - Conselho Regional de Medicina

CRPMI - Comitê Regional de Prevenção da Mortalidade Infantil

CVE - Coordenadores de Setores de Epidemiologia 
DATASUS - Departamento de Informática do SUS

DIR-Diretores

DN - Declaração de Nascido Vivo

DO - Declaração de Óbito

DSC - Discurso do Sujeito Coletivo

ECA - Estatuto da Criança e do Adolescente

ECH - Expressões chave

EEUU - Estados Unidos

EUA - Estados Unidos da América

FREQ - frequência

GM - Gabinete do Ministro

HIV/AIDS - Sindrome da Imunodeficiência adquirida

IBGE - Instituto Brasileiro de Geografia e Estatística

IC - Idéias Centrais

INF - Técnicos dos sistemas de informações sobre mortalidade infantil

IPDSC - Instituto de Pesquisa do Discurso do Sujeito Coletivo

ISEP - Instituto de Saúde do Estado do Paraná

MCPOIF - Manual dos Comitês de Prevenção do Óbito Infantil

MDG - Millennium Development Goals

MI - Morte Infantil

MP - Mortalidade Perinatal

MS - Ministério da Saúde

N-Norte

$\mathrm{N}^{\circ}$ - número

NE - Nordeste

NOAS - Norma Operacional de Assistência à Saúde

NOB - Norma Operacional Básica

NV - Nascidos Vivos

OMS - Organização Mundial de Saúde

ONG - Organização não governamental

ONU - Organização das Nações Unidas

OPAS - Organização Pan-americana de Saúde 
PACS - Programa dos Agentes Comunitários de Saúde

PAISM - Programa Integral de Saúde da Mulher

PALS - Pediatric Advanced Life Support

PHPN - Programa de Humanização do Pré-natal e Nascimento

PPI -Programação Pactuada Integrada

PR - Paraná

PREPS - Pólos Regionais de Educação Permanente

PSF - Programa Saúde da Família

QQ - Software Qualiquantisoft ${ }^{\circledR}$

RegS - Regionais de Saúde

RH - Recursos Humanos

RN - Recém-nascido

S-Sul

SE - Sudeste

SERV - Enfermeiros e Médicos da rede básica de saúde e de hospitais

SESA - Secretaria do Estado de Saúde

SIAB - Sistema de Informação da Atenção Básica

SIATE - Serviço Integrado de Atendimento ao Trauma em Emergência

SIM - Sistema de Informação de Mortalidade

SIMI - Sistema de Informação de Mortalidade Infantil

SINASC - Sistema de Informação de Nascidos Vivos

SISPRENATAL - Sistema de Registro do Pré-natal

SISVAN - Serviço de Informações sobre Vigilância Nutricional

SMS - Secretaria Municipal de Saúde

SUS - Sistema Único de Saúde

TMI - Taxa de Mortalidade Infantil

TMIPN - Taxa de Mortalidade Infantil Pós-natal

TMPN - Taxa de Mortalidade Pós-natal

TRO - Terapia de Reidratação Oral

UBS - Unidade Básica de Saúde

UCI - Unidade de Cuidados Intermediários

UEM - Universidade Estadual de Maringá 
URSS - União das Repúblicas Socialistas Soviéticas

UTI - Unidade de Terapia Intensiva

UTIN - Unidade de Terapia Intensiva Neonatal

UTIP - Unidade de Terapia Intensiva Pediátrica

$\%$ - por cento

$\%$ - por mil 


\section{INTRODUÇÃO}

\subsection{A OPÇÃO PELO TEMA}

A presente pesquisa originou-se de meu envolvimento, como enfermeira e professora do ensino superior, com a Prevenção do Óbito Infantil, no contexto mais específico da implantação e operacionalização dos Comitês de Prevenção de Mortalidade Infantil, no estado do Paraná. Para os Comitês e, de igual maneira, neste trabalho o óbito infantil é considerado como um evento sentinela das condições de saúde da população e de seus determinantes. Além do que, pode ser utilizado como base para o estabelecimento e, também, a continuidade da vigilância, além de subsidiar a proposição de ações e estratégias para reduzi-lo.

A experiência do estado do Paraná no acompanhamento do óbito infantil como um evento sentinela do acesso e qualidade dos serviços de saúde, já construiu, com sucesso, uma parte de sua história mediante a atuação dos Comitês Estadual, Regionais e Municipais. Entretanto, sempre há o quê aprender, discutir, investigar, avaliar e adequar. O Paraná, assim como outros estados que mantêm esta ação investigativa, têm grande contribuição a dar para a implantação da estratégia dos Comitês em território nacional.

As mortes de crianças menores de um ano de idade para serem consideradas evitáveis dependem de uma investigação. $\mathrm{Na}$ investigação se procede à identificação dos fatores de risco incidentes e das condições de vida, nesse percurso, pode ocorrer a eleição de aç̃̃es em relação a seus múltiplos determinantes. Assim, é possível abrir possibilidades que impeçam novos óbitos infantis. Portanto, o evento óbito infantil mantém estreita e complexa relação com as condições de vida da população e com a implementação de Política Pública de Saúde, estruturação de Programas, de Projetos, de iniciativas governamentais e não governamentais que Promovam a Saúde, Previnam a Doença e permitam a vida, com dignidade e respeito ao ser humano.

Desse modo, os Coeficientes de Mortalidade Infantil nos trazem a dimensão numérica dessa problemática em todo o mundo; quando quantificado o obito infantil 
e, relacionado aos nascimentos vivos temos o Coeficiente ou Taxa de Mortalidade Infantil - TMI. Esses números suscitam discussões, comparações entre o nível de saúde de todos os países do mundo, são utilizados para planejamento de serviços de saúde e para o traçado de metas. No entanto, os números isolados não nos permitem entender sua determinação social, não nos mostram as realidades locorregionais, não trazem as recomendações para diminuí-los, não apresentam a problemática da estruturação dos serviços de saúde, dentre outras situações. Enfim, isolados, os TMI não falam por si sós. Como afirma LAURENTI (1975, p. 535):

\begin{abstract}
Calculamos os coeficientes reais e verificamos que eles estão sub ou superestimados. Entretanto, quando temos em mira o estabelecimento de um programa visando à diminuição da mortalidade infantil, não interessa somente reduzir seu número. Em outras palavras, o número ou valor da mortalidade infantil está alto porque algumas causas são responsáveis, $e$ é sobre estas que é necessário atuar.
\end{abstract}

Como podíamos ir além das TMI quando trabalhamos com o óbito infantil? Orientada por esta pergunta e motivada com o processo de vigilância e investigação dos óbitos infantis, nos Comitês de Prevenção da Mortalidade Infantil no Paraná, além da vivência das dificuldades que se apresentam na sua estruturação, elaborou-se a presente pesquisa aliando quatro instâncias importantes: 1) a vivência da pesquisadora junto ao contexto preventivo do óbito infantil, no Paraná; 2) a busca de informações documentais; 3) a leitura dos números indicadores da dimensão da mortalidade infantil, fornecidos pelos sistemas informatizados de mortalidade infantil e 4) as entrevistas com os atores sociais envolvidos com a Saúde e com a Prevenção da MI. As visões de prevenção dos entrevistados foram trabalhadas segundo o método do Discurso do Sujeito Coletivo, no Qualiquantisoft. As entrevistas foram realizadas com a intenção de identificar o conhecimento dos profissionais sobre as iniciativas no estado do Paraná que previnem o óbito infantil; para conhecer as dificuldades encontradas para a sua operacionalização e colher sugestões elaboradas pelos próprios atores. Enfim, resumidamente, para conhecer suas experiências e significado em relação à prevenção da mortalidade infantil.

Com este percurso teórico e metodológico pretendeu-se contribuir com o debate, fortalecimento e reconhecimento das ações de prevenção do óbito de crianças menores de um ano de idade no âmbito do trabalho da vigilância epidemiológica do 
estado do Paraná, especificamente, no contexto dos Comitês de Prevenção da Mortalidade Infantil. Trata-se de uma avaliação do impacto da proposta e atuação dos Comitês de Prevenção da MI e do contexto preventivo em saúde infantil, com a participação do parecer dos profissionais que trabalham com prevenção para se pensar na superação de suas lacunas e dificuldades em uma área de trabalho essencial para uma qualidade de vida de uma nação. 


\subsection{CONTEXTUALIZAÇÃO DA MORTALIDADE INFANTIL}

Neste item apontamos alguns aspectos do contexto da mortalidade infantil. A Mortalidade Infantil (MI) é um indicador de saúde clássico e universal, por meio do qual se avalia a higidez dos agregados humanos; o acesso e a qualidade da assistência à saúde materno-infantil; as condições políticas, sociais, econômicas, ambientais e sanitárias locais. Devido à obrigatoriedade de registro dos óbitos em todo o mundo a análise da MI torna-se uma ferramenta que permite comparabilidade inter e intra-regionais, em diferentes grupos populacionais. Apesar de a morte ser o evento final do ciclo da vida a partir do momento em que é vista e trabalhada como um indicador negativo de saúde, os estudos sobre o tema são capazes de acionar mecanismos de investigação e vigilância pelos serviços de saúde e poder público. Pode, assim, ser considerado um índice sintetizador do desenvolvimento locoregional (MEDRONHO et al., 2004; PEREIRA, 1995; ARAÚJO et al., 2005; LANSKY et al. 2002a; LANSKY et al. 2002b; MALTA e DUARTE, 2007; VIDAL et al. 2003; HARTZ et al. 1996; SZWARCWALD et al., 1997; LAURENTI et al. 1985; ARAÚJO, 1992).

São muitas as utilidades da Taxa de Mortalidade Infantil ${ }^{1}$ (TMI), como uma ferramenta estatística de mortalidade. Essa ferramenta pode ser útil para revelação da situação da saúde infantil e da população da qual esse segmento faz parte. É útil, também, para fins de diagnóstico da multicausalidade do óbito infantil; como parâmetro no estabelecimento de objetivos e metas a serem alcançadas; para avaliação do risco de evento ou agravo à saúde que se apresentam na região; para a mensuração do impacto, resultados e efetividade das ações implantadas na atenção à saúde materno-infantil (LAURENTI et al., 2006; BRASIL, 2004b, 2006, 2007a).

A vigilância sistemática da TMI pelos gestores dos sistemas de saúde é de extrema relevância por monitorar o risco de morte de uma coorte de crianças nascidas naquela região, município, estado ou país, ao longo de seu primeiro ano de vida. Com base nas TMI, os gestores valem-se do diagnóstico local, de subsídios ao

luO coeficiente ou taxa de mortalidade infantil (TMI) é uma estimativa do risco de morte a que está exposta uma populaçlo de nascidos vivos em uma determinada área e periodo, antes de completar o primeiro ano de vida" (MEDRONHO et al., 2004, p. 39). 
planejamento de saúde e do acompanhamento das flutuações e tendências históricas do padrão de $\mathrm{MI}$ de diferentes coletividades consideradas à mesma época e em diversos períodos de tempo (MEDRONHO et al., 2004; LANSKY et al, 2002a; MALTA e DUARTE, 2007).

Segundo MEDRONHO et al. (2004, p. 74) o conceito de vigilância epidemiológica consolidado internacionalmente é de "um conjunto de ações que proporciona o conhecimento a deteç̧ão ou prevenção de qualquer mudança nos fatores determinantes e condicionantes de saúde individual ou coletiva, com a finalidade de recomendar e adotar as medidas de prevenção e controle das doenças ou agravos". Assim, as atividades de vigilância ${ }^{2}$ são fundamentais para o "planejamento, o desencadeamento e a avaliação dos impactos das medidas destinadas a interromper a ocorrência de agravos" (MEDRONHO et al., 2004, p.74)

Os indicadores e/ou variáveis da dimensão social e econômica merecem maior refinamento pelas pesquisas para explicar as diversidades encontradas na distribuição das doenças e das mortes, em particular do óbito infantil. A crescente preocupação com as repercussões das desigualdades na distribuição da morbimortalidade nos ambientes, expressão das iniqüidades sociais, vem, nas últimas décadas, mais acentuadamente, orientando e despertando o interesse dos profissionais dos setores sociais, em especial os da Saúde em todo o mundo (GOLDBAUM, 1997; MALTA e DUARTE, 2007; LEAL e SZWARCWALD, 1997; SZWARCWALD et al., 1997; MONTEIRO, 1982; MONTEIRO e NAZÁRIO, 1995; GOLDANI et al., 2001; BODSTEIN, 1997; CARVALHO e CARVALHO, 2000; DEVIDÉ, 2001; DRUMOND JR e BARROS, 1999; VIEIRA, 2001; ISSLER et al., 1996; VON RUDEN et al., 2006; HOUWELING et al., 2006; VICTORA, 2001).

Há uma relação de oposição entre a MI e o nível socioeconômico, ou seja, os baixos níveis de saúde e de desenvolvimento social e econômico podem ser refletidos em altas taxas de MI. Alerta-se para o fato de que as taxas reduzidas também podem encobrir as más condições de vida em segmentos sociais específicos. Em qualquer situação pode-se dizer que a TMI tem uma elevada sensibilidade social, pois, incontestavelmente, os "principais determinantes do nível de vida -

\footnotetext{
${ }^{2}$ Săo atividades da vigilancia epidemiologica: "a coleta, o processamento, a análise e a interpretaçăo dos dados; a recomendacilo, a promogillo e a avaliaplito da eficácia e da efetividade das medidas de controle; $e$ a divulgaçlo das informacoes obtidas" (MEDRONHO et al., 2004, p.74).
} 
alimentação, moradia, acesso aos serviços de saúde, entre outros" exercem significativa influência sobre a "probabilidade de sobrevivência no primeiro ano de vida" (MONTEIRO, 1982, p. 7; BRASIL, 2004b).

Quantitativamente, os valores da TMI considerados altos ou baixos são arbitrários e sujeitos a controvérsia. As comparações entre diferentes populą̧ões, ou entre períodos diferentes, são úteis na avaliação da sua magnitude. Geralmente, são consideradas baixas as TMI inferiores a 20 óbitos infantis por mil nascidos vivos ( $\boldsymbol{x}_{0}$ NV); intermediárias as taxas entre 20 e 49\% NV e elevadas as iguais ou superiores a 50 óbitos \%o NV. No entanto, pode-se considerar que a TMI deva ter apenas um dígito e quanto menor o for, maior estará sendo o impacto das Políticas Públicas de atendimento integral à saúde Materno-Infantil (MEDRONHO et al., 2004; PEREIRA, 1995).

Entende-se que o perfil epidemiológico da comunidade, com sua dinamicidade intrínseca, determina os ajustes periódicos desses parâmetros. Atualmente, vários países desenvolvidos apresentam valores abaixo de $10 \%$ NV (BRASIL, 2007a). Destaque é feito à persistência dos diferenciais socioeconômicos entre os países, desenvolvidos ou não, e mesmo das regiōes de cada país, apesar da redução da MI em níveis absolutos, deve-se considerar nesse processo a evolução do arsenal de tecnologia médica, sanitária e das informações. Essa persistência pode ser devida ao acesso a todos os elementos sociais e de avanços no setor saúde que definem a qualidade de vida, definindo as classes sociais (MONTEIRO, 1982).

Neste sentido, permite-se inferir, com as informações mostradas no Gráfico 1, que continentes com menor acesso à saúde e ao avanço tecnológico para a totalidade de seus países, como África, parte da América, com ênfase à Latina e, algumas regiōes da Ásia, mostram persistência de taxas consideradas elevadas, na década de 90, mediante esse indicador epidemiológico sensível que é a MI.

Segundo YUNES e ROCHENZEL (1974) utilizando-se de estudos de Giorgio Mortara (1941, 1956 e 1961), contando com um grande sub-registro de óbitos infantis e, principalmente, de nascimentos na época da realização da pesquisa, a MI no Brasil variou de 202,33\% NV, em 1941, para 108,68\% NV, em 1970, mostrando redução percentual de $46,2 \%$ em 30 anos. 
Gráfico 1: Taxa de Mortalidade Infantil (\%o NV) segundo continentes e países do mundo, $1990-2004$.

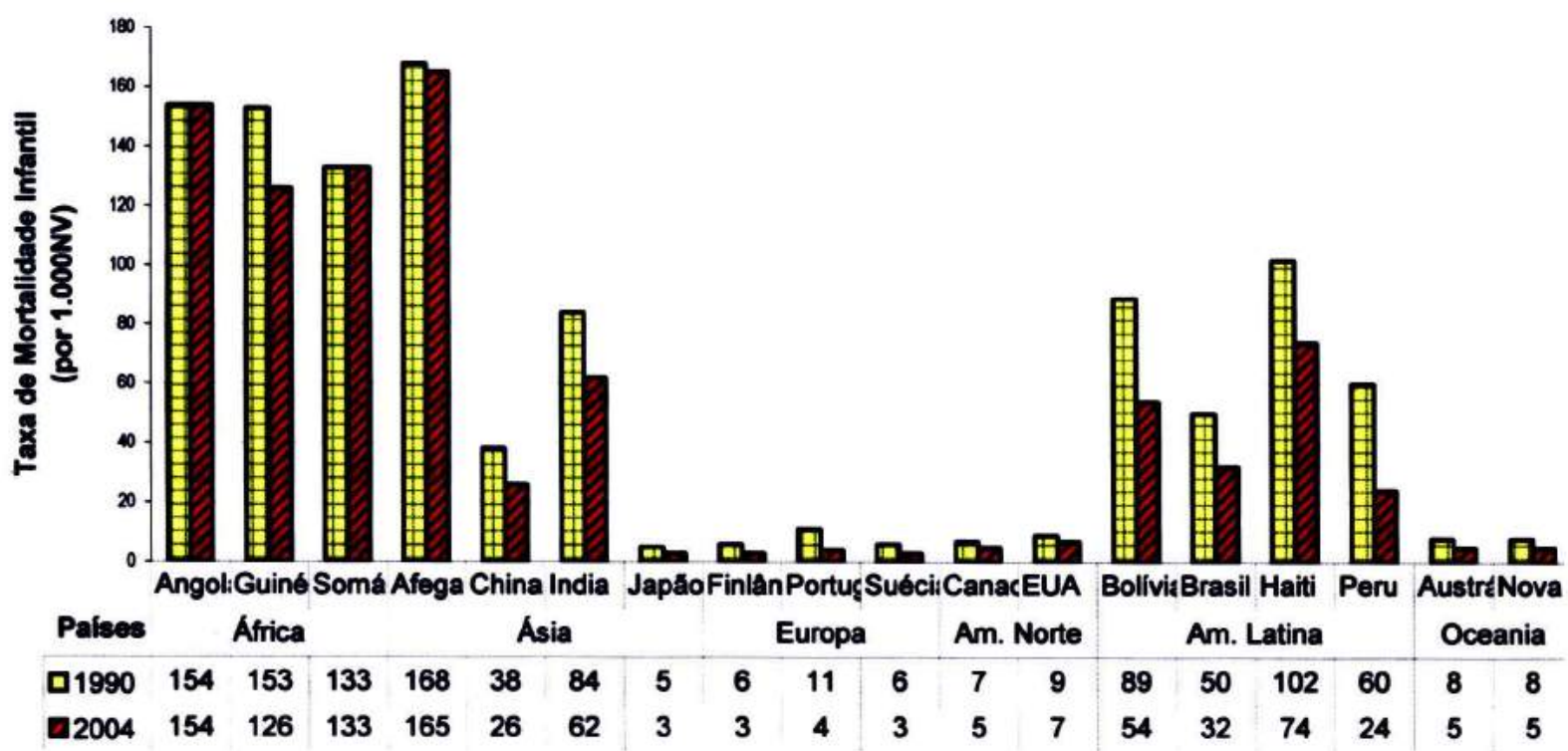

Fonte: Millenium Development Goals Report, 2006. Devinfo acesso www.deveinfo.info, dados brutos.

A redução de MI por Região foi de 72,0\% para o Centro-Oeste, $68,6 \%$ para o Norte, $68,2 \%$ para o Sul, $43,4 \%$ para o Nordeste e $40,8 \%$ para o Sudeste. Tal como aconteceu na mortalidade geral, a região que mais contribuiu para a redução da mortalidade infantil foi a Centro-Oeste seguida das regiões Norte, Sul, Nordeste e Sudeste. Os autores alertam para o fato de que as regiőes que apresentavam maiores coeficientes em 1941 também apresentaram maiores reduções, fugindo a essa tendência o Nordeste (YUNES e RONCHEZEL, 1974).

Ao comparar os dados encontrados com outros países, YUNES e RONCHEZEL (1974) constataram uma notória diferença entre os valores encontrados para os países mais desenvolvidos, como a URSS de $24,41 \%$ NV (1970), EUA de 19,8\% NV (1970), Canadá de 19,3\% NV (1969) e Japão de 15,3\%。 NV (1969). Também compararam com o Chile, por ser um País da América Latina, com boas estatísticas vitais, onde o valor encontrado foi de 91,6\% NV, em 1969. 
Foram apontados, por YUNES e ROCHENZEL (1974) fatores que influenciaram na mortalidade geral e infantil no Brasil, na época da pesquisa e, como mais importante fator encontrou-se o econômico. Nesse fator incluiu-se a distribuição de renda favorecendo os setores secundários e terciários da economia e, o declínio do salário médio dos estratos populacionais inferiores, como consequêencia do rápido desenvolvimento e crescimento populacional. Deste modo, com a redução do poder aquisitivo da população aumentam os problemas alimentares, principalmente na infância, levando à desnutrição, à predisposição para doenças infecciosas e parasitárias e óbito. Outros problemas foram: o analfabetismo populacional (na ordem de $32 \%$ ); ausência de água encanada (ausente em cerca de $40 \%$ dos municípios) e da rede de esgoto (ausente em cerca de $60 \%$ dos municípios), bem como o saneamento básico, apontados como aquém do desejável (YUNES e RONCHEZEL, 1974).

LAURENTI (1987) estudou comparativamente a MI nos EUA, Suécia e Estado de São Paulo, no período de 1950 a 1981 . Observou, no período, uma redução de 57,2 \% para os CMI em São Paulo. No entanto, os CMI continuaram elevados, em 1982 foi de 47,9\%o NV. Os Estados Unidos e Suécia, os quais já apresentavam baixos coeficientes em 1950 (29,2 e 21,1\% NV, respectivamente), apresentaram também reduções para 11,2 e 6,8\% NV.

A MI na Suécia era tão baixa que pequenas flutuações poderiam mostrar declínio ou elevação, o quê, na realidade, não demonstrava nenhum significado prático. A mortalidade do vigésimo oitavo dia até completar um ano de vida (pósneonatal) e que está intimamente ligada a fatores ambientais, sempre foi bastante baixa e inferior à neonatal, no período de 1950 a 1982, nos Estados Unidos e Suécia (mais inferior ainda), em 1982 representaram 3,6 e 2,2 \% NV respectivamente. No estado de São Paulo, as mortes pós-neonatais representaram a maior parte da MI, 24,4\% NV, em 1982 (LAURENTI, 1987).

CÉSAR (1990) cita Rico-Velasco (1983) na análise da tendência da MI no período de 1950/55 a 1975/80; mostrou que, mundialmente, houve uma queda acentuada. Para os países desenvolvidos essa queda foi de 164 para aproximadamente 100 óbitos de menores de um ano $\%_{0} \mathrm{NV}$, queda relativa de $40 \%$. 
É incontestável para o Brasil o descenso da TMI à semelhança de muitos países do mundo, porém de maneira mais lenta do que para a maioria dos países americanos. Essa redução mesmo irregular e não tão constante como esperado, está na dependência das importantes diversidades, especificidades e desigualdades socioambientais regionais e locais. No entanto, ainda temos índices elevados como no Nordeste e Norte (VICTORA, 2001; MEDRONHO et al., 2004)

A fase de implantação e crescimento da industrialização no país (entre 1940 e 60) marcou o início da tendência de declínio da MI. Entre 60 e 70, essa tendência sofre uma desaceleração simultânea ao êxodo rural. Isto levou a uma aglomeração populacional em centros urbanos, a desvalorização do salário mínimo e a concentração, cada vez maior da renda, nos extratos dominantes. $\mathrm{Na}$ década de 70, a tendência decrescente é retomada, em função das políticas sociais de infra-estrutura urbana, de saúde coletiva e, também pela queda da fecundidade (MEDRONHO et al., 2004; SIMÕES, 2002).

O Perfil de Saúde e de Mortalidade no Brasil - 2002 (SIMŌES, 2002) demonstra que a MI no Brasil, no período de 1990/2000 passou de 48,4\% NV para $33,6 \%$ NV. Ou seja, houve uma queda de 30,6\%, alcançando. Desse modo, a MI alcançou os limites da meta estipulada pela Cúpula Mundial pela Infância para 0 período, considerando-se possíveis desvios normalmente associados às estimativas.

Os valores médios da TMI continuam elevados, sobretudo nas regiões Nordeste e Norte, ainda há necessidade de melhoria da qualidade do preenchimento das DOs e da resolução de problemas de sub-notificação e sub-registro de óbitos (SZWARCWALD et al., 2002; HARTZ et al., 1996).

LAURENTI et al. (2006) afirmam que, apesar da obrigatoriedade do registro do óbito, de maneira geral, ainda hoje, apresentam-se algumas falhas qualitativas, de fidedignidade da informação e quantitativas, de cobertura do Sistema de Informação sobre Mortalidade Infantil (SIM). O sub-registro do evento com predomínio entre menores de um ano de idade; o registro tardio; a não observância das definições oficiais de eventos vitais; a perda do dado entre o Cartório do registro Civil e o Instituto Brasileiro de Geografia e Estatística (IBGE) podem estar originando os problemas com o SIM (SZWARCWALD et al., 2002; HARTZ et al.,1996). 
Outros fatores apontados como 'problemas' potenciais quanto ao uso do SIM são: a dissociação entre objetivo da inclusão das variáveis nas Declarações de Óbitos (DOs) e seu uso social; o sub-registro dos nascimentos; a dificuldade para obtenção das informações relativas a algumas variáveis tidas ainda como secundárias; a precisão na determinação da causa básica do óbito, principalmente quando se trata de óbito materno-infantil e devido à Causas Externas (BARROS et al., 2002; CARVALHO et al., 1990; STROZZI et. al., 1985; LAURENTI, 1975; MENDONÇA et. al., 1994; MELLO JORGE et. al., 1996).

$\mathrm{O}$ perfil da $\mathrm{MI}$ nas últimas décadas também pode ser atribuído à modificação nos padrões de fecundidade e de natalidade, em virtude da redução no número de nascimentos (MELLO JORGE et al, 2001). Além de ser a tendência de descenso do óbito infantil em todo o território nacional brasileiro uma realidade que reflete a melhoria nas condições de vida e saúde da população brasileira, bem como os efeitos de intervenções públicas nas áreas da saúde: a melhoria do acesso e na qualidade do pré-natal; Programa Saúde da Família (PSF) e dos Agentes Comunitários da Saúde (PACS); Imunização; Terapia da Reidratação Oral (TRO); saneamento básico e nível educacional (MELLO JORGE et al., 2001; FERREIRA, 1990; MONTEIRO, 1982; FRIAS et al., 2005; SOUZA e GOTLIEB, 1993).

Destacam-se ainda o impacto para a redução da mortalidade infantil produzido pelo incentivo, apoio e promoção do aleitamento materno e todas as ações derivadas como: Iniciativa Hospital Amigo da Criança (IHAC), Iniciativa Unidade Básica Amiga da Amamentação (IUBAM) e o bem como o Método Canguru (MC) (VENÂNCIO et al., 2002; ESCUDER et al., 2003; BRASIL, 2002a; NEVES, 2006).

As Regiões Nordeste e Norte apresentaram, nitidamente, no período de 1997 a 2004, TMI superiores à média do Brasil, embora em descenso, como se observa no Gráfico 2. A Região Sul apresentou o menor coeficiente comparado às demais regiōes do País, 15,8\% NV, em 2004, o estado do Paraná apresentou TMI de $15,53 \%$ NV no mesmo ano (Gráfico 2). 
Gráfico 2: Taxa de Mortalidade Infantil (\%o NV), Brasil e Regiões, Brasil, 1997 a 2004.

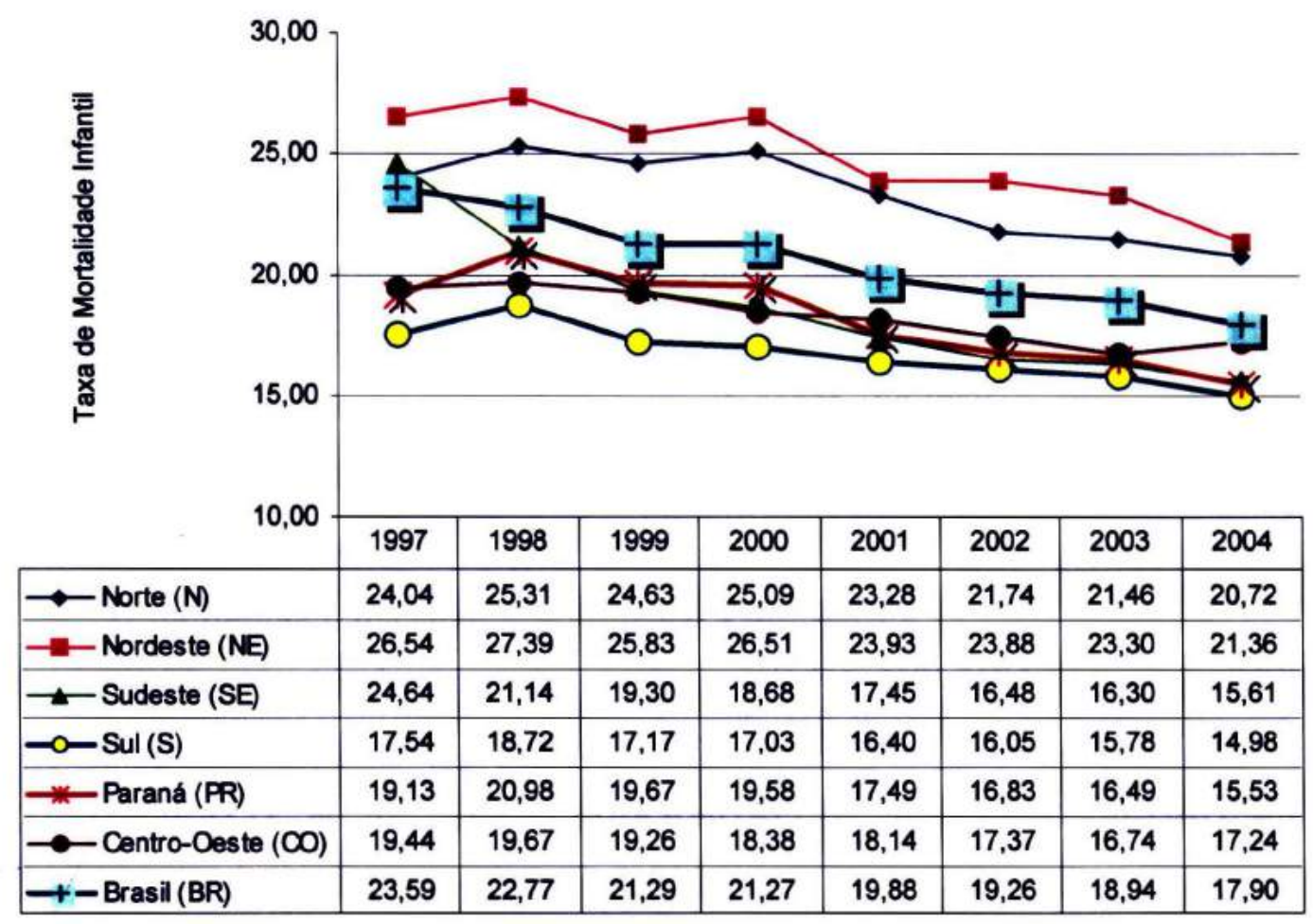

Fonte: Brasil, Ministério da Saúde: SIM, SINASC, 1997 a 2004; disponíveis on line [www.datasus.gov.br], dados brutos.

A mortalidade infantil pode ser dividida em dois componentes: $o$ neonatal correspondendo aos 27 primeiros dias de vida (de 0 a 27 dias) e o pós-neonatal ou infantil tardio (de 28 dias de vida até completar um ano). Essa divisão é devida à variação do risco de morte ao longo do primeiro ano, principalmente, quanto às causas de morte e seus fatores determinantes. $O$ período neonatal ainda é subdividido em neonatal precoce que considera os sete primeiros dias de vida (do zero ao $6^{\circ}$ dia) e neonatal tardio (do $7^{\circ}$ ao $27^{\circ}$ dia de vida) (MEDRONHO, et al., 2004). 
No processo de declínio da MI é verificado, inicialmente, o decréscimo no componente infantil tardio mediante impacto das ações básicas de saúde, do fluxo adequado no atendimento à saúde, da qualidade no atendimento e, de saneamento básico, com a melhoria da qualidade da água, da rede de esgotos, bem como de outros fatores sociais ligados à qualidade de vida. Nesse sentido, o componente neonatal adquire maior expressão, pois constitui um grupo de mais difícil redução devido associação direta com acesso ao pré-natal, parto e atendimento em Unidades de Terapia Intensiva ou Semi-Intensiva. No óbito neonatal as causas são, com maior freqüência, as anomalias congênitas e afecções perinatais que, geralmente, determinam a prematuridade e o baixo peso ao nascer (MELLO JORGE et al., 2001; LANSKY et al., 2002a).

A mortalidade neonatal é o principal componente da MI, no Brasil, desde a década de 90, para a maior parte das regióes e estados, com concentração no período neonatal precoce (BRASIL, 2004b; LEAL e SZWARCWALD, 1996, 1997; SZWARCWALD et al., 1997; MARANHÃO et al., 1999; SCHRAMM e SZWARCWALD, 2000; ARAÚJO et al. 2000).

A mortalidade neonatal geralmente está vinculada a causas endógenas ao processo reprodutivo (parto pré-termo, baixo peso ao nascer, à disponibilidade e à qualidade da assistência ao pré-natal e parto), enquanto que a pós-neonatal depende, na maior parte de fatores exógenos, das situações relacionadas com o meio ambiente (problemas nutricionais, infecções, acidentes, violências, acesso e qualidade dos serviços primários de saúde) (BRASIL, 2004b).

Os óbitos infantis pós-neonatais são devidos a causas evitóveis, conceito discutido mais adiante, na grande maioria das vezes. São vinculados à baixa qualidade da assistência médica e, geralmente, referentes a problemas infecciosos gastro-intestinais e respiratórios, associados ou não, à desnutrição proteico-calórica. A assistência médica constitui importante fator de risco para crianças menores de um ano. Sinaliza para a falta de integração entre as ações ambulatoriais e as hospitalares. O componente pós-neonatal torna-se bastante sensível às intervenções sanitárias, com ações em nível primário e secundário; é fortemente associado a condições socioeconômicas e culturais, ou seja, às 'condições de vida' da família (CALDEIRA 
et al. 2001, 2002; NIOBEY et al., 1992; POST et al., 1992; SANTA HELENA e ROSA, 2003).

Há que se considerar que é na mortalidade perinatal ${ }^{3}$ que reside a maior resistência na queda da MI pela estreita e complexa relação que guarda com os fatores determinantes de ordem biológica, social, econômica, política, demográfica e de assistência a saúde. Algumas dessas causas de MP podem ser consideradas como causas preveniveis ou evitáveis, pois podem ser minimizadas e até mesmo resolvidas mediante acesso ampliado e utilização otimizada de serviços de saúde, com a melhoria da qualidade da assistência pré-natal, ao parto e ao recém-nascido. Por consistirem em sensíveis indicadores para adequação dos programas de intervenção na área obstétrica e neonatal, e do impacto dos programas de intervenção nessa área, as pesquisas recomendam maior conhecimento sobre os determinantes dos óbitos perinatais, com o objetivo de prevenção (LANSKY et al., 2002a; LANSKY et al., 2002b; ARAUJO et al., 2000; ALBERMAN, 1980; BARROS et al. 2002; LEITE, 1997; LEITE et al., 1997; WIGGLESWORTH, 1994; VIDAL et al., 2003; SEADE, 1991).

Estudando-se as mudanças no perfil de morbi-mortalidade da população brasileira, observa-se a chamada de transição epidemiológica, na qual as doenças infecciosas e parasitárias dão lugar à maior incidência de crônico-degenerativas e aos acidentes e às violências (PEREIRA, 1999; MEDRONHO et al., 2004). Ressalta-se que, para a população de menores de um ano, a necessidade de valorização das causas externas, tanto os acidentes de vários tipos, como também as violências ${ }^{4}$, os maus-tratos (MELLO JORGE, 1999). A violência é, por conceito, e na prática relacional, um fenômeno complexo histórico e socialmente construído; pode ser encontrada como componente cultural fortemente arraigado e/ou banalizado (MYNAIO e SOUZA, 1999).

As causas violentas, muitas vezes, deixam de ser identificadas e conhecidas. Essas são informadas como 'acidentes'. Quando as crianças são levadas aos serviços

\footnotetext{
${ }^{3}$ A mortalidade perinatal (MP), se refere aos obitos ocorridos a partir do inicio da $22^{4}$ semana de gestaçlio, ou peso maior ou igual a $500 \mathrm{~g}$, atte o $7^{\circ}$ dia completo de vida da criança (OMS, 2003).

É na pediatria nos EUA e Canadh, na década de 60 e 70 que se inicia o estudo, diagnostico e tratamento da sindrome do bebé espancado, o reconhecimento dos maus-tratos leva a criacilo de Programas de prevençlo primária e secundária, al criaçlo de centrais de denúncia que torna público e passivel de intervençäo o problema. No Brasil, bem como em toda a sociedade ocidental, na década de 80 o tema violéncia "entra com maior vigor na agenda de dehates e no campo programático da saude, tendendo a se consolidar no final dos anos $90^{\prime \prime}$ (MYNAIO e SOUZA, 1999, p.9).
} 
de saúde as verdadeiras situações podem ser são mascaradas pela família e/ou não diagnosticada pela equipe que a atende. Todavia, a violência faz parte do universo da saúde pública e pode, não só afetar a saúde e deixar seqüelas físicas e emocionais, como provocar a morte. De qualquer forma todas as conseqüências da violência convergem para a saúde, mas não é esta a responsável da totalidade das dimensões que compõem a violência e sua transcendência (MYNAIO e SOUZA, 1999; DESLANDES, 1999; REICHENHEIM et al., 1999).

\section{[...] levando-se em conta a tradição e a credibilidade do setor (saúde) nas intervenções preventivas e promocionais no nivel dos grupos populacionais e na atenção às vítimas, consideramos que as instituições c os profissionais de saúde desempenham um papel fundamental no âmbito das politicas de superação da violência $e$ de suas conseqüências (MINAYO e SOUZA, 1999, p. 12)}

Em relação às instituições ambulatoriais e hospitalares discute-se o medo em lidar com questões tratadas pelo direito criminal e segurança pública; o despreparo técnico; a falta de conhecimento sobre as vias de encaminhamento social pela instituição. Estes fatores, dentre outros, encontram-se imbricados, formando uma rede de causalidade centrada no monopólio do modelo biomédico que é o da ênfase na história natural da doença. Ou seja, esse modelo tende a incorporar o social apenas como uma variável ambiental na produção da doença (MINAYO e SOUZA, 1999). Cabe, assim, a operacionalização de um sistema de vigilância em saúde pública específico com objetivos e identificação dos componentes do sistema bem estabelecidos (WALDMAN e MELLO JORGE, 1999).

Essas considerações, apesar de não pretenderem esgotar o tema, nos remetem a reflexão de que a não identificação e ação específica, pelos próprios profissionais e instituições, na situação de violência a crianças, equivale a perpetrar a violência estrutural e organizacional (NETO e MOREIRA, 1999). Este fato deve ser debatido à luz da ética profissional e do compromisso com a vida e qualidade dos serviços, principalmente, pelas instituições hospitalares que, normalmente trabalham desintegradas da rede básica de saúde (CALDEIRA et al, 2001).

A dimensão técnica profissional determina a qualidade do atendimento oportuno e adequado de maneira integral à criança. É indiscutível sua importância para a preservação da vida dos menores de um ano que chegam aos serviços e 
necessitam da equipe capacitada, com condições adequadas de conhecimentos técnicos, bem como, de recursos tecnológicos necessários ao atendimento de urgência ao binômio mãe-filho (SARINHO, 2001; CALDEIRA et al. 2001, 2002; POST et al., 1992).

As pesquisas sobre causas evitáveis de doença, incapacidade e morte infantil, definem-na como eventos, total ou parcialmente, preveníveis "por açð̃es efetivas dos serviços de saúde que estejam acessíveis em um determinado local e época" (MALTA et al, 2007). Assim, com a utilização do conjunto de recursos tecnológicos e de conhecimento atualizado em saúde esses eventos não deveriam ocorrer (MALTA E DUARTE, 2007).

O precursor deste debate foi David D. Rustein (RUSTEIN et al., 1976, p. 583) que conceituou o evento evitável de saúde (sentinel helth evetn) como a ocorrência desnecessária de enfermidades, incapacidade, ou óbito inesperado (untimely death) que justifica uma cuidadosa investigação científica de suas causas determinantes (underlying causes) passíveis de melhoria, ou que suscitam incertezas sobre o sucesso no encaminhamento da situação ocorrida.

Desta maneira, o óbito infantil evitável "pode derivar, em algum grau, indicadores sensíveis à qualidade da atenção à saúde prestada pelo sistema de saúde e, portanto, pode derivar medidas de resultado ou de impacto dessa atenção" (MALTA et al., 2007, p. 5). Nesta perspectiva, pode-se entender a ocorrência do óbito evitável como evento sentinela da qualidade de assistência à saúde, "uma vez que sinaliza a possibilidade de que algum elo em uma adequada e hipotética cadeia da atenção integral à saúde não está funcionando bem, indicando que a qualidade da atenção deva ser melhorada" (MALTA e DUARTE, 2007, p. 2; HARTZ et al., 1996; RUSTEIN et al., 1976).

Assim, o evento sentinela constitui-se como uma ocorrência denunciadora da existência de situações inadequadas (de vida e assistência à saúde) que precipitaram o óbito. Para isso, deve haver pesquisa de evidências acerca da porção que potencialmente pode ser evitada pela intervenção em saúde disponível em um espaço e momento histórico. Pela vigilância do evento são bem definidos quais os critérios de evitabilidade que poderão ser utilizados na leitura de cada um deles, de cada 
óbito, considerando-se as circunstâncias que o determinam (MALTA e DUARTE, 2007; VIDAL et al., 2003).

Para que ocorra essa determinação da evitabilidade, no conceito de evento sentinela é necessário que haja a investigação de cada ocorrência tida como evitável, tanto no nível individual quanto no coletivo, para que sejam propostas medidas cabíveis, a fim de que outro evento deixe de acontecer mediante circunstâncias e situações semelhantes (HARTZ et al., 1996).

Todo esse processo de determinação da evitabilidade, ou seja, esse processo investigativo do evento evitável, no caso do óbito infantil, propiciará a produção de novos conhecimentos, que aliados à disponibilidade de novas práticas e tecnologias em saúde geram avanços e determinam que esses indicadores sejam sempre revistos, pois se constituem em índices sintetizados, construídos, a partir de múltiplas situações sociais, técnicas e tecnológicas dinâmicas e complexas (MALTA e DUARTE, 2007; MALTA et al., 2007). 


\subsection{O SISTEMA ÚNICO DE SAÚDE (SUS) \& PROMOÇÃO DA SAÚdE \& POLÍTICAS PÚBLICAS}

Neste item apresentar-se-á a discussão acerca do debate do Sistema Único de Saúde e a promoção da saúde por meio das políticas públicas. Pode-se iniciar 0 debate expondo-se o que prescreve a Constituição Cidadã de 1988.

A Constituição da República Federativa do Brasil, de 1988, em Texto consolidado até a Emenda Constitucional n 53 de 19 de dezembro de 2006, Brasília - 2006, em seu Título II, no qual são tratados os Direitos e Garantias Fundamentais do brasileiro descreve em seu $\mathrm{Art}^{\circ} 6$ que: "São direitos sociais a educação, a saúde, o trabalho, o lazer, a segurança, a previdência social, a proteção à maternidade e à infância, a assistência aos desamparados, na forma desta Constituição."

No Artigo 196 (Título VIII, Capítulo II, Seção II) lemos que a saúde é direito de todos e dever do Estado, garantido mediante políticas sociais e econômicas que visem à redução do risco de doença e de outros agravos e ao acesso universal $e$ igualitário às ações e serviços para sua promoção, proteção e recuperação (BRASIL, 1988).

O Artigo 197 considera de relevância pública as ações e serviços de saúde, cabendo ao poder público dispor, nos termos da lei, sobre sua regulamentação, fiscalização e controle, devendo sua execução ser feita diretamente ou através de terceiros e, também, por pessoa fisica ou juridica de direito privado (BRASIL, 1988).

A seguir, no Artigo 198 (BRASIL, 1988), vimos que o Sistema Único de Saúde (SUS) deve ser constituído por uma rede regionalizada e hierarquizada, integrada por ações e serviços públicos de saúde e deve se organizado de acordo com as seguintes diretrizes:

I - descentralização, com direção única em cada esfera de governo;

II - atendimento integral, com prioridade para as atividades preventivas,

sem prejuizo dos serviços assistenciais;

III - participação da comunidade. 
Esta Constituição de 1988 foi chamada de Constituição Cidadã. Ela nasceu da luta de muitos deputados comprometidos com a democratização do Brasil após a ditadura militar. Todavia, nos anos 80 do século $\mathrm{XX}$, enquanto o Brasil encontrava uma saída democrática, ocorria uma crise econômica no resto do mundo. Assim, enquanto a democratização nos anos 80 favoreceu o debate na área da saúde e se refletiu nos avanços da Constituição Brasileira de 1988; nos anos 90 a consolidação dos princípios do Sistema Único de Saúde esteve em contínua tensão devida a obstáculos estruturais e conjunturais (LEVCOVITZ et al., 2001).

A descentralização dos serviços da saúde tem enfrentado resistências e dificuldades para delimitar claramente as responsabilidades financeiras e assistenciais de cada esfera de governo, para se ter equipamentos sociais que atendam às mais diversas realidades desse país com tantas diferenças loco-regionais. No entanto, a política de saúde pública mostra-se em processo de avanço constante principalmente no que diz respeito à assistência primária universal. Nesse processo ênfase deve ser dada a ações de imunização e vigilância de agravos nutricionais que com a criação do Programa Saúde da Família, e cooperação de Organizações Não Governamentais (ONGs) como a Pastoral da Saúde e da Criança e outras, vem conquistando melhores níveis de saúde materno-infantil (LEVCOVITZ et al., 2001).

Acredita-se que uma forma de ampliar o debate acerca do óbito infantil como um evento multicausal seja por meio da aplicação do conceito de vulnerabilidade $\mathrm{e}$ seus indicadores, na análise deste evento para conhecer as suas circunstâncias, expôlas na agenda da saúde local e implementar medidas de impacto mais efetivo para sua redução.

O conceito de vulnerabilidade teve sua origem com a luta pelos direitos humanos. Foi desenvolvido na Saúde Publica quando ocorreu o enfrentamento da epidemia de AIDS, por diferentes setores da sociedade. $O$ conceito surgiu quando se ultrapassou a noção de risco individual para compreensão da vulnerabilidade social (AYRES et al., 1999).

Vulnerabilidade é, assim, a chance de exposição das pessoas ao adoecimento como resultante de um conjunto de diferentes condições: individuais e coletivas, contextuais que acarretam maior suscetibilidade ao fenômeno e, de modo 
inseparável, maior ou menor disponibilidade de recursos de todas as ordens para se proteger (AYRES et al., 1999).

A vulnerabilidade enfoca três dimensões para a concretização das ações na saúde, a saber: o comportamento individual, o contexto social $e$ as açöes programáticas. $\mathbf{O}$ conceito de vulnerabilidade social tem suas raízes nos indicadores relacionados à estrutura econômica, das políticas públicas, e em especial de educação e saúde, e índices de desenvolvimento humano (MANN et al., 1992).

Esse percurso no Brasil pode ser visualizado na área da saúde, no contexto das ações programáticas para proteger a vida materno-infantil. São propostas estratégias, ações, programas, firmados pactos, implantadas Políticas Públicas. Verdadeiras 'cruzadas' são organizadas e empreendidas no setor para sensibilização e capacitação de profissionais com a missão de promover e proteger a saúde, bem como prevenir a enfermidade e o óbito potencialmente evitáveis.

Como afirma CASTELLANOS (1997, p. 148) “ [...] não basta o crescimento econômico para que se alcance melhorias sustentadas na situação da saúde", as políticas econômicas devem considerar seu impacto sobre as iniquiidades da situação de vida e saúde da população. $\mathrm{O}$ fato de se desenvolver a capacidade estadual para estudar e vigiar as iniquidades em saúde tem maior relevância para gestão, do que para conhecimento das desigualdades (inter)nacionais (CASTELLANOS, 1997).

A vigilância da saúde e a sua produção social devem ser vistos, não só de gestores responsáveis pela saúde em seus diversos níveis, mas também de todos os profissionais da saúde, da educação, do judiciário, do meio ambiente ${ }^{1}$, da sociedade civil organizada e, fundamentalmente, da população para que a saúde seja vista como um constructo social, uma produção da sociedade organizada.

Para a efetivação desse constructo social, três grandes grupos de ações combinam-se e resultam nas estratégias de intervenção da vigilância da saúde ${ }^{2}$, a

\footnotetext{
'MINAYO (2006) enfatiza que a relaçlo e debate entre saude e ambiente parte de dois pressupostos basicos: 1)a essencialidade da relacllo entre seres humanos e natureza e 2) o conceito do ambiente é construido pela aclio humana.

${ }^{2}$ Trata-se da elaboracllo de diagnostico de cada municipio, regilo, mediante a busca ativa dos condicionantes e dos determinantes de doencas, de riscos e de agravos à saúde (NUNES, 2002). Vigilancia $\mathrm{em}$ saúde pública é a conthua e sistemática coleta, andilise e interpretagulo de dados essencias de saide para planejar, implementar e avaliar pritticas de sanide priblica, intimamente integrada com a periodicidade de disseminagio desses dadas para aqueles que necessitam conhece-tos (WALDMAN, 2006).
} 
saber: a promoção da saúde ${ }^{3}$, a prevenção de doenças e acidentes e a atenção curativa (NUNES, 2002; WALDMAN, 2006).

BARROS (1997) também evidencia o papel privilegiado da intervenção para Promoção e Proteção da Saúde, do diagnóstico, do controle, da cura e da reabilitação que exercem os serviços de saúde. Recomenda para a concretização desse papel a análise das condições de saúde de segmentos populacionais tomando a delimitação geográfica das áreas urbanas de acordo com um modelo de organização de um sistema de saúde hierarquizado, regionalizado e descentralizado.

À medida que os serviços de saúde e suas unidades básicas assumem a incumbência das ações de saúde pública em locais geograficamente definidos, a lógica do sistema tenderia a se alterar e reverter enfatiza BARROS (1997), pois reconhece a tendência dos serviços de saúde em se distribuir, diferencialmente, reproduzindo e reforçando, na saúde, as desigualdades sociais provenientes da dinâmica das sociedades capitalistas e, conseqüentemente, mantêm a iniqüidade ${ }^{4}$.

Como aponta CASTELLANOS (1997, p.149), as políticas de saúde devem considerar a "definição de prioridades em função do impacto potencial, da eficácia social na redução das Brechas Redutíveis de Mortalidade/BRM ${ }^{5}$ e nas condições de vida".

CASTELLANOS (1997) ainda afirma que as BRM estão associadas não somente com o nível de desenvolvimento econômico dos países, mas, também, ao grau de desenvolvimento social acumulado e as condições de vida predominantes em suas populações (medidos em termos de acesso a bens e serviços mínimos, mediante um 'indicador geral de acessibilidade ao desenvolvimento social acumulado' IGADSA $^{6}$ ).

\footnotetext{
${ }^{3}$ Promoção da Saúde é definida como a capacitação das pessoas e comunidades para modificarem os determinantes da saúde em benefício da própria qualidade de vida, segundo a Carta de Ottawa (WHO, 1986).

4 Segundo CUNHA (1997) entende-se que a equidade significa a "disposição de reconhecer igualmente o direito de cada um; ou igualdade, retidäo, equanimidade" (p. 219).

'Brechas Redutiveis de Mortalidade / BRM constituisse na diferença entre as taxas de mortalidade do grupo observado e as taxas de referência - que sẵo as que se encontrou em outros paises e grupos sociais em circunstâncias similares; este enfoque se dá sob a perspectiva da equidade.

${ }^{6}$ O IGADSA foi construído considerando-se um conjunto de variáveis referidas a 5 dimensóes: acessibilidade acumulada a serviços básicos de saúde; aces. relativa a recursos econômicos; aces. acum. a nutrientes; aces. acum. ao sistema educativo; aces. acum. a saneamento básico. Os valores das variáveis foram de diferentes fontes publicadas (Naçoes Unidas, PNUD, BM, BID FAO, UNESCO, e outras; além das obtidas diretamente pela OPS/OMS), no periodo de 1989 90, foram ajustadas a uma escala de 1 a 5 . Assim o Índice é o valor de promédio do conjunto das cinco dimensð̃es (CASTELLANOS, 1997).
} 
De acordo com BUSS (2003, p.27) "o desenvolvimento de habilidades $e$ atitudes pessoais ${ }^{7}$..." "[...] favoráveis à saúde em todas as etapas da vida encontra-se entre os campos de ação da promoção da saúde". Assim também ocorre o empowerment ${ }^{8}$ da população à medida que esta tenha acesso a informações úteis $\mathrm{e}$ valiosas (aquisição de conhecimento) para que possa entender sua situação de saúde (plano individual) e adquira uma consciência política para atuar em prol da sua saúde (SÍCOLI e NASCIMENTO, 2003; WESTPHAL, 2006). Essa promoção da saúde cria o cidadão protagonista, consciente, isto é, aquele que desenvolve a habilidade e o poder de atuar em benefício da própria qualidade de vida como sujeitos e/ou comunidades ativas.

O processo de construção do SUS no Brasil, vinculado à proposta resultante do Movimento Sanitário, além de ter como princípios básicos a universalidade, a integralidade e a eqüidade, tem como diretrizes a regionalização, a hierarquização e o controle social. Orienta-se pelo resultado da vigilância em saúde e, são construídas e propostas decisões e ações federais imperativas: as Políticas Públicas; que são formuladas como ações estrategicamente selecionadas para programar as decisões tomadas (LEVCOVITZ et al., 2001; BARBOSA, 2000; APM, 2002; COHN, 2006).

Essas políticas públicas têm como principal característica a autoridade do Poder Público o que determina sua natureza imperativa, sua dimensão do exercício do poder. Outra dimensão a ser observada na política é a da racionalidade; que está envolvida na escolha de prioridades e sua (re)organização dentre as várias possibilidades de fazer frente aos problemas de saúde da população. Assim, como ferramenta de organização de demandas de saúde e, originadas por novos problemas ou atores sociais, as políticas públicas permitem a tomada de decisões e a criação de ações coordenadas e reguladas, no nível federal, para as instâncias subnacionais de governo (COHN, 2006; LEVCOVITZ et al., 2001; BARBOSA, 2000).

\footnotetext{
${ }^{7}$ A I Confertencia Internacional sobre Promoçlo da Saúde, ocorreu em Ottawa, Canadá, em 1986 A Carta de Ottawa propóe cinco campos centrais de actio: 1. elaboractio e implementactlo de 'políticas públicas saudáveis'; 2. criaclio de 'ambientes favordveis à saúde'; 3. reforço da 'ą̧lo comunitária'; 4. desenvolvimento de 'habilidades pessoais' e 5 . 'reorientaçlo do sistema de saúde'. Além de enfatizar que as perspectivas para a saúde demandam de açoes coordenadas entre todas as partes envolvidas: governo, setor saúde e outros setores sociais e económicos, organizagoes voluntárias e n\$o governamentais autoridades locais, midia e indústria (BUSS, 2003; WESTPHAL, 2006).

o conceito de empowerment diz respeito à fundamentagalo das praticas sociais que se orientam pela autonomia dos atores sociais na luta por seus direitos e na elaboraç\$o de suas estratégias e açoes. É uma versta do conceito de Paulo Freire, conscientizaça social.
} 
Estabelecem-se as Agendas Políticas Nacionais; os Planos (planejamento em médio prazo, com os objetivos e metas a serem atingidas); os Programas (instrumento de organização da atuação governamental que articula um conjunto de ações que concorrem para um objetivo comum pré-estabelecido, mensurado por indicadores instituídos num plano, o Programa é o módulo integrador entre o plano e orçamento); as Ações (atividades e projetos, que são instrumentos utilizados para a viabilização dos programas); as Atividades (instrumento de programação utilizado para alcançar o objetivo de um Programa, envolvendo um conjunto de operações que se realiza de modo contínuo e permanente da qual resulta um produto) e os Projetos (instrumento de programação utilizado para alcançar o objetivo de um Programa, envolvendo um conjunto de operações, limitado no tempo, do qual resulta um produto).

Nesse sentido, as políticas públicas são um conjunto articulado de plano, ações, programas e projetos do governo (muitas vezes, em parceria com organizações da sociedade civil), previstos em orçamento, visando a redução da desigualdade social e a qualidade de vida de todas as pessoas nas áreas de educação, saúde, moradia, segurança, esporte, lazer etc .

As políticas públicas voltadas para as crianças, adolescentes e jovens são fundamentais para a garantia dos seus direitos. São essas políticas que fazem sair do papel tudo o que já é lei e está na Constituição Federal e no Estatuto da Criança e do Adolescente (ECA) (DARLAN, 1998).

Nessa ótica tomam-se como diretrizes para as ações mundiais os Objetivos do Desenvolvimento do Milênio (ODM), derivados da Declaração das Nações Unidas para o Milênio, adotada por 189 nações, em 2000. Foram determinados metas e objetivos para serem atingidos até 2015 , baseadas na situação global durante a década de 90 (WHO, 2005b).

Observa-se que no Relatório sobre Saúde do Mundo de 2000 da OMS, o Brasil foi classificado em antepenúltimo lugar segundo eqüidade das contribuições financeiras aos sistemas de saúde, numa lista de 191 Estados-Membros (MOREL, 2004). 
Muitos indicadores dos países envolvidos no ODM, como a mortalidade infantil e desnutrição, por exemplo, são originários de pesquisas de avaliação fidedignas e divulgadas pelas agências internacionais. Em cada país, os órgãos responsáveis por agregar as informações loco-regionais são responsáveis pela produção dos dados (WHO, 2005b).

A avaliação do avanço do ODMs nos países é dificultada pela falta de dados adequados para traçar os indicadores. Por isso, é necessário que cada país esteja participante, identifique suas falhas e lance ações urgentes para estruturar seus serviços estatísticos, os dados econômicos e sociais para o desenvolvimento de programa de ação na saúde (WHO, 2005a).

O último ODM traça 08 metas para os países envolvidos nessa ação: 1) erradicar a extrema pobreza e fome; 2) alcançar uma educação primária universal; 3) promover a eqüidade entre os gêneros e "empoderar" a mulher; 4) reduzir a mortalidade infantil; 5) melhorar a saúde materna; 6) combater HIV/AIDAS, malária e outras doenças; 7) garantir a sustentabilidade do ambiente; 8) desenvolver uma parceira global para o desenvolvimento (WHO, 2005b)

No que diz respeito à saúde materna e infantil, o Brasil sempre preocupado com essas questões e, demonstrando avanços significativos com outras iniciativas, lança o Pacto Nacional pela Redução da Mortalidade Materna e Neonatal, em 2004. Esse pacto foi prioridade do Ministério da Saúde e compromisso do governo federal (BRASIL, 2004b).

Foi editado, ainda, como estratégias que compõem esta iniciativa, o Manual dos Comitês de Prevenção da Mortalidade Infantil e Fetal, com objetivo de estruturar a vigilância dos óbitos infantis em âmbito nacional (BRASIL, 2004b).

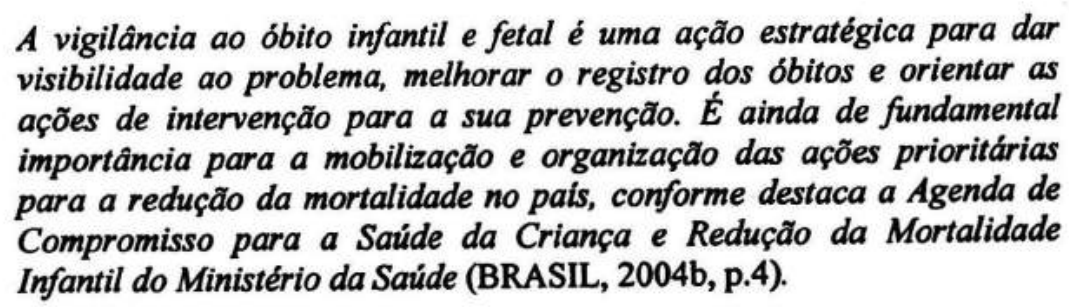

O Manual é referência para a estruturação dos Comitês no país (municipais, regionais e estaduais), fornece subsídios e orientações para o seu funcionamento e 
para a investigação dos óbitos e disponibiliza modelos de formulários para a investigação (BRASIL, 2004b).

O estado do Paraná tem uma experiência pioneira seguindo a estratégia de prevenção do óbito infantil, que se orienta pela recomendação de: estruturação e implantação dos Comitês de Prevenção da Mortalidade Infantil. Este percurso histórico da estruturação dos Comitês é o objeto desse trabalho de pesquisa. Será apresentado nos próximos capítulos. 


\subsection{A AVALIAÇÃO: UM CAMINHO PARA A MELHORIA}

\section{DAS AÇÕES EM SAÚDE}

Nesta sessão tratar-se-á de alguns aspectos sociais que levaram à avaliação do sistema de saúde. $\mathrm{O}$ marco para a avaliação da saúde pode-se dizer está no período pós Segunda Guerra Mundial. Nos países centrais do capitalismo, após esse período, iniciou-se um movimento de avaliação das ações da saúde por meio de novos métodos e técnicas científicas, dos programas e projetos sociais, em virtude de um grande investimento em políticas públicas de bem-estar social. Pode-se dizer que a avaliação passou nos últimos 60 anos, "a fazer parte da pauta de investimentos teóricos e práticos, ao lado das pesquisas sociais, visando à maior eficiência na aplicação de recursos e à efetividade nas ações" (MINAYO, 2005a, p.21).

No início da década de 90, no Brasil, com a chamada crise financeira com a qual o país se defrontava e com a diminuição da participação do Estado nas áreas de interesse público e, com o desenvolvimento de espaços de participação e de controle social no Brasil, "houve um aumento significativo do interesse por resultados, por processos mais efetivos e por iniciativas transparentes e socialmente responsáveis". Nesse contexto, a avaliação passa a "ocupar posição de importância crescente na sociedade brasileira" (SILVA e BRANDÃO, 2003, p.3).

São muitas as definições de avaliação, CONTANDRIOPOULOS et al, (2000) afirmam, que cada avaliador constrói a sua. No entanto, cita-se aqui a definição objeto de um amplo consenso nos dias atuais: "Avaliar consiste fundamentalmente em fazer um julgamento de valor a respeito de uma intervenção ou sobre qualquer um de seus componentes, com o objetivo de ajudar na tomada de decisões" (CONTANDRIOPOULOS et al, 2000, p.31; TANAKA e MELO, 2001).

A Organização Mundial da Saúde - OMS (1985) enfatiza que "a avaliação em saúde compreende todo o processo de emissão de juízo de valor, aplicado à questão saúde: serviços, programas e atividades de saúde". Na avaliação de saúde os parâmetros, ou marcos possíveis ou "optimum possivel" podem ser universais ou 
ajustados a uma realidade de tempo e lugar, em relação aos aspectos técnicos e sócioculturais (CARVALHO et al., 2000, p.74).

Segundo MINAYO (2005a, p.23) avaliar, em sentido bem amplo, "significa julgar, estimar, medir, classificar, analisar criticamente alguém ou algo". Para MINAYO (2005, p.23) a avaliação "é um processo essencialmente humano e realizado cotidianamente pelo senso comum".

Pabon (1985, apud MINAYO, 2005a, p. 23) traz uma definição acadêmica e tradicional de avaliação: "É a sistemática para medir um fenômeno ou o desempenho de um processo, comparar o resultado obtido com os critérios estabelecidos e fazer uma análise crítica, considerando-se a magnitude da direção da diferença". Nessa conceituação a ênfase está na avaliação "como uma intervenção externa aos objetos e sujeitos avaliados".

Já para SILVA e BRANDÃO e (2003, p.3):

[...] a avaliação consiste na elaboração, negociação e aplicação de critérios explicitos de análise, em um exercício metodológico cuidadoso e preciso, com vistas a conhecer, medir, determinar ou julgar o contexto, mérito, valor ou estado de um determinado objeto, a fim de estimular $e$ facilitar processos de aprendizagem e de desenvolvimento de pessoas $e$ organizações.

De acordo com SILVA e BRANDÃO (2003) e COHEN e FRANCO (1993) existem diversas maneiras de estruturarmos um processo avaliativo em projetos e programas sociais. No entanto nota-se que a relevância do conceito de avaliação está no "sentido construcionista e de parceria no processo". É uma conceituação mais inovadora e contemporânea, no movimento atual de críticas à avaliação formal e surgimento de outras tentativas conceituais (MINAYO, 2005a, p.24).

SILVA e BRANDÃO $(2003$, p.2) lançam os quatro elementos da avaliação, por meio de um exercício metafórico que ajuda "a aproximar a pessoas do tema e desmistificar alguns dos receios que ainda acompanham o pensamento sobre avaliação". São expostos quatro eixos para a avaliação de programas sociais, segundo algumas propriedades de elementos da natureza: ar, terra, água e fogo. A classificação é a seguinte:

I. Ar: reflete a constante busca por atribuir sentido aos processos avaliativos, o 'por quê avaliar?' (de natureza reflexiva e abstrata). $\mathrm{O}$ alinhamento dos conceitos sobre a avaliação 
(em torno de um padrão ćonceitual do objeto de ação), o fortalecimento da equipe de trabalho, são favorecidos pela construção do sentido da avaliação.

II. Terra: reflete os esforços em desenvolver formas metodológicas adequadas para a investigação da realidade em cada processo avaliativo; fase na qual são expostos os esforços mais volumosos (de natureza científica, concreta, ferramental). Compreende sete passos metodológicos, a saber, (1) a elaboração da pergunta avaliativa, (2) a elaboração dos indicadores, (3) a escolha dos indicadores, (4) a escolha das formas de coleta de informações, (5) o trabalho de campo, coleta das informações, (6) a análise das informações, (7) a comunicação dos resultados. Todas úteis e necessárias para os avaliadores, em qualquer desenho de avaliação; a seqüência de passos metodológicos claros e interrelacionados assegura a consistência de um processo de avaliação.

III. Agua: a preocupação na condução de processos avaliativos pautados em princípios éticos (natureza transparente, capacidade de lubrificar as relações, unir virtudes, e de cuidar pra que os processos sejam "limpos"). Devido à ética obedecer a contextos culturais e temporais de cada povo, deve-se na avaliação zelar por alguns pontos: respeitar todos os individuos envolvidos no processo; explicitar as intenções em cada etapa do processo; realizar avaliações justas, examinar e registrar tanto as informações de caráter positivo quanto as e caráter negativo do programa avaliado, tomando-se os mesmos cuidados na análise e divulgação dos resultados; transparência na comunicação; responsabilidade fiscal, que pressupõe a clareza e detalhamento do orçamento e a correta alocação de recurso e prestação de contas transparente para financiadores.

IV. Fogo: a necessidade de construir capacidade avaliativa na sociedade brasileira, aspecto que ultrapassa os limites de um projeto ou programa específico, olha para as organizações de um ponto de vista sistêmico (natureza multiplicadora de forças, de cruzar fronteiras, visitar territórios, combustível, geradora de conhecimentos e práticas). Os autores tratam da construção de capacidade avaliativa por meio de cinco componente: (1) necessidade de buscar identidade: buscar entendimento; (2) necessidade de enfrentar o desafio de transferência de poder: conquista de autonomia, de desenvolvimento de capacidade avaliativa, "alguns chamam de empowerment evaluation, ou avaliação emancipadora, terá esta como uma de suas dimensões principais" (p.15); (3) necessidade de buscar motivação: esforços acessando o "desejo de aprender existente nas pessoas e nas organizações que se lançam no caminho da avaliação de suas práticas" (p. 15); (4) necessidade de desenvolver competências em avaliação: relacionado ao preparo das pessoas em três grandes campos de 
competência para atuarem como avaliadores: competência para a facilitação de processos; competência para a gestão de processos; competência para investigação da realidade. (5) alocar recursos.

Pela avaliação normativa prescreve-se o julgamento resultante da aplicação de critérios e de normas, e por meio da pesquisa avaliativa, é elaborado um procedimento científico. Ambas podem coexistir em uma intervenção, entendida pelo "conjunto dos meios - físicos, humanos, financeiros, simbólicos - organizados em um contexto específico, em um dado momento, para produzir bens ou serviços com o objetivo de modificar uma situação problemática" (CONTANDRIOPOULOS et al, 2000, p.31).

A pesquisa avaliativa, para COHEN e FRANCO (1993, p.78), baseados no conceito de Henningan et al. (1982) consiste num subconjunto de um processo de avaliação; pois, a avaliação é "o processo de gerar informações sobre as operações e o impacto da aplicação de programas e políticas" a pesquisa avaliativa como "aplicação de métodos empíricos ou de pesquisa científicos à avaliação de programas para chegar a afirmações causais e logicamente defensáveis sobre a eficácia dos mesmos". Afirmam COHEN e FRANCO (1993) que realmente muitos autores utilizam como sinônimos, a avaliação e a pesquisa avaliativa.

Os objetivos 'oficiais', segundo CONTANDRIOPOULOS et al. (2000, p.34), de uma avaliação são de quatro tipos:

1. Ajudar no planejamento e na elaboração de uma intervenção (objetivo estratégico);

2. fornecer uma informação para melhorar a intervenção em seu decorrer (objetivo formativo);

3. determinar os efeitos de uma intervenção para decidir se ela deve ser mantida, transformada de forma importante ou interrompida (objetivo somativo);

4. contribuir para o progresso dos conhecimentos, para a elaboração teórica (objetivo fundamental).

A avaliação em saúde não pode encerrar-se em si mesma; ela completa-se quando é instrumento desencadeador de ações para reafirmar a exatidão daquilo que

\footnotetext{
' Os autores enfatizam que sắo numerosos os objetivos de uma avaliaç̆o, e alem dos oficiais citados acima, há os oficiosos dos diferentes atores - administradores, avaliadores, usuários, e pessoal de uma organizaçato - explicitos ou implicitos, consensuais ou conflitantes, aceitos por todos os atores ou somente por alguns.
} 
foi objeto de avaliação ou, de outro lado, modificar e transformar estruturas ou ações que não estejam cumprindo sua finalidade última" (CARVALHO et al., 2000).

Escudero (1989) citado por CARVALHO et al. (2000) afirma que a verdadeira intencionalidade da avaliação em sua concepção global e holística é apoiar a tomada de decisões, ainda que se refira a resultados. O objetivo final da avaliação em saúde deve ser sua utilização prática nas várias fases do planejamento dos serviços e programas de saúde (TANAKA e MELO, 2001).

A delimitação do objetivo da avaliação é a primeira etapa ou fase da avaliação. Após definição do objetivo, define-se o objeto da avaliação. É importante que, para cada situação, se defina objetivo e objeto, para que a escolha do método avaliativo seja coerente e correto. $O$ objeto da avaliação pode ser: a estrutura, o processo ou o produto. Há necessidade de determinar o que vai se buscar na medição da informação, para que haja planejamento da coleta e sistematização (CARVALHO et al., 2000; TANAKA e MELO, 2001; CANO, 2004; COHEN e FRANCO, 1993).

Definidos esses pontos, a etapa seguinte da avaliação consiste na escolha do ponto de comparação, "a determinação e definição dos parâmetros que serão utilizados ao se fazer a comparação, a aplicação da valorização, do juízo de valor ante o encontrado e o ideal estabelecido desejado" (Donabedian, 1982, apud CARVALHO et al., 2000, p.75). Esses parâmetros podem ser definidos por indicadores, que busquem o optimum, como comparação no ajuizamento de valor, isto se configura como a busca da qualidade.

Assim pode-se ter, de acordo com CONTANDRIOPOULOS et al. (2000), CARVALHO et al. (2000), TANAKA e MELO (2001) e COHEN e FRANCO (1993) um processo de avaliação sistêmica, na qual a estrutura estuda o input à atenção à saúde, o processo com todos os seus componentes, o resultado como 0 output e as consequêencias, como o impacto. A qualidade da avaliação será medida pelo desenvolvimento dialético do pesquisador mediante a interação dos três tipos. Desse modo, tem-se:

a) Apreciação / Avaliação da Estrutura: enfoca características dos recursos e condições destinados à prestação de assistência à saúde, compreende os insumos básicos. Parte-se do pressuposto de que a garantia das condições mínimas de funcionamento dos serviços de saúde facilita a obtenł̧ão dus resultados esperados. Comparam-se recursos da intervenção, 
sua organização, critérios e normas correspondentes. A eqüidade, como componente da qualidade e de determinação do impacto social da intervenção, em parte pode ser avaliada nesta fase, ao se visualizar e adequar a oferta de serviços à demanda de necessidades. Assim são colocados quatro elementos estruturais como necessários para satisfazer às necessidades de saúde de uma comunidade: 1 . facilidades físicas e equipamentos; 2 . qualidade da mão de obra, do corpo técnico; 3 . conhecimento biomédico e 4 . habilidade para fazer uso do conhecimento; a satisfação destes elementos deve ser pela ordem que estão expostos, como especifica Geyndt (1970) citado por CARVALHO et al. (2000).

b) Apreciação / Avaliação do Processo ou conteúdo: interessa saber em que medida os serviços são adequados para atingir os resultados esperados. Pode ser decomposta em três dịmensões: técnica, das relações interpessoais entre clientes e produtores do cuidado e organizacional; estes últimos dizem respeito à acessibilidade, à cobertura, globalidade (entendida como o caráter multiprofissional e interorganizacional) e continuidade dos cuidados (CONTANDRIOPOULOS et al., 2000).

c) Apreciação / Avaliação dos Resultados: é realizada comparando-se os resultados alcançados com os critérios, normas e resultados esperados.Esta avaliação de maneira isolada pode ser insuficiente para fazer um julgamento válido sobre os resultados da intervenção.

CONTANDRIOPOULOS et al. (2000) indicam a pesquisa avaliativa por ser mais completa e por permitir uma emissão de juízo mais válida e pertinente, devido aos seus métodos científicos. Esta avaliação pode ser decomposta em seis tipos de análise (estratégia, intervenção, produtividade, efeito, rendimento e implantação). Dessa maneira, buscam-se várias estratégias de pesquisa e se considera as perspectivas dos diversos atores envolvidos na intervenção. MINAYO (2005a) refere-se ao conceito de Contandriopoulos como uma avaliação com fundamentos científicos e que acresce ao processo normativo os elementos do contexto.

CARVALHO et al. (2000) relacionam as variáveis mais utilizadas como indicador de qualidade em saúde, em processos de avaliação: a EFICÁcı que é a medida do resultado conseguido por determinada ação, ou o efeito que se pretende ter; a EFICIÊNCIA é a medida do resultado em relação ao seu custo de produção, comparação entre resultados e meios utilizados - relação custo-benefício; a EFETIVIDADE é a eficácia com aceitabilidade social; a PERTINÊNCIA é a 
compatibilidade entre a política de saúde adotada e as políticas sociais e econômicas; a SUFICIÊNCIA é relação entre as necessidades da população e os serviços disponíveis, bem como suas distribuição eqüitativa; a QUALIDADE TÉCNICO CIENTíFICA é a incorporação dos conhecimentos técnico-científicos socialmente aceitos à atenção à saúde; a INTEGRALIDADE é a atenção prestada ao indivíduo como um todo com ações interativas a EQƯIDADE é a atenção prestada a todos, no entanto, equiitativa em resposta à quantidade e qualidade da necessidade de cada indivíduo; e a INTERAÇÃo MÉDICO-PACIENTE, relação interpessoal dentro do respeito de igualdade como seres humanos em diferentes papéis.

Quadro1: Oposições complementares entre os papéis da pesquisa acadêmica de avaliação e a investigação avaliativa.

\begin{tabular}{|c|c|c|}
\hline MotrVAÇAo & $\begin{array}{l}\text { Satisfaz curiosidades por meio de avanços } \\
\text { no campo do conhecimento. }\end{array}$ & $\begin{array}{l}\text { Contribui para a soluçăo de problemas } \\
\text { práticos. }\end{array}$ \\
\hline $\begin{array}{l}\text { OBJETIVO DA } \\
\text { INVESTIGAÇAOO }\end{array}$ & Busca conclusões. & Leva a decisóes. \\
\hline AUTONOMIA & $\begin{array}{l}\text { Empreendimento mais ou menos } \\
\text { independente e autônomo. }\end{array}$ & $\begin{array}{l}\text { Conduzida de acordo com o escopo } \\
\text { delimitado pelos clientes. }\end{array}$ \\
\hline $\begin{array}{l}\text { PROPRIEDADES DO } \\
\text { FENÓMENO } \\
\end{array}$ & $\begin{array}{l}\text { Feita primordialmente para gerar } \\
\text { conhecimento. }\end{array}$ & $\begin{array}{l}\text { Visa analisar a utilidade social e o valor de } \\
\text { uma proposta. }\end{array}$ \\
\hline $\begin{array}{l}\text { CRITÉrios de } \\
\text { AdEQuaÇÃo }\end{array}$ & Julgada pela sua validade interna e externa. & $\begin{array}{l}\text { O julgamento deve levar em conta: } \\
\text { precisð̃o, credibilidade, utilidade, } \\
\text { viabilidade e propriedade. }\end{array}$ \\
\hline CuEnTES & $\begin{array}{l}\text { Procura ser conduzida a partir de uma idéia } \\
\text { muito genérica de quem poderia usar seus } \\
\text { resultados. }\end{array}$ & $\begin{array}{l}\text { Deve iniciar identificando claramente seus } \\
\text { destinatários e seu alvo. }\end{array}$ \\
\hline LIMITES DO TEMPO & $\begin{array}{l}\text { Organiza seu cronograma com critérios } \\
\text { cientificos e orçamentários. }\end{array}$ & $\begin{array}{l}\text { Prende-se aos cronogramas restritos dos } \\
\text { rumos da intervençăo e da demanda dos } \\
\text { destinatários. }\end{array}$ \\
\hline $\begin{array}{l}\text { ASPECTOS } \\
\text { DISCIPLINARES }\end{array}$ & $\begin{array}{l}\text { Pode ou nåo ser interdisciplinar, cabe ao } \\
\text { pesquisador definir. }\end{array}$ & $\begin{array}{l}\text { Precisa lançar måo de amplo espectro de } \\
\text { perspectivas e técnicas para aferir } \\
\text { resultados qualitativos e quantitativos de } \\
\text { várias ordens. }\end{array}$ \\
\hline PreparaçAo & $\begin{array}{l}\text { Pesquisador atua dentro do limite de sua } \\
\text { disciplina, geralmente. }\end{array}$ & $\begin{array}{l}\text { Avaliador precisa estar familiarizado com } \\
\text { ampla variedade de métodos e técnicas, } \\
\text { visando à diversificaçăo e combinaçăo das } \\
\text { informaços (sociais, econômicas, } \\
\text { organizacionais e outras) requeridas pelos } \\
\text { destinatários. }\end{array}$ \\
\hline
\end{tabular}

Fonte: Worthen e Sanders (2004) apud MINAYO (2005a, p.25-26). Quadro elaborado pelo pesquisador.

É interessante notar o enfoque de MINAYO (2005a, p.25) em relação à investigação avaliativa e, sua distinção da noção de pesquisa acadêmica, quando ressalta que os pesquisadores e avaliadores "trabalham dentro do mesmo paradigma de investigação, mas assumem papéis gerenciais diferentes e atuam para diferentes 
audiências". MYNAIO (2005a) relata também algumas "oposições complementares que distinguem esses papéis", segundo Worthen e Sanders (2004 apud MINAYO, 2005a, p.25-26), que são apontadas no Quadro 1.

A avaliação na presente pesquisa é orientada, à semelhança das tentativas contemporâneas, como um processo com desafios complexos, não um evento isolado, no qual interagem e integram-se o avaliador e o(s) sujeito(s) avaliado(s) em busca de comprometimento do aperfeiçoamento dos indivíduos, grupos, programas $\mathrm{e}$ instituições. Considera-se uma boa avaliação de uma ação estratégica para o fortalecimento organizacional, aquela que é criadora de espaço de reflexão sobre a prática e propicia a tomada de decisões relevantes (MINAYO, 2005a; BRANDÃO et al., 2005; SILVA e BRANDÃO, 2003). Essa posição insere-se na modalidade de uma pesquisa acadêmica por meio de uma investigação avaliativa (CONTANDRIOPOULOS et al., 2000; HARTZ, 1997; SILVA e FORMIGLI, 1994).

Ainda segundo COHEN e FRANCO (1993) a constante dentre os diferentes modelos de avaliação, é:

\begin{abstract}
[...]por um lado, a pretensão de comparar um padrão almejado (imagemobjetivo em direção à qual se orienta a ação) com a realidade (a medida potencial na qual esta vai ser modificada, ou o que realmente ocorreu como consequência da atividade empreendida), por outro lado, a preocupação em alcançar eficazmente os objetivos propostos (COHEN e FRANCO 1993, p.73).
\end{abstract}

Considerando o parecer de COHEN e FRANCO (1993, p. 16) de que "sem dúvida alguma, a avaliação inclui explicitamente a qualidade e a possibilidade de medi-la".

O Ministério da Saúde (BRASIL, 2004a) como base das orientações ao Programa Nacional de Avaliação de Serviços de Saúde (PNASS) enfatiza que:

[...]A avaliação em saride tem como pressuposto a avaliação da eficiência, eficácia e efetividade das estruturas, processos e resultados relacionados ao risco, acesso e satisfação dos cidadãos frente aos serviços públicos de saúde na busca de resolutividade e qualidade. A avaliação é, em especial, parte fundamental no planejamento e na gestão do sistema de saúde. Um sistema de avaliação efetivo deve reordenar a execução das ações $e$ serviços, redimensionando-os de forma a contemplas as necessidades de seu público, dando maior racionalidade ao uso dos recursos (BRASIL, 2004a, p. 5). 
Por meio dos conceitos, idéias e discussão aduzidos neste capítulo permitimonos concluir que um processo de avaliação conduzido com seriedade, objetivos claros e fins determinados será útil para a melhoria, (re)adequação e (re)definição de caminhos possíveis para a continuidade e consolidação de programas em saúde, em especial, a prevenção da mortalidade infantil. Neste sentido, procurou-se no presente trabalho de tese conduzir uma investigação avaliativa, de caráter dialético e compreensivo, sobre a prevenção da mortalidade infantil utilizando-se de métodos quanti e qualitativos. 


\subsection{O ESTADO DO PARANÁ}

\subsubsection{CARACTERÍSTICAS GEOGRÁFICAS E POPULACIONAIS}

O Estado do Paraná localiza-se na região Sul do Brasil. Faz fronteira, ao Norte, com o estado de São Paulo; ao Sul, com o estado de Santa Catarina; a Oeste com o estado do Mato Grosso do Sul e, também, com o Paraguay e Argentina.

O Paraná conta com uma área de $199.304 \mathrm{~km}^{2}$ e uma população estimada em 2005 de 10.261.856 habitantes, distribuída em 399 municípios, segundo as informações sobre Estados do Instituto Brasileiro de Geografia e Estatística (IBGE, 2007). De acordo com o Plano de Regionalização do Estado (PR/SESA, 2001), em 2001 havia $54 \%$ dos municípios com menos de 10.000 habitantes, $26 \%$ com menos de 20.000 habitantes e $20 \%$ com mais de 20.000 habitantes.

Os dados demográficos do DATASUS (Departamento de Informática do SUS; BRASIL, 2007b) no período de interesse para a pesquisa, de 1997 a 2005, agrupado em três Triênios, o Brasil apresentou um incremento populacional de $11,29 \%$, entre o primeiro período (1997/99) e o último triênio (2002/05) (Tabela 1). No entanto, afirmando mais uma vez a diversidade brasileira no que diz respeito à população, constatou-se para cada região incrementos diferentes. Numa escala descendente de incremento se obteve a seguinte ordem: Região Norte - 19,50\%, Centro-Oeste - 14,81\%, Sudeste - 11,27\%, Sul - 9,45\%, Nordeste - 9,32\%. A Região Sul, se comparada às demais, apresentou um das menores proporções de crescimento no período em questão (Apêndice 1).

Pode-se explicar essa diferença mediante a Teoria da Transição Demográfica (TD) composta pela resultante do perfil de fecundidade, natalidade e movimentos migratórios (entre áreas rurais e urbanas e inter-regionais). A TD acompanhando a Transição Epidemiológica presente nas Regiões, de acordo com suas peculiaridades de contexto sócio-político, econômico e cultural (PEREIRA, 1995; MEDRONHO et al., 2004).

MELLO JORGE et al. (2001) estudaram a evolução da população brasileira em 60 anos, de 1940 a 2000, na ordem de $312 \%$. Apontam o crescimento como 
decorrente do rápido "decréscimo da mortalidade geral e infantil, mantendo-se alta a taxa de fecundidade ${ }^{1}$, que só começou a cair em meados da década de 70" (MELLO JORGE et al., 2001, p.13).

Desta maneira, foi observado por MELLO JORGE et al. (2001) que, em 1970, a taxa de fecundidade no Brasil era de 5,8 filhos por mulher; esta se reduziu para 2,9 filhos em 1991 e para 2,3 filhos por mulher em 2000. Os autores chamaram a atenção para o fato do valor da taxa de fecundidade da região Sudeste, de 2,1 filhos por mulher, ser próximo ao nível de reposição popular.

Estudada a taxa média de incremento populacional anual no Brasil e Regiões, MELLO JORGE et al. (2001) observaram que as mesmas foram heterogêneas e, no período de 1991 a 2000, as maiores taxas médias aconteceram para as regiões Norte $(2,9 \%)$ e Centro-Oeste $(2,4 \%)$ e a menor para a região Nordeste $(1,3 \%)$, talvez devido à emigrações. As regiões Sudeste e Sul apresentaram 1,6\% e 1,4\%, respectivamente.

Tabela 1: Distribuição (n e \%) da população do Brasil segundo Regiões e Triênios, Brasil, 1997 a 2005.

\begin{tabular}{l|rr|rrrr}
\hline \multicolumn{1}{c}{$\begin{array}{c}\text { Ano } \\
\text { REGIÃo }\end{array}$} & $1^{\bullet}$ Triênio (1997-1999) & $2^{\bullet}$ Triênio (20002-2002) & \multicolumn{2}{c}{$3^{\bullet}$ Triênio (2003-2005) } \\
\hline Norte & \multicolumn{1}{c}{$\mathrm{N}^{\circ}$} & $\%$ & \multicolumn{1}{c}{$\%$} & \multicolumn{1}{c}{$\%$} & $\mathrm{~N}^{\circ}$ & $\%$ \\
Nordeste & 35.606 .570 & 7,34 & 39.650 .332 & 7,67 & 42.548 .007 & 7,88 \\
Sudeste & 137.434 .671 & 28,32 & 144.918 .048 & 28,04 & 150.238 .843 & 27,81 \\
Sul & 206.885 .226 & 42,62 & 220.330 .592 & 42,63 & 230.197 .684 & 42,62 \\
C.Oeste & 72.462 .612 & 14,93 & 76.295 .219 & 14,76 & 79.313 .597 & 14,68 \\
\hline Total & 32.984 .836 & 6,80 & 35.623 .687 & 6,89 & 37.870 .328 & 7,01 \\
\hline
\end{tabular}

Ao se investigar o contingente da população menor de um ano pode-se confirmar a situação de menor natalidade para as regiões Centro-Oeste, Norte e Sul quando comparadas às regiões Nordeste e Sudeste, em todo o período (Tabela 2). Essa leitura não deve ser realizada de maneira unilateral, pois a dimensão da população de menores de um ano nas regiões brasileiras é determinada também pela

\footnotetext{
' A Taxa e Fecundidade Total representa o número médin de filhns nascidos vivos tidos por uma mulher na faixa ettria de 15 a

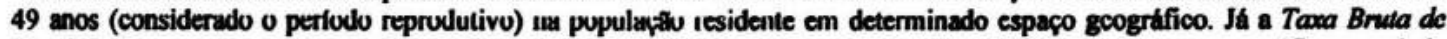
Natalidade representa o número de nascidos vivos por mil habitantes na populaçăo residente num espaco geográfico e periodo considerado, segundo os Indicadores Bdsicos para a Saúde no Brasill: conceltos e aplicaçס̃es (BRASIL, 2002c).
} 
ncidência de óbitos infantis e pelos processos migratórios, além dos próprios rascimentos.

A Região Sul apresentou menor incremento na população de crianças nenores de um ano em todo o país, $2,29 \%$ entre o primeiro e o último triênio, znquanto o país como um todo apresentou $6,61 \%$ de crescimento populacional de menores de um ano, no mesmo período. Numa escala também decrescente de incremento populacional de menores de um ano observou-se: Região Norte $14,79 \%$, Sudeste $-7,80 \%$, Centro-Oeste - 6,33\%, Nordeste - 4,66\% e Sul - 2,29\% (Tabela 2).

Tabela 2: Distribuição ( $\mathrm{n}^{\circ} \mathrm{e} \%$ ) da população de menor de um ano do Brasil segundo Regiões e Triênios, Brasil, 1997 a 2005.

\begin{tabular}{|c|c|c|c|c|c|c|}
\hline \multirow{2}{*}{$\begin{array}{c}\text { Ano } \\
\text { REGIÃo }\end{array}$} & \multicolumn{2}{|c|}{$1^{\bullet}$ Triênio (1997-1999) } & \multicolumn{2}{|c|}{$2 \bullet$ Triênio (20002-2002) } & \multicolumn{2}{|c|}{$3^{\circ}$ Triênio (2003-2005) } \\
\hline & $\mathbf{N}^{\circ}$ & $\%$ & $\mathbf{N}^{\circ}$ & $\%$ & $\mathbf{N}^{\circ}$ & $\%$ \\
\hline Norte & 923.760 & 9,60 & 986.776 & 10,08 & 1.060 .359 & 10,34 \\
\hline Nordeste & 2.999 .233 & 31,18 & 3.025 .400 & 30,91 & 3.138 .904 & 30,61 \\
\hline Sudeste & 3.657 .256 & 38,02 & 3.766 .284 & 38,48 & 3.942 .613 & 38,45 \\
\hline Sul & 1.352 .823 & 14,06 & 1.328 .112 & 13,57 & 1.383 .867 & 13,50 \\
\hline C.Oeste & 685.319 & 7,13 & 681.643 & 6,96 & 728.683 & 7,11 \\
\hline Total & 9.618.391 & 100,00 & 9.788 .215 & 100,00 & 10.254 .426 & 100,00 \\
\hline
\end{tabular}

Fonte: DATASUS / MS. Informaçoes de Saúde, Dados Demográficos e Económicos; dados brutos (BRASIL, 2007b).

Não é de interesse dessa tese o aprofundamento da discussão demográfica geral e, de menores de um ano, para o Brasil e Regióes, o objetivo central deste trabalho é buscar a constatação de que há uma redução no incremento populacional infantil menor de um ano, em todo o País, principalmente nas Regiões Norte e Sul, como reflexo de sua transição demográfica. Por esse aspecto também se justifica a preservação da vida e ações que evitem o óbito infantil.

\subsubsection{DIVISÃO ADMINISTRATIVA DA SAÚDE}

O Plano de Regionalização do Estado do Paraná é o principal instrumento de ordenamento do processo de regionalização, com base na Norma Operacional de Assistência à Saúde do Sistema Único de Saúde, $\mathrm{n}^{\circ}$ 01, do ano de 2001 - 
NOAS/SUS-01/2001 - , segundo a Portaria n ${ }^{\circ} 95$ de 26/01/2001, do Ministério da Saúde, que, dentre outras providências, amplia as responsabilidades dos municípios na atenção básica de saúde (PR/SESA, 2001).

Com base neste documento do estado do Paraná é observado que o estado exerce seu papel administrativo na área da saúde mediante a Secretaria de Estado da Saúde (SESA) e de suas 22 unidades Regionais de Saúde (RegS), as quais representam as instâncias administrativas intermediárias junto aos 399 municípios. A SESA tem como atribuição o apoio, cooperação técnica e investimentos nos municípios e nos Consórcios Intermunicipais de Saúde (PR/SESA, 2001).

$\mathrm{O}$ desenvolvimento da inteligência necessária para apoiar os municipios, em todas as áreas, e para influenciar na gestão das questões regionais, fomentando a busca contínua e crescente da eficiência com qualidade são funções das RegS (PR/SESA, 2001).

Foram organizadas, com a finalidade de administração da saúde, sete Macrorregionais de Saúde: Metropolitana, Campos Gerais, Centro, Norte, Noroeste, Oeste e Sudoeste, que não constituem novas instâncias administrativas estruturadas. Seu objetivo é articular as RegS em conjuntos que permitam ser somados esforços na solução de problemas comuns, bem como a troca de experiências (PR/SESA, 2001).

São considerados municípios pólos estaduais, um total de doze, por oferecerem serviços ambulatoriais e hospitalares de média e alta complexidade que atendem a população além da microrregião (PR/SESA, 2001).

Segundo o Plano Diretor de Regionalização, de 2001, dos 399 municípios, 13 encontravam-se em Gestão Plena do Sistema Municipal ${ }^{2}$ e os outros 386 em Gestão Plena da Atenção Básica, pela NOB/SUS-01/96. O Estado está habilitado em Gestão Plena do Sistema Estadual de Saúde, desde dezembro de 1999 (PR/SESA, 2001).

Uma das atribuições da gestão estadual de saúde é a elaboração de uma Agenda de Compromissos e Quadro de Metas, com estabelecimento de "eixos prioritários de intervenção, os objetivos, as metas e os indicadores a serem utilizados na sua avaliação", instrumento também que servirá para a emissão de relatório de gestão. Chama-se a atenção para a atualização das atribuições, condições de gestão,

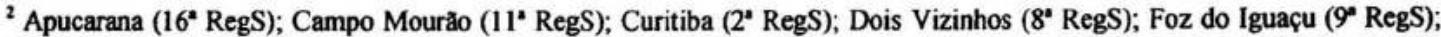

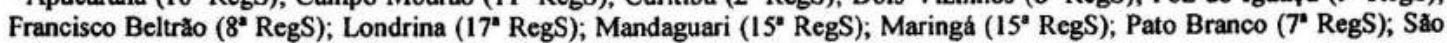
Jorge do Patrocinio (12 Reg S); Terra Boa (11 ${ }^{\wedge}$ RegS); Umuarama (12^ RegS).
} 
as prerrogativas dos gestores estaduais e municipais foram atualizadas mediante a NOAS/SUS/2002 (PR/SESA, 2003, p.1).

A Agenda de Saúde do Paraná de 2003 definiu cinco principais eixos de ação: 1) Descentralização das Ações e Serviços de Saúde; 2) Reorganização da Atenção à Saúde; 3) Gestão de Recursos Humanos para o SUS; 4) Informação como Instrumento Gerencial; 5) Adequação do Orçamento do Estado ao Preceito Constitucional de Saúde - Emenda Constitucional/EC $29^{3}$ (PR/SESA, 2003).

O objetivo estratégico da SESA de Promover a prevenção, a proteção $e$ a atenção à saúde, de forma integrada, descentralizada e regionalizada é contemplado mediante as 05 diretrizes citadas, bem como por seus eixos de atuação (PR/SESA, 2003)

Os eixos-programas prioritários sobre os quais estabelecem-se metas e compromissos são: prevenção, proteção e atenção à saúde; qualificação de recursos humanos para a saúde e financiamento (PR/SESA, 2003).

São apontados, na seqüência, alguns objetivos referentes à saúde maternoinfantil, em especial para a saúde das crianças menores de um ano de idade, que são contemplados pelos eixos-programas estabelecidos para o estado do Paraná, em 2003. Não será realizado nenhum comentário relativo ao quinto-eixo devido a não se constituir objetivo deste trabalho a discussão do orçamento do governo (PR/SESA, 2003).

Em relação ao Eixo I, ou seja, o de Prevenção à Saúde, são identificados objetivos que privilegiam, direta ou indiretamente, o cuidado com a saúde da criança menor de um ano, dentre eles ressaltam-se:

* Reativar a Comissão Estadual de Epidemiologia.

* Manter a cobertura por Tetravalente, Pólio, Hepatite, BCG.

* Manter a cobertura por Tríplice Viral (em população menor de um ano).

* Reduzir o número de casos de sarampo e assegurar a não circulação do vírus.

* Implantar o Controle de Qualidade do leite para o Projeto Leite das Crianças.

\footnotetext{
${ }^{3}$ Altera os arts. 34, 35, 156, 160, 167 e 198 da Constituiģło Federal e acrescenta artigo ao Ato das Disposiços Constitucionais Transitórias, para assegurar os recursos mínimos para o financiamento das açoes e serviços públicos de saúde.
} 
No Eixo II, de Proteção à Saúde encontra-se a Redução da Mortalidade Infantil e como meta preservada a redução de $3 \%$ ao ano do $\mathrm{CMI}$, tomando como base o CMI de 16,4 por mil NV em 2002. Dentre outras ações de Proteção à Saúde Materna e Infantil encontram-se nesse eixo:

* Implementar Protocolo Estadual de Neonatologia, com cursos de capacitação, em parceria com a Sociedade Brasileira e Paranaense de Pediatria.

* Reduzir a Desnutrição Infantil, contemplando 843.890 beneficiários com o Projeto Bolsa Alimentação, do SISVAN; situação de atendimento em 2002 foi de 121.208 entre crianças, gestantes e nutrizes.

* Implantar o Teste da Orelhinha como Projeto Piloto em Curitiba.

* Reduzir a Mortalidade Materna, em 3\% ao ano, com base na razão de mortalidade materna de 57 por cem mil NV em 2002.

* Acompanhar as gestantes atendidas pelo SUS com no mínimo 04 consultas de pré-natal; situação do indicador em 2002 era de $99,5 \%$ das gestantes.

* Adquirir equipamentos complementares de UTI Neonatal para 48 hospitais de referência em Gestação de Alto Risco (12 definidos pelo MS e 36 pelo Estado); situação em 2002 foi de cessão de equipamentos para 06 hospitais pela Secretaria Estadual de Saúde.

Com relação ao Eixo III, de Atenção à Saúde verificam-se as seguintes pautas:

- Expandir o Programa Saúde da Família com cobertura de equipes de saúde da família para $40 \%$ da população; em 2002 havia cobertura de $38,1 \%$.

* Implantar o Incentivo ao PSF para municípios com menos de 100 mil habitantes, para $50 \%$ desses municípios; em 2002 esse incentivo não existia.

* Implementar o Sistema Estadual de Atendimentos de Urgências e Emergências/ Pré Hospitalares, com aquisição de 28 ambulâncias para o SIATE. Em 2002 havia a cessão de equipamentos para 30 hospitais e 02 Pronto Atendimentos, mediante o Projeto Paraná Urgência e Emergência.

* Aprimorar as ações de Serviços de Saúde executadas pelos Hospitais de referência regional. Implantar incentivo financeiro de custeio para 3 Hospitais Universitários e 13 Filantrópicos. Em 2002, não havia esse incentivo.

Pertinente ao Eixo IV, de Qualificação de Recursos Humanos para a saúde, verificou-se as seguintes pautas:

* Implantar Pólos Regionais de Educação Permanente em Saúde (PREPS) como espaço de articulação regional. Em 2002 havia a existência de 5 Pólos Macro-Regionais do PSF.

* Formar trabalhadores da área de saúde de nível médio e pós-médio. 
* Capacitar e desenvolver trabalhadores / usuários da saúde em ações de promoção, prevenção e recuperação. Mediante a realização de eventos formadores (40 eventos).

* Incentivar uma política de educação para o SUS, estimulando mudanças na formação superior e técnica dus profissiunais de saúde. Mediante a conclusãu da propusta do PróSaúde Paraná.

- Formular proposta de pesquisa para avaliação dos sistemas de atenção à saúde em parceria com os PREPS.

Ressalta-se também que o estado do Paraná apresenta uma experiência pioneira na vigilância e investigação dos óbitos infantis (desde 1997). Foram estruturados, implantados e implementados os Comitês de Prevenção da Mortalidade Infantil nas 22 Regionais de Saúde e, em vários Municípios do estado. Essa história é parte da presente investigação e será relatada nos Capítulos subseqüentes.

Como se pode observar são vários os objetivos e metas traçadas para melhoria do nível da qualidade e dos indicadores de saúde da população paranaense e, em especial, para a criança menor de um ano e para as mulheres, no estado do Paraná. $\mathrm{O}$ alcance e manutenção dos mesmos dependerão de cada município, dos gestores e profissionais envolvidos nas instâncias pertinentes, bem como da contribuição da população.

$\mathrm{O}$ acompanhamento dos indicadores de saúde, principalmente os de morbimortalidade, deve ser realizado pelos próprios serviços e, também devem ser estudados em pesquisas que busquem por evidências de impacto e efetividade das ações implementadas. Nesta linha de raciocínio enquadra-se este estudo que tem seus objetivos especificados a seguir. 


\section{OS OBJETIVOS}

Diante de inúmeras possibilidades para realizar uma leitura de como está a Mortalidade Infantil no Paraná e sua prevenção; conhecer o andamento do trabalho de investigação dos óbitos infantis no estado e também saber o que pensam os profissionais da saúde sobre a prevenção da mortalidade infantil no Paraná, seguiu-se os objetivos:

\subsection{OBJETIVO GERAL}

1) Avaliar O IMPACTO DO TRABALHO PREVENTIVO DO ÓBITO INFANTIL DESENVOlVIDO NO ESTADO dO PARANÁ E SUA REPRESENTAÇão SOCIAL PARA OS PROFISSIONAIS DA SAÚDE.

\subsection{OBJETIVOS ESPECÍFICOS}

1) Analisar os óbitos infantis registrados no Sistema de Informação de Mortalidade Infantil / SIMI, no período de 2000 a 2005 segundo as variáveis: sexo; idade; percentuais de investigação; evitabilidade; determinantes causais; medidas de prevenção e intervenção na mortalidade infantil.

2) Identificar ações conhecidas pelos profissionais de saúde em relação à prevenção da morte infantil, em algumas Regionais de Saúde do estado do Paraná.

3) Conhecer as dificuldades relatadas pelos atores sociais para implementação de ações de prevenção da morte infantil em algumas Regionais de Saúde do estado do Paraná.

4) Identificar as sugestões dos profissionais de saúde para a estratégia de prevenção do óbito infantil dos Comitês de Prevenção da Mortalidade Infantil. 


\section{A METODOLOGIA}

\subsection{A FUNDAMENTAÇÃO TEÓRICA ACERCA DO MÉTODO}

Para que se possa lidar com emoções, valores e subjetividade nas ciências sociais de modo diverso da visão positivista é necessário utilizar-se de uma metodologia em um contexto de significado para os atores sociais que se pretende investigar. Assim, na pesquisa qualitativa o pesquisador se preocupa com o aprofundamento da compreensão de um grupo social, de uma organização, de uma instituição, de uma trajetória etc e, não com tão somente com a representatividade numérica (GOLDENBERG, 2003).

Pode-se pontuar a pesquisa qualitativa, de acordo com MINAYO (2004) quando Max Weber (1864-1920) apropriou-se da idéia do filósofo alemão Wilhelm Dilthey (1833-1911), um dos primeiros críticos do emprego dos métodos das ciências naturais nas ciências sociais, dada a diferença entre seus objetos de estudo. Dilthey (apud MINAYO, 2004, p.50) afirma “que os fatos humanos não são suscetíveis de quantificação e de objetivação porque cada um deles tem sentido próprio e identidade peculiar, exigindo uma compreensão específica e concreta". Nas ciências sociais a compreensão interpretativa das experiências dos indivíduos dentro do contexto em que foram vivenciadas (o chamado verstehen ${ }^{l}$ ) é o que importa (GOLDENBERG, 2003).

GOLDENBERG (2003) apresenta, então, a sociologia compreensiva, cujo maior representante foi Max Weber. Para Weber (apud GOLDENBERG, 2003, p.20) "o principal interesse da ciência social é o comportamento significativo dos indivíduos engajados na ação social", cada ator reinterpreta, agrega significado a seu comportamento, considerando os outros indivíduos; visão que se opõe à positivista de objetividade e de separação radical entre sujeito e objeto.

\footnotetext{
1 Dilthey diferencia o método das ciências naturais e das sociais, por meio de dois conceitos: "erklanen que busca generalizaçöes e a descoberta de regularidades" e o verstehen que visa a compreensåo (GOLDENBERG, 2003, p.19).
} 
Alfred Schütz ${ }^{2}$ que era familiarizado com as idéias de Max Weber, também buscou os fundamentos de uma sociologia compreensiva. Para ele, a Sociologia deveria se preocupar com os significados subjetivos da ação humana, com o ator social que constrói tipificações do mundo para compreendê-lo e comunicar-se com seu semelhante (MINAYO, 2004).

Schütz traz para o campo de ação de preocupações da fenomenologia social o mundo da vida cotidiana onde o homem se situa com suas angristias e preocupações em intersubjetividade com seus semelhantes (companheiros, predecessores, sucessores e contemporâneas). $O$ espaçotempo privilegiado nessa teoria é a vida presente e a relação face a face (MINAYO, 2004, p.56).

No final do século XIX surgiu o termo Escola de Chicago, designando um conjunto de pesquisas interacionistas realizadas na cidade de Chicago/EUA, na qual postulou-se que o pesquisador deveria estar envolvido com a vida de sua cidade e se interessar por sua transformação social - interacionismo simbólico ${ }^{3}$. Um dos nomes mais representativos da Escola de Chicago foi E. Burgess (1927) que apontava para a interação fecunda entre os métodos qualitativos e quantitativos (GOLDENBERG, 2003).

Com Émile Durkheim (1858 - 1917) nasceu o conceito de REPRESENTAÇÃO. Seu trabalho principal é na reflexão e no reconhecimento da existência de uma “Consciência Coletiva", o homem aprendendo hábitos e costumes característicos de seu meio social para conviver no meio deste, esse processo de aprendizagem é denominado por ele de "Socialização". Durkheim afirma que durante esse processo se forma a consciência coletiva e esta é responsável por tudo que está na mente do ser humano e o orienta a ser, comportar-se e sentir. Esse "tudo" Durkheim chamou de "Fatos Sociais"; estes fatos eram os objetos de estudo da Sociologia. Durkheim argumentou que os "fatos sociais" deveriam ser tratados como "coisas", idéia não bem recebida na época (HOROCHOVSKI, 2004).

\footnotetext{
${ }^{2}$ Segundo MINAYO (2004, p.55) ele te o representante mais significativo do pensamento fenomenológico nas Ciencias Sociais. $\mathrm{Na}$ fenomenologia percebem-se influencias weberianas, mas sua fundamentaflo metodológica está na filosofia de Husser, cujo argumento te o mesmo de Dilthey e Weber. "os attos sociais envolvem uma propriedade que nilio esth presente nos outros setores do universo abarcados pelas ciencias naturais: OSIGNIFICADO".

'Nomes: George Herbert Mead e John Dewey - lecionou em Chicago de 1894 a 1904 (GOLDENBERG, 2003).
} 
É fato social toda maneira de fazer, fixada ou não, suscetivel de exercer sobre o individuo uma coerção exterior; ou ainda, toda maneira de fazer que é geral na extensão de uma sociedade dada e, ao mesmo tempo, possui uma existência própria, independente de suas manifestações individuais (Durkheim, 1987 apud HOROCHOVSKI, 2004 p.91).

De acordo com HOROCHOVSKI (2004, p.93) a produção teórica de Durkheim "objetivava consolidar a sociologia, enquanto ciência conferir-lhe estatuto cientifico" transportando para a mesma a necessidade de objetivação, verificação e experimentação. Durkheim em As regras do método sociológico também atribuiu à sociologia a análise dos estados de consciência coletiva, suas leis e REPRESENTAÇõES que, para ele eram diferentes dos estados de natureza individual (HOROCHOVSKI, 2004).

EsSaS REPRESENTAÇÕES COLETIVAS traduzem a maneira pela qual o grupo se enxerga nas relações com os objetos que o afetam e que são distintas dos sujeitos e dos objetos; alerta para a necessidade de consideração da natureza social e não individual considerando que o mundo é todo feito de REPRESENTAÇõES. Durkheim aponta para a importância de conhecer a concepção de determinada instituição formulada pelo grupo, não apenas individualmente, enfatizando ser essa concepção socialmente eficaz. A partir daí são construídas discussões acerca das representações com um conceito re-elaborado na encruzilhada entre os conceitos sociológicos e psicológicos, segundo HOROCHOVSKI (2004).

ARRUDA (2002) diz que a partir dos anos 80 as noções de representação e memória social receberam especial atenção. Embora oriunda da sociologia foi, na psicologia social que a representação social ganhou teorização desenvolvida por Serge Moscovici ${ }^{4}$ e aprofundada por Denise Jodelet. Essa teorização passou a ser ferramenta para outros campos como o da saúde, da educação, do meio ambiente etc.

Moscovici foi o responsável pela modificação do termo REPRESENTAÇÃo COLETIVA para REPRESENTAÇÃo SOCIAL. Justificou essa mudança pelo trato dos fenômenos gerais que ocorrem nas representações coletivas relacionando-as a práticas ou realidades não igualmente gerais. No entanto, em sua obra recentemente traduzida, no Brasil, Representações Sociais: investigação em psicologia social,

\footnotetext{
4 "A obra seminal de Moscovici, La psychanalyse, son image, son public, que contem a matriz da teoria, surge em 1961 na França, causando especie nos meios intelectuais pela novidade da proposta. [...] A teoria ntlo vinga de imediato, fazendo sua reapariçૈo com força total no inicio dos anos $80^{n}$ (ARRUDA, 2002, p.129).
} 
Moscovici conclui que há pouca diferença entre os termos "coletivas" e "sociais", pois ambos revelam a dimensão plural das associações humanas e a presença de idéias gerais ou "forças coletivas" na sociedade. Assim apresenta sua Teoria das Representações Sociais (TRS) (OLIVEIRA, 2004).

Serge Moscovici desde 1961 pesquisou a relação entre grupos, atos e idéias (imagens), com o resgate de representações coletivas de Dukheim e uma análise de como a "psicanálise era percebida (representada), difundida e propagandeada ao público parisiense". Conclui que: 1) as representações sociais mediavam o entendimento científico da psicanálise e o entendimento da sociedade francesa; 2 ) as representações não eram iguais para todos os membros da sociedade, dependiam do contexto sócio-cultural c do conhecimento de scnso comum (ou popular) de cada indivíduo; 3) mediante cada situação ou objeto novos o processo de representar indicava uma seqüência lógica: tornar familiar o objeto novo, desconhecido, por meio de um duplo mecanismo - amarração (veio a chamar-se ancoragem, 'amarrar / ancorar o barco num porto seguro') e objetivação (acoplamento de imagens concretas, reais e compreensíveis, extraídas de seu cotidiano, "aos novos esquemas conceituais que se apresentam e com os quais tem que lidar") (OLIVEIRA, 2004, p.181).

O senso comum, o pensamento primitivo e ciência são para Moscovici, segundo OLIVEIRA (2004), práticas mentais e sociais que assumem uma forma de representação da realidade.

\footnotetext{
Portanto, segundo Moscovici, é em função das representaçães (e não necessariamente das realidades) que se movem individuos $e$ coletividades. Saber como se formam ou como operam essas representações - onde se misturam a um só tempo pensamento primitivo, senso comum e ciência - tece a trama da discussão apresentada (OLIVEIRA, 2004, p.182)
}

Por meio desse percurso teórico Denise Jodelet foi a campo estudar como a loucura podia ser socialmente representada à luz da teoria moscoviciana. Divulgando e explanando a obra de Moscovici, propôs a "TRS como alternativa teórica às análises sobre os fatos sociais nas mais diversas áreas de aplicação" (JODELET, 2005). 
A tomada de consciência das teorias que os indivíduos formulam, sobre diversos aspectos da realidade, podem ser conduzidas mediante inquéritos sobre determinados assuntos, diz Jodelet (JODELET, 2005).

As RS transformam o desconhecido em conhecido, o não familiar em familiar, torna o estranho em algo próximo, um processo determinado pela linguagem, imagem e idéias compartilhadas por um dado grupo. Têm-se assim, conhecimentos socialmente partilhados e elaborados. Desse modo, as representações são maneiras de interpretar e comunicar, e também, de produzir e elaborar novos conhecimentos (HOROCHOVSKI, 2004).

A definição de RS mais consensual entre os pesquisadores da área, de acordo com ARRUDA (2002, p.22), é a de Denise Jodelet:
[...] as representações sociais são inicialmente pontos de balizamento; fornecem uma posição ou uma perspectiva a partir da qual um individuo ou um grupo observa e interpreta os acontecimentos, as situações etc. Fornecem, sobretudo, pontos de referência pelos quais uma pessoa se comunica com outra, permitindo-lhe situar-se e situar seu mundo. Basta uma simples palavra ou frase, como a pergunta inicial, para mobilizar uma representação social (JODELET, 2001, p. 208-209).

Assim, as Representações Sociais são uma forma de conhecimento socialmente elaborado e compartilhado, com um objetivo prático, e que contribui para a construção de uma realidade comum a um conjunto social (JODELET, 2001).

Uma das conseqüências mais importantes dos trabalhos de Jodelet (JODELET, 2005, p. 2726) é relembrar aos leitores a "importância em atentar ao pensamento do senso comum", pois grande parcela da "humanidade vive de acordo com noções oriundas das experiências do cotidiano, das conversas entretidas em seus grupos de pertença, do saber que escorre pelos meios de comunicação".

Jodelet, em sua pesquisa de campo sobre a representação social da loucura, utilizou-se de metodologia quantitativa extensa, pois construiu amostragem de pessoas que deveriam ser pesquisadas com base nas diferenças das práticas e os estilos de vida de pacientes em hospitais. Jodelet realizou este trabalho combinando abordagens qualitativas para a coleta de dados com consultas a documentos; observação de práticas sociais; conversa com pessoas (família, anfitriãs, pacientes e funcionários de saúde) (JODELET, 2005). 
Geralmente, numa avaliação tradicional de políticas sociais, os instrumentos quantitativos analisam a estrutura do programa, como eles se processam e quais são seus resultados. Ao considerarmos a avaliação como um processo e uma construção, a partir da metade dos anos 80 passou-se a falar em avaliação qualitativa ${ }^{5}$ quando as investigações apropriaram-se de estratégias de abordagem antropológica para avaliação de programas e serviços (MINAYO, 2005b).

A proposta apresentada por MINAYO et al. (2005, p.28) e adotada pela presente pesquisa é denominado de "investigação avaliativa convencional", classifica-se em sua tipologia utilizando os conceitos de Contandriopoulos et al. (1997 apud MINAYO et al., 2005).

No entanto, para a alcançar os objetivos traçados nesta pesquisa adotou-se a investigação avaliativa por triangulação ${ }^{6}$ de métodos proposta por MINAYO et al. (2005). Nesse desdobramento metodológico e prático MINAYO et al. (2005) retomam os três pilares da avaliação tradicional e a eles agregam os princípios básicos da sociologia compreensiva, não como superposição e, sim como síntese. MINAYO et al. (2005) abordam de forma complementar e dialética interagindo as questões objetivas com as subjetivas, privilegiando a análise dos consensos, dos conflitos e das contradições que são indícios de mudanças.

Desta maneira, compreende-se a avaliação por triangulação de métodos como uma expressão dinâmica de investigação que integra, no presente trabalho de tese: a) a análise do impacto da proposta dos Comitês de Prevenção da Mortalidade Infantil no estado do Paraná mediante a investigação do óbito; b) a compreensão das relações sociais envolvidas na implementação das ações de prevenção de Mortalidade Infantil, assim como a representação que expressam os atores sociais envolvidos com a estratégia; c) e norteando todo esse processo estão as os Pactos internacionais e nacionais, as Políticas Públicas, e as recomendações de vigilância, de monitoramento da ocorrência e investigação dos óbitos infantis.

\footnotetext{
'MINAYO (2005b) adverte para a diferença existente entre 'avaliaçlo qualitativa' e 'avaliaçlo da qualidade'; essa última nふ̌ necessariamente utiliza estratégia qualitativa e, tradicionalmente mede procedimentos.

6 "Triangulaçlio té um conceito que vem do interacionismo simbólico e é desenvolvido, dentro dessa corrente, primeiramente por Denzin (1973), significando a combinaçlo e o cruzamento de múltiplos pontos de vista; tarefa conjunta de pesquisadores com formaçăo diferenciada; a visło de vários participantes e o emprego de uam variedade de técnicas de coleta de dados que acompanha o trabalho de investigaça. Seu uso, na prática, permite interaçäo, critica intersubjetiva e comparacklo" (MINAYO, 2005a; p. 29).
} 
Nesta proposta, os atores não são apenas objetos de análise, mas, principalmente sujeitos de auto-avaliação (MINAYO, 2005a).

\begin{abstract}
Essa postura ética e teórica que se fundamenta nos principios da filosofia comunicativa (Habermas, 1987) propicia meios para que, no desenvolvimento do processo de análise, os que o implementam ou recebem seus influxos se apropriem da compreensão dos dados quantitativos e qualitativos gerados pelo trabalho e recolham subsidios para as mudanças necessárias (MINAYO, 2005a, p. 30).
\end{abstract}

Em consonância com a noção de "postura dialética" de MINAYO (2005a, p.32), em relação à triangulação de métodos que leva a compreensão da inseparabilidade e interdependência entre os dados objetivos - quantitativos (indicadores, distribuição de frequêencia e outros) e os dados subjetivos - qualitativos (intencionalidade, significados, participação e interação), foi possível criar um processo de dissolução de dicotomias entre: o quanti e o qualitativo, entre macro e micro, entre interior e exterior, entre sujeito e objeto (MINAYO, 2004, 2005a).

Assumindo a triangulação de métodos, sabe-se, então que as especificidades desse método não se dissolvem, haverá questões que exigiram uma ou outra abordagem. Samaja (1992), de acordo com MINAYO (2005a), chama atenção para a desigualdade teórico-metodológica que ocorre quando há combinação de métodos e teorias, e uma se sobrepõem à outra.

Como pré-requisitos desse método, segundo MINAYO (2005a) tem-se duas condições imprescindíveis: 1) a dependência de pessoas dispostas mental e emocionalmente ao diálogo e a experimentar a complementação entre diferentes disciplinas e métodos, de preferência equipes constituídas multidisciplinarmente; 2 ) assegurar ao conhecimento do objeto um aprofundamento teórico-metodológico mediante a competência disciplinar de cada componente do grupo. No entanto, mesmo considerando as dificuldades postas por MINAYO (2005a), nesta pesquisa a incursão por três instâncias metodológica não será concretizada por uma equipe, fato que pode nos expor a alguns vieses na leitura e interpretação dos resultados obtidos.

Desta forma, nesta investigação optou-se por trabalhar de forma dialética a integração entre a pesquisa quantitativa e a qualitativa. A parte quantitativa ocorreu mediante análise das Taxas de Mortalidade Infantil, no estado do Paraná, no período de 1997 a 2005, como contextualização para a discussão dos óbitos investigados no 
periodo de 2000 a 2005. A parte qualitativa foi realizada por meio da análise dos discursos dos atores sociais envolvidos na formulação, gestão e operação de medidas de prevenção da morte infantil no Estado; também por meio da consulta documental da implantação e implementação dos Comitês de Prevenção de Mortalidade Infantil, no estado do Paraná e do resgate da memória da pesquisadora.

Enfim, foram utilizados dimensões metodológicas quantitativas e qualitativas para avaliar o IMPACTO do trabalho preventivo do óbito infantil no estado do Paraná. Baseados na definição de impacto de COHEN e FRANCO (2004, p. 109) queremos conhecer em que medida a prevenção da mortalidade infantil avança em seus objetivos no estado do Paraná, contando com o trabalho realizado pelos Comitês; bem como, conhecer quais os efeitos da recomendação da vigilância e investigação do óbito infantil na percepção do cotidiano de trabalho dos profissionais de saúde. Na seqüência serão especificados os métodos utilizados.

\subsubsection{Abordagem QuANTITATIVA}

A pesquisa quantitativa baseada em informações epidemiológicas é amplamente utilizada na área da saúde. Essa abordagem faz parte da presente pesquisa para análise contextual das Taxas de Mortalidade Infantil e seu comportamento ao longo dos anos, no período de 1997 a 2005 , referente ao estado do Paraná. Esses dados foram extraídos do Banco de Dados Sistema de Informação sobre Mortalidade - $\operatorname{SIM}^{7}$ e do Sistema de Informações de Nascidos Vivos SINASC, do Departamento de Informática do SUS - DATASUS, do Ministério da Saúde (MS, 2005, 2006 e 2007). Também se utilizou o Banco de Dados do SIM, ainda não consolidado, da Secretaria de Estado da Saúde do Paraná, para trabalho dos óbitos infantis ocorridos em 2005.

Do ponto de vista quantitativo, os dados trabalhados pelo SIM representam em torno de $\mathbf{8 0 , 0 \%}$ dos óbitos totais estimados para o país. São apontados como

\footnotetext{
' Segundo LAURENTI et al. (2006, p. 23) o MS em 1975, "reconhecendo a importancia dos dados de mortalidade para apoes especificas no setor e a exemplo do que já ocorria em alguns Estados, idealizou a implantaçăo de um Sistema de Informaques em Saúde - SIS- para o qual um sub-sistema sobre mortalidade, com dados abrangentes e confiáveis constituia-se em um primeiro passo".
} 
fatores intervenientes desse percentual o sub-registro (enterramentos que acontecem sem o registro do óbito, motivo pelo qual esse evento não é computado no sistema, levando a uma subenumeração dos óbitos); e a cobertura incompleta do sistema. Esses fatores são mais importantes nas regiões Norte, Nordeste e Centro-Oeste, como apontam MELLO JORGE e GOTLIEB (2000).

Em relação ao sub-registro de óbitos na região Sul do Brasil VICTORA (2001) mostrou que, em 1996, o percentual foi de 1,8\%, em contraposição a $44,9 \%$ do Nordeste e $41,3 \%$ do Norte, a média nacional foi de $19,1 \%$. A região Sudeste apresentou-sc na época com o menor sub-registro (1,7\%) e a Centro-Oeste teve $17,4 \%$. Uma das possibilidades é que esses óbitos tenham ocorrido em áreas rurais, alerta VICTORA (2001).

A proporção de causas mal definidas de morte, na quais estão englobados os óbitos sem assistência médica e aqueles atribuídos a sinais e sintomas inespecíficos, também pode ser considerada como sinalizadora de qualidade da assistência e da vigilância à saúde. Ressalta-se também o impacto na qualidade do Banco de Dados, $\mathrm{e}$ preenchimento das Declarações de Óbito, que alimentam o Sistema de Informação sobre Mortalidade (SIM), principalmente no trabalho com causas básicas de morte.

MELLO JORGE et al. (2001) apontam para o Brasil, no ano de 1995 e de 1999, percentual de óbitos devidos a causas mal-definidas variando $16,2 \%$ para $15,15 \%$. Nesse período a proporcionalidade variou na região Sul e Paraná de $9,4 \%$ e $10,8 \%$ para $7,1 \%$ e $6,6 \%$ dos óbitos, respectivamente. No Nordeste foi de $34,4 \%$ a $30,3 \%$, para 1995 e 1999.

No Brasil, até meados da década de 80 , havia nessa rubrica "mais de $20 \%$ dos óbitos captados pelo SIM (maior freqüência em 1984, equivalente a 22,5\%). Cerca de dez anos mais tarde, essa proporção havia declinado para cerca de $16 \%$ " (LAURENTI et al., 2006, p. 65). Embora venha decaindo esse percentual de forma diversa entre os estados e regióes brasileiras, LAURENTI et al. (2006), afirmam que ainda se está longe de ser resolvida a situação de óbitos mal definidos. Os autores alertam para a necessidade de melhor esclarecimento da causa mal definida no momento de claboração da DO (neste sentido os médicos devem estar mais bem preparados) ou mesmo, posteriormente, como tarefa dos encarregados do sistema, no nível local. 
No traçado das TMI alerta-se, também, para o sub-registro de nascimentos ou nesmo aos registros tardios. Esse problema foi minimizado a partir do final de 1997 som a obrigatoriedade da implantação e utilização do SINASC (Sistema de Informação sobre Nascidos Vivos), mediante o Piso de Atenção Básica (PAB), nova forma de repasse financeiro do MS aos municípios. Em relação ao preenchimento da Declaração de Nascidos Vivos (DN) que vai remeter à qualidade do SINASC, MELLO JORGE et al. (1996, 2000) e MELLO JORGE e GOTLIEB (2001) afirmam que vem melhorando em todo o país.

O trabalho realizado pelo Centro Brasileiro de Classificação das Doenças em Português - CBCD -, em 2006, celebrando seus 30 anos de existência, apresenta uma história do SIM, da sua concepção, criação e implantação até o ano 2006. Nela, os autores LAURENTI et al. (2006) indicam a superação de captação de óbitos pelo SIM sobre o Sistema de Registro Civil (dados do IBGE - Instituto Brasileiro de Geografia e Estatística). Assim, a partir do ano 2000, depois de muito trabalho de aprimoramento do Sistema, do fluxo da Declaração de Óbito, de treinamento e apoio técnico-científico e, devido também aos processos de municipalização, o SIM passou a captar mais óbitos do que o Registro Civil. Em 1979 a diferença relativa à captação pelo SIM sobre o IBGE era de $-11,1 \%$. Decresceu até $1999(-1,8 \%)$ e passou a ser positiva em 2000 (+0,3\%), chegando a +0,9\% em 2004 (LAURENTI et al., 2006).

Quanto à qualidade das informações LAURENTI et al. (2006, p.55) observam que "lenta e gradativamente, vem sendo obtida uma melhora". A proporção de variáveis com informações ignoradas ou não preenchidas cada vez mais são reduzidas, indicando essa melhoria da qualidade do SIM.

Com a criação da RIPSA - Rede Interagencial de Informações para a Saúde a partir de 1996-, as estimativas do número de óbitos, totais e de menores de um ano, realizada pelo IBGE, têm sido utilizadas para avaliação do SIM. Assim, a RIPSA apresenta dentre seus indicadores de saúde a "Razão entre os óbitos informados pelo SIM e os estimados pelos métodos indiretos, imaginando que esse valor possa refletir, ainda que de forma grosseira, a cobertura do SIM" (LAURENTI et al., 2006, p. 52). Desta maneira, esse indicador pode ser utilizado para "analisar variações geográficas e temporais na proporção de dados coletados pelo SIM", podendo, então, se ter uma avaliação da consistência do Sistema, parâmetros para estimar a sub- 
enumeração de dados do SIM, servir de critério para utilização da base do SIM e contribuir para o desenvolvimento operacional do Sistema, indicando áreas que requerem mais atenção (LAURENTI et al., 2006).

Em retrospectiva, a partir da disponibilidade da RIPSA, em 1997, até 2002, tem-se a razão entre o total de óbitos informados pelo SIM e estimados pelo IBGE mostrando uma cobertura que varia de entre $56,2 \%$ no Nordeste e $95,5 \%$ no Sudeste, com média Brasil de $80 \%$, para 1997. Já em 2002 a relação para todo país ultrapassou 83\%, apresentando queda na Região Sudeste para 90,6\%. A Região Sul apresentou nesse ano maior proporção dentre as Regiбes, ou seja, de 94,6\%. O Norte e o Nordeste preservaram as menores proporções de cobertura, $72,2 \%$ e $68,8 \%$, respectivamente. A Região Centro-Oeste mantêm-se com proporção ao redor de $85 \%$ ao longo do período analisado, de 1997 a 2002 (LAURENTI et al., 2006).

Por essa ótica permite-se afirmar que, para o Estado do Paraná, da região Sul, tomar os dados do SIM significa trabalhar com dados confiáveis sem o viés do subregistro e com qualidade de preenchimento.

Para análise dos dados quantitativos objetos específicos dessa investigação, a tese valeu-se de informações originadas do SIMI - Sistema de Informação de Mortalidade Infantil. O SIMI caracteriza-se por dados parciais, isto é: fazem parte deste sistema os óbitos que foram investigados no estado. O sistema foi desenvolvido por técnicos da Secretaria de Estado de Saúde do Paraná (SESA/PR) com os objetivos de: fazer a guarda dos dados obtidos mediante a investigação; proporcionar o acesso das RegS aos dados para gerência do evento e implementação de aç̃̃es; bem como, para facilitar relatórios gerenciais do Estado quanto o impacto das ações mediante as algumas características analisadas, a saber, de evitabilidade, critérios de redutibilidade, medidas de prevenção e intervenção, dentre outras características dos óbitos ocorridos e investigados. 


\subsubsection{ABordagem Qualitativa}

Para este estudo realizou-se a consulta a documentos relativos a constituição dos Comitês de Prevenção da Mortalidade Infantil, do Estado em 1997, como baseline para a compreensão de questões operacionais de implantação e implementação de ações, específicas à estratégia dos Comitês. Nesta fase resgatouse, também, a memória da pesquisadora por ter sido participante dessa história desde o ano de 1997, como representante da Universidade Estadual de Maringá (UEM), Paraná, indicada pelo Departamento de Enfermagem.

Para a investigação documental foram consultados documentos emitidos pela Secretaria de Estado da Saúde do Paraná (SESA) sobre a implantação do Comitê Estadual e Regionais, com recomendações para as três instâncias de gestão: estadual, regional e municipal. Um deles foi a Resolução SESA nº 0262/98, na qual também foi referendado o Regimento Interno do Comitê Estadual de Prevenção da Mortalidade Infantil. Também foi consultada a Resolução SESA 229/99 que determinou aos Hospitais e Maternidades a disponibilização de cópias de prontuários aos serviços de epidemiologia das Secretarias Municipais de Saúde (PR/SESA, 1998, 1999).

Outro documento muito utilizado foi o Manual para Preenchimento da Ficha de Investigação ${ }^{8}$, lançado em 2006 (PR/SESA, 2006).

Para as investigações dos óbitos infantis é utilizado um tipo de protocolo para eleição dos Critérios de Redutibilidade e das Medidas de Prevenção e Intervenção do óbito infantil. Esses documentos também foram consultados (Anexo 4 e 5), bem como, a "Ficha Confidencial de Investigação do Óbito Infantil tardio (28 dias a 1 ano) e do óbito neonatal (até 27 dias)" para maior clareza dos campos que alimentam o SIMI (Anexos 1, 2 e 3).

O Manual dos comitês de prevenção do óbito infantil e fetal, lançado em 2004, pelo Ministério da Saúde, foi bastante consultado. Esse Manual, como uma das estratégias que compõem do Pacto Nacional pela Redução da Mortalidade Materna e Neonatal, foi construído com a participação de estados e municípios que já tinham

\footnotetext{
'Documento publicado internamente pela Secretaria de Estado da Saúde do Paraná, em 2006, nåo disponível para consultas.
} 
experiência de estruturação de Comitês de Prevenção da Mortalidade Infantil. Assim, este documento contribuiu de forma significativa e objetiva para o esclarecimento do conceito de vigilância da mortalidade infantil e fetal, definindo-a como:

\begin{abstract}
[...]uma açẫo estratégica para dar visibilidade ao problema, melhorar 0 registro dos b́bitos $e$ orientar as ações de intervenção para sua prevenção. É ainda de fundamental importância para a mobilização $e$ organização das açz̃es prioritárias para a redução da mortalidade no pais, conforme destaca a Agenda de Compromisso para a Saúde Integral da Criança e Redução da Mortalidade Infantil do Ministério da Saúde (BRASIL, 2004b, p. 4).
\end{abstract}

Como essas fontes não são apropriadas para evidenciar o cotidiano da prática profissional, em uma segunda fase qualitativa, buscaram-se os DISCURSos dos atores sociais: profissionais da saúde, ou que atuavam na gestão da área da saúde. Sujeitos que de alguma maneira participam do processo de redução e prevenção da mortalidade infantil.

Motivados por questões organizacionais e de implementação de estratégias e ações preventivas em saúde, mais especificamente em relação à mortalidade infantil, a presente pesquisa constituiu como atores sociais gestores e profissionais de saúde, tanto da rede básica como hospitalar. São sujeitos sociais detentores de conhecimento e experiência profissional na prevenção do óbito infantil, e foram eleitos como portadores de representações acerca de suas esferas de trabalho preventivo do óbito infantil, no estado do Paraná.

Essa procura, pelo conhecimento e significado da prevenção da morte infantil, junto aos profissionais remeteu-nos aos olhares dos atores sociais, na gestão de serviço de saúde ou na sua operacionalização. Na representação social cada profissional assume sua introspeç̧ão sobre a temática, com a observação das possibilidades e limites, bem como, com ênfase a questões que podem passar desapercebidas para tantos outros atores (MINAYO, 2004).

A Representação Social foi escolhida para obter subsídios para avaliação do impacto ocorrido junto aos profissionais em relação à implantação dos Comitês de Prevenção da Mortalidade Infantil no Paraná, bem como de todo o movimento de vigilância que a rede prevê. COHEN e FRANCO (1993, p.93-94) conceituam o impacto como "consequência dos efeitos de um projeto (...) expressa o grau de 
consecução dos objetivos em relação à população-meta do projeto (...) pode ser medido em distintas unidades de análise: a do indivíduo ou grupo familiar, ou em distintos conglomerado societários (comunitário, regional, nacional)". Neste sentido a contribuição dos atores sociais tornou-se importante, pois pode nos apontar a existência de conhecimento da proposta dos Comitês, a adesão, a contribuição, a valorização, as dificuldades, as sugestões dentre outros aspectos.

A contribuição dos sujeitos sociais se dá pela sua experiência biográfica, por seus olhares sobre os objetos que os circundam e, também pelo contexto de cada indivíduo, em suas estruturas de relevância e, na expressão da representatividade que o tema assume para si e em seu cotidiano profissional. A tudo isto se denomina estoque de conhecimento (Schütz apud MYNAIO, 2004, p.57). Esse "estoque de conhecimento do ator social funciona como marco de referência, através do qual interpreta o mundo e pauta suas ações" (MINAYO, 2004, p.57).

$\mathrm{Na}$ base empírica da pesquisa dos conceitos desenvolvidos por Schütz está a passagem do conceito individual para o grupal e comunitário por meio da reciprocidade de perspectiva, de comunicação, de comunidade de objetivos e de interpretação inter-subjetiva (de relação de uns com os outros). Segundo Schütz (apud MINAYO, 2004) por nossos pais e professores recebemos a maior parte de nossos conhecimentos; recebemos uma visão de mundo e um conhecimento que vai do "familiar" (permite a captação do outro como único em sua individualidade sob a forma do nós) ao "anônimo" (que afasta a unicidade e individualidade do outro e produz a generalização) que nos coloca "face a face" com o mundo, no nível da vida prática (MINAYO, 2004, p.57-58).

MINAYO (2004) alerta para três grandes obstáculos encontrados em pesquisas que fazem análise de dados obtidos no campo (documentos e entrevistas) como no caso desta pesquisa. Trata-se da "ilusão da transparência", noção de Bourdieu, de acordo com MINAYO (2004, p.197). Esta noção é o primeiro obstáculo às investigações. Refere-se ao "perigo da compreensão espontânea como se o real se mostrasse nitidamente ao observador". Quanto mais familiaridade do pesquisador com o objeto, mais perigosa se torna essa "ilusão", ou seja, a projeção de sua própria subjetividade. $\mathrm{O}$ segundo obstáculo é a "fidedignidade às significações presentes no material e referidas a relações sociais dinâmicas"; o pesquisador pode sucumbir à 
magia dos métodos e das técnicas esquecendo-se de ser fiel ao que coletou. $\mathbf{O}$ terceiro obstáculo constitui-se na "dificuldade de se juntarem teorias e conceitos muito abstratos com os dados recolhidos no campo"; apresenta-se como um distanciamento entre a as descrições e a elaboração teórica (MINAYO, 2004, p. 197).

LEFÈVRE e LEFÈVRE (1998, p. 35) utilizando-se das Representações Sociais, posicionam-se pela recuperação da "fala do social" trabalhadas por Jodelet. Essas são objetos de pesquisas qualitativas com matéria prima empírica: são os depoimentos obtidos mediante entrevistas abertas com indivíduos, obviamente portadores de conhecimento produzidos socialmente, portadores de representações sociais (RS).

LEFĖVRE e LEFÈVRE (1998) propõem que as falas não sejam "atomizadas" ou "matematizadas". Elas são coletivas e não podem ser tratadas como a soma e percentual sobre $o$ todo de cada idéia, valor, comportamento, práticas etc dos entrevistados, pois essa operação não garante o resgate efetivo do pensamento, da reflexão, do sentimento, do comportamento do indivíduo frente a um largo espectro de fenômenos que podem ser vistos como objetos de RS. Também, é necessário assegurar a redução da arbitrariedade e artificialidade presente nas pesquisas empíricas de tipo quantatitativo sobre as RS. Assim, no proposto Discurso do Sujeito Coletivo - DSC, os autores respeitam a natureza eminentemente discursiva do pensar dos indivíduos, no plano individual construindo o coletivo (LEFÈVRE e LEFÈVRE, 1998, p. 5; LEFËVRE e LEFÈVRE, 2007).

De acordo com a base conceitual da proposta de Fernando Lefêvre a Ana Maria Cavalcanti Lefêvre, adotada por este trabalho de pesquisa investigativa avaliativa, tem-se que "o DSC é uma estratégia metodológica que, utilizando uma estratégia discursiva, visa tornar mais clara uma dada representação social, bem como o conjunto das representações que conforma um dado imaginário" (LEFÈVRE e LEFĖVRE, 2003, p. 19).

\subsubsection{O DiscurSO dO SUJEITO COLETIVO - DSC}

Em um processo investigativo, basear-se na produção de um pensamento sobre a experiência vivida, significa centrá-la nas representações dos sujeitos. Nesta 
tese fez-se a opção de estudar a realidade social e coletiva por meio de narrativas individuais e vividos singulares, mas também se verificou a existência objetiva dos modos de prevenir o óbito infantil (SCHRAIBER, 1995).

A opinião coletiva como fato empírico, se veiculada apenas pelo metadiscurso do pesquisador ou por meio de alguma fórmula matemática, perde sua forma discursiva. O DISCURSo é considerado por LEFÈVRE e LEFĖVRE (2006, p.518) como matéria significante do pensamento, previamente desconhecido, que ao ser obtido, indutivamente, apresenta-se como uma variável qualitativa, "ou seja, como um produto a ser qualificado a posteriori, como output, pela pesquisa". Esse pensamento configura-se, também, como uma variável quantitativa, pois se trata de um pensamento coletivo, deve expressar as "opiniões compartilhadas por um quantitativo de indivíduos, que configuram a coletividade pesquisada" (LEFĖVRE e LEFÈVRE, 2006, p.518).

Desse modo, segundo LEFÈVRE e LEFÈVRE (2006), TER um pensamento sobre determinado tema significa, na linguagem das conversas informais, que o indivíduo / coletividade professam, adotam ou usam discursos sobre o tema; situação diferente de se ter cabelos claros ou escuros. Anteriormente à qualquer pesquisa empírica já é fato a existência de ALGO. No entanto, quando se PROFESSA ALGO essa variável se manifesta virtualmente até que seja re-construída durante ou por meio do processo de investigação. Professar idéias, opiniões e pensamentos é emitir um DISCURSO. Cada discurso é composto pela coleta, processamento e apresentação das idéias e opiniões professadas. "Pensamentos pertencem à família das línguas e linguagem e, portanto, à ordem do discurso ou do texto" (LEFÈVRE e LEFÈVRE, 2003, p.14).

Como expressar esse pensamento coletivo, como constituir um sujeito portador de um discurso coletivo, um sujeito-que-fala garantindo sua unicidade e sua concomitante pluralidade, bem como a autenticidade do que é falado?

O tratamento científico e sistemático do objeto "opinião coletiva" vai requerer construtos metodológicos especificos que permitam que seja mantido o necessário vínculo com a realidade empirica, e que a opinião coletiva possa ser reconstituida artificialmente (já que não é possivel, neste caso não ser artificial) como um objeto qualitativo (LEFĖVRE e LEFĖVRE, 2006, p.519). 
tese fez-se a opção de estudar a realidade social e coletiva por meio de narrativas individuais e vividos singulares, mas também se verificou a existência objetiva dos modos de prevenir o óbito infantil (SCHRAIBER, 1995).

A opinião coletiva como fato empírico, se veiculada apenas pelo metadiscurso do pesquisador ou por meio de alguma fórmula matemática, perde sua forma discursiva. O DISCURSO é considerado por LEFÈVRE e LEFÈVRE (2006, p.518) como matéria significante do pensamento, previamente desconhecido, que ao ser obtido, indutivamente, apresenta-se como uma variável qualitativa, "ou seja, como um produto a ser qualificado a posteriori, como output, pela pesquisa". Esse pensamento configura-se, também, como uma variável quantitativa, pois se trata de um pensamento coletivo, deve expressar as "opiniões compartilhadas por um quantitativo de indivíduos, que configuram a coletividade pesquisada" (LEFÈVRE e LEFÈVRE, 2006, p.518).

Desse modo, segundo LEFĖVRE e LEFÈVRE (2006), TER um pensamento sobre determinado tema significa, na linguagem das conversas informais, que o indivíduo / coletividade professam, adotam ou usam discursos sobre o tema; situação diferente de se ter cabelos claros ou escuros. Anteriormente à qualquer pesquisa empírica já é fato a existência de ALGO. No entanto, quando se PROFESSA ALGO essa variável se manifesta virtualmente até que seja re-construída durante ou por meio do processo de investigação. Professar idéias, opiniões e pensamentos é emitir um DISCURSO. Cada discurso é composto pela coleta, processamento e apresentação das idéias e opinióes professadas. "Pensamentos pertencem à familia das línguas e linguagem e, portanto, à ordem do discurso ou do texto" (LEFÈVRE e LEFÈVRE, 2003, p.14).

Como expressar esse pensamento coletivo, como constituir um sujeito portador de um discurso coletivo, um sujeito-que-fala garantindo sua unicidade e sua concomitante pluralidade, bem como a autenticidade do que é falado?

O tratamento científico e sistemático do objeto "opinião coletiva" vai requerer construtos metodológicos específicos que permitam que seja mantido o necessário vínculo com a realidade empírica, e que a opinião coletiva possa ser reconstituida artificialmente (já que não é possivel, neste caso não ser artificial) como um objeto qualitativo (LEFÈVRE e LEFĖVRE, 2006, p.519). 
Pelo método do DSC constitui-se um sujeito coletivo que fala como indivíduo, isto é, "um sujeito de discurso natural, mas veiculando uma representação com conteúdo ampliado", é a coletividade falando na primeira pessoa do singular (LEFÈVRE e LEFÈVRE, 2006, p.519). O DSC apresenta, portanto dupla representatividade - QUALITATIVA E QUANTITATIVA - das opiniões de entrevistados que emergem coletivamente da pesquisa. Quanto à representatividade qualitativa, apresentam-se OS DISCURSOS construídos por semelhanças de conteúdos e argumentos que permeiam a fala de cada ator social. A dimensão quantitativa é dada pela expressão numérica indicando a força de representatividade, de compartilhamento das idéias agrupadas, como se indicasse quantos depoimentos constituem cada discurso (LEFRÈVE e LEFÈVRE, 2006).

LEFRÈVE et al. (2007a) contextualizam o DSC teoricamente à idéia de COMPLEXIDADE, pois esse método de pesquisa empírica de Representação Social abre novas possibilidades de relações de diálogo:

\section{[...] entre o todo $e$ as partes, entre $o$ individual $e$ o coletivo, entre $o$ teórico e o empírico, entre a descrição e a interpretação, entre a sintese $e$ $a$ análise, entre o paradigma e o sintagma, last-but not least, entre $o$ qualitativo e o quantitativo, o que justifica, e talvez exija a sua inserção no quadro das reflexões atuais sobre o tema da complexidade" (LEFRÈVE et al., 2007a, p. 4).}

LEFRÈVE et al., (2007a, p.4) enfatizam que a COMPLEXIDADE, contrariamente ao sentido que se tem no cotidiano - de dificuldade -, é uma palavra originária "do latim complexus, diz respeito ao que abrange muitos elementos ou partes", ou ainda, ao conjunto de coisas, fatos ou circunstâncias que têm qualquer ligação ou nexo entre si".

A noção de complexidade de estudiosos como Edgar Morin, Henry Atlan, Varela, Michel Serres (apud LEFÈVRE et al., 2007a, p.5) que contribuíram nas últimas décadas para a construção da idéia de COMPLEXIDADE "aponta principalmente para a necessidade da interação entre sistemas, sem perder o potencial da diversidade". Desse modo, o todo não é a soma das partes, mas a INTERAÇÃo que se dá entre elas, internamente no sistema e externamente com o ambiente, numa "rede causal circular, dinâmica, amparada nos conceitos de ordem, desordem e auto-organização" (LEFÈVRE et al., 2007a, p.5). 
A tese defendida por LEFÈVRE et al. (2007a) na abordagem do DSC sob a ótica das realidades complexas refere-se às representações sociais como:

[...] esquemas sócio-cognitivos de que lançam mão para emitirem, no cotidiano de suas vidas, juizos ou opiniões, que são condiç̃̃es necessárias para viver e se comunicar em sociedades complexas. Esses esquemas sócio-cognitivos, acessáveis através de depoimentos individuais, são entidades virtuais que, por isso, precisam ser reconstituidas através de pesquisas sociais que comportem uma dimensão qualitativa e quantitativa (LEFRÈVE et al., 2007a, p.6-7).

LEFÈVRE et al (2007a, p.7) apontam para três níveis de complexidade quando indicam as relações entre DSC e a noção de complexidade:

Nivel 1: PRODUÇÃo INDIVIDUAL DAS RS - É a produção da matéria prima para o DSC. Traduz-se na constatação de que o pensamento coletivo implica num cuidado complexo, pois diz respeito à articulação entre o virtual (os esquemas), o individual (depoimentos) e o coletivo (esquemas internalizados nas interaçð̃es e comunicaçðes sociais). Pensar que na produção de um só texto narrativo, não formado por fragmentos apenas dos discursos individuais, há que se fazer o recorte do tema por meio das respostas às perguntas, que devem ter sido elaboradas para obterem o melhor acesso possível às representaçð̌es sociais. Nesse nível constituísse como maior output a produção dos depoimentos, como matéria prima de qualidade para a pesquisa de RS.

NIVEL 2: RE-PRODUÇÃo COLETIVA DAS RS - Tratamento da matéria prima produzida no Nivel 1 mediante Seleção de Expressóes Chave/EC dos discursos individuais, identificando as Idéias Centrais/IC e/ou Ancoragens/AC existentes. Assim culminando com a aproximaçăo das RS semelhantes ou complementares construindo um discurso coletivo sintese na primeira pessoa do singular. A produção nas pesquisas que usam o DSC, das RS, como painéis discursivos necessita de articulação teórico-metodológica entre o nível teórico ("desvirtualização" das RS) e o propriamente metodológico (encadeamento das operações de transformação do depoimento bruto em trabalhado, identificação dos sentidos, categorização e reunião dos semelhantes num só depoimento).

NIVEL 3: RESSIGNIFICAÇÃO INTERPRETATIVA DAS RS OU EMERGÊNCIA DO DIÁLOGO - É o que normalmente se apresenta nos relatórios, na discussão e interpretação dos dados. $O$ sujeito da produção de sentido das RS passa do sujeito empírico (trabalhados nos outros níveis) para o "pesquisador-portador-da-teoria ou do discurso sobre a realidade". Nesse nível se dão as relações entre o substrato empírico dos DSC em painel (que expressam descritivamente as RS) e o metadiscurso do pesquisador, em sua tarefa de interpretação dos dados.

Deve-se notar que, ao se integrarem os dois primeiros níveis de complexidade, tem-se um MODELO sobre o que é o pensamento coletivo e uma 
METODOLOGIA destinada a fazer emergir na pesquisas empíricas pensamentos coletivos sobre temas especificos, com a seguinte postulação:

Os pensamentos coletivos ou representaçס̃es sociais são metabolizações pessoais ou individuais de matrizes discursivas existentes virtualmente nas formações sociais, acessadas através de pesquisas com individuos questionados através de perguntas abertas, metabolizações essas que, visando a atualização e expressão concreta, em forma de opinið̄es coletivas, das matrizes discursivas virtuais, são sob a forma de constructos, agrupadas, por semelhança semântica, em discursos sintese redigidos na primeira pessoa do singular, de modo a configurar um sujeito coletivo portador de uma opinião, ou de um "eu acho..." social (LEFÉVRE et al., 2007a, p.10).

Em face de essas três complexidades postula-se que a grande novidade da metodologia do DSC consiste em que:

[...] as relações entre descrição e interpretação, entre discurso e metadiscurso na pesquisa do pensamento coletivo devem ser muito MAIS HORIZONTAIS, ou seja, DE DIALOGO, do que costuma acontecer normalmente, o mundo empírico aparece demasiadamente subordinado ao meta-discurso teórico do pesquisador (LEFÈVRE et al., 2007a, p.10).

$\mathrm{Na}$ investigação metodológica para o desenvolvimento desta tese utilizou-se o método do DSC em razão, pode-se dizer, de pelo menos dois pressupostos: 1) por acreditar que as instâncias gerenciais da saúde precisam "ouvir" os operadores das ações que estão na ponta, com papel de implementadores das ações e estratégias e, 2) por acreditar que o painel de discursos construídos com o 'eu penso', com o 'eu acho' sobre ações preventivas de mortalidade infantil, dos atores eleitos para a abordagem veiculam importantes representações sociais sobre o tema. Representações Sociais essas que poderão ser aplicadas tanto na gestão e (re)organização dos serviços de saúde como no próprio cotidiano de atividades de profissionais da saúde. 


\subsection{OS PROCEDIMENTOS METODOLÓGICOS}

A proposta de pesquisa para o desenvolvimento desta tese que apresentamos foi analisada e aprovada pelo Comitê de Ética em Pesquisa da Faculdade de Saúde Pública da Universidade de São Paulo - COEP, em sua $1^{\text {a }}$ Sessão Ordinária de 2005, em 15 de fevereiro de 2005, de acordo com os requisitos da Resolução CNS de $\mathbf{n}^{\circ}$ 196 de 1996.

Para alcançar os objetivos traçados nesta pesquisa encaminhamos o trabalho de investigação avaliativa para subsidiar a discussão sobre a Prevenção da Mortalidade Infantil no Estado do Paraná. Desse modo, além dos indicadores numéricos construídos, realizou-se, também, com base na Teoria das Representações Sociais conhecer os profissionais envolvidos com os Programas, Estratégias e Ações de Prevenção do óbito infantil, assim como, suas representações acerca das dificuldades que enfrentam no processo preventivo e suas sugestões para minimizar ou resolver problemas da área.

Neste Capítulo apresentam-se, então, os passos metodológicos tomados para a obtenção e tabulação dos dados para a investigação avaliativa da Mortalidade Infantil no Estado do Paraná, no período de 1997 a 2005, com enfoque na Prevenção. Para melhor organização do Capítulo, este é dividido em duas partes que tratam da Mortalidade Infantil no Paraná e das Representações Sociais diante do Discurso do Sujeito Coletivo. Tem-se, dessa forma:

3.2.1. A MORTALIDADE INFANTIL NO PARANÁ - contextualizando como se apresentam, no período pesquisado, os Coeficientes de Mortalidade Infantil traçados de acordo com Sistema de Informações sobre Mortalidade Infantil, do Ministério da Saúde, no período de 1997 a 2005;

3.2.2. OS ÓBITOS INFANTIS INVESTIGADOS - trabalho realizado pelos Comitês de Prevenção da Mortalidade Infantil; como se deu a evolução da investigação dos óbitos infantis no Estado, bem como algumas das variáveis do SIMI - Sistema de Informação de Mortalidade Infantil, do Paraná, no período de 2000 a 2005. São trabalhados dados secundários.

3.2.3. As REPRESENTAÇÕES SOCIAIS e o método de análise para o Discurso do Sujeito Coletivo (DSC) trabalhado no Qualiquantisoft ${ }^{\circledR}$. 


\subsubsection{A MORTALIDADE INFANTIL NO PARANÁ: análise contextual com os dados secundários}

Para esta tese, consideradas as limitações dos Bancos de Dados, foram utilizados os dados do SIM referentes a óbitos de menores de um ano de idade, filhos de mães residentes no Paraná, Região Sul do Brasil, ocorridos no período de 1997 a 2005. Esses dados se destinaram a uma das etapas metodológicas do trabalho de eleição das Regionais de Saúde a serem entrevistadas, bem como para contextualizar a mortalidade infantil no período.

A Taxa de Mortalidade Infantil (TMI) foi calculada pelo método direto com a utilização do Sistema de Informação sobre a Mortalidade (SIM) e o Sistema de Informações sobre Nascidos Vivos (SINASC) do Ministério da Saúde. Para o Estado do Paraná não há necessidade de correções do sub-registro de óbitos e nem de nascidos vivos.

Iniciou-se pelo ano de 1997, pois nesse ano ocorreu o início dos movimentos de vigilância e investigação dos óbitos infantis no Estado do Paraná, com formação dos Comitês Regionais e, conseqüentemente, a organização e a implementação de ações investigativas nas Regionais de Saúde (RegS) e Municípios. $O$ ano de 2005 foi determinado pela disponibilidade de informações dos óbitos infantis de residentes no Estado mediante o Sistema de Informação de Mortalidade Infantil, da Secretaria de Estado da Saúde, do Paraná. Embora para o ano de 2005 o Banco de Dados não estivesse consolidado em nível federal, optou-se por incluí-lo para que o período pudesse ser dividido em três triênios, em virtude da flutuação das Taxas determinada por pequenos números de óbitos e para que se pudesse trabalhar com informações mais recentes possíveis.

O período de nove anos, portanto, foi dividido em três triênios, a saber, o $I^{\circ}$ Triênio representando o período de 1997 a 1999; o $2^{\circ}$ Triênio composto pelos anos de 2000 a 2002 e o último período, de 2003 a 2005, como o $3^{\circ}$ Triênio.

O fato de o ano de 2005 não estar consolidado no Banco de Dados não se constituiu em problema metodológico, pois em averiguação realizada para esta pesquisa, em relação aos anos anteriores consolidados, detectou-se que um 
percentual menor de $1 \%$ pode ser acrescido ao Banco na consolidação, realizada em nível federal. Esse percentual foi considerado baixo, ou seja, uma parcela pequena de óbitos infantis de mães residentes no estado do Paraná ocorre fora do Estado, desconsiderando-se então como prejuízo aos dados para esta tese.

$\mathrm{O}$ número de óbitos de menores de um ano de idade e o de nascidos vivos, bem como, os dados populacionais foram extraídos do Sistema de Informação on line, na página www.datasus.gov.br, do Ministério da Saúde, Brasil, durante os anos de 2005, 2006 e 2007. Para extração dos dados acessou-se neste site o ícone INFORMACÕES DE SAÚDE em direção às opções: 1) informações sobre ESTATÍsTICAS VITAIS - MORTALIDADE E NASCIDOS VIVos e 2) informações Demográficas e SócioEconômicas (que têm como Fonte o IBGE - Instituto Brasileiro de Geografia e Estatística com os Censos Demográficos, 1980, 1991 e 2000; e Contagem Populacional, 1996; para os anos intercensitários, estimativas preliminares dos totais populacionais, estratificadas por idade e sexo pelo DATASUS/ MS) (BRASIL, 20007b; MS, 2005, 2006, 2007).

Todas as informações foram extraídas para Brasil, regiões e para o estado do Paraná. $O$ estado do Paraná também foi estudado em suas 22 Regionais de Saúde. Dessa maneira, construiu-se a TMI que aponta o número de óbitos de menores de um ano de mães residentes no Estado em relação ao total de crianças que nasceram vivas naquela mesma região, no caso Regional de Saúde ou até mesmo Macrorregional de Saúde, no período abordado (Triênios) multiplicado por 1000. O resultado encontrado foi um número de óbitos de menores de um ano por mil crianças nascidas vivas (\%o NV), ou seja, a chance de morte de crianças menores de um ano dentre mil crianças que nasceram no mesmo local e período.

Paralelamente a esse levantamento, trabalhou-se com o Banco de Dados "bruto" (assim denominado por não permitir uma extração categorizada como permite o Sistema Tabwin do DATASUS, no SIM) conferência dos óbitos ocorridos. O trabalho com esse Banco previu foi minucioso, realizado com filtros e entendimento de cada variável da Declaração de Óbito que alimenta o SIM. Foi esse trabalho permitiu que se detectasse uma pequena diferença entre os dados consolidados ou não. 
Trabalhou-se com o número absoluta e distribuição percentual dos óbitos infantis segundo as variáveis:

$\checkmark$ idade ao morrer: do 0 ao $6^{\circ}$ dia de vida, o período neonatal precoce; do $7^{\circ}$ ao $27^{\circ}$ dia de vida, o período neonatal tardio; do $28^{\circ}$ até 364 dias, 23 horas, $59 \mathrm{~min}$. e $59 \mathrm{seg}$, o período pós-neonatal;

$\checkmark$ sexo: masculino, feminino ou ignorado;

$\checkmark$ duração da gestação (em semanas): menos de 28 semanas; de 28 a 36 semanas; 37 a 41 semanas; de 42 e mais semanas e ignorada;

$\checkmark$ peso ao nascer (em gramas): menos de 500; 500 a $999 ; 1000$ a $1499 ; 1500$ a 2499 ; 2500 a 2999; 3000 a 3999; 4000 e mais; ignorado;

$\checkmark$ idade da mãe (em anos): 10 a $14 ; 15$ a $19 ; 20$ a $24 ; 25$ a $29 ; 30$ a $34 ; 35$ a $39 ; 40$ a 44; 45 a 49 ; 50 a 54; ignorada;

$\checkmark$ escolaridade da mãe (em anos): nenhuma; 1 a 3; 4 a 7; 8 a 11; 12 e mais; ignorada.

Foram escolhidas apenas essas variáveis do SIM, para uma caracterização do óbito infantil ocorrido, não desprezando o valor que têm as demais variáveis do Sistema, no entanto, não foram objetos desta pesquisa. Na presente investigação as Causas Básicas de morte infantil, apesar da relevância não foram objeto de estudo, pois isto demandaria um tempo maior para concretização e finalização da pesquisa.

\subsubsection{OS ÓBITOS INFANTIS INVESTIGADOS}

O Sistema de Informação de Mortalidade Infantil (SIMI) foi implantado no ano de 2000 em todas as Regionais de Saúde do Estado do Paraná, assim foram trabalhadas apenas para o período de 2000 a 2005. Na implantação foram capacitados técnicos das Regionais para seu manuseio; é na instância administrativa das RegS que se digitam os dados, os mesmos são exportadas para a Central do Estado. Os dados que alimentam o SIMI são fornecidos por uma síntese da Ficha Confidencial de Investigação do Óbito infantil neonatal (Anexo 1) ou tardio (Anexo 
2) denominada de Análise Final do Óbito (Anexo 3). Assim, via intranet da SESA/PR, é estabelecido o fluxo dos óbitos infantis investigados (MANSANO et al., 2004).

Para acesso ao Banco de Dados da SESA/PR foi encaminhada, à diretoria do Centro de Informações e Diagnóstico em Saúde (CIDS), um requerimento de solicitação de acesso aos dados, juntamente com a aprovação da pesquisa pelo Comitê de Ética da Faculdade de Saúde Pública da Universidade de São Paulo.

Do Banco de Dados do SIMI, portanto, obtiveram-se dados apenas dos óbitos infantis investigados, que não representaram a totalidade dos óbitos ocorridos. Esses dados foram extraídos do MS Access versão 1997, por meio de consultas de seleção e desnormalização das tabelas e salvo no Excel, no qual foram tabulados e, realizadas Tabelas e Gráficos de interesse para este estudo.

O Sistema permite estratificar as informações por RegS e Municípios, e oferece a opção de gerar 22 Tabelas e 6 Gráficos que mostram os números absolutos e a distribuição percentual dos óbitos ocorridos segundo as seguintes variáveis:

\footnotetext{
$\checkmark$ nome do Município de residência da criança;

$\checkmark$ identificação da Regional de Saúde;

$\checkmark$ data e hora do óbito;

$\checkmark$ data de encerramento da análise;

$\checkmark$ sexo da criança;

$\checkmark$ causa básica do óbito infantil, de acordo com a Declaração de Óbito;

$\checkmark$ causa básica após a investigação;

$\checkmark$ evitabilidade ou redutibilidade do evento;

$\checkmark$ determinantes causais, antes denominados por responsabilização do óbito;

$\checkmark$ qualidade da Ficha (mais precisamente das informações encontradas na Ficha Confidencial de Investigação);

$\checkmark$ critérios de redubilidade, antes denominados critérios de evitabilidade;

$\checkmark$ medidas de prevenção e intervenção na mortalidade infantil;

$\checkmark$ breve resumo do óbito e

$\checkmark$ identificação dos participantes do fechamento da análise.
} 
Com estas informações geradas pelo SIMI devem ser emitidos Boletins periódicos e, realizados encaminhamentos gerenciais e operacionais junto às Regionais e Municípios.

As causas básicas podem ser alteradas no fechamento da análise, segundo as evidências obtidas. Quando o forem, serão também alteradas as causas básicas digitadas no SIM/DATASUS.

A Ficha Confidencial para Investigação de Óbito Infantil desde o início do trabalho dos Comitês foi utilizada e passou por adequações necessárias e sugeridas pelas Regionais e Municípios. No ano de 2006 o primeiro modelo do Manual para preenchimento de Ficha Confidencial foi implantado no Estado.

Atualmente são utilizadas Fichas de Investigação específicas para a investigação de óbitos neonatais (Anexo 1) e pós-neonatais (Anexo 2), as mesmas apresentam pequenas diferenças entre si. Entretanto, de maneira geral, é composta por seis grandes blocos, a saber:

I. IDENTIFICAÇÃo: bloco de registro de informações retiradas da Declaração de Óbito (DO) e de Nascido Vivo (DN) que dizem respeito a nomes e idades da criança e da mãe, endereço, data de nascimento e sexo da criança que foi a óbito.

II. DADOS DO ÓBrTO: extraídos da DO, como a data do óbito, idade (meses, horas e dias); local de ocorrência; Causa Básica do óbito (Parte I e II); opção pela realização de necropsia e resultado se afirmativo.

III. DADOS DO PRÉ-NATAL: extraídos da Carteira da Gestante e/ou de prontuários ambulatoriais e hospitalares. Essas informações dizem respeito a realização ou não do prénatal e local, se afirmativo; ao registro de possíveis fatores de risco, ao risco detectado; exames realizados; encaminhamentos para serviços de referência e a anamnese obstétrica.

IV. DADOS DO PARTO: são informações extraídas do prontuário materno hospitalar e da DN. São referentes ao parto propriamente dito, como local, hora, tipo de parto (se foi Cesário há espaço para anotação da indicação), indução, duração da gestação, anestesia, complicações maternas durante o parto, se houve óbito materno ou não e atendimento do parto por médico ou não. Neste campo também são registradas algumas informações do RN como peso, APGAR e complicações.

V. DAdOS DO PRONTUÁRIO hospitalaR DA CRIANÇA: como data, hora, local do internamento, transferência / encaminhamento e grau de dificuldade, último registro do peso, 
diagnóstico na internação e informações mais relevantes sobre evolução do quadro, exames e tratamento. Essas informações são mais detalhadas na investigação de óbito infantil pósneonatal, com dados também da puericultura.

VI. VISITA DOMICILIAR: essas informações serão obtidas mediante relato da família, em primeira instância, se encontrada; na ausência da família tenta-se obter algumas informações nos registros, com vizinhos ou profissionais de saúde que saibam informar. As informações deste bloco também são mais detalhadas na investigação de óbito infantil tardio ou pósneonatal, como tempo de amamentação, alimentação, costumes da criança que foi a óbito, resultados de exames dentre outras categorias. Este bloco é subdividido em:

1) Dados sociais e econômicos da família, mãe e pai (escolaridade, situação conjugal, renda, profissão e hábitos de tabagismo, álcool, droga) bem como dados gestacionais (número de gestações, filhos vivos, mortos, abortos, data do último parto)

2) Informações sobre o parto da criança em investigação: tempo decorrido até o atendimento, serviços procurados, duração do parto, qualidade do atendimento e quem realizou o parto.

3) História de internações anteriores da criança em investigação: número e motivos.

4) Sobre a doença que levou a criança ao óbito: quais foram os primeiros sintomas e a data dos mesmos, onde foi atendida, a qualidade do atendimento, o que foi realizado. A mãe é indagada sobre o motivo que levou o filho ao óbito, para se fazer registrar a sua percepcão sobre o processo de atendimento e óbito da criança.

Assim, depois de preenchida esta Ficha da Investigação com todos os dados que são solicitados e anexados todos os documentos necessários, isto é, após todo o processo de investigação do óbito, é realizada uma análise final pela equipe multiprofissional com a presença indispensável de um profissional médico pediatra, $\mathbf{e}$ preenchida a Ficha de Análise Final do Óbito que será utilizado para alimentação do SIMI.

Metodologicamente, para a realização da presente tese, trabalhou-se com o SIMI para obtenção de informações dos óbitos investigados nos Triênios eleitos com o objetivo de caracterizá-los segundo algumas variáveis. Com isso, pretendeu-se, 
além da caracterização dos óbitos investigados, obter subsídios para o trabalho com os discursos dos profissionais. As informações foram trabalhadas em número absoluto e distribuição percentual segundo as seguintes variáveis:

$\checkmark$ óbitos investigados (número absoluto e proporcional) em cada RegS;

$\checkmark$ sexo: masculino e feminino.

$\checkmark$ idade da criança: atendendo aos componentes neonatal precoce, tardio e pósneonatal;

$\checkmark$ consideração sobre a evitabilidade do óbito: evitável, não evitável, inconclusivo ou ignorada;

$\checkmark$ qualidade dos dados da Ficha de Investigação: satisfatória, insatisfatória e pouco satisfatória;

$\checkmark$ responsabilização pelo óbito: assistência médica ou hospitalar ou ambulatorial; social; família; inevitável; inconclusivo;

$\checkmark$ medidas de prevenção e intervenção da mortalidade infantil.

As Medidas de Prevenção e Intervenção da Mortalidade Infantil (Quadro 3; Anexo 5) podem ser distribuídas para várias situações, as quais se iniciam com a promoção de saúde e prevenção primária, passam pela assistência básica como o prénatal e medidas ambulatoriais, chegam à atenção hospitalar secundária e terciária. As medidas de prevenção intervenção também contemplam as medidas sociais.

Para cada grupo de medidas há um alerta para o foco conceitual central. No caso de medidas recomendadas para melhor assistência médica relacionam-se às mortes evitáveis por maiores estudos, capacitação profissional, intercâmbio de informações profissionais e ponderação em relação aos cuidados médicos prestados para evitar a repetição de circunstâncias semelhantes. Para essas situações recomendam-se aos órgãos de classe e da direção dos serviços mais atenção e correção das medidas de prevenção. Os recursos humanos, nesse caso, devem ser coordenados para providenciar as ações e o funcionamento adequado dos equipamentos hospitalares de modo a resultar na assistência adequada compõem a categoria de melhor assistência hospitalar, segundo o Manual do Paraná. 
As medidas educativas e informativas dizem respeito à educação e informação em saúde operacionalizada junto à família / pais / responsáveis. Nesse caso, a atenção é direcionada à resposta da família às orientações, no sentido de entendimento e cooperação, e não enfaticamente para a responsabilidade do profissional em fazê-lo.

As condições de vida, de saneamento básico e de acesso aos serviços de saúde fazem parte das medidas sociais. São medidas que enfatizam, uma vez melhoradas as condições de vida, a tendência é diminuir o impacto da mortalidade infantil na população menos privilegiada.

Não foram trabalhados os Critérios de Redutibilidade (antes denominado de Evitabilidade; Anexo 4), por não terem sido objetivo do presente trabalho, a discussão das causas básicas do óbito, admitindo-se que essas duas categorias mantêm estreita ligação, conforme observado na síntese no Quadro 2.

Quadro 2: Grupos de Critérios de Redutibilidade do Óbito Infantil, Comitês de Prevenção da Mortalidade Infantil, SESA, Paraná, 2007.

\begin{tabular}{|c|c|c|}
\hline Grupos & Critérios & $\begin{array}{c}\text { Descriçã } 0^{\star} \\
\text { Obitos reduzfveis por.... }\end{array}$ \\
\hline 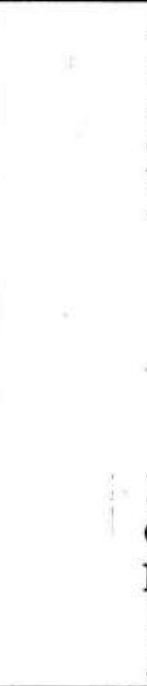 & \begin{tabular}{lr|}
$\mathbf{A}$ & \\
$\mathbf{B}$ & \\
$\mathbf{C}$ & \\
$\mathbf{D}$ & \\
$\mathbf{E}$ & \\
& $\mathbf{E} \mathbf{~ I}$ \\
& $\mathbf{E}$ II \\
& $\mathbf{E}$ III \\
& $\mathbf{E} \mathbf{V}$ \\
$\mathbf{F}$ & $\mathbf{E} \mathbf{~ V I}$ \\
$\mathbf{G}$ & \\
$\mathbf{H}$ & \\
$\mathbf{I}$ & \\
$\mathbf{J}$ &
\end{tabular} & $\begin{array}{l}\text { Imunoprevenção } \\
\text { Adequada atenção à gestação } \\
\text { Adequada atenção ao parto } \\
\text { Adequada atenção ao recém-nascido } \\
\text { Diagnóstico e tratamento precoce } \\
\text { Doenças Infecciosas e Parasitárias } \\
\text { Doenças das Glândulas Endócrinas e Metabólicas } \\
\text { Doenças do Sistema Nervoso } \\
\text { Doenças do Aparelho Circulatório } \\
\text { Doenças do Aparelho Respiratório } \\
\text { Doenças de Outros Órgãos ou Aparelhos } \\
\text { Adequada Atenção, orientação e cuidados com a criança } \\
\text { Óbito vinculado ao risco pela malformação congênita } \\
\text { Óbitos por malformaçð̃es congênitas não viáveis } \\
\text { Óbitos por causas mal definidas } \\
\text { Óbitos dificilmente reduziveis (neoplasias) }\end{array}$ \\
\hline
\end{tabular}

Fonte: PR/SESA, 2006.

Nota:

*A cada grupo de descriçło sấo relacionadas as causas básicas que sắo contempladas pelo grupo (Anexo 4). 
O Manual para o preenchimento da Ficha de Investigação do Óbito Infantil, no Paraná (PR/SESA, 2006), contém as seguintes observações no instrumento de orientação à eleição da redutibilidade / evitabilidade do óbito infantil:

\begin{abstract}
Obitos preventveis ou evildiveis: são aqueles que levando em consideração a ciência e tecnologia existentes atualmente poderiam ter sido prevenidos ou não deveriam ter ocorrido. Este é um critério dinâmico e mutável com o tempo.

Óbitos nåo preveniveis ou näo evitáveis: são aqueles que considerando o estado atual das ciências e da tecnologia não puderam ser prevenidos. Considerar todas as ciências (sociais, biológicas, etc.) e todas as técnicas políticas, médicas, administrativas existentes.
\end{abstract}

O trabalho com as variáveis registradas no SIMI foi de extrema importância para avaliação das estratégias, programas e ações realizadas pela saúde no estado do Paraná. Esse enfoque nos proporciona evidências de situações inadequadas de assistência à saúde e de condições de vida da população. Assim, alertam para a necessidade de readequação e reflexão sobre vários parâmetros de qualidade de vida, de gestão e cuidados à saúde.

As informações registradas no SIMI também foram importantes para ouvir e compreender os profissionais - na gestão ou na operacionalização - envolvidos com ações de prevenção ao óbito infantil. A discussão proporcionada pelo estudo do SIMI mostrou-se útil para subsidiar e reforçar a discussão sobre os discursos-síntese, originados das entrevistas com os atores sociais, questão metodológica que será tratada no item seguinte. 
Quadro 3: Grupos de Medidas de Prevenção e Intervenção da Mortalidade Infantil, Comitês de Prevenção da Mortalidade Infantil, SESA, Paraná, 2007.

\begin{tabular}{|c|c|c|}
\hline Grt & Medidas & Medidas especificas de prevenção e intervenção \\
\hline 1 & $\begin{array}{l}\text { Medidas de } \\
\text { promoção de } \\
\text { saúde e } \\
\text { prevenção } \\
\text { primária }\end{array}$ & $\begin{array}{l}\text { 1.A Educação em saúde } \\
\text { 1.B Cobertura vacinal adequada } \\
\text { 1.C Planejamento familiar } \\
\text { 1.D Avaliação de risco gestacional } \\
\text { 1.E Acesso ao pré-natal } \\
\text { 1.F Busca ativa à criança de risco } \\
\end{array}$ \\
\hline 2 & $\begin{array}{l}\text { Medidas para } \\
\text { pré-natal }\end{array}$ & $\begin{array}{l}\text { 2.A Disponibilidade de consultas } \\
\text { 2.R (Qualidade da cmnsulta } \\
\text { 2.C Disponibilidade/realização de exames laboratoriais } \\
\text { 2.D Disponibilidade de medicamentos } \\
\text { 2.E Orientaçóes básicas (hábitos, sinais de trabalho de parto, cuidados com o } \\
\text { RN, etc) } \\
\text { 2.F Vigilância do risco gestacional }\end{array}$ \\
\hline 3 & $\begin{array}{l}\text { Medidas para } \\
\text { atenção } \\
\text { ambulatorial } \\
\text { infantil }\end{array}$ & $\begin{array}{l}\text { 3.A Acesso ao tratamento } \\
\text { 3.B Adequada assistência (diagnóstico e tratamento) } \\
\text { 3.C Disponibilidade de medicamentos } \\
\text { 3.D Adequado encaminhamento hospitalar (disponibilidade e rapidez) } \\
\text { 3.E Qualidade nas orientaçóes (quanto ao tratamento, quanto a gravidade do } \\
\text { caso, retornos) }\end{array}$ \\
\hline 4 & $\begin{array}{l}\text { Medidas para } \\
\text { atenção } \\
\text { ambulatorial } \\
\text { materna }\end{array}$ & $\begin{array}{l}\text { 4.A Acesso ao tratamento } \\
\text { 4.B Adequada assistência (diagnóstico e tratamento) } \\
\text { 4.C Disponibilidade de medicamentos } \\
\text { 4.D Adequado encaminhamento hospitalar (disponibilidade e rapidez) } \\
\text { 4.E Qualidade nas orientaçø̃es (quanto ao tratamento, quanto a gravidade do } \\
\text { caso, retornos) }\end{array}$ \\
\hline 5 & $\begin{array}{l}\text { Medidas para } \\
\text { atenção } \\
\text { ambulatorial } \\
\text { infantil } \\
\end{array}$ & $\begin{array}{l}\text { 5.A Garantir acesso ao internamento } \\
\text { 5.B Presteza e qualidade no atendimento } \\
\text { 5.C Recursos adequados ao atendimento (UTI) } \\
\text { 5.D Disponibilidade terapêtica } \\
\end{array}$ \\
\hline 6 & $\begin{array}{l}\text { Medidas para } \\
\text { atenção } \\
\text { hospitalar } \\
\text { materna } \\
\end{array}$ & $\begin{array}{l}\text { 6.A Garantir acesso ao internamento } \\
\text { 6.B Presteza e qualidade no atendimento } \\
\text { 6.C Recursos adequados ao atendimento (UTI) } \\
\text { 6.D Disponibilidade terapêutica } \\
\end{array}$ \\
\hline 7 & $\begin{array}{l}\text { Medidas de } \\
\text { suporte social }\end{array}$ & $\begin{array}{l}\text { 7.A Suplementação alimentar } \\
\text { 7.B Melhoria de infra-estruturas básicas (saneamento, habitação) } \\
\text { 7.C Visita domiciliar } \\
\text { 7.D Apoio ao tratamento de drogadição / alcoolismo } \\
\text { 7.E Outras medidas de apoio à melhoria das condiçøes sociais (escolaridade, } \\
\text { renda) }\end{array}$ \\
\hline
\end{tabular}

Fonte: PR/SESA, 2006. 


\subsubsection{AS REPRESENTAÇÕES SOCIAS: Discurso do Sujeito Coletivo e o Qualiquantisof:}

Uma das dimensões metodológicas da presente investigação, importante e valorizada foi a "escuta" dos atores sociais envolvidos com a prevenção da MI. A intenção nessa "escuta" foi verificar o que sabem sobre as Estratégias, Ações ou Programas que estão sendo realizados no estado do Paraná para que se previna a ocorrência do evento sentinela: o óbito infantil. Esse objetivo surgiu, sobretudo, para sondar o conhecimento que os profissionais da área têm da existência e ações dos Comitês de Prevenção da Mortalidade Infantil. Outras situações verificadas junto aos atores, com o objetivo maior de conhecer a percepção dos profissionais da área da saúde quanto a prevenção da Mortalidade Infantil no estado do Paraná, foram as dificuldades presentes no processo preventivo e, as sugestões elaboradas pelos atores sociais entrevistados.

Para atingir esse objetivo elegeu-se como enfoque teórico-metodológico as REPRESENTAÇõES SOCIAIS, teorização desenvolvida por Serge Moscovici e aprofundada por Denise Jodelet (OLIVEIRA, 2004; JODELET, 2001, 2005). Como método optou-se pelo DISCURSo do SUJEITo COLETIVo - DSC de LEFĖVRE e LEFÈVRE (2003) e, com o apoio operacional do software Qualiquantisof ${ }^{\circ}$ (QQ), foi possível acessar, com rigor metodológico os discursos individuais originais e, construir os discursos-síntese para o conhecimento das Representações Sociais dos atores em relação à Prevenção do Óbito Infantil, foi a reprodução coletiva da RS (LEFÈVRE et al., 2007b).

Essa questão de 'como percebe' de 'saber algo' das pessoas que emitem sua opinião, é a idéia de cada um, que é proferida mediante o discurso individual, é o nível da produção individual das RS (LEFÈVRE et al., 2007b). Esses discursos individuais servem de matéria prima, quando trabalhados no QQ, para a construção do discurso coletivo coerente, redigido na primeira pessoa do singular, preservando originalmente as falas individuais, de modo que cada ator possa reconhecer-se ao ler ou ouvir o discurso. 
Dessa maneira, como proposto por LEFÈVRE e LEFĖVRE (2003), partiu-se dos discursos originais brutos, constituídos pelas respostas dos entrevistados, transcritas literalmente. Esses discursos foram submetidos a um trabalho analítico de decomposição. Esse trabalho que consistiu em localizar no discurso transcrito, trechos que deviam ser marcados salientados, pelo pesquisador como reveladores da essência do depoimento. Ou seja, do conteúdo discursivo da resposta a cada pergunta. Os fragmentos de respostas às perguntas realizadas são denominados Expressões Chave (ECH); é com essa matéria-prima que são construídos os Discursos dos Sujeitos Coletivos (LEFĖVRE e LEFÈVRE, 2003).

Num segundo momento analítico-discursivo, em cada trecho, ou 'pedaço do discurso' marcado, foram 'garimpadas' as Idéias Centrais (IC). A IC se constitui por um nome ou expressão lingüística que revelam, de modo mais fidedigno possível e sinteticamente, o sentido de cada conjunto homogêneo das ECH. Assim, a cada ECH poderão existir uma ou mais IC, que podem ser categorizadas em grupos iguais ou semelhantes. Essa análise é favorecida pelo conhecimento e pela intimidade do pesquisador com o tema. Desse modo, uma IC advém de um conjunto de ECH identificadas a partir de diferentes respostas à determinada pergunta proposta pelo questionário que está sendo aplicado (LEFĖVRE e LEFÈVRE, 2003).

Portanto, foi da articulação das ECH extraídas com fidedignidade das respostas individuais transcritas, relativas a cada IC especificamente, que se chegou à identificação de diferentes discursos-sintese. Portanto, o conjunto dos discursossíntese referentes à determinada pergunta é a "revelação da base coletiva da fala de cada um dos sujeitos da pesquisa, isto é, o Discurso do Sujeito Coletivo e traduz o essencial do conteúdo discursivo, é como se o discurso de todos fosse o discurso de um" (LEFÈVRE e LEFÈVRE, 2001, p. 83).

Não se optou pela utilização da ferramenta de filtros e nem a eleição de ancoragens (AC) nesta pesquisa devido ao tempo destinado para a mesma e ao alcance dos objetivos propostos sem essa especificação.

Para a construção do DSC é preciso aproveitar o máximo das idéias presentes nos depoimentos originais para se ter um produto completo, de modo que no "garimpo textual" as idéias apresentam-se repetidas, dentre as várias idéias repetidas 
selecionou-se apenas um "exemplar", de modo a produzir um texto narrativo limpo; sem 'corte de idéias' e, tampouco, sobreposição das mesmas.

Com o Qualiquantisoft ${ }^{\oplus}$ pode-se lançar mão de um recurso da informática para facilitar a realização de pesquisas nas quais se utilizam a técnica do DSC. Com isso, realizou-se essa pesquisa com mais segurança e eficiência. Este Programa oferece suporte ao pesquisador, no trabalho de garimpagem dos discursos individuais e, também para a lapidação dos DSC síntese, gerando maior rapidez no processamento dos dados. $\mathrm{O} \mathrm{QQ}$ constitui-se num avanço para a investigação social (LEFÈVRE, et al. 2007b).

Uma peculiaridade importante do $\mathrm{QQ}$ é permitir a associação de "pensamentos, crenças, valores, representações às características objetivas dos portadores destas representações, tais como sexo, idade, grau de instrução, renda e sutras", esta é a parte quantitativa do software (LEFÈVRE, et al. 2007b, p.3; JEFÈVRE e LEFÈVRE, 2007).

Como componentes do Qualiquantisoft ${ }^{\oplus}$ pode-se citar, de acordo com .EFÈVRE, et al. (2007b, p.3):

\footnotetext{
+ Cadastros: permitem arquivar dados e banco de dados relativos a entrevistados, pesquisas, perguntas, cidades, distritos, grupos de entrevistados, faixa de renda, grau de instrução e faixa etária; - Análise: quadros e processos que permitem a realização de todas as tarefas necessárias à construção dos DSC;

- Ferramentas: permitem a exportação e a importação de dados $e$ resultados de pesquisas.

+ Relatórios: organizam e permitem a impressão dos principais resultados das pesquisas.
}

O Programa Qualiquantisoft ${ }^{\oplus}$ foi trabalhado na segunda fase desta ıvestigação sob a orientação e supervisão da equipe idealizadora no Instituto de esquisa do Discurso do Sujeito Coletivo - IPDSC, durante 15 dias interruptamente, em maio de 2007. Foi um momento de aquisição de bastante speriência, de uma riqueza ímpar na troca de informações e de muita motivação ra a continuidade da pesquisa mediante a nobreza das idéias das Representações sciais apresentadas pelos DSC lapidados.

Inicialmente a reflexão dos pesquisadores se deu sobre a construção de um strumento que supostamente 'desse conta' de obter essas representações, e 
também, não menos importante, sobre a eleição dos atores. Que profissionais poderiam deter maior riqueza de idéias sobre a prevenção da Mortalidade Infantil e quais deles poderiam também subsidiar as Representações sobre os Comitês de Prevenção da Mortalidade Infantil? Como se poderia abranger todo o estado do Paraná?

Após um tempo relativamente extenso de reflexão e incerteza sobre a factibilidade da pesquisa, delineou-se o caminho a ser percorrido nesta etapa da pesquisa, que é tida e colocada como essencial para a pesquisadora, foram definidas as etapas que serão explanadas a seguir.

\subsubsection{DEFINIÇÃO DA POPULAÇÃO PARA ENTREVISTA}

As Regionais de Saúde (RegS) são as unidades administrativas da rede de aaúde no Paraná que ficaram responsáveis pelo gerenciamento do modus operandi los Comitês Regionais e Municipais de Prevenção da Mortalidade Infantil, com o lirecionamento para o efetivo apoio, monitoramento e avaliação das investigações os municípios que lhe são afetos.

Como os objetivos desta pesquisa se direcionaram para o Estado, como um odo, a primeira questão resolvida foi a geográfica, pois seria impossível para a ıesquisadora percorrer as 22 RegS por todo o estado do Paraná, somado a mais 22 Municípios-sede (um para cada RegS) e, realizar um número muito grande de ıntrevistas. Esta limitação se pôs à pesquisadora não só pelo tempo que demandaria, nas também pela extensão de conteúdos discursivos a ser trabalhada. Na verdade, rovavelmente seriam muitos discursos, talvez com idéias sobrepostas que acabariam iendo eliminadas no processo de lapidação; além do custo que geraria todo esse ircuito pelo Estado.

Para delimitar a região de abrangência para as entrevistas resolveu-se utilizar เ Divisão Administrativa da Saúde por Macrorreginais Metropolitana, Centro, Jampos Gerais, Oeste, Sudoeste, Noroeste e Norte (Figura 1) (PR/SESA, 2001).

No Quadro 4 pode-se visualizar informações básicas à respeito da omposição das Macrorregionais e Regionais que as compõem, número de 
municípios por cada RegS, sobre a população total de menores de um ano, de acordo com informações do IBGE no censo de 2000, disponibilizadas pelo DATASUS/MS (BRASIL, 2007b). Observa-se que a população de menores de um ano no estado do Paraná, no Censo de 2000 foi responsável por 1,8\% de toda a população. As macrorregionais com maior número de municípios são a Norte e Noroeste, 81 e 115, respectivamente.

Para definição da região de abrangência das entrevistas os pesquisadores verificaram a TMI de todas as macrorregionais de saúde e, elegeram para entrevistas as que apresentassem maior e menor TMI ao longo de 08 anos, ou seja, de 1997 a 2004.

Tabela 3: Macrorregionais do Estado do Paraná segundo Taxa Média de Mortalidade Infantil (\%o NV) e sua classificação na pesquisa (maior, médio e menor), 1997 2004.

\begin{tabular}{c|cc}
\hline Macrorreginal & TMI média (1997 a 2004) & Classificação TMI \\
\hline Noroeste & 16,71 & Menor \\
Norte & 16,87 & Menor \\
Oeste & 17,21 & Médio \\
Metropolitana & 17,89 & Médio \\
Sudoeste & 18,04 & Médio \\
Campos gerais & 21,95 & Médio \\
Central & 24,12 & Maior \\
\hline
\end{tabular}

Fonte: SIM/SINASC/Datasus (MS, 2007), dados brutos.

Assim, para cada Macrorregional traçou-se a Taxa de Mortalidade Infantil / TMI ano a ano no período de 1997 a 2004 . Ao final calculou-se, com a somatória do número de óbitos e do número de nascidos vivos em cada Macro, a TMI média para o período. A segui, elegeu-se a Macro com maior e menor TMI para a busca de atores sociais a serem entrevistados. $\mathrm{O}$ pré-teste foi realizado numa Macro que apresentou TMI denominada de "média", isto é, estava entre a de maior e menor TMI no período (Tabela 3, Apêndice 3).

Após esse trabalho de seleção elegeu-se, portanto as Macrorregionais a serem visitadas: para pré-teste, a Metropolitana e, para entrevistas definitivas as macrorregionais Norte (menor TMI no período) e a Centro-Sul (maior TMI no período). 
Figura 1: Mapa do Estado do Paraná com divisões por Regionais e Macrorregionais de Saúde, Paraná, 2007.

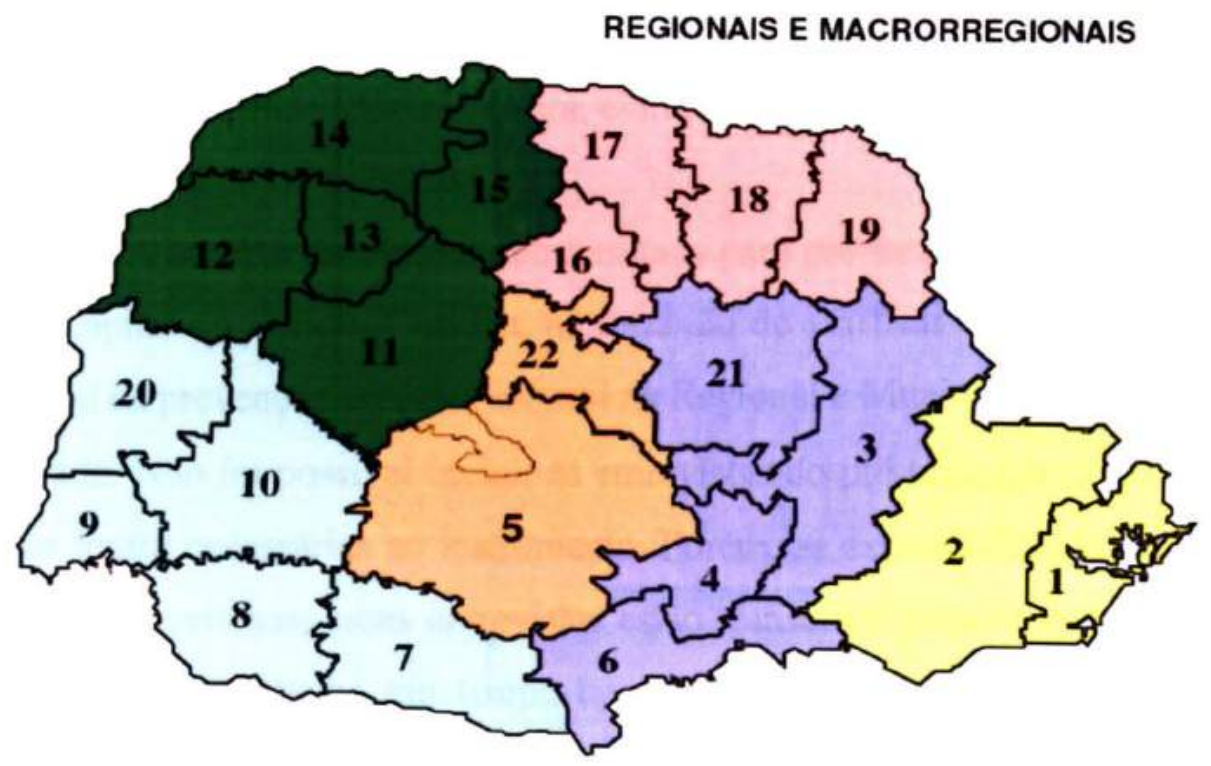

Fonte: extraida do site www saude pr gov br, acesso em 2007.

Quadro 4: Macrorregionais segundo Regionais de Saúde que as compõem municípios-sede e número de municípios adstritos com a população total e menor de um ano, Paraná, 2007.

\begin{tabular}{|c|c|c|c|c|c|c|c|}
\hline MACRORREGIONAIS & RS & Municipios Sede & $\begin{array}{l}N^{\bullet} \text { de } \\
\text { Municipios }\end{array}$ & $\begin{array}{l}\text { Total } \\
\text { Municípios }\end{array}$ & $\begin{array}{l}\text { População } \\
\text { Total* } \\
\end{array}$ & $\begin{array}{c}\text { Menor de } 1 \\
\mathbf{N}^{\circ} \quad \% \\
\end{array}$ & no* \\
\hline \multirow[t]{2}{*}{ Metropolitana } & $1^{2}$ & Paranaguá & $\begin{array}{r}7 \\
\end{array}$ & \multirow[t]{2}{*}{36} & 273.977 & 5.545 & 2,0 \\
\hline & $2^{a}$ & Curitiba & 29 & & 3.234 .411 & 60.206 & 1,9 \\
\hline \multirow[t]{4}{*}{ Campos Gerais } & $3^{n}$ & Ponta Grossa & 12 & \multirow{4}{*}{37} & 563.740 & 11.322 & 2,0 \\
\hline & $4^{2}$ & Irati & 9 & & 155.284 & 3.060 & 2,0 \\
\hline & $6^{a}$ & União da Vitória & 9 & & 164.801 & 3.517 & 2,1 \\
\hline & $21^{2}$ & Telêmaco Borba & 7 & & 164.565 & 3.518 & 2,1 \\
\hline \multirow[t]{2}{*}{ Centro-Sul } & $5^{\circ}$ & Guarapuava & 20 & \multirow[t]{2}{*}{36} & 450.923 & 10.217 & 2,3 \\
\hline & $22^{a}$ & Ivaiporă & 16 & & 135.357 & 2.313 & 1,7 \\
\hline \multirow[t]{2}{*}{ Sudoeste } & $7^{*}$ & Pato Branco & 15 & \multirow[t]{2}{*}{42} & 242.047 & 4.852 & 2,0 \\
\hline & $8^{a}$ & Francisco Beltråo & 27 & & 315.634 & 5.855 & 1,8 \\
\hline \multirow[t]{3}{*}{ Oeste } & $9^{a}$ & Foz do Iguaçu & 9 & \multirow[t]{3}{*}{52} & 432.032 & 8.572 & 1,9 \\
\hline & $10^{\circ}$ & Cascavel & 25 & & 493.390 & 8.952 & 1,8 \\
\hline & $20^{n}$ & Toledo & 18 & & 323.173 & 5.091 & 1,6 \\
\hline \multirow[t]{5}{*}{ Noroeste } & $11^{\circ}$ & Campo Mourito & 25 & \multirow{5}{*}{115} & 321.088 & 5354 & 1,7 \\
\hline & $12^{*}$ & Umuarama & 21 & & 240.511 & 3.766 & 1,6 \\
\hline & $13^{\prime \prime}$ & Ciamorte & 11 & & 129.247 & 2. 108 & 1,6 \\
\hline & $14^{4}$ & Paranasai & 28 & & 232822 & 3.959 & 1,6 \\
\hline & $15^{\circ}$ & Maringh & 30 & & 694295 & 10.6751 & 1.5 \\
\hline \multirow[t]{4}{*}{ Norte } & $16^{a}$ & Apucarana & 17 & \multirow{4}{*}{81} & 331.363 & 5.397 & 1,6 \\
\hline & $17^{a}$ & Londrina & 20 & & 825.769 & 13.894 & 1,7 \\
\hline & $18^{\circ}$ & Cornélio Procópio & 22 & & 245.560 & 4.066 & 1,7 \\
\hline & $19^{a}$ & Jacarezinho & 22 & & 271.851 & 4.565 & 1,7 \\
\hline Todas & $1^{a} / 22^{a}$ & & 399 & 399 & 10.261 .840 & 186.834 & 1,8 \\
\hline
\end{tabular}

Fontes: informaç̃̃es populacionais do Ministério da Saúde a partir dos resultados do CENSO 2000 - IBGE; SESA/ISEP, dados on line dos municipios, acesso em 2007, dados brutos (BRASIL, 2007b, PR/SESA, 2007).

Nota:

**Percentual aproximado. 
As macrorregionais Norte e Noroeste apresentaram os menores TMI em todo o período de estudo; a diferença foi mínima entre elas. No entanto, em virtude da convivência da pesquisadora com a Macro Noroeste e com a implantação do Comitê Regional de Prevenção da Mortalidade Infantil na mesma, optou-se pela macro Norte, pretendendo, dessa maneira, evitar "vieses" devido ao envolvimento com as situações locais de trabalho.

A escolha da Macro Metropolitana para pré-teste foi devido ao pertencimento da Capital do Estado, Curitiba, na intenção de verificar como se dá a representação social da prevenção do óbito infantil na Regional e Município-sede mais populoso do Estado. Não foi possível incluir as entrevistas do pré-teste em razão das adequações que foram necessárias ao instrumento. Porém, as experiências das entrevistas foram muito proveitosas; essas entrevistas estão transcritas para, quem sabe, a elaboração de um outro trabalho em tempo oportuno. Após re-adequação do instrumento foi realizado o pré-teste em um dos municípios-sede de uma Regional de Saúde que integra a Macro Noroeste; estas entrevistas foram incluídas na análise.

Para realização das entrevistas percorreram-se cerca de $4.000 \mathrm{Km}$ no estado, no período compreendido entre os meses de fevereiro a abril. Alerta-se para a demanda econômico-financeira e o esforço para se proceder a entrevistas que intentem buscar representações sociais que possam ter legitimidade para todo o estado.

\subsubsection{ELEIÇÃO DOS ATORES SOCIAIS}

Optou-se por uma escolha intencional dos sujeitos a serem investigados, devido ao envolvimento da pesquisadora com o tema e contexto, e também devido à organização das responsabilidades para o processo investigativo nas Regionais de Saúde e Municípios.

Esta escolha teve como o escopo incluir indivíduos que representassem duas categorias básicas de profissionais: os FORMULADORES E GESTORES das Políticas / Programas / Estratégias / Ações, bem como os trabalhadores dessas situações na ponta do processo, ou seja, os PROFISSIONAIS DE SAÚDE, inseridos nos serviços de 
spidemiologia, no contexto da rede básica de saúde e de hospitais, de preferência som atendimento terciário.

Dentro de uma concepção mais teórica de inserção profissional enfatiza-se que houve a seleção de profissionais em nível de GESTÃo DOS SERVIÇOS, desde os nais ligados à priorização, formulação e avaliação das ações (Diretores de Regionais) até os responsáveis por setores e serviços de referência para a vigilância $\mathrm{e}$ investigação dos óbitos infantis (Coordenadores da Epidemiologia e dos Comitês). Por outro, como portadores de representação mais voltada à prática da implementação das ações, escolheram-se PROFISSIONAIS QUE ESTÃO NA PONTA DOS SERVIÇOS, são os responsáveis pelo processo de trabalho, pela assistência à saúde.

Em relação à Rede Básica de Saúde, optou-se entrevistar médicos e ənfermeiros de uma unidade urbana e de uma unidade rural devido à diversidade de zontexto sócio-cultural e ambiental e devido, também, a diversidade de acesso a serviços de referência. De maneira geral, quase a totalidade das Unidades por todo o Estado têm implantado o Programa de Saúde da Família (PSF) e/ou o de Agente Jomunitário de Saúde (PACS), não constituindo essa situação diferencial para leterminação da entrevista em Unidade Básica de Saúde.

A preferência foi dada aos Hospitais que tivessem atendimento de Unidade de Terapia Intensiva Neonatal e/ou Pediátrica - UTIN ou UTIP, público ou filantrópico, com leitos habilitados pelo SU. Nestes locais foram abordados diretores nédicos, médicos e enfermeiros responsáveis, diretos ou não, pelo setor de terapia intensiva.

Pensou-se, também, na importância de se obter representações técnicojperacionais dos Comitês de Prevenção da Mortalidade Infantil dos níveis Municipal : Regional, considerando que a recomendação para o estabelecimento dos Comitês se dá para as Regionais de Saúde e, na seqüência, para os municípios que as sompõem. Quanto aos representantes dos Comitês procurou-se incluir dos níveis Regionais, Municipais e, quando presente, do nível Hospitalar.

Assim, elegeram-se atores sociais das instâncias das Regionais de Saúde, bem zomo dos Municípios-sede das Regionais compondo o seguinte grupo de pessoas intrevistadas: 
$>$ Diretores de Regionais de Saúde e Hospitalares que compuseram a categoria DIR na análise do DSC, com 9 entrevistados;

$>$ Coordenadores de Setores de Epidemiologia da Regional e do Município que compuseram os CVE no DSC, com 11 entrevistados;

Coordenadores dos Comitês Regionais, Municipais e Hospitalares que foram categorizados como CRPMI para análise do discurso, com 16 entrevistados;

$>$ Técnicos dos Sistemas de Informação sobre Mortalidade (SIM) e de Mortalidade Infantil (SIMI) compondo o grupo dos INF no DSC, com 9 entrevistados;

Enfermeiros e Médicos da Rede Básica de Saúde e de Hospitais que formaram a categoria dos SERV no discurso, com 35 entrevistados.

Foram previstas de 90 a 108 entrevistas (Apêndice 4), com a inclusão de mais ıma RegS como pré-teste do instrumento re-adequado, gerou-se mais 18 entrevistas, sortanto a previsão final era de 108 a 126 entrevistas. Dessa previsão houve apenas luas recusas, uma de Diretor Clínico de um dos Hospitais, outra de um profissional nédico de UBS rural. Houve situações de impossibilidade de encontro com o rofissional-alvo, em virtude do turno de trabalho, falta por motivo de doença amiliar, horário de expediente do setor, sobreposição de funções e reuniões de serviço. Assim, ao todo se conseguiu 80 entrevistas com sucesso, com as quais trabalhou-se no Qualiquantisoft ${ }^{\circledR}$.

O pré-agendamento das entrevistas aconteceu, prioritariamente, com os Diretores de Regionais de Saúde pela grande mobilidade que apresentam no zotidiano de trabalho com viagens a municípios e à Capital do Estado, os horários de lisponibilidade destes gestores são bastante concorridos por atividades internas. As lemais instâncias Regionais e Municipais foram marcadas em função da lisponibilidade do Diretor da RegS, para os dias que a pesquisadora estivesse resente em cada Município-sede, foram de um a três dias de permanência em cada nunicípio. Nestes dias, procedeu-se a entrevistas por mais de 8 horas diárias, ncluindo-se o tempo de deslocamento de um lugar para o outro, na tentativa de nelhor adequar o horário de disponibilidade dos diferentes atores sociais. Houve seríodos de espera da pesquisadora, mas não foram muitos. 
De maneira geral, as entrevistas ocorreram num tempo médio de 30 a 40min e houve boa vontade e receptividade dos serviços e dos próprios gerentes. Em algumas situações, os próprios gerentes se ofereceram para conduzir a pesquisadora às UBS rurais, as quais demandaram um trajeto e tempo maior.

\subsubsection{INSTRUMENTOS DE PESQUISA}

Foi elaborado um Instrumento de Pesquisa (Anexo 6), contendo algumas perguntas abertas e amplas de forma a suscitar a elaboração reflexiva do conhecimento prático de cada ator social e a emissão de 'sua idéia', 'seu parecer' sobre a prevenção da MI.

A dificuldade maior concentrou-se na formulação de perguntas, pois estas questões deveriam ser amplas e, ao mesmo tempo, suscitar respostas específicas que pudessem ser apresentadas para uma grande diversidade de atores (gestores e profissionais técnicos) numa mesma forma, numa mesma linguagem.

$\mathrm{O}$ primeiro instrumento elaborado e pré-testado teve de ser re-adequado, pois foram utilizadas perguntas diferentes para cada ator social, impossibilitando a utilização para a categorização no Qualiquantsoft. Assim, o instrumento re-adequado passou a ter 10 questões denominadas gerais e 6 denominadas específicas, essas últimas foram aplicadas à técnicos dos SIM e SIMI e para coordenadores dos Comitês (Anexo 6).

Nesta pesquisa não foi trabalhada a totalidade das questões realizadas porque, ao iniciar a operação no $\mathrm{QQ}$, percebeu-se que mediante as respostas a três perguntas gerais colheu-se subsídios importantes para a constituição dos Discursos do Sujeito Coletivo e suas representações sociais sobre as ações preventivas do óbito infantil. Outro motivo foi o tempo destinado à pesquisa e a grande quantidade de informações a serem discutidas, correndo o risco na discussão de desviar-se do foco original. Pretende-se trabalhar as demais perguntas em tempo possível. Assim foram trabalhadas as seguintes questões: 
1) Você pode me dizer algumas ações, estratégias ou Programas que têm sido desenvolvidos nesse municipio / Regional de Saúde, por recomendação e incentivo da Secretaria de Estado da Saúde do Paraná, para prevenir-se a morte de uma criança antes de completar seu primeiro ano de vida, ou seja, prevenir o óbito infantil?

2) Fale-me um pouco sobre as dificuldades enfrentadas para implantação dos Comitês de Prevenção da Mortalidade Infantil // para a realização do trabalho preventivo do óbito infantil.

3) Que sugestões você tem a fazer para que essas dificuldades citadas sejam minimizadas ou sanadas?

A primeira pergunta propositalmente omite a menção aos Comitês, pois se sondava o conhecimento dos atores sociais em relação a Programas e Estratégias de prevenção da Mortalidade Infantil. Tendo em vista a diversidade de atores sociais e o desconhecimento do Comitê, foi necessário adequar-se as perguntas focando apenas ações no cotidiano de trabalho que previnam o óbito infantil.

$\mathrm{O}$ instrumento também contava com uma parte de cadastro pessoal do qual colheu-se informações registradas pelo próprio entrevistado sobre: instituição de trabalho, sexo, idade, profissão, cargo ou função, há quanto tempo ocupa esse cargo ou função e escolaridade. Trabalhou-se quantitativamente no Qualiquantisoft ${ }^{\circledR} \mathrm{com}$ as variáveis: sexo, idade e escolaridade. A variável profissão foi trabalhada apenas para os profissionais entrevistados na rede básica e hospitalar. As informações dos cargos e funções não foram analisadas neste momento, pois em seu preenchimento houve alguma dificuldade por parte dos entrevistados. Embora a representação social possa ser influenciada pela inserção do profissional no serviço, nesta etapa da pesquisa a pesquisadora não destacou como objetivo a construção dos DSC por categoria profissional, o que é permitida pela utilização do filtro no QQ.

O Termo de Consentimento Livre e Esclarecido de acordo com a Resolução do Conselho Nacional de Saúde $\mathrm{n}^{\circ} 196$ de 1996 foi incluso na mesma página da Ficha Cadastral, assim no verso ficaram as questões que seriam respondidas. Optouse por este formato para reduzir a quantidade de folhas a serem manuseadas. 
Previamente ao agendamento das entrevistas foram encaminhadas, conforme solicitação, por e-mail solicitações de entrevistas às Regionais de Saúde, Secretarias Municipais de Saúde, bem como aos Hospitais.

Cada entrevistado passou a ter uma Ficha denominada Instrumento de Pesquisa (Anexo 6). Essa Ficha era entregue ao entrevistado, no início da entrevista, para que procedesse à leitura da parte do Consentimento que explicava a pesquisa, 0 zaráter de sigilo das informações e o anonimato.

Depois de realizada a leitura pelo entrevistado a pesquisadora expunha um pouco mais sobre os objetivos da pesquisa e dirimia as dúvidas que foram poucas. $\mathrm{O}$ sigilo das informações foi garantido. Houve, em algumas explanações ao entrevistado, a necessidade de repetir os objetivos da entrevista por inúmeras vezes, até mesmo durante a entrevista. Pareceu-nos que havia um sentimento de "medo da represália". O anonimato também foi garantido explicando-se brevemente como seriam trabalhados os discursos, ou seja, a metodologia do DSC.

Quando o entrevistado concordava em participar da investigação, lhe era solicitado que datasse o instrumento, escrevesse seu nome por extenso e o assinasse. Logo após, a pesquisadora solicitava o preenchimento da Ficha Cadastral. A entrevistadora dizia que as perguntas estavam no verso da folha, mas solicitava que não fossem lidas anteriormente para se manter um padrão de abordagem para todo 0 universo de entrevistados; até porque alguns respondentes queriam "ensaiar" a resposta antes de gravar, fato que levaria à perda da primeira elaboração mental espontânea.

Para a gravação das entrevistas utilizou-se um aparelho gravador portátil da Panasonic, RN 305 e fitas cassetes pequenas. Foram necessárias 20 mini-fitas que, depois de transcritas, foram arquivadas pela pesquisadora. No Termo de Consentimento assinado por cada entrevistado, constava também a disponibilização do material gravado e transcrito, caso houvesse interesse ou dúvida do entrevistado quanto ao conteúdo.

As dificuldades técnicas na utilização da gravação foram: um ambiente tranqüilo, pois nem sempre se conseguiu um ambiente livre de ruídos para garantir a qualidade da gravação, aconteceram até entrevistas em corredor de hospitais, 'cantinhos' de unidades, em ambientes com ar condicionado ligado, todos esses 
fatores dificultaram a transcrição. Outra dificuldade foi monitorar o término da fita, pois a pesquisadora fixava-se tanto na "escuta" e se esquecia da gravação. Uma dificuldade que precisa ser relatada quando se trata de material gravado é a transcrição. Esse trabalho é demorado, exige habilidade auditiva, e de informática simultâneas além de ser um trabalho caro. A pesquisadora preferiu contratar a transcrição, devido ao grande número de fitas, pois também fez a revisão dos textos transcritos ouvindo as gravações, antes de alimentar o software com os discursos.

A dificuldade de interação entre o 'gravador' (que, por vezes, parecia uma terceira pessoa no espaço de entrevista), pois alguns entrevistados falavam olhando para ele; e 'o entrevistado' também se constituiu como problema, pois vários deles não gostavam de gravar suas vozes, outros tinham receio que a gravação pudesse prejudica-lo em seu serviço. Situações como essas demandaram um tempo maior para 'quebrar o gelo' da entrevista e torná-la mais informal. A pesquisadora se limitou apenas a realizar as perguntas e explicá-las caso não houvesse entendimento, o que foi raro. 


\section{OS RESULTADOS E DISCUSSÃO}

\subsection{A MORTALIDADE INFANTIL NO PARANÁ}

\subsubsection{OS ÓBITOS INFANTIS OCORRIDOS: contextualização}

Verificou-se que, ao longo dos Triênios em estudo, o risco de morte de crianças menores de um ano decresceu para o Estado do Paraná as TMI comportaram-se da seguinte maneira: $1^{\circ}$ Triênio - 19,91; $2^{\circ}$ Triênio - 18,01 e $3^{\circ}$ Triênio - 15,48 óbitos de menores de um ano por \%o NV. Portanto, o risco de crianças menores de um ano, filhas de mães residentes no Paraná, virem a morrer, sofreu decréscimo de aproximadamente $22 \%$, entre o $1^{\circ}$ e o $3^{\circ}$ Triênio (Quadro 5).

Quadro 5: Regionais de Saúde do estado do Paraná segundo TMI (\%o NV) no $1^{\circ}$ Triênio (1997/99) e $3^{\circ}$ Triênio (2003/05) e percentual de redução da TMI no período e ano a ano, Paraná, 1997 - 2005.

\begin{tabular}{|c|c|c|c|c|c|}
\hline \multirow{2}{*}{\multicolumn{2}{|c|}{ Regionais de Saúde }} & \multirow{2}{*}{\multicolumn{2}{|c|}{ TMI }} & \multirow{3}{*}{$\begin{array}{c}\begin{array}{l}\text { Decréscimo } \\
(\%)\end{array} \\
-41,60 \\
\end{array}$} & \multirow{3}{*}{$\begin{array}{r}\begin{array}{l}\text { Decréscimo } \\
\text { ano a ano* }\end{array} \\
4,62 \\
\end{array}$} \\
\hline & & & & & \\
\hline $4^{a}$ & Irati & $\begin{array}{r}1^{\circ} \text { Triênio } \\
29,88\end{array}$ & $\begin{array}{r}3^{\circ} \text { Triênio } \\
1745\end{array}$ & & \\
\hline $20^{2}$ & Toledo & 20,17 & 12,89 & $-36,09$ & 4,01 \\
\hline $14^{2}$ & Paranavaí & 19,15 & 12,91 & $-32,58$ & 3,62 \\
\hline $15^{a}$ & Maringá & 16,98 & 11,49 & $-32,33$ & 3,59 \\
\hline $6^{2}$ & União da Vitória & 20,90 & 14,55 & $-30,33$ & 3,37 \\
\hline $1^{2}$ & Paranaguá & 24,77 & 17,86 & $-27,90$ & 3,10 \\
\hline $19^{2}$ & Jacarezinho & 26,33 & 19,31 & $-26,67$ & 2,96 \\
\hline $2^{2}$ & Metropolitana & 19,14 & 14,07 & $-26,49$ & 2,94 \\
\hline $3^{a}$ & Ponta Grossa & 23,44 & 17,52 & $-25,26$ & 2,81 \\
\hline $17^{\mathrm{a}}$ & Londrina & 14,82 & 11,47 & $-22,60$ & 2,51 \\
\hline $10^{2}$ & Cascavel & 19,15 & 14,87 & $-22,35$ & 2,48 \\
\hline $9^{a}$ & Foz do Iguaçu & 18,92 & 14,70 & $-22,30$ & 2,48 \\
\hline $5^{2}$ & Guarapuava & 27,94 & 22,18 & $-20,62$ & 2,29 \\
\hline $11^{2}$ & Campo Mourão & 19,30 & 15,46 & $-19,90$ & 2,21 \\
\hline $18^{2}$ & Cornélio Procópio & 21,86 & 18,03 & $-17,52$ & 1,95 \\
\hline $12^{2}$ & Umuarama & 21,98 & 18,15 & $-17,42$ & 1,93 \\
\hline $13^{a}$ & Cianorte & 14,34 & 13,12 & $-8,51$ & 0,94 \\
\hline $16^{2}$ & Apucarana & 17,70 & 17,60 & $-0,56$ & 0,06 \\
\hline
\end{tabular}

Fonte: SIM e SINASC / MS / DATASUS, dados brutos (MS, 2005, 2006, 2007)

Nota:

* Esse decréscimo foi calculado apenas para uma possivel leitura de resultados, no entanto, não foram checadas TMI ano a ano. 
Esse perfil decrescente aconteceu de maneira diversa para cada RegS do estado (Anexo 8) como se pode visualizar no Gráfico 3 e Quadro 5. A grande parte das Regionais de Saúde, 19 delas, apresentou TMI considerada baixa (menos do que 20\% NV), no último Triênio. No entanto, observou-se que quatro Regionais não apresentaram índices decrescentes mas, sim crescentes, entre os primeiro e último Triênios pesquisados: a de Pato Branco $\left(7^{\mathrm{a}}\right)$ teve acréscimo de $4,93 \%$, Francisco Beltrão $\left(8^{a}\right)$, com $19,23 \%$ de acréscimo de óbitos infantis, ambas constituem a Macrorregional Sudoeste, além de Telêmaco Borba $\left(21^{a}\right)$ com $8,33 \%$ de acréscimo no contingente de óbitos infantis e Ivaiporã com elevação na ordem de 2,96\%. Esta situação exige maior atenção dos gestores estaduais e municipais.

As demais Regionais apresentaram resultados positivos quanto à redução dos óbitos infantis, a RegS de Irati $\left(4^{a}\right)$ apresentou maior decréscimo, na ordem de $41,60 \%$ e a de Apucarana (16 $)$ de $0,56 \%$, menor percentual de redução (Quadro 6).

Nessa discussão deve-se atentar para o fato de que reduzir a TMI fica cada vez mais difícil, pois os óbitos pós-neonatais reduzem com maior rapidez diante de ações de atenção primária em saúde e ficam, como mais dificeis de redução, os óbitos neonatais, principalmente os precoces, que são diretamente dependentes de estruturas mais complexas (recursos humanos, unidades de saúde e tecnologia) de atendimento secundário e terciário em saúde. Em países desenvolvidos, o resíduo de óbitos que mantém suas taxas em um dígito apenas, geralmente refere-se a malformações congênitas não compatíveis com a vida (BRASIL, 2004b; LEAL e SWARCWALD, 1996, 1997; SZWARCWALD et al., 1997; MARANHÃO et al., 1999; CALDEIRA et al., 2001, 2002; NIOBEY et al., 1992; POST et al., 1992; SANTA HELENA e ROSA, 2003).

Vários fatores assistenciais e sociais podem ter concorrido para que a TMI não decrescesse ao nível esperado, ou nada em algumas RegS; esse perfil per si aponta para a necessidade de melhor investigação nas Regionais destacadas, com evidenciação dos determinantes causais e estabelecimento de medidas que possam minorar as situações desfavoráveis. 
Gráfico 3: Taxa de Mortalidade Infantil (\%。 NV) segundo Regional de Saúde e Triênios, estado do Paraná, 1997 a 2005.

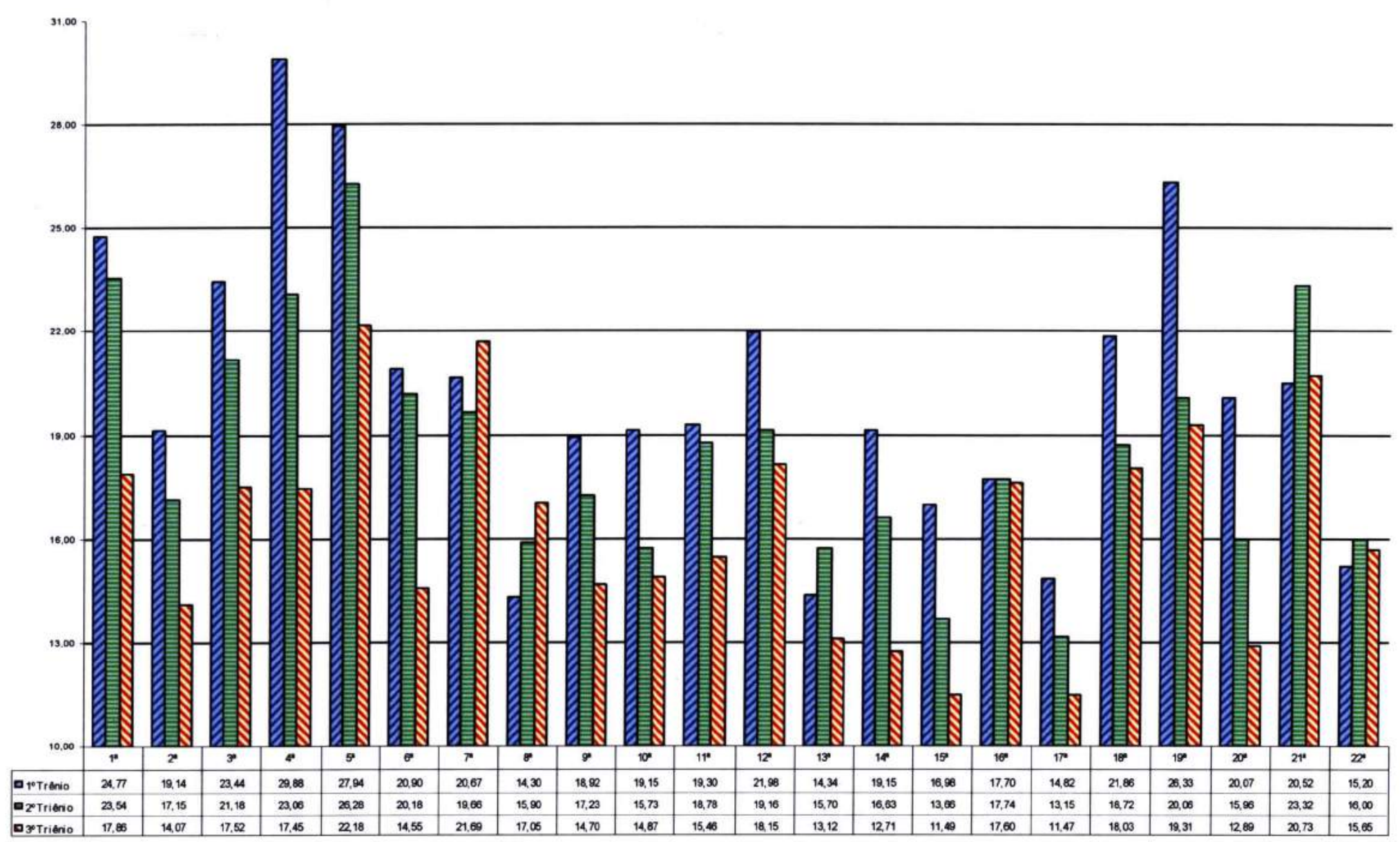

Fonte: SIM e SINASC / MS / DATASUS, dados brutos (MS, 2005, 2006, 2007). 
Quanto ao SEXO observou-se que a ocorrência da morte infantil em meninos foi proporcionalmente maior do que em meninas menores de um ano, em todos os Triênios. Os óbitos de crianças do sexo masculino estiveram em todo o período acima de $55 \%$ do total de óbitos infantis. A razão entre os sexos esteve por volta de 1,35 óbitos masculinos para um feminino (Tabela 4).

Tabela 4: Distribuição (freqüência e \%) dos óbitos infantis nos Triênios segundo sexo e faixa etária, estado do Paraná, 1997 a 2005.

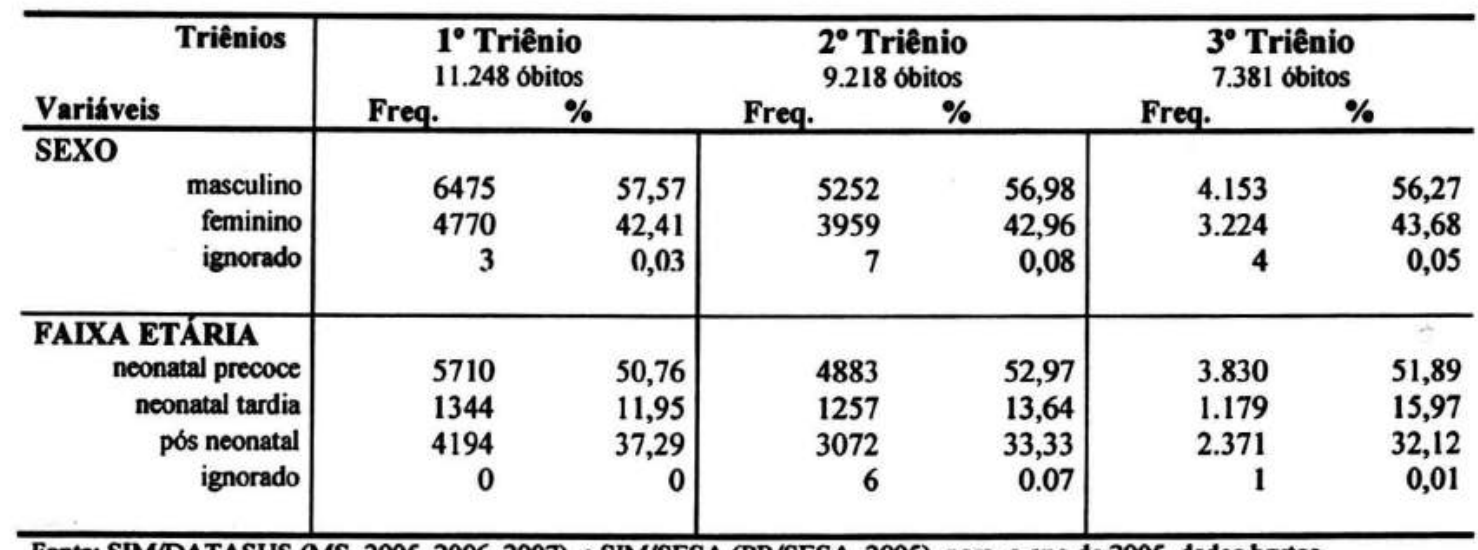

Fonte: SIM/DATASUS (MS, 2005, 2006, 2007) e SIM/SESA (PR/SESA, 2005), para 0 ano de 2005, dados brutos.

CALDEIRA et al. (2001) também encontraram nos óbitos infantis estudados, um maior percentual de crianças do sexo masculino $(66,8 \%)$.

Já SOUZA e GOTLIEB (1993, p.451) em estudo da probabilidade de mortes em área urbana da região Sul, ressaltam que paradoxalmente a várias pesquisas, nas quais há sempre sobremortalidade infantil masculina, dentre "as crianças nascidas em 1989, as do sexo feminino apresentaram risco de morrer 1,4 vezes o correspondente ao sexo masculino", o resultado é exposto como casual. Neste sentido SOUZA e GOTLIEB (1993), baseadas em outros estudos, explicam que a prevalência de óbitos masculinos ocorre devido ao processo de maturação dos pulmões das crianças do sexo masculino ser mais lento durante o desenvolvimento fetal. No entanto, esse diferencial aparece distintamente de acordo com os subgrupos etários. Por outro lado, emergem as questões culturais de discriminação ao sexo feminino permeando a maior ocorrência de morte, devido aos prejuízos devidos a cuidados e atenção a menores e um ano do sexo feminino, segundo as autoras. 
Pode-se observar como indicador de qualidade no preenchimento das DOs, a freqüência dos óbitos infantis com idade ignorada, no Brasil, entre o período de 1997 a 2000 essa variável sofreu um decréscimo. Isto significa que as informações assinaladas nas DOs melhoram. A partir de 2001, os óbitos infantis com idade ignorada sofrem um abrupto incremento nas regióes Sudeste e Nordeste (Apêndice 2 e 3).

Entretanto, a variável idade categorizada como ignorada para o período de 1997 a 2004, em todas as regiões do Brasil não ultrapassou 1\% dos óbitos infantis, com predomínio absoluto para a região Nordeste, em todo n períndo. Enquanto na Regiåo Sul, bem como, no Estado do Paraná esse problema apresenta-se quase que totalmente inexistente, indicando boa qualidade no preenchimento da Dos. A rigor não deveria existir nenhum óbito com registro de idade ignorada. Há que se realizar registros de todas as variáveis da DO e a idade é uma variável essencial, principalmente se tratando de óbito infantil (Apêndice 2 e 3).

Quanto aos SUBGRUPOS ETÁRIOS, aponta-se para os óbitos infantis que ocorreram no período, em maioria (mais de $50 \%$ ), no período neonatal precoce, é o componente que abrange crianças de 0 a 6 dias completos de vida. Esse componente passou a ser o principal da MI em termos proporcionais a partir dos anos 90 , vem se mantendo estabilizado em níveis elevados, não só no Paraná, mas em todo o Brasil (BRASIL, 2004b; LANSKY et al., 2002a; MARANHÃO et al., 1999; LEAL e SZWARCWALD, 1996, 1997; SZWARWALD et al., 1997; LILJESTRAND, 1999; SHRAMM e SZWARCWALD, 2000; SOUZA E GOTLIEB, 1993; SOUZA, 1992).

SOUZA (1992) em estudo realizado em Maringá, em 1989, constatou que $77,30 \%$ dos óbitos infantis ocorreram no período neonatal. Esse componente apresentou redução pouco significativa no período de $1980 / 88$, ressaltando a aecessidade de avaliar a eficácia e a eficiência da assistência obstétrica e ao parto. Em especial, dentro do período pré-natal o componente neonatal precoce mantém elação estreita com a assistência materna demandada em ambulatórios de pré-natal e naternidades. A mortalidade neonatal adquire uma "expressão sem precedentes, pois ts ações necessárias para o seu controle são ainda pouco sistematizadas e incipientes 
no âmbito nacional, demandando por uma mobilização e priorização na agenda para todos os gestores da saúde" (BRASIL, 2004b, p.7).

Em estudo de mortalidade neonatal em Maringá, SERAFIM (2002) observou que, em 1997, a TMI neonatal foi de 12,33\% NV, em 1998 de 8,46\% NV, em 1999, foi de 9,22\% NV e, no último ano de estudo, em 2000, apresentou TMI neonatal de $10,22 \%$ NV. A autora observou que os valores distribuíram-se de maneira irregular. Se, eventualmente fosse avaliado apenas $01^{\circ}$ e o último ano de estudo, até poderíamos fazer conjecturas que houve um decréscimo, em quatro anos, na ordem de $17 \%$ nesse componente da MI, em Maringá, um dos municípios-pólo, referência regional para atendimento terciário a gestantes e crianças, do estado do Paraná. No entanto, observa-se no decorrer do período redução ainda maior, no ano de 1998, para $8,46 \%$ NV, assim recomendou-se avaliar com cautela os números advindos do traçado de indicadores, associando-os sempre à avaliação da situação de acesso e assistência.à saúde materno-infantil locais (SERAFIM, 2002).

SERAFIM (2002) também investigou que, no período de estudo da mortalidade neonatal em Maringá, de 1997 a 2000, 80,83\% dos óbitos ocorreram até o sexto dia de vida da criança.

Os óbitos pós-neonatais decrescem primeiramente quando há redução da MI. No Brasil, para os períodos de $1985-87$ e $1995-97$ passaram de $53,60 \%$ para $40,80 \%$, queda de 20,40\% (VICTORA, 2001). Na região Sul como as TMI podem ser consideradas baixas, os óbitos pós-neonatais tendem a cair mais lentamente, pois, como explica VICTORA (2001) permanece um resíduo de mortes pós-neonatais, de difícil redução, enquanto os neonatais continuam em decréscimo. Esse resíduo geralmente é determinado, segundo VICTORA (2001) por mortes súbitas, neoplasias e causas externas.

No Paraná a proporção de óbitos pós-neonatais permaneceu em torno de $35 \%$ de todos os óbitos infantis, nos Triênios pesquisados. Essa situação de não decréscimo na incidência da mortalidade pós-neonatal aponta para a necessidade de se (re)pensar e avaliar a efetividade e, em especial, a manutenção das intervenções direcionadas à saúde materno-infantil no estado, tendo em vista que esse componente é o de mais rápido decréscimo pela relação estreita que tem com: 
[...] a implementação de ações de promoção, proteção e apoio ao Aleitamento Materno, o aumento da cobertura do saneamento básico, a ampliação do acesso aos serviços de saúde, o avanço das tecnologias médicas, em especial a imunização e a terapia de reidratação oral, a melhoria do grau de instrução das mulheres, a diminuição da taxa de fecundidade, entre outros (BRASIL, 2004b).

A Taxa de Mortalidade Pós-neonatal (TMPN, no Brasil, decresceu 30\% de 1997 a $2004^{1}$, passou de 7,14 \% NV para 4,99 \% NV maior decréscimo do que o observado para a região Sul (20,00\%). Já para o Nordeste registram-se taxas pósneonatais de $12,14 \%$ NV para 7,51\% NV, no mesmo período, com redução proporcional de $38 \%$. Percebe-se que a região com maior TMI, no período, apresenta a TMIPN com maior decréscimo, no mesmo período, observação consistente com a discussão de VICTORA (2001).

Tabela 5: Distribuição (freqüência e \%) dos óbitos infantis nos Triênios segundo duração da gestação e peso ao nascer, estado do Paraná, 1997 a 2005.

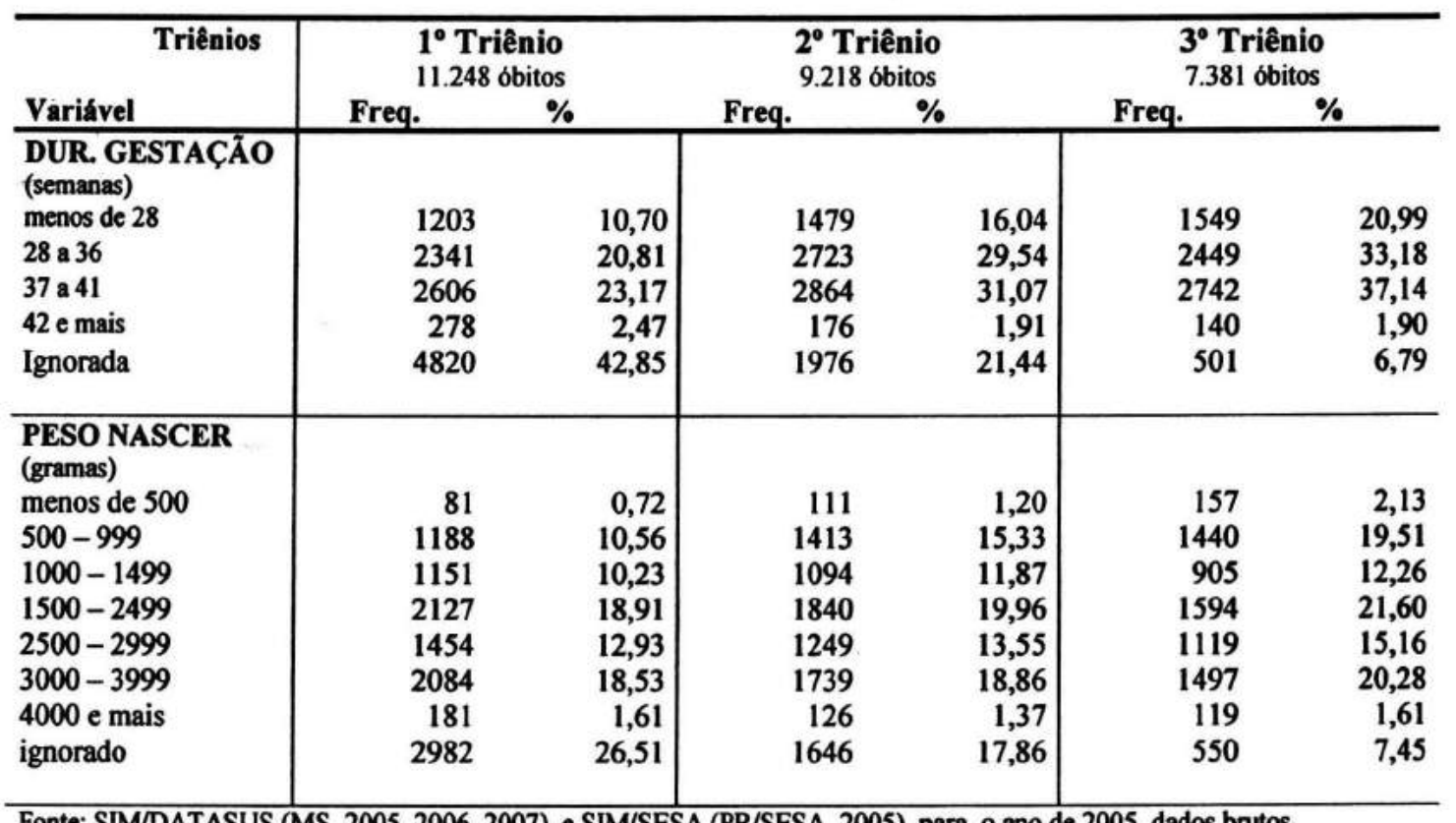

Fonte: SIM/DATASUS (MS, 2005, 2006, 2007) e SIM/SESA (PR/SESA, 2005), para o ano de 2005, dados brutos.

Pesquisas internacionais e nacionais apontam que a chance de sobrevivência da criança é diretamente proporcional à idade gestacional. Assim, é importante a qualidade de registro da variável DURAÇÃO DA GESTAÇÃO na DO. Os dados de óbito infantil demonstram para o Paraná qualidade crescente, a expectativa é de contínua

\footnotetext{
${ }^{1}$ Vide planilha de dados no Capitulo 1.2. A Mortalidade Infantil: contextualização.
} 
melhoria em virtude da investigação dos óbitos, pois a proporção de duração da gestação ignorada foi do $1^{\circ}$ ao último triênio de 42,85\%,21,44\% e 6,79 (Tabela 5). A investigação estimula a melhoria da qualidade dos dados informados nos sistemas, quer seja estadual (SIMI) quer federal (SIM), pois além de visibilidade ao problema, recomenda ações que possam melhorar a informação veiculada pelos sistemas.

Frente à grande proporção de duração da gestação ignorada, mesmo que em descenso, não é possível afirmar nada sobre o comportamento da variável, que nos fala sobre a situação da prematuridade nas crianças que foram a óbito, no período em estudo. Nesta pesquisa observou-se que mais de $50 \%$ das crianças que foram a óbito, no último período do estudo (2003/05), apresentaram nascimento prematuro (abaixo de 36 semanas) (Tabela 5). Esta situação dificulta o monitoramento (ALMEIDA et al., 2006), com a investigação dos óbitos infantis realizado pelos Comitês de Prevenção do estado do Paraná

ALMEIDA et al. (2006) em pesquisa sobre as condições de uso dos sistemas de informações para monitoramento da mortalidade perinatal, em oito Unidades Federativas (Espírito Santo, Rio de Janeiro, São Paulo, Paraná, Santa Catarina, Rio Grande do Sul, Mato Grosso do Sul e Distrito Federal), em 2002, encontraram ausência elevada de informação sobre idade gestacional $(17,79 \%)$ e peso ao nascer $(22,64 \%)$ nas DOs de óbitos neonatais precoces. O estado do Paraná e o do Mato Grosso do Sul se destacaram quanto à qualidade do preenchimento das DOs, em todas as variáveis estudadas a ausência de registro ficou abaixo de $10 \%$, segundo ALMEIDA et al. (2006). Assim, o Paraná apresentou 4,15\% e 3,40\% de ausência de registro não da duração da gestação e peso ao nascer, respectivamente, na pesquisa de ALMEIDA et. al. (2006).

Hack e Faranoff (2000) apud LANSKY et al., (2000a) discutiram a sobrevivência de crianças de 23, 24 e 25 semanas de gestação, e dizem que existe a sobrevivência de $2 \%$ a $35 \%$ e $35 \%$ a $72 \%$ respectivamente. As variações ocorreram de acordo com a as diferenças assistências e de acordo com os critérios para a interrupção da gravidez.

Já Lorenz (2000) apud LANSKY et al., (2002a) afirmam que a maioria das crianças acima de 25 semanas, sobrevivem atualmente, mas consideram que o conceito de limite da viabilidade é vago na clínica e na ética. 
WEN et al. (2004) consideram os nascimentos pré-termos como a maior preocupação da saúde pública em países industrializados, citando-os com responsáveis por $70 \%$ da mortalidade e $75 \%$ da morbidade neonatais.

A situação de idade gestacional ao nascer inadequada mostrada na frequeência dos óbitos infantis ocorridos no estado do Paraná é alarmante para o contexto preventivo da MI. Há que se rever com urgência a qualidade da assistência obstétrica no estado, pois segundo a literatura consultada, a sobrevida está diretamente ligada às condições de nascimento $\mathrm{e}$, a prematuridade é um componente de importância crescente. $\mathrm{O}$ nascimento pré-termo também implica em melhor hierarquização e referência dos serviços de saúde, pela necessidade criada para leitos em unidades secundárias e terciárias de assistência ao recém-nato e à mãe, discussão abordada mais adiante.

Quanto ao PESO AO NASCER das crianças que foram a óbito, nesta pesquisa notou-se que existiu proporção decrescente da variável não informada (peso ignorado) $26,51 \%, 17,86 \%$ e $7,45 \%$ respectivamente para os Triênios (Tabela 5). Embora tenha ocorrido melhoria dos registros do peso nas DOs, provavelmente propiciada pelo trabalho dos Comitês, ainda assim, frente à essas proporções não se pode discutir a ocorrência de baixo peso ao nascer para os óbitos estudados.

Observou-se que no último Triênio em estudo, do total de crianças que foram a óbito, quase $35 \%$ apresentaram peso ao nascer entre 1000 e 2500 gramas e cerca de $20 \%$ nasceram com peso inferior a $1000 \mathrm{~g}$, ou seja, com extremo baixo peso ao nascer; mais de $55 \%$ das crianças que morreram no período de 2003/05 apresentaram baixo peso ao nascer. Este fato também corrobora com a forte sinalização de necessidade de melhoria do pré-natal, seu acesso e qualidade, além de prescindir de leitos secundários e terciários, bem como de capacitação técnico-operacional dos profissionais que atendem a essas situações de extremo (abaixo de $1000 \mathrm{~g}$ ) e muito baixo peso ao nascer (abaixo de $1500 \mathrm{~g})^{2}$ (OMS, 1994).

\footnotetext{
${ }^{2}$ Nascimentos de baixo peso ao nascer săo os nascimentos com peso inferior a $2500 \mathrm{~g}$, segundo a Classificaçăo Intemacional de Doenças (CID-10 Revisđa). Os rectm nascidos com peso inferior a 1500 g salo considerados como muito baixo peso ao nascer $\mathrm{e}$ os com peso inferior a $1000 \mathrm{~g}$ como extremo baixo peso ao nascer (OMS, 1994).
} 
LANSKY et al. (2002a, p.764) relatam a discussão lançada pelo Canadá, há mais de duas décadas, sobre o "mínimo irredutível" para mortalidade neonatal, na época tido como 2,6 óbitos \%o NV com peso acima de $1000 \mathrm{~g}$; variações ocorreram para outros países, de 2,2 à $2,7 \%$ na dependência de anomalias congênitas letais.

LANSKY et al. (2002a) em trabalho de revisão de literatura sobre mortalidade perinatal e evitabilidade apontam consenso entre os pesquisadores sobre a sobrevivência de crianças acima de $1.000 \mathrm{~g}$ (exceto em algumas situações de crianças portadoras de malformação congênita).

ALMEIDA et al. (2006, p. 57) enfatizam que a CID-10 "propõe o uso de taxas que consideram os óbitos fetais de $1000 \mathrm{~g}$ ou mais, correspondendo aos óbitos fetais de 28 semanas e mais, para possibilitar a comparação internacional".

SERAFIM (2002) em seu estudo de mortalidade neonatal, no período de 1997 a 2000, em município do estado do Paraná, de referência à assistência ao risco materno e infantil, encontrou a incidência de $72,5 \%$ de óbitos em crianças que nasceram com peso inferior a $2.500 \mathrm{~g}$.

A melhoria da nutrição materna e a redução do tabagismo durante a gravidez são discutidas por VICTORA (2001) como duas medidas específicas para reduzir o baixo peso ao nascer no Brasil. No entanto, o autor enfatiza que a redução do baixo peso ao nascer é uma difícil tarefa até mesmo em países desenvolvidos.

A prevalência do baixo peso ao nascer, relatam ALMEIDA et al. (2002, p. 95), "tem sido associado a condições socioeconômicas desfavoráveis, atenção prénatal inadequada, mães adolescentes ou mães idosas, paridade elevada, intervalo interpartal reduzido, presença de desnutrição materna e hábito de fumar".

Segundo dados da RIPSA a proporção de nascimentos com baixo peso ao nascer no Brasil é de $7,68 \%$ e varia de $6,33 \%$ na região norte a $8,45 \%$ na região sudeste (BRASIL, 2007). No entanto, é necessário cuidado ao se utilizar este dados, principalmente nas regiões norte e nordeste, pois estes podem estar subestimados em decorrência de falhas na cobertura do SINASC.

A probabilidade de morte entre crianças nascidas em hospitais de Maringá, em 1989, mostrou relação inversa ao peso ao nascer. Ou seja, à medida que o peso aumentou a probabilidade de morrer diminuiu. Assim, as nascidas com peso inferior a $1500 \mathrm{gr}$ apresentaram a possibilidade de morte no primeiro ano de vida de 757,6 por 
mil e, entre as nascidas com peso mínimo de $3000 \mathrm{~g}$, a probabilidade foi de 8,3 por mil, segundo SOUZA e GOTLIEB (1983).

Em estudo sobre a importância da investigação de óbitos infantis de crianças de extremo baixo peso (abaixo de $1.000 \mathrm{~g}$ ), realizado com dados da $15^{\mathrm{a}}$ Regional de Saúde do Paraná, em 1999, ORLANDI e CARVALHO (2001) concluíram que a despeito das limitações existentes em relação a assistência à mulher e à criança, e da impossibilidade, momentânea de se investigar $100 \%$ dos óbitos infantis, a investigação dos óbitos de criança abaixo de $1.000 \mathrm{~g}$ tem valor reforçado para melhor diagnóstico regional e estabelecimento de condutas de intervenção. As autoras alertam, ainda, sobre o custo tecnológico para assistência dessa clientela que justifica também uma melhor avaliação dos fatores que têm determinado essa situação.

ALMEIDA (2006) discute sobre a dificuldade da pesquisas em utilizar as variáveis peso ao nascer e idade gestacional como critério de evitabilidade para óbitos infantis. Isso se dá, segundo a autora, em virtude da inexistência dos dados e, também por sua informação ser veiculada pelos sistemas em agrupamentos por categoria. Enfatiza também que "só será possivel considerar como inevitáveis os óbitos com menos de $750 \mathrm{~g}$, quando o peso ao nascer estiver registrado na declaração de óbito". Discorre sobre a possibilidade de se vincular a eleição da evitabilidade ao acesso que tiveram à UTI, no entanto alerta para o fato da essa não ser a realidade para grande parte da população (ALMEIDA, 2006, p. 6).

Ressalta-se que na publicação do Ministério da Saúde sobre os Comitês de Prevenção da MI e Fetal é enfatizada a necessidade de incorporação na rotina dos serviços de saúde o trabalho de análise da ocorrência dos óbitos perinatais (BRASIL, 2004), posto que há pouca informação a esse respeito no país em virtude da sua complexidade em termos do sub-registro, e da qualidade das informações, nas DOs e escassez de registros em prontuários (ALMEIDA et al. 2006; PEDROSA et al., 2005; LANSKY et al., 2002b).

Aponta-se uma questão importante: o processo de regionalização dos serviços, principalmente para gestantes de risco e neonatos prematuros. No Brasil, esse movimento tem acontecido, mas não de acordo com as desigualdades sociais e médico-sanitárias, como aponta publicação da Organização Pan-americana da Saúde (OPAS, 1999). 
De acordo com Papiernik e Keith (1995) e Audibert et al. (1999) apud LANSKY et al. (2002a), a maior mortalidade peri-neonatal na França quando comparada a outros países europeus, foi devida ao processo de regionalização insuficiente. Os pesquisadores apontam, também, para maiores chances de sobrevida e menor morbi-mortalidade infantil mediante transferência materna a centros especializados ao invés da transferência do neonato após o nascimento. Logo a transferência de uma criança considerada de risco deve ser realizada ainda intraútero, como um dos recursos para propiciar a sua sobrevida.

Assim, como enfatizam ALMEIDA e MELLO JORGE (1998) e WEN et al. (2004), o aumento da sobrevida de recém-nascidos de baixa idade gestacional depende da expansão dos cuidados neonatais intensivos, com avanços na tecnologia médica e ampla implementação de regionalização da assistência perinatal.

Concordando com LANSKY et al. (2002a), a distribuição de leitos de Unidade de Terapia Intensiva Neonatal (UTIN), exemplo de desenvolvimento tecnológico da assistência neonatal, é uma questão que merece muita atenção por parte das diversas instâncias de gestão, não é uma questão de benefício e de simplesmente possibilitar a sobrevivência da criança. Essa questão é bastante complexa, não devendo ser vista apenas como uma questão de 'números necessários' nesta ou naquela região / regional; envolve toda a dinâmica familiar em situação de desorganização e sofrimentos advindos de valores, autonomia de vida, recurso financeiro e culpabilidade.

São apontados por LANSKY et al. (2002a) pesquisas brasileiras comparadas às internacionais que demonstram taxa de mortalidade perinatal brasileira de 2 a 3 vezes maior em relação ao País de Gales, diferença que se acentua conforme o peso ano nascer diminui. Em relação à mortalidade neonatal precoce com menos de $2000 \mathrm{~g}$ os estudos brasileiros indicam diferença de 10 a 20 vezes maior, indicando maior dificuldade de acesso a leitos de UTI ou pior qualidade de assistência maternoinfantil, principalmente do pré-natal, no Brasil.

A dificuldade de acesso é uma questão complexa; não deve ser interpretada somente observando a existência ou não de leitos, mas também, a existência de uma rede de transportes especiais na região, município e país, munido de equipe médica e paramédica capacitada, bem como as condições de percurso geográfico com presença 
de barreiras geográficas que oferecem risco ao tráfico de usuários e veículos de transportes. Essas pontuações emergem como problemas para a prevenção da mortalidade infantil nos discursos coletivos nesta pesquisa.

A ocorrência de óbitos infantis está fortemente ligada a determinantes distais $^{3}$, considerados por VICTORA (2001). Esses são responsáveis pelos altos níveis de mortalidade e pelas disparidades regionais e, contemplam os fatores sociais, econômicos e culturais que, em curto prazo, não são passíveis de modificação.

Aponta-se, como associado aos determinantes distais nesta pesquisa a IDADE DAS MÃES das crianças que foram a óbito pela importância do risco que representa, tanto para as mulheres como para as crianças, a gestação incidindo nas faixas extremas da idade, ou seja, em idade cada vez menor ou maior (ALMEIDA et al., 2002).

Para a variável idade da mãe, também se encontrou uma proporção alta de categorias não informadas, fato que dificulta qualquer afirmação mais categórica quanto ao comportamento. O monitoramento dos óbitos indantis pode ter contribuído para a melhor qualidade ao longo do período do estudo, que se apresentou, respectivamente nos Triênios com: $21,36 \%, 15,50 \%$ e 5,99\% (Tabela 6).

Verificou-se para o último Triênio que mais da metade (56,79\%) das mães de crianças falecidas no período não apresentavam a idade como possível fator de risco para seus filhos, ou seja, a faixa etária entre 20 a 34 anos. A população de mães adolescentes (até 19 anos) constituiu percentual também de alerta, 25,81\%, no último Triênio.

Mães adolescentes e não realização do pré-natal constituíram fatores de risco para a mortalidade neonatal em estudo realizado por ALMEIDA et al. (2002). A MI, segundo dados de São Paulo, é cerca de $68 \%$ mais elevada em filhos de mulheres entre 15 e 19 anos do que filhos de mulheres de 20 a 24 anos (CAMARANO, 1998).

SOUZA e GOTLIEB (1998) relatam que a probabilidade da criança falecer no primeiro ano de vida foi de 71,4 óbitos \%o NV, quando suas mães tinham menos

\footnotetext{
${ }^{3}$ VICTORA (2001) utiliza-se da metodologia de Mosley e Chen (1984) e caracteriza os determinantes dos óbitos infantis dentro de 3 grupos: as causas imediatas ou proximais (são as que determinam o óbito clinicamente, ou seja, as causas básicas); os determinantes distais (são os de maior impacto na redução da TMI, no entanto não alcançáveis a curto prazo, relacionam-se com fatores sociais, económicos e culturais) e os determinantes intermediários (que determinam o grau de exposição ao fator de risco e a falta de acesso a fatores de proteção, como as vacinas, atenção pré-natal etc).
} 
de 15 anos e a probabilidade em faixa etária materna subseqüente, de 15 a 19 anos, foi menor, de $25,4 \%$ NV.

No Brasil, segundo SANTOS JR (1999) estima-se que 20-25\% do total das mulheres gestantes são adolescentes, apontando que 1 em cada 5 gestantes são adolescentes; além do que a faixa etária está em redução, encontra-se gestantes cada vez mais jovens, ou melhor dizendo 'crianças gestantes'. SANTOS JR (1999) pondera sob vários aspectos ao abordar os fatores etiológicos relacionados à gravidez na adolescência: a menarca; a iniciação sexual; a família; a escola; o pensamento mágico; o acesso a métodos contraceptivos, e o manuseio dos mesmos; a deficiência dos serviços de saúde; o projeto de vida.

Considera-se, também, quando se aborda a gravidez precoce, a interrupção da escolaridade dessas adolescentes (para cuidado do filho e/ou participação na renda familiar), a vulnerabilidade de seus filhos a causas exógenas que afetam sua saúde, falta de cuidados adequados e conseqüente aumento de episódios mórbidos infectocontagiosos, gastrintestinais, acidentes etc, aumentando o perigo de morte dessas crianças. Além disso, para a mulher, há a possibilidade de elevação da mortalidade materna, incidência maior de hipertensão arterial, maior risco de eclampsia, infecções urinárias e anemia (CAMARANO, 1998; ORLANDI, 2000)

CAMARANO (1998) relata que a região Norte, em 1996, apresentava a maior percentagem de gravidez na adolescência (15 a 19 anos): $24 \%$ das mulheres desta faixa etária já tinham passado pelo menos por uma gestação; enquanto na região Sul essa percentagem estava em torno de 16\%. ALMEIDA et al (2002) enfatizam que o aumento da gravidez na adolescência tem apresentado maior impacto em grupos sociais menos favorecidos.

Reforça-se que os serviços de saúde devem estar alertas para a realidade locorregional, trabalhando com as informações disponíveis, eventualmente mais problemas mórbidos e de morte exigirão referência secundária e terciária organizadas e claramente definidas para atenderem à demanda de gestantes, sem gerar peregrinação por serviço. É necessário dizer também que os profissionais da saúde inseridos na rede básica, hospitalar e escolar devem promover a sensibilização da clientela feminina para os riscos dessa mãe e filhos. 
Seria oportuno conclamar a parceria das escolas de ensino fundamental e médio para esta conscientização, mesmo considerando a consideração de VICTORA (2001, p.27) de que a "rapidez do declínio da fecundidade no Brasil e a tendência crescente ao uso de anticoncepcionais sugerem que fatores de risco reprodutivos terão um papel de menor importância na etiologia da mortalidade infantil no futuro".

Tabela 6: Caracterização das mães das crianças menores de um ano que foram a óbito nos Triênios segundo idade e escolaridade, estado do Paraná, 1997 a 2005.

\begin{tabular}{|c|c|c|c|c|c|c|}
\hline \multirow{2}{*}{$\begin{array}{r}\text { Triênios } \\
\text { Variáveis (anos) } \\
\end{array}$} & \multicolumn{2}{|c|}{$\begin{array}{l}1^{\circ} \text { Triênio } \\
11.248 \text { óbitos }\end{array}$} & \multicolumn{2}{|c|}{$\begin{array}{l}2^{\circ} \text { Triênio } \\
9.218 \text { obitos }\end{array}$} & \multicolumn{2}{|c|}{$\begin{array}{l}3^{\circ} \text { Triênio } \\
7.381 \text { obitos }\end{array}$} \\
\hline & Freq. & $\%$ & Freq. & $\%$ & Freq. & $\%$ \\
\hline IDADE & & & & & & \\
\hline 10 a 14 & 138 & 1,23 & 149 & 1,62 & 95 & 1,29 \\
\hline 15 a 19 & 2394 & 21,28 & 2105 & 22,83 & 1.810 & 24,52 \\
\hline 20 a 24 & 2499 & 22,22 & 2229 & 24,18 & 1.840 & 24,93 \\
\hline 25 a 29 & 1753 & 15,58 & 1532 & 16,62 & 1.394 & 18,88 \\
\hline 30 a 34 & 1157 & 10,29 & 953 & 10,34 & 957 & 12,97 \\
\hline 35 a 39 & 664 & 5,90 & 611 & 6,63 & 610 & 8,26 \\
\hline 40 a 44 & 209 & 1,86 & 186 & 2,02 & 214 & 2,90 \\
\hline 45 a 49 & 31 & 0,28 & 23 & 0,25 & 19 & 0,26 \\
\hline 50 a 54 & 0 & - & 1 & 0,01 & 0 & - \\
\hline ignorada & 2403 & 21,36 & 1429 & 15,50 & 442 & 5,99 \\
\hline ESCOLARIDADE & & & & & & \\
\hline Nenhuma & 1058 & 9,50 & 565 & 6,13 & 361 & 4,89 \\
\hline 1 a 3 & 151 & 1,34 & 1507 & 16,35 & 1.027 & 13,91 \\
\hline 4 a 7 & 1731 & 15,39 & 2697 & 29,26 & 2.379 & 32,23 \\
\hline 8 a 11 & 1187 & 10,55 & 1669 & 18,11 & 2.231 & 30,23 \\
\hline 12 e mais & 304 & 2,70 & 595 & 6,45 & 780 & 10,57 \\
\hline Ignorado & 6817 & 60,61 & 2185 & 23,70 & 603 & 8,17 \\
\hline
\end{tabular}

Em virtude da alta proporção de ESCOLARIDADE DA MÃE ignorada somente foi possível afirmar que o ensino fundamental quer completo ou não, considerando-o zomo escolaridade de 1 a 7 anos, predominou nas mães das crianças que foram a óbito antes de completarem seu primeiro ano de vida, no último Triênio do estudo, com proporção de quase $50 \%(46,14 \%)$ (Tabela 6). Acredita-se que isso seja devido aos incentivos à adesão ao estudo, por parte do governo federal e estadual, com implantação de programas educativos que favorecem o acesso à educação escolar.

ALMEIDA e MELLO JORGE (1998) em estudo dos fatores de risco para nascimentos pequenos para a idade gestacional (PIG), no estado de São Paulo, realizado com dados de 1992, encontraram mães com grau de instrução inferior ao $1^{\circ}$ 
Grau completo que apresentaram uma chance $70 \%$ superior de gerar filhos com retardo de crescimento intra-uterino (RCIU) do que as de mães que tinham o $1^{\circ} \mathrm{Grau}$ completo ou mais de instrução. Demonstram, portanto, que o nível de instrução pode ser considerado como fator de risco para o RCIU, que por sua vez pode determinar a prematuridade, em questão neste trabalho (ALMEIDA e MELLO JORGE, 1998).

$\mathrm{O}$ risco de morte infantil, também, mostrou-se elevado para nascidos vivos com RCIU que sejam prematuros e que sejam filhos de mães com de 35 anos e mais de idade (explicado pela "tendência, já observada em outros países, do retardo do processo produtivo em mulheres com maior escolaridade") (ALMEIDA E MELLO JORGE, 1998, p.221).

Em trabalho utilizando-se de casos e controles para identificação de fatores de risco para a mortalidade neonatal no município de Maringá, Paraná, SERAFIM (2002), em análise estatística univariada dos resultados, encontrou crianças do sexo masculino, nascidas de parto normal, com baixo peso (menor de $2.500 \mathrm{~g}$ ), com idade gestacional inferior a 37 semanas e mães com idade inferior a 20 anos, que estiveram mais expostas ao risco de morrer. Observou também que a baixa escolaridade materna e a idade das mães acima ou igual a 35 anos "aumentaram o risco de óbito, porém sem significância estatística" (SERAFIM, 2002, p. 80).

A variáveis maternas, idade e escolaridade, apresentaram em pesquisa de ALMEIDA et al. (2006) alta proporção de não informação em DOs de óbitos neonatais, $27,9 \%$ e $38,5 \%$ repectivamente, em oito estados brasileiros. O Paraná apresentou melhor qualidade destas informações com ausência de registros em menos de $10 \%$ dos óbitos; $3,20 \%$ para idade da mãe e 5,92\% para a escolaridade, em 2002.

Constata-se com os resultado dessa investigação contextual que a vigilância epidemiológica do óbito infantil, de sua distribuição proporcional nas variáveis e suas Taxas de Mortalidade, confere-lhe visibilidade. Se as informações deste perfil epidemiológico, obtido com dados do SIM, for somado a um processo investigativo, como proposto pelos Comitês de Prevenção, se caracteriza o óbito infantil como um evento sentinela. Desta maneira, em conseqüência desse processo gestores e profissionais, em todos os níveis de governo, poderão ser subsidiados por 
informações da vigilância e de investigação. Esse processo permite identificar falhas e inadequações assistenciais, sociais e econômicas, para as quais deverão ser delineadas estratégias que evitem outros óbitos, nas mesmas condições.

Não foi objetivo desta pesquisa analisar o conjunto complexo de fatores de risco e determinantes do óbito infantil, pois para isso seria preciso maior detalhamento de análise específica e, da rede de interação desses determinantes. Mas, pode-se discutir que a situação de informação das variáveis registradas no SIM, de maneira geral, tem melhorado no Estado e, que sua correlação e aplicação às realidades regionais deve ser feita com cautela, pontuando-se a disponibilidade dos serviços e as diversas necessidades apresentadas pela população. Neste sentido, a as ações dos Comitês de Prevenção da Mortalidade Infantil no estado do Paraná parece ter sido importante como promovedora de melhoria no SIM.

Deste modo o escopo foi de caracterizar algumas variáveis dos óbitos infantis ocorridos no período, de 1997 a 2005, organizado em Triênios, à luz de pesquisas já realizadas, para obter algumas informações que aliadas às informações dos óbitos investigados, trabalhados no SIMI, pudessem acrescentar à discussão dos DSC. 


\subsubsection{PIONEIRISMO NA INVESTIGAÇÃO DOS ÓBITOS INFANTIS: OS} COMITÊS DE PREVENÇÃO DA MORTALIDADE INFANTIL

\section{É objetivo do Pacto Nacional pela Redução da Mortalidade Materna e} Neonatal articular atores sociais mobilizados em torno da melhoria da qualidade de vida das crianças e mulheres. Lançado em oito 08 de março de 2004, e aprovado na Comissão Intergestores Tripartide e no Conselho Nacional de Saúde, até o presente ano conta com a adesão de 26 Unidades Federadas ${ }^{1}$ e diversas instâncias governamentais e civis ${ }^{2}$ articuladas (BRASIL, 2007a).

O acompanhamento, a observação e análise dos óbitos infantis devem se constituir como rotina de trabalho nos municípios de todo o Brasil. Esta vigilância precisa ser executada pelas Secretarias Municipais de Saúde $^{3}$ em parceria com os Comitês Regionais e Estaduais, instâncias de responsabilidade das Secretarias Estaduais de Saúde. A participação dos serviços de vigilância epidemiológica, municipais e estaduais, é de fundamental importância, bem como a participação dos setores responsáveis pela assistência direta, pois os principais objetivos desse trabalho estão além da melhoria estatística, estão na "qualidade e organização do cuidado de saúde" (BRASIL, 2004b, p.12).

O Ministério da Saúde recomenda que os Comitês de Prevenção do Óbito Infantil e Fetal devam ser interinstitucionais e de caráter eminentemente educativo. Enfatiza que a vigilância do óbito infantil, por meio de sua identificação, acompanhamento e monitorização dão visibilidade ao problema. Assim, a vigilância da a mortalidade infantil tem o compromisso com sua redução e metas a serem atingidas; se firma como instrumento de avaliação da assistência à saúde; bem como beneficia as políticas públicas e ações de intervenção que têm como escopo a redução dos indicadores negativos. A vigilância deve ser operacionalizada por

\footnotetext{
' A saber: Acre, Roraima, Rondônia, Amapá, Amazonas, Pará, Maranhåo, Piaui, Ceará, Rio Grande do Norte, Paraiba, Pernambuco, Alagoas, Sergipe, Bahia, Minas Gerais, Distrito Federal, Espírito Santo, Rio de Janeiro, Goiás, Mato Grosso, Mato Grosso Sul, Santa Catarina, Paraná e Rio Grande do Sul, de acordo com o relatório de trés anos do Pacto (BRASIL, 2007a).

${ }^{2}$ Secretarias Estaduais e Municipais de Saúde, Conselho Nacional de Secretários de Saúde - CONASS, Conselho Nacional de Secretários Municipais de Saúde - CONASEMS, Secretaria Especial de Políticas de Promoçăo da Igualdade Racial -SEPPIR e a Secretaria Especial de Direitos Humanos, entre outras instituiçoes governamentais e da Sociedade Civil (BRASIL, 2007).

${ }^{3}$ A Portaria $n^{\circ} 1399$ do Ministério da Saúde, publicada em 15 de dezembro de 1999 estabelece na seção III artigo $3^{\circ}$, inciso XIII, que a vigilância epidemiológica da mortalidade infantil e materna é um das atribuiçð̃es do município, que deve garantir estrutura e equipes compativeis para exercer tais atividades (BRASIL, 2004b, p.12).
} 
instituições governamentais e da sociedade civil e sempre contar com a multiprofissionalidade, diz documento do governo federal (BRASIL, 2004b).

O estado do Paraná conta com essa estratégia de vigilância e investigação dos determinantes causais imediato, intermediários e distais do óbito infantil desde 1997.

O Comitê Estadual de Prevenção do Óbito Infantil (CEPMI) teve sua implantação iniciada em 1994 com a nomeação de membros e elaboração do Regimento Interno e Resolução no 126/94, de 04 de novembro do mesmo ano, no entanto, sua ação não foi de fato iniciada. Passados três anos, em 1997, aconteceu a proposta de (re)organização do Comitê Estadual e Regionais, que ainda não existiam na prática, mediante novas estratégias de operacionalização nos níveis Estadual, Regionais e Municipais (MANSANO et al, 2004).

Os Comitês Regionais e Municipais de Prevenção da Mortalidade Infantil foram organizados de acordo com as possibilidades locais de conjugação com os trabalhos dos Comitês de Prevenção de Mortalidade Materna, que já existiam por ocasião de sua implantação.

Essa proposta de reorganização emergiu vinculada à proposta de criação de uma rede de integração das ações de promoção da saúde materno-infantil: a "Rede de Proteção à Vida", que ficou conhecida em todo o Estado como o "Protegendo a Vida". Nessa época, estabeleceu-se o óbito infantil como "evento sentinela" e foi instituída sua investigação para o conhecimento de suas causas e fatores determinantes visando propiciar a correção de falhas que o tornaram possível e garantir um funcionamento adequado do sistema de saúde (PR/SESA, 1997).

Neste período também foram criadas as Fichas Confidenciais de Investigação do Óbito Infantil e um novo Regimento; também se estruturou o fluxo das investigações nas três instâncias administrativas (PR/SESA, 1997).

Para a implantação dessa proposta houve a necessidade de preparo de profissionais para a investigação dos óbitos e análise dos mesmos. Assim em agosto de 1998 foi realizado o I Treinamento de Multiplicadores para Investigação dos Óbitos Infantis e Organização dos Comitês Regionais, pela Secretaria de Estado da Saúde do Paraná e Instituto de Saúde do Estado (SESA/ISEP) (MANSANO et al. 2004). Para tanto, foram convidados profissionais de saúde das RegS e dos Municípios. Participaram dessa mobilização profissionais que de alguma forma já 
trabalhavam com prevenção, houve treinamento para análise de Causas Básicas de óbito, orientação à questão da abordagem às famílias nas entrevistas domiciliares e questões éticas que cercam um evento dessa natureza, principalmente quanto ao sigilo das informações e dados obtidos e investigados (MANSANO et al., 2004).

As Universidades Estaduais do Estado também participaram do processo de capacitação pela sua contribuição com discussões, pesquisas e treinamentos desde 1994.

A reorganização dos Comitês Regionais e Municipais e a redefinição das atribuições do Estadual foram determinadas pela Resolução SESA $n^{0}$ 0262/98 (PR/SESA, 1998), na qual também é referendado o Regimento Interno do Comitê Estadual de Prevenção da Mortalidade Infantil. Este ficou vinculado administrativamente à Diretoria de Vigilância e Pesquisa da SESA, no Centro de Informações e Diagnósticos de Saúde/CIDS, com o apoio do Comitê Estadual de Prevenção da Mortalidade Infantil.

O Regimento privilegiava a inter-instituição e a multi-profissionalidade em sua constituição. Assim como o "caráter ético, técnico, científico, educativo e de assessoria, visando à prevenção dos condicionantes do obituário infantil e apontando medidas de intervenção às instituições participantes para correção de possíveis distorções" (PR/SESA, 1998, p.1).

De acordo com o Regimento (PR/SESA, 1998, p.1) e Resolução supracitados os Comitês Regionais de Prevenção da Mortalidade Infantil, doravante identificados no trabalho como CRPMI nesta pesquisa, possuem as seguintes atribuições:

\footnotetext{
$>$ Acompanhar periodicamente a incidência dos óbitos infantis nos municípios e avaliar os indicadores de mortalidade infantil, perinatal, neonatal precoce, neonatal tardia e pós-neonatal.

> Avaliar a atuação dos Comitês Municipais, analisar os óbitos investigados, atuando prioritariamente nos municipios com Coeficiente de Mortalidade Infantil superior à medida do estado, ou que esteja apresentando tendência de elevação do número absoluto de óbitos.

$>$ Elaborar relatórios periódicos da situação dos municipios da sua área de abrangência.
}

O CEPMI congregou representações de profissionais de várias áreas, organizações não governamentais e governamentais, órgãos de categorias 
profissionais, instituições de ensino de diversas regionais do estado. Seu perfil interinstitucional e multi-profissional (com ênfase à necessidade de participação de profissional médico pediatra) tem caráter consultivo e de assessoria técnica, baseado em princípios éticos e confidenciais (PR/SESA, 1998).

À medida da operacionalização da investigação dos óbitos infantis surgiram as dificuldades, principalmente as de acesso aos prontuários hospitalares para a coleta de dados. Nesse sentido, foi criada a Resolução SESA 229/99 que determinou aos Hospitais e Maternidades a disponibilização de cópias de prontuários aos serviços de epidemiologia das Secretarias Municipais e Regionais de Saúde (PR/SESA, 1999).

A vigilância do óbito infantil é iniciada nos municípios, com o preenchimento da Ficha Confidencial de Investigação do Óbito Infantil Tardio (28 dias a 1 ano) ou Obito Neonatal (até 27 dias), composta por dados de atendimento à saúde da mãe e da criança que foi a óbito, inclusive com dados colhidos em entrevista domiciliar, com a mãe e/ou responsável pela criança. São anexados a esta ficha, cópia de diversos documentos referentes à assistência (prontuários, carteira de pré-natal, exames etc).

Com essa Ficha completada e com todos os documentos anexados a ela é realizada, pelos Comitês Regionais a Análise Final do Óbito. Na Análise Final, com as evidências obtidas, opta-se pela manutenção ou redefinição da causa básica do óbito, procede-se à definição pela evitabilidade ou redutibilidade do evento em análise, são estabelecidos os critérios de redutibilidade, as instâncias de responsabilidade para com o evento e a eleitas as medidas de prevenção e intervenção. Alguns profissionais dos Comitês Regionais / Municipais são treinados periodicamente para esta análise em Câmaras Técnicas. Até o momento essas análises nas Câmaras técnicas são realizadas em Curitiba.

No início houve, por parte da Secretaria de Estado da Saúde (PR/SESA, 1997, p. 3), a eleição de critérios de seleção dos óbitos a serem investigados. Estes critérios foram questionados e modificados à medida da experiência e capacidade técnica de cada RegS, principalmente das mais envolvidas com a proposta. Os critérios estabelecidos apontaram para a seguinte delimitação: 


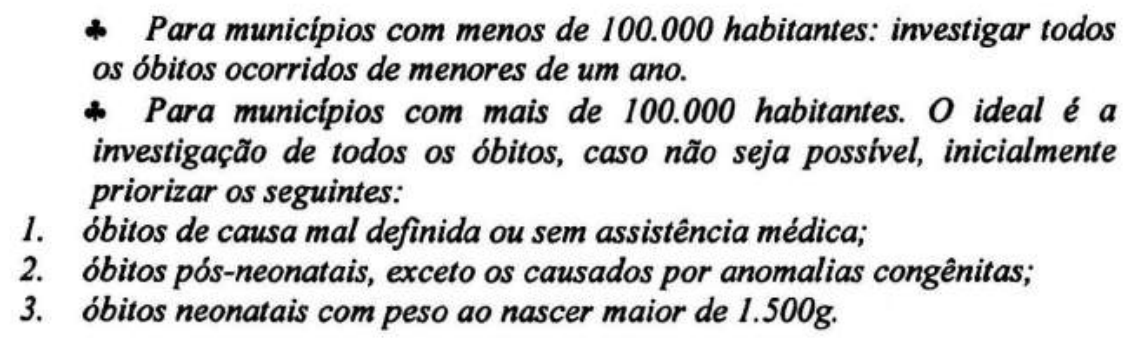

$\mathrm{O}$ critério, apesar de contemplar o número de habitantes dos municípios, na prática o peso ao nascer foi mais utilizado: óbitos de crianças a partir de 1.500 gramas de peso ao nascer, com exceção das situações de malformações congênitas; a posteriori estabeleceu-se novo limite de peso, ou seja, crianças nascidas com 1.000 gramas ou mais.

Para melhor operacionalização das informações foi criado, no ano 2000, um programa com base de dados em Acces, denominado SIMI (Sistema de Investigação da Mortalidade Infantil). Esse sistema utiliza-se das informações da ficha de Análise Final do Óbito e é alimentado nas Regionais; o mesmo permite a exportação dos dados para o Comitê Estadual, através de rede (MANSANO et al., 2004).

Nas reuniões do CEPMI, que acontecem na capital do estado, Curitiba, são discutidos os novos dados regionais e outras questões, antigas ou emergentes, que afetam a vida das crianças; são consolidados os dados do SIMI; é promovida avaliação contínua das mudanças no perfil dos óbitos no nível regional e municipal; são elaborados e divulgados boletins informativos e relatório analítico; são apresentadas propostas às autoridades competentes de medidas de intervenção para efetiva prevenção dos óbitos; são organizados encontros anuais entre representantes das diversas RegS para discussão das investigações e capacitações técnicas, mediante as Câmaras Técnicas (MANSANO et al, 2004).

Cabe às instâncias Regionais o papel regulador, apoiador e técnico perante os municípios. Para tanto, há necessidade de pessoal capacitado e habilitado, no quadro de recursos humanos das RegS. Articular todos os municípios não é uma simples tarefa administrativa das regionais considerando que cada Regional tem em média 18 municípios adstritos, faixa de variação entre 7 a 30 municípios por Regional. Ressaltam-se as peculiaridades de desenvolvimento social, ambiental, políticoadministrativo e econômico de cada município que compõe uma RegS. 
O Estado estimula os Comitês Regionais, de responsabilidade administrativa e operacional das RegS, ao apoio e incentivo técnico à constituição de Comitês Municipais e Hospitalares, em cada município com o intuito de consolidar uma verdadeira Rede de Combate ao Óbito Infantil Evitável. Atualmente, em levantamento sobre o número de Comitês ${ }^{4}$ existentes, se tem que além dos 22 Comitês Regionais, há 217 Comitês Municipais e 30 Comitês Hospitalares. Segundo informações do CEPMI, há Comitês Municipais na grande maioria dos municípios com população acima de 100.000 habitantes.

As investigações dos óbitos infantis são realizadas, geralmente, por profissionais do Setor/Serviço de Vigilância Epidemiológica de cada município. Esses profissionais pesquisam os dados em prontuários ambulatoriais, hospitalares, realizam visita domiciliar, preenchem a Ficha Confidencial. Esse sistema de vigilância busca potencializar as intervenções do Estado, tendo em vista, a agilidade das informações.

A vigilância ativa denota um sistema em que se faz visitas de campo a serviços de saúde, aos profissionais e pacientes, revisando os registros da equipe de saúde. Geralmente, este tipo de vigilância traz maior especificidade e fidedignidade dos dados registrados. Além do que, se espera que os profissionais que processam estas visitas estejam preparados para assumir esta responsabilidade (GORDIS, 2004).

As equipes multiprofissionais e interinstitucionais ao analisarem o óbito infantil, procuram por em evidência as situações que colaboraram com a ocorrência do evento, observam a ordem de ocorrência e associação dos eventos. Sempre são investigadas as "brechas" que favorecem a redutibilidade da morte infantil. Procurase responder o tempo todo: Na ausência dessas situações o óbito poderia ter sido evitado?

Enfocando a prática das atividades, observa-se que os CRPMI ficam com toda a articulação de informações entre os municípios de ocorrência do óbito e os de residência da criança / família. Com este fim, faz a mediação das informações entre os Hospitais, Ambulatórios, Redes Básicas; solicita documentação necessária para a coleta de informações e monitora sua chegada, com cobranças freqüentes. e cobra

4 Informaçøes relativas ao início do ano de 2007 e obtidas diretamente no Centro de Informações e Diagnóstico em Saúde da SESA/PR, Coordenação Estadual dos Comitês de Prevenção de Mortalidade Infantil, em agosto de 2007. 
quantas vezes for necessário pelo solicitado. Ao mesmo tempo, os CRPMI buscam integrantes voluntários tentando, com esforço, contemplar a constituição interinstitucional e a multi-profissional; agenda reuniões e organiza as mesmas; distribui as atribuições para os integrantes do grupo e alimentam o SIMI. Profissionalmente, conclui-se que não há como desenvolver e responder por esta relação de atividades sem a constituição de uma equipe e sem o comprometimento dos profissionais que a constituem.

No Manual dos comitês de prevenção do óbito infantil e fetal (MCPOIF) (BRASIL, 2004b, p. 17) há a sugestão de que os Comitês Regionais / Municipais mantenham vínculo e articulação com o Comitê Estadual, para obtenção de apoio técnico-administrativo e assessoria técnica, "principalmente para a correção das estatísticas oficiais".

É interessante mencionar o rol de atribuições que no Manual do Ministério (BRASIL, 2004b, p. 15-16) está designado para os Comitês Regionais e Municipais, pois vão além das relacionadas em Resoluções do Paraná, mas não da prática que vem sendo realizada no estado neste período. São elas:

$\Rightarrow$ Estimular a investigação dos óbitos infantis e fetais pela Secretaria Municipal de Saúde segundo critérios estabelecidos pelo Comitê Nacional / Ministério da Saúde $e$ de acordo com a realidade $e$ interesse local, assumida como uma responsabilidade institucional cotidiana.

$\Rightarrow$ Promover e favorecer a articulação $e$ integração entre os setores $e$ profissionais da vigilância epidemiológica $e$ da atenção à saúde na investigação dos óbitos, garantindo o enfoque adequado ao problema da Mortalidade Infantil e Fetal, que envolve a investigação e análise dos casos para $o$ adequado planejamento e organização das intervenções de assistência de saúde de maneira a prevenir novas ocorrências.

$\Rightarrow$ Avaliar periodicamente os principais problemas observados no estudo dos óbitos e as medidas realizadas de intervenção para redução da mortalidade infantil e perinatal no âmbito municipal/regional.

$\Rightarrow$ Divulgar sistematicamente os resultados, com elaboração de material especifico (relatório / boletim periódico).

$\Rightarrow$ Promover $e$ estimular a qualificação das informações sobre mortalidade, com a ampliação da cobertura do sistema de informação e melhoria dos registros na DO e registros de atendimento.

$\Rightarrow$ Consolidar periodicamente os dados de investigação para o envio ao Comitê Regional / Estadual.

$\Rightarrow$ Elaborar propostas para a construção de políticas municipais dirigidas à redução da mortalidade infantil e perinatal.

$\Rightarrow$ Acompanhar a execução das medidas propostas. 
Com base em nossa vivência e experiência junto aos Comitês (Regional e Estadual) podemos inferir que estas atribuições são factíveis por uma parcela dos Municípios e das Regionais do estado do Paraná, devido, principalmente, à organização e disponibilidade de pessoal qualificado para tais ações. Além da comprovação desta afirmação com a demonstração do percentual de investigação variado nas 22 RegS (Tabela 7), de $6 \%$ a 100\%, nos Triênios em estudo; essa percepção também chama a atenção no DSC, como realidade concreta desfavorável de trabalho na investigação, relatada por alguns dos entrevistados.

No tocante à emissão de relatórios, em especial no nível municipal foca-se a necessidade de preparo técnico-metodológico, epidemiológico e relacional. Há que se considerar a possibilidade de se 'esbarrar' em sítios profissionais não muito permeáveis às observações críticas, particularmente, as condutas médicas e organizacionais privadas e/ou filantrópicas; assim como na complexidade organizacional e funcional das instituições de assistência à saúde de caráter público.

É previsto que os CRPMI (PR/SESA, 1998), se adequando às possibilidades e realidade locais, sejam compostos por categorias de representantes listados a seguir.

$>$ Representantes da Secretaria de Estado da Saúde: da Diretoria de Vigilancia e Pesquisa, da Diretoria de Serviços e Saúde, do Grupo de Planejamento e Coordenaçăo.

$>$ Representantes de associaçס̃es não governamentais: como a Pastoral da Criança e outras que existam nas Regionais e Municípios.

$>$ Representantes de Sociedades Cientificas Profissionais: Associação Brasileira de Enfermagem / ABEn - Seção Paraná; Sociedade Paranaense de Pediatria / SPP; à medida da participação profissional são permitidos e bemvindas as associaçð̃es e sociedades de outras profissర̃es.

$>$ Representantes de Conselhos Profissionais: Conselho Regional de Medicina I CRM; Conselho Regional de Enfermagem / COREN; Conselho Regional de Serviço Social / CRESS; podendo ser acrescidos de outras profissð̃es.

$>$ Representantes de entidades de formação profissional: são as Universidades Públicas e Privadas, de preferência de Departamentos ou Centros de Ciências da Saúde, com representações eleitas entrepares e encaminhadas por nomeação da Universidade.

$>$ Representantes de prestadores de Serviços de Saúde: de representante da Federação dos Hospitais e de Estabelecimentos e Serviços de Saúde no Estado do Paraná.

Dentre as associações não governamentais ainda se pode incluir as organizações religiosas, que independentes da denominação, ou forma de 
organização, exercem, na prática, um importante papel social preventivo e educativo junto a famílias e mães. A participação social diversificada além de ser um princípio norteador para as políticas públicas brasileiras, permite conhecer, entender e 'ouvir' mais atentamente os problemas, necessidades e expectativas da população com a qual se trabalha e, abre espaço para a responsabilidade social.

Quanto à participação de instituições formadoras, ou seja, Universidades e Faculdades públicas e privadas, ainda não está plenamente consolidado o modo como deve ser feita, talvez para boa parte das RegS. Há espaço para ser ocupado, no sentido de poder contar com um maior aprofundamento da discussão de investigação e análise, assim como para a elaboração de propostas de ação preventiva, ou seja, de intervenção. Esta participação deve incluir outras áreas da saúde, como Nutrição, por exemplo, bem como ultrapassar seus limites e incluir as Ciências Humanas e Sociais. Com certeza, estas ciências poderão contribuir, proficuamente, com a discussão, principalmente, quanto aos determinantes distais da mortalidade infantil, ou seja, com os fatores sociais, econômicos e culturais. Acredita-se que mediante a divulgação do trabalho realizado pelos Comitês em cada RegS num formato que suscite maior integração para a proposta de pesquisa, de iniciativas de extensão e de ensino, seja gerada uma contribuição de impacto para o enriquecimento do processo de vigilância, investigação e ação.

O MCPOIF (BRASIL, 2004, p.18) assinala que as características e o interesse locais, referentes a "organização da população e entidades existentes" é que determinarão a composição dos Comitês Regionais e Municipais. É enfatizada a importância da "participação de representantes instituições diretamente envolvidas na assistência à saúde da gestante e da criança, além dos técnicos que lidam com as estatísticas vitais" para se obter "maior sucesso e efetividade na incorporação da avaliação na rotina do trabalho em saúde, e conseqüentemente o encaminhamento de propostas de melhoria da assistência".

Assim, recomenda-se a seguinte constituição dos Comitês Estaduais, Regionais e Municipais (BRASIL, 2004b, p. 19):

$\Rightarrow$ Representantes da Secretaria de Saúde: Área de Saúde da Criança e Adolescente; Area de Saúde da Mulher; Programa de Saúde da Familia; Programa de Agentes Comunitários de Saúde; Vigilância Epidemiológica e Controle e Avaliação. 
$\Rightarrow$ Conselho de Saúde.

$\Rightarrow$ Conselhos Regionais de Entidades Profissionais.

$\Rightarrow$ Faculdades de Medicina, de Enfermagem, de Saúde Pública.

$\Rightarrow$ Conselho de Direitos da Criança e do Adolescente.

$\Rightarrow$ Sociedades cientificas. Obstetricia, pediatria, enfermagem, outras.

$\Rightarrow$ Entidades da sociedade civil organizada. Pastoral da Criança, Unicef, outras.

$\Rightarrow$ Representantes dos Hospitais locais.

Quanto à representação de prestadores de serviços de saúde, esta ainda é incipiente, mas com urgência precisa ser agilizada, pois os desfechos dos eventos sentinelas acontecem em toda a Rede de Assistência à Saúde e, não apenas nas Instituições credenciadas / habilitadas pelo SUS, ou mediante em instituições públicas. Esse caminho poderia abrir uma integração com resultados inusitados sobre a responsabilidade profissional no processo, visualiza-se que seja um caminho para fomentar a reflexão, a responsabilidade coletiva pelo evento, além de ações mais definidas e claras junto aos serviços.

Por meio dessas considerações é possivel a admissão de que a posição de Coordenador dos Comitês Regionais, bem como de sua Presidência (que não necessariamente é exercida por profissional do Estado e vinculado às RegS, pode ser eleita dentre o grupo de profissionais participantes, de acordo com o Regimento) não é uma tarefa fácil. Para isso é exigida muita integração, articulação e poder de governo.

Antes de abordar dos óbitos investigados nas Regionais de Saúde ressaltamse as atribuições dos Comitês Municipais de Prevenção da Mortalidade Infantil (CMPMI), os quais são destacadas no Regimento do Estado do Paraná, pois é no Município, ou seja, nos 399 municípios do Estado que devem acontecer a:

> Identificação dos Óbitos Infantis:

O Município (geralmente pelo Serviço de Epidemiologia) coleta informações dos óbitos através das Declaraç⿸丆es de Obitos, DOs elou busca ativa dos mesmos nos Hospitais, Serviços Funerários, informaçz̃es obtidas por Agentes Comunitários de Saúde / ACS, lideres da Pastoral da Criança ou outras fontes.

$>$ Investigação dos Óbitos Infantis:

O Município (através do Serviço de Epidemiologia ou outros, como por exemplo, as Coordenaçz̃es Locais de Saúde) realiza investigação mediante os dados da DO, da 
Declaração de Nascimento / DN, os dados dos prontuários (hospitalar, ambulatorial e da rede básica), visita domiciliar e entrevista com o médico se necessário.

$>$ Análise dos Óbitos Infantis:

O Comitê Municipal (ou outro sistema municipal organizado) analisa os óbitos investigados, checando a Causa Básica colocada na $D O$, verificando sua evitabilidade e propõe medidas de prevenção. Encaminha as informações ao Comitê Regional periodicamente.

Toda a estratégia de investigação municipal pressupõe serviços organizados, contingentes de pessoal capacitado, treinamentos constantes e, ainda mais, apoio político para que se cumpram as investigações, se obtenham os documentos necessários, se realizem as entrevistas necessárias dentre em todas as outras atividades.

Após quase 10 anos de trabalho dos Comitês no estado do Paraná ainda faltam 182 CMPMI, ou seja, 45,60\% dos municípios ainda não têm Comitês organizados. Dentro do contexto de trabalho das Secretarias Municipais, na maioria das vezes, o Serviço de Epidemiologia tem um profissional responsável para cuidar do Comitê e das investigações. Este distribui as tarefas para os Agentes Comunitários de Saúde (ACS) e para os enfermeiros e técnicos da Rede Básica de Saúde. A responsabilidade pelo preenchimento integral da Ficha de Investigação é distribuída e, nesse processo, são anexadas as cópias dos documentos (possíveis de serem localizados), após o que tudo é encaminhado para o CRPMI. Processo que não inclui, na maioria das vezes, a análise final do óbito, pois geralmente o profissional médico pediatra não está disponível nas instâncias municipais para participar da análise.

Os Comitês Hospitalares $(\mathrm{CH})$ que têm importância fundamental devido a maior visibilidade do evento sentinela, não têm sido estruturados. Existem $30 \mathrm{CH}$, mais centrados nas cidades maiores do Estado e referência para o atendimento ao risco gestacional e infantil (Curitiba, Londrina e Maringá, dentre algumas outras). No entanto, são incipientes e carentes de fortalecimento e apoio, não só das instâncias administrativas hospitalares como das Regionais de Saúde e Municípios.

$\mathrm{Na}$ verdade, a organização dos $\mathrm{CH}$ é requisito para o funcionamento das Maternidades que fazem parte do Programa de Gestação de Alto Risco e de 
Humanização do Pré-natal e Nascimento (PHPN) do $\mathrm{MS}^{5}$. Se existem esses Comitês em Maternidades privadas, de maneira geral, de rotina não mantém representantes nos Comitês municipais, nem regionais.

Nos $\mathrm{CH}$ acontece a reflexão crítica de cada óbito ocorrido no estabelecimento pelo grupo de profissionais, possivelmente até que tenham atendido à criança. Com isto, podem identificar maneiras de correção necessárias aos serviços ambulatoriais e hospitalares, principalmente para os óbitos categorizados como evitáveis, de modo que venha a se evitar outros acontecimentos semelhantes. Quanto maior a participação profissional maior a diversidade de pontuação de aspectos importantes para a prevenção. É recomendado pelo MCPOIF que o $\mathrm{CH}$ tenha como participantes: representante da Diretoria Clínica, de profissionais (médicos e enfermeiros) das equipes de assistência hospitalar dos setores de Obstetrícia, Pediatria, Neonatologia e, demais interessados (BRASIL, 2004b).

No documento Ministerial as instâncias Regionais e Municipais se mesclam em termos de atribuições de modo diverso ao Regimento do Estado do Paraná. Essas atribuições do Comitê de Prevenção do Óbito Infantil e Fetal são definidas no MCPOIF e demonstradas no Quadro 7.

\footnotetext{
${ }_{5}^{5}$ Portarias MS/GM 3016, 3482 e 3477 de 1998 e Portarias GM/MS 569, 570, 571 e 572 de 2000 (BRASIL, 2004b, p.19).
} 
Quadro 7: Atribuições do Comitê de Prevenção do Óbito Infantil e Fetal segundo ações que as compõem, Brasil, Ministério da Saúde, 2004.

\begin{tabular}{|c|c|}
\hline ATRIBUIÇCós & ESPECIFICAÇÃO DAS AÇŌES \\
\hline \multirow{2}{*}{ INVESTIGAÇÃo } & $\begin{array}{l}\text { Estimular a investigação dos óbitos pelas equipes de saúde, segundo critérios } \\
\text { definidos, preferencialmente com a participação integrada dos profissionais de } \\
\text { vigilância epidemiológica e da área de assistência de saúde (PACS/PSF/UBS e } \\
\text { setores da área de assistência das Secretarias de Saúde). }\end{array}$ \\
\hline & $\begin{array}{l}\text { Estimular a constituição de Comitês Hospitalares, com estudo e análise dos } \\
\text { óbitos ocorridos no estabelecimento pelas equipes dos hospitais e maternidades. }\end{array}$ \\
\hline \multirow{4}{*}{ ANÁLISE dOS ÓbITOS } & Analisar os óbitos segundo a possibilidade de sua prevenção. \\
\hline & 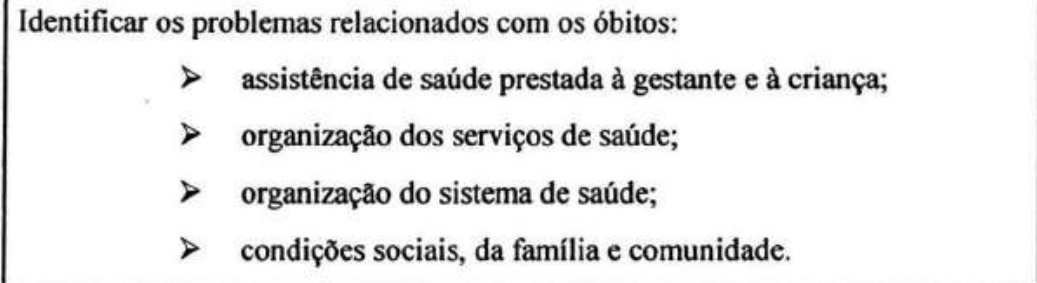 \\
\hline & $\begin{array}{l}\text { Promover a análise e discussão de casos com as equjipes de saúde envolvidas e } \\
\text { responsáveis pela população da área de abrangência do óbito: atenção básica, } \\
\text { secundária, serviços de urgência e hospitais. }\end{array}$ \\
\hline & $\begin{array}{l}\text { Informar e encaminhar para os órgãos e instituiçð̃es competentes as falhas na } \\
\text { assistência de saúde e demais problemas observados. }\end{array}$ \\
\hline \multirow[b]{2}{*}{$\begin{array}{l}\text { QUALIFICAÇÃO DA } \\
\text { INFORMAÇÃO }\end{array}$} & $\begin{array}{l}\text { Contribuir para a melhoria da informação em saúde, com a correção das estatisticas } \\
\text { oficiais e qualificação da informação registrada da declaração de óbito e na declaraçăo de } \\
\text { nascido vivo. }\end{array}$ \\
\hline & $\begin{array}{l}\text { Contribuir para a melhoria dos registros de saúde, sensibilizando os } \\
\text { profissionais para o preenchimento completo dos prontuários, fichas de } \\
\text { atendimento, Cartão da Gestante e Cartão da Criança. }\end{array}$ \\
\hline $\begin{array}{l}\text { DEFINIÇão de MEdidAS de } \\
\text { PREVENÇão }\end{array}$ & $\begin{array}{l}\text { Elaborar propostas com medidas de prevenção e intervenção necessárias para } \\
\text { prevenção de novas ocorrÊncias e encaminhar para o poder público / órgãos } \\
\text { competentes. }\end{array}$ \\
\hline \multirow{3}{*}{ DIVULGaÇÃo / EduCAÇÃo } & $\begin{array}{l}\text { Divulgar e dar visibilidade ao problema, com a realização de ações educativas e } \\
\text { sensibilizadoras, com a elaboração de relatórios, promoção de debates, } \\
\text { seminários, boletins e outras iniciativas de socialização das informações. }\end{array}$ \\
\hline & $\begin{array}{l}\text { Divulgar relatórios para todas as instituições e órgãos competentes que possam } \\
\text { intervir na redução das mortes infantis e fetais. }\end{array}$ \\
\hline & $\begin{array}{l}\text { Promover a discussão sobre a persistência de niveis elevados de mortalidade infantil e } \\
\text { fetal e as circunstâncias que envolvem os óbitos, realizando capacitaçðes, treinamentos e } \\
\text { reciclagens para educação continuada, com a produção de material educativo. }\end{array}$ \\
\hline \multirow[t]{2}{*}{ MOBILIZAÇÃo } & $\begin{array}{l}\text { Promover a interlocução entre todas as instituições do poder público e da } \\
\text { sociedade civil, de modo a congregar os esforços para a redução da mortalidade. }\end{array}$ \\
\hline & $\begin{array}{l}\text { Mobilizar o poder público, instituições e sociedade civil organizada para } \\
\text { garantir a execução das medidas propostas. }\end{array}$ \\
\hline
\end{tabular}

Fonte: Manual dos comitês de prevenção do óbito infantil e fetal (BRASIL, 2004, p. 13-14. 
Diante da estratégia preventiva do óbito infantil exposta pelo governo federal, os Estados, mesmos os que já há algum tempo trabalham nesse sentido, precisam refletir sobre suas experiências, possibilidades, dificuldades e necessidades.

Os dircursos-síntese fornecem representações sociais de valoroso impacto para a presente fase da história de vigilância e investigação dos óbitos infantis no Estado do Paraná, em que são necessárias medidas renovadas e pautadas nas experiências até aqui acumuladas, mediante participação dos atores que até aqui contribuíram e contribuem para a prevenção do óbito infantil.

À luz dessa explanação fundamentada em documentos que direcionam a estratégia de prevenção mediante o trabalho dos Comitês de Prevenção da Mortalidade Infantil, no estado do Paraná, avalia-se a seguir algumas informações quantitativas e qualitativas obtidas do SIMI.

\subsubsection{OS ÓBITOS INFANTIS INVESTIGADOS}

Optou-se por apontar por RegS o número e percentual de óbitos infantis investigados devido à leitura por RegS e, na seqüência, realizar a leitura de algumas variáveis para todo o Estado, sem a especificação por Regionais, por ser um detalhamento gerador de números pequenos, a despeito da organização em Triênios. Permite-se, dessa forma, contribuir com a integração entre a presente discussão e a dos DSC, pois estes não foram construídos por Regionais e, sim por categorias dos atores sociais entrevistados.

Depois de ter mostrado um pouco do trabalho que ocorre em cada uma dessas investigações e que se transformam num "percentual de trabalho realizado" e ressaltar que este não é um simples preencher de "papéis institucionais" ou de formulários, passamos a discutir os óbitos investigados.

A proporção de óbitos investigados apresentou-se bastante heterogênea no Paraná, como mostra a Tabela 7 variou nas 22 Regionais de $6 \%$ a $100 \%$, pode-se dizer que de um extremo a outro, mostrando um gradiente que reflete a capacidade organizacional e operacional de cada região. 
O Estado não impõe obrigatoriedade de investigação da totalidade dos óbitos ocorridos, mas estabelece metas a serem atingidas. Cada uma das Regionais e seus Municípios devem se planejar para investigar de maneira quantitativamente crescente os óbitos de crianças filhas de mães residentes nas regiões que lhe são afetas.

Ao longo dos anos as RegS se organizaram a medida de suas possibilidades de recursos humanos, de capacidade de articulação, de apoio técnico-profissional local, de espaço físico para a manutenção de uma estrutura física adequada para o trabalho e, foram, por motivação intrínseca ao processo de trabalho e, com apoio e retaguarda do Comitê Estadual, abrindo seus espaços na investigação. São histórias de avanços e retrocessos que puderam lograr para algumas RegS a investigação de $100 \%$ de seus óbitos infantis, atualmente e, para outras, ainda hoje menos de $50 \%$ de investigação. Um pouco dessa história ficará mais clara na representação social da prevenção do óbito infantil com o relato de suas dificuldades.

Para que uma RegS investigue $100 \%$ dos óbitos infantis de mães residentes no estado, todos os seus municípios devem participar com $100 \%$ de investigações, meta a ser atingida pelos enfrentamentos das diversas dificuldades regionais. No entanto, essa realização dos municípios depende, prioritariamente, de vários fatores gerenciais, políticos e operacionais locais.

No $2^{\circ}$ Triênio foram investigados $59,03 \%$ dos óbitos infantis do estado (média de 68,14\% entre as RegS), no $3^{\circ}$ Triênio ocorreu investigação de 77,21\% dos óbitos (média de $81,73 \%$ entre as RegS); elevação de aproximadamente $31 \%$ na investigação em 6 anos, cerca de $5 \%$ ao ano. Em relação à mediana dos óbitos investigados no $2^{\circ}$ Triênio, verifica-se que foi de $66,50 \%$ e no $3^{\circ}$ Triênio de $81,00 \%$ (Tabela 7).

Na Programação Pactuada Integrada (PPI) da SESA, de 2003, entre os parâmetros de programação para ações de epidemiologia e controle de doenças, foi traçada como meta para o estado a investigação de $70 \%$ dos óbitos de menores de um ano de idade (PR/SESA, 2003). Desta forma, a meta foi superada, considerando que ela havia sido traçada para 2003. Além do mais, observa-se o processo contínuo de aumento no número de investigações do óbito infantil. Na atual situação há que se focar e apoiar as RegS que apresentaram maiores problemas para manter ou elevar a proporção de óbitos investigados. 
Observa-se a ocorrência de investigação em mais de $100 \%$ dos óbitos ocorridos em três RegS, Campo Mourão $\left(11^{a}\right)$, Cianorte $\left(13^{a}\right)$ e Toledo $\left(20^{a}\right)$, este fato sinaliza por erro na alimentação do sistema ou, talvez, a duplicidade de informações de um mesmo óbito (Tabela 7).

Tabela 7: Distribuição dos óbitos investigados (frequeência e \%) nos Triênios segundo Regional de Saúde e proporção investigada (em relação ao SIM), estado do Paraná, 2000 a 2005.

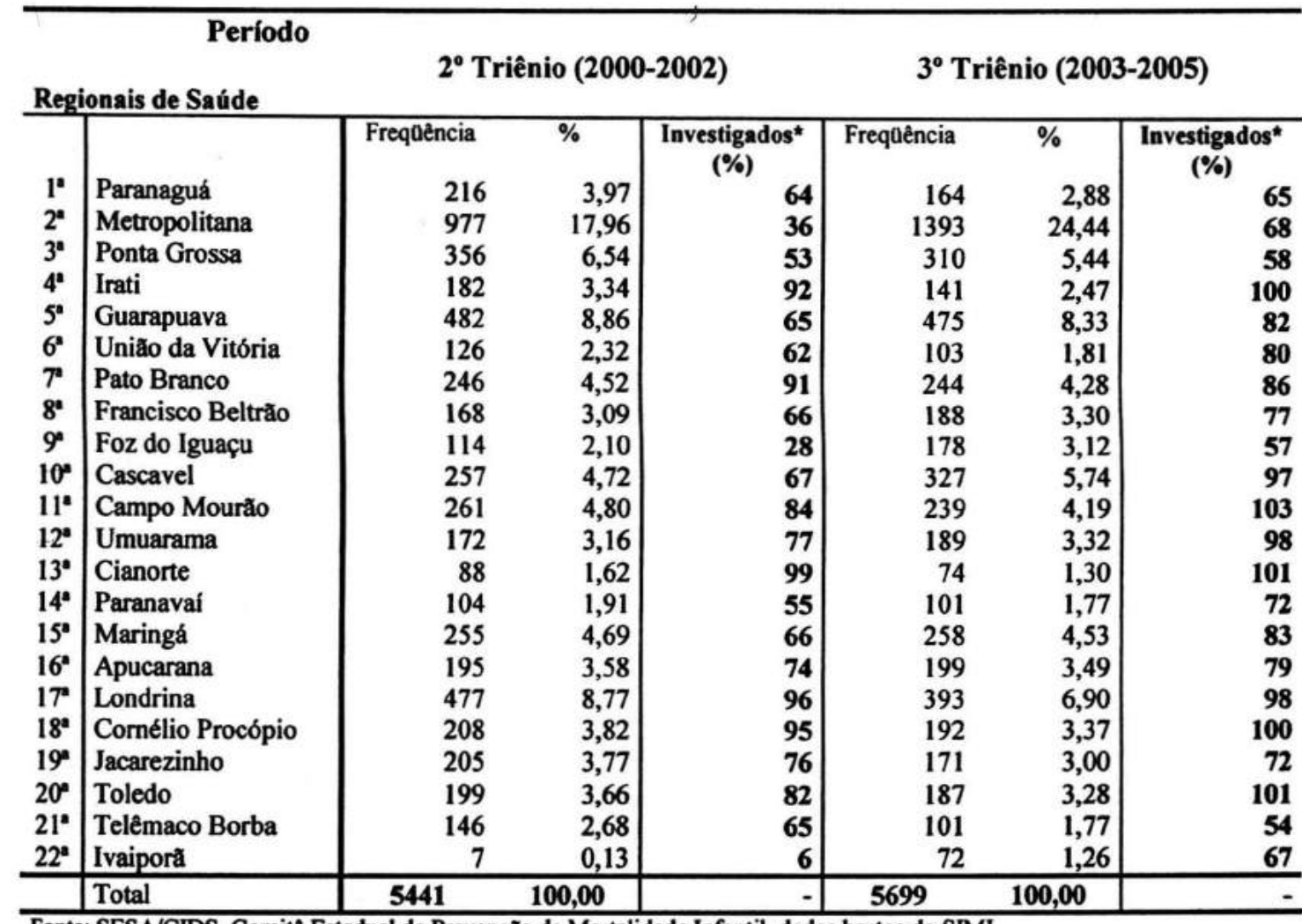

Fonte: SESA/CIDS, Comite Estadual de Prevençẫo da Mortalidade Infantil, dados brutos do SIMI.

*Proporçăo de óbitos infantis investigados em relaçăo aos óbitos ocorridos (SIM): no $2^{\circ}$ Triênio ocorreram 9.218 obitos infantis totais, assim foram investigado $59,03 \%$ dos obitos infantis no estado; no $3^{\circ}$ Triênio foram investigados $77,21 \%$ dos óbitos ocorridos (7.381).

Dentre as RegS que apresentaram TMI crescentes no período, Pato Branco $\left(7^{a}\right)$, de Francisco Beltrão $\left(8^{a}\right)$, de Telêmaco Borba $\left(21^{a}\right)$ e Ivaiporã $\left(22^{a}\right)$, atentou-se para a de Telêmaco Borba apresentou, também, decréscimo na investigação de $65 \%$, no $2^{\circ}$ Triênio, para $55 \%$, no $3^{\circ}$ Triênio. Esta situação sinaliza para problemas regionais que devem ser diagnosticados e enfrentados para que, além do cumprimento da investigação, possam também estabelecer ações com metas para a redução da mortalidade infantil regional (Tabela 7). 
Em contrapartida outra situação que chama a atenção é a da RegS de Ivaiporã que de $6 \%$ de investigação passa para $67 \%$ respectivamente entre o $2^{\circ}$ e $3^{\circ}$ Triênios. Fato que revela o empenho político-administrativo e reconhecimento do valor da investigação para a prevenção do óbito infantil (Tabela 7).

A RegS Metropolitana, mesmo tendo apresentado elevação no número de óbitos investigados, ainda se apresenta abaixo de $70 \%$ de investigação dos óbitos ocorridos. Assim pode ser considerada como não atendendo à PPI do estado .

Considerando-se apenas o $3^{\circ}$ Triênio relacionam-se as RegS que ainda estão fora da meta tida como parâmetro das programações e ações do estado em relação à mortalidade infantil que foi de $70 \%$ para 2003 , são elas: Telêmaco Borba $\left(21^{a}\right)$ 54\%; Foz do Iguaçu ( $\left(9^{a}\right)$ - 57\%; Ponta Grossa ( $\left.3^{a}\right)$ - 58\%; Paranaguá $\left(1^{a}\right)-65 \%$; Ivaiporã $\left(22^{a}\right)-67 \%$ e Metropolitana $\left(2^{a}\right)-68 \%$ (Tabela 7$)$.

Quanto ao SEXo das crianças menores de um ano que foram a óbito verificouse no SIMI que o percentual acompanha o percentual do total de ocorrência dado pelo SIM. Ou seja, os óbitos infantis ocorreram na maioria para crianças do sexo masculino; estes foram proporcionalmente mais investigados, $57,95 \%$ e $56,87 \%$ nos Triênios (Tabela 8).

Tabela 8: Caracterização do óbito infantil investigado (frequêencia e \%) nos Triênios segundo sexo e faixa etária, estado do Paraná, 2000 a 2005.

\begin{tabular}{|c|c|c|c|c|}
\hline \multirow{3}{*}{\begin{tabular}{lr}
\multicolumn{2}{|c}{ Triênios } \\
Varidíneis \\
SEXO & $\begin{array}{r}\text { masculino } \\
\text { feminino } \\
\text { ignorado }\end{array}$ \\
& \\
&
\end{tabular}} & \multicolumn{2}{|c|}{$\begin{array}{c}2^{\circ} \text { Triênio } \\
5.441 \text { obitos investigados }\end{array}$} & \multicolumn{2}{|c|}{$\begin{array}{c}3^{\circ} \text { Triênio } \\
5.699 \text { obitos investigados }\end{array}$} \\
\hline & Freq. & & Freq. & \\
\hline & $\begin{array}{r}3153 \\
2283 \\
5\end{array}$ & $\begin{array}{r}57,95 \\
41,96 \\
0,09\end{array}$ & $\begin{array}{r}3241 \\
2453 \\
5\end{array}$ & $\begin{array}{r}56,87 \\
43,04 \\
0,09\end{array}$ \\
\hline $\begin{array}{r}\text { FAIXA ETARIA } \\
\text { neonatal precoce } \\
\text { neonatal tardia } \\
\text { pós neonatal } \\
\text { com } 365 \text { dias } \\
\text { perdido* }\end{array}$ & $\begin{array}{r}2841 \\
705 \\
1891 \\
4 \\
0\end{array}$ & $\begin{array}{r}52,21 \\
12,96 \\
34,76 \\
0,07 \\
-\end{array}$ & $\begin{array}{r}3022 \\
883 \\
1789 \\
3 \\
2\end{array}$ & $\begin{array}{r}53,03 \\
15,49 \\
31,39 \\
0,05 \\
0,04\end{array}$ \\
\hline
\end{tabular}

Em relação à FAIXA ETÁRIA das crianças nota-se que esta segue o mesmo padrão da ocorrência; mais de $50 \%$ das investigações são de óbitos neonatais 
precoce, que ocorreram também em mais de $50 \%$ da população de menores de um ano de idade, segundo dados do SIM. O mesmo raciocínio é válido para as outras faixas etárias, significando que não há priorização pela investigação de alguma faixa etária, tampouco, há priorização relativa ao sexo da criança. (Tabela 8).

No último Triênio os óbitos ocorridos apontam para 4 óbitos registrados com sexo da criança ignorado (dados do SIM); na avaliação do SIMI aparecem 5 óbitos, para o mesmo período, sugerindo, possível erro na digitação para o Sistema (Tabela 8). Fato semelhante acontece com a idade de 365 dias, ou seja, criança com um ano de idade registrada no SIMI inadequadamente. Também aparecem idades negativas, que denotam erro de alimentação do Sistema. Situações que sinalizam problemas com o sistema de informação e pode estar denotando necessidade de capacitação de seus operadores, ou adequação do sistema.

A análise das variáveis a seguir, registradas no SIMI, normalmente devem ser utilizadas para nortear as ações relacionadas a eventuais fatores predisponentes e desencadeantes do evento sentinela.

Ao se realizar a análise do óbito diante dos documentos ambulatoriais e hospitalares, encontram-se várias dificuldades relacionadas à presença e conteúdo das anotações, que são utilizadas para o preenchimento da Ficha Confidencial. Ao fazer a síntese da análise, a Análise Final do Óbito, documento utilizado para alimentar o SIMI, a equipe assinala sobre a QUALIDADE DOS DADOS que foram disponibilizados na Ficha Confidencial e emite juízo à qualidade dos dados a ser considerada: satisfatória, insatisfatória, pouco satisfatória. Em algumas vezes (cerca de $2 \%$ ) essa variável não foi registrada, considerada nessa pesquisa como "em branco" (Tabela 9).

Observa-se que o grau de satisfação da transcrição e elaboração das informações da Ficha Confidencial advindas de anotações nos prontuários hospitalares e ambulatoriais, bem como dos relatórios das visitas domiciliares e da análise dos óbitos foi fortemente apontada como "satisfatórios" e "pouco satisfatórios", ambos somam cerca de $84 \%$ e quase $90 \%$ nos $2^{\circ}$ e $3^{\circ}$ Triênios respectivamente. A "insatisfação" pelas anotações fica expressa ao redor de $10 \%$ (Tabela 9). 
Tabela 9: Caracterização do óbito infantil investigado (freqüência e \%) nos Triênios, segundo qualidade das informações da Ficha Confidencial de Investigação, estado do Paraná, 2000 a 2005.

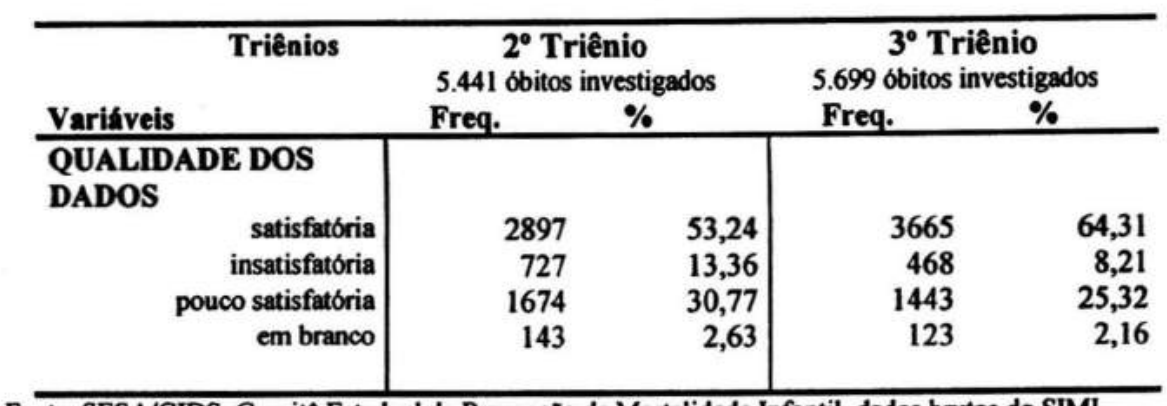

Fonte: SESA/CIDS, Comite Estadual de Prevençâo da Mortalidade Infantil, dados brutos do SIMI.

Pode-se inferir que, no geral, os profissionais de análise, mesmo com a existência de queixas (expressas no DSC) de anotações ilegíveis, ausência de prontuários, dificuldades com a obtenção das informações, têm considerado os dados registrados na Ficha Confidencial de boa (cerca de 53\% e 64\%, nos Triênios) para razoável (30\% e $25 \%$ aproximadamente, nos Triênios) qualidade (Tabela 9). Enfim a qualidade das informações é crescente, este fato denota o esforço investigativo. Acredita-se que à medida que haja maior conscientização, mediante processos de capacitação dos profissionais que realizam a assistência nos serviços de saúde, essa qualidade das informações registradas no atendimento possa melhorar de modo que as mesmas gerem maior credibilidade, pois ao que parece nos DSC, atualmente, não existe de maneira plena.

SERAFIM (2002) utilizando-se de informações em prontuário de crianças que foram a óbito no período neonatal apontou para contradições existentes nos registros, em alguns casos ora a equipe descrevia as crianças como natimortas, ora como nascidas vivas que vieram a falecer logo após o nascimento. A autora registra a demonstração de falta de preparo para a assistência neonatal por parte de alguns profissionais, fato que pode distorcer estatísticas de saúde, bem como as condutas de atendimento.

Vários autores, dentre eles citam-se ALMEIDA et al. (2006) e PEDROSA et al. (2005, p. 416), reforçam a necessidade de capacitação dos profissionais para a melhoria dos sistemas de informação, pois parecem que no cotidiano do trabalho os "profissionais de saúde desconhecem ou subestimam sua capacidade de gerar 
informações que permitam conhecer e analisar a realidade local". Além disso, enfatizam também a necessidade de melhor divulgação das informações para que possam ser mais utilizadas e se aprimore sua qualidade (ALMEIDA et al., 2006)

A EVITABILIDADE do óbito deve ser a variável mais utilizada para os processos de incentivo epidemiológico à investigação, assim como para o delineamento e implementação de ações preventivas, pois traduzem a possibilidade de se manter vidas mediante adequação de situações e falhas detectadas. Somente se chega à conclusão de que um óbito poderia ter sido evitado ou não, diante do complexo processo de investigação.

Neste trabalho de tese encontrou-se a ocorrência crescente de óbitos considerados evitáveis pela investigação. No $2^{\circ}$ Triênio representaram 43,50\% dos óbitos ocorridos (9.218; dados SIM) e no $3^{\circ}$ Triênio (7.381; dados SIM), 55,37\%, considerando para esta leitura a investigação de parte dos óbitos ocorridos ( $2^{\circ}$ Triênio $-59,03 \%$ e $3^{\circ}$ Triênio $77,21 \%$ ) (Tabela 10 ).

$\mathrm{Na}$ totalidade de óbitos investigados, a representação dos evitáveis é sobremodo elevada, mais de $70 \%$, nos dois períodos. Os óbitos considerados não evitáveis constituíram cerca de $15 \%$ e $20 \%$ nos Triênios (Tabela 10). Para todo o processo de avaliação do óbito são consideradas todas as variáveis preenchidas na Ficha de Investigação (Anexos 1 e 2), está anexada cópia da DN e da DO, resultados de exames, laudo de necropsia se houver, além de cópias de prontuários ambulatoriais e hospitalares. Assim, para a eleição da evitabilidade e das outras variáveis a equipe multiprofissional tem toda a documentação possível em mãos.

Quando se analisam os óbitos considerados não evitáveis no período mais recente, nota-se que seu percentual aumenta na ordem de $35,68 \%$ sobre o $2^{\circ}$ Triênio (Tabela 10). Neste ponto resgata-se a ocorrência de baixo peso ao nascer e a duração da gestação menor do que 27 semanas, que aconteceram para mais de $50 \%$ das crianças que morreram no último Triênio do estudo (Tabela 5).

Mesmo não dispondo de informações no SIMI quanto ao peso ao nascer e duração da gestação para se promover uma discussão, deve-se estar atendo a esta situação. Mesmo considerando as dificuldades colocadas por ALMEIDA (2006) para 
a utilização dessas variáveis, ela pode estar sinalizando por evidências de que a prematuridade tem acometido de maneira fatal as crianças nascidas no estado. Sobretudo, podem denunciar problemas relativos à assistência pré-natal, principalmente, na identificação e acompanhamento dos riscos; do monitoramento adequado do parto (manejo obstétrico), e qualidade da assistência à criança em sala de parto; bem como de regionalização da assistência secundária e terciária.

Entre as pesquisas sobre evitabilidade do óbito infantil, comenta-se a de VIDAL et al. (2003) em estudo dos óbitos infantis evitáveis em hospital de referência estadual do Nordeste, segundo critério de evitabilidade dos óbitos proposto pela Fundação SEADE, concluíram que apenas $24 \%$ teriam sido não evitáveis, explicando que o hospital é referência para as malformações congênitas.

LANSKY et al. (2002b), utilizando enfoque de evitabilidade de Wigglesworth modificado para pesquisa em Belo Horizonte, em 1999, observaram que cerca de $40 \%$ dos óbitos perinatais e $60 \%$ dos neonatais poderiam ter sido evitados. Essa evitabilidade ocorreria se houvesse melhor organização da rede assistencial, qualificação dos serviços de referência, e adequação dos serviços clínicos às mães e crianças.

Em estudo de mortes perinatais LEITE et al. (1997), em Fortaleza, em 1995, fundamentados na classificação de Wigglesworth modificada e assumindo certo grau de arbritariedade na definição da morte infantil evitável, apresentam: $34,6 \%$ dos óbitos como redutíveis diante da assistência pré-natal e manejo obstétrico e 32,5\% pela assistência em sala de parto e berçário, totalizando $67,3 \%$ dos óbitos como evitáveis, ou redutíveis. Sinalizam também para a imaturidade (crianças com peso menor ou igual a $1.500 \mathrm{gr}$ ) em $28,4 \%$ dos casos, crianças inclusas na análise da redutibilidade.

Em pesquisa da mortalidade ocorrida em todas as idades por causas evitáveis na Europa, no do período de 1980 a 1997, TREURNIET et al. (2004), mostram que a diferença da tendência (decrescente em todo o período) entre as mortes evitáveis e não evitáveis foi pequena, assinalando $-2,4 \%$ e $-1,5 \%$ respectivamente para $1980 \mathrm{e}$ 1997. Em países considerados em desenvolvimento, o mesmo estudo confirmou que a MI evitável, embora em declínio, ainda se encontrava em patamares muito elevados e distantes da não evitável. 
Também HARTZ et al. (1996) em suas considerações, relacionam a necessidade de se conhecer o perfil de causalidade do óbito infantil para evitar a subestimação da proporção de ocorrências preveníveis.

A categorização do óbito infantil como evitável, pelas equipes de análise do óbito infantil, supõe recursos políticos, tecnológicos e científicos, ou seja, recursos de todas as áreas do conhecimento que existam na atualidade para o atendimento à criança, de acordo com o critério adotado pelo Comitê Estadual do Paraná (PR/SESA, 2006).

Esses parâmetros foram adotados pelo CEPMI, segundo conceito da Associação Médica Americana (PR/SESA, 1997; MANSANO et al., 2004). E a equipe de análise emite esse juízo com base nessas condições, digamos "ideais" de organização social, de estrutura e acesso ao serviço e de avanço tecnológico. Concluir pela evitabilidade ou não, frente a esses critérios, não deixa os integrantes da equipe de análise à vontade, pois estes conhecem a realidade de seus serviços, da comunidade da qual emergem os óbitos infantis e sabem que, para muitas realidades, as condições ideais são inimagináveis.

Neste sentido, VIDAL et al. (2003, p.286) discutem a eleição dos critérios de evitabilidade com base nos avanços técnicos disponíveis para toda a população em nivel mundial. Apontam críticas em relação à desconsideração do estágio de desenvolvimento dos municípios e da oferta de serviços de saúde loco-regionais. No entanto, a contra-argumentação é feita com base na importância "da construção de imagem objetiva a ser vislumbrada a partir da viabilidade de um sistema nacional de saúde, com acesso e qualidade da atenção adequada".

Uma reflexão pode ser realizada neste sentido, pois ao desconsiderar as condições locorregionais pode-se incorrer no viés de aumento dos óbitos avaliados como evitáveis. Esta situação pode gerar uma ilusão de resolutividade, pois as condições inadequadas, se não forem apontadas, expostas e minimizadas o contexto dos problemas será mantido. Nesse sentido há que se discutir o padrão de qualidade adotado para que permita a possibilidade de mudanças efetivas.

No MCPOIF (BRASIL, 2004b), a orientação é que cada Comitê construa seus critérios de evitabilidade para serem utilizados na análise de cada óbito, de acordo com a sua realidade loco-regional. A sugestão feita é para definir claramente os 
problemas / falhas ocorridas nos diversos níveis de assistência à saúde e das dificuldades sócio-familiares, pois isto pode colaborar muito para a definição da área de evitabilidade e na proposição de ações que bloqueiem novos eventos. Ao final do instrumento sugerido pelo MCPOIF, no fechamento da análise é feita uma pergunta para a equipe de análise: A equipe avalia que este óbito poderia ter sido evitado? Por que? Assim não existe um campo específico para se afirmar, categoricamente, se aquele óbito foi evitável ou não. Além disso, existe um campo aberto para o registro das situações que definam ou não pela evitabilidade do evento em análise.

Para a construção dos critérios de evitabilidade, o MCPOIF sugere como apoio: a) as classificações da Fundação Sistema Estadual de Análise dos Dados de São Paulo / SEADE, que não considera o peso ao nascer; b) a classificação de Wigglesworth que se restringe apenas aos óbitos perinatais, não contemplam os pósneonatais (BRASIL, 2004b).

MALTA e DUARTE (2007, p. 3) relatam que:

\begin{abstract}
Os usos dos indicadores de mortes evitáveis na literatura incluem: análises de séries temporais; construção de atlas de mortalidade por causas evitáveis segundo niveis de atenção; comparação de ocorrência de causas evitáveis segundo faixa etária, sexo, extratos socioeconômicos; $e$ análise do impacto dos diferentes níveis de prevenção na sua redução, entre paises e grupos étnicos.
\end{abstract}

Em publicação atual MALTA et al. (2007, p. 10), após revisão bibliográfica, propõem duas listas de mortes evitáveis adequadas para a realidade brasileira, com 0 cuidado de preservar certo grau de comparabilidade internacional, dentre outros aspectos. Um aspecto que serviu de diretriz na construção das listas foi "incluir óbitos evitáveis a luz de tecnologia disponível no Sistema Único de Saúde”. Uma das listas é para crianças menores de 5 anos e a outra para a faixa de 5 a 75 anos.

Os autores MALTA et al. (2007) observam que na construção dos instrumentos classificatórios de evitabilidade de morte deve-se ter em mente que quanto maior a inclusão de causas, menor será a "especificidade e seu poder descriminatório", assim os indicadores discriminados serão menos sensíveis às intervenções em saúde. Enfatizam que a lista de Tobias e Jackson (2001) trabalhada por (MALTA e DUARTE, 2007) discrimina indicadores para os três níveis de prevenção (primária, secundária e terciária) e trabalha com um número reduzido de 
causas, assim conseguem-se mais evidências de sua evitabilidade (MALTA et al., 2007).

Se a opção por evitabilidade inconclusiva estiver ligada fortemente à não disponibilidade de informações adequadas para a análise, pode-se dizer que a qualidade das informações melhorou muito entre os dois Triênios de análise, com diminuição em cerca de $30 \%$ sobre os óbitos inconclusivos do $2^{\circ}$ Triênio (Tabela 10 ). No ${ }^{\circ}$ Triênio a evitabilidade inconclusiva respondeu por menos de $10 \%$ dos óbitos investigados. Corroborando com este progresso também se pode pensar na experiência de análise das equipes multiprofissionais dos Comitês que aumenta a cada ano, mesmo contando com a grande rotatividade de profissionais (como aponta o DSC) e, por conseguinte, suas análises ficam mais precisas.

Tabela 10: Caracterização do óbito infantil investigado (freqüência e \%) nos Triênios segundo evitabilidade e determinantes causais* pelo óbito, estado do Paraná, 2000 a 2005.

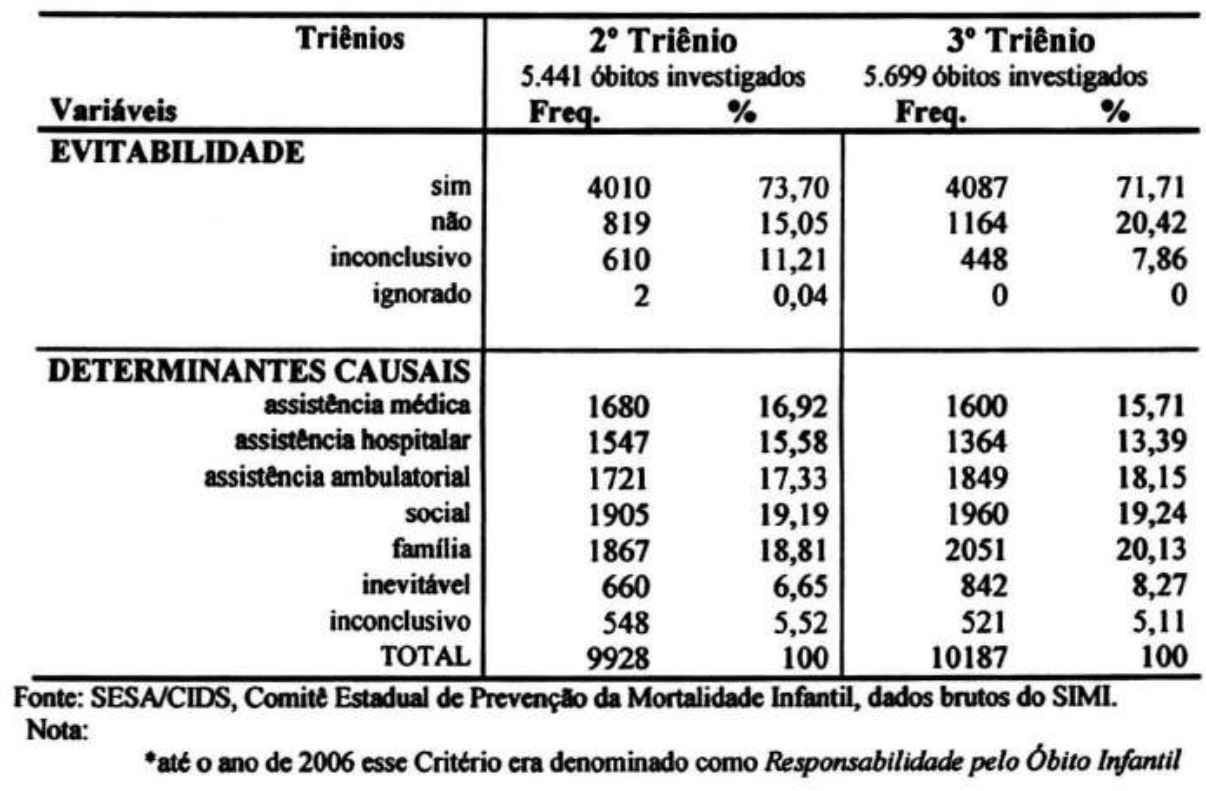

Os CRITÉrios de DETERminantes CAUSAIS do ÓBITo sempre suscitam muita discussão na equipe de análise nos CPMI, pois dentre eles estão apontados os fatores médico-assistenciais, os ligados à família e à sociedade local. Ressalta-se que, para cada óbito infantil investigado e analisado, é atribuído mais de um determinante causal. 
Como orientação na eleição dos determinantes causais e de critérios de redutibilidade há um alerta reforçado para a importância da constituição de equipe multiprofissional para minimizar vieses mediante a subjetividade, como também para a legitimidade das conclusões elaboradas e para reforço das decisões tomadas. A possibilidade de troca de conhecimento e de diferentes visões das situações pode ajudar muito na redução da subjetividade analítica (PR/SESA, 2006). Diante destas considerações que nem sempre são concretizadas, principalmente quanto a multiprofissionalidade, existe a proposição, pelo Estado (PR/SESA, 2006) de situações que definem pela eleição dos determinantes causais, são estas:

\begin{abstract}
ASSISTÊNCIA MÉDICA:
Quando ocorre erro por não obediência às normas assistenciais, falta de conhecimento cientifico do médico que presta assistência (incompetência do clínico geral, obstetra, pediatra) desleixo do profissional de qualquer natureza, prescrição incorreta de medicamentos. São chamados erros grosseiros.
\end{abstract}

ASSISTENCCIA AMBULATORIAL E HOSPITALAR:

São também chamados erros administrativos, quando as condições hospitalares e ambulatoriais são insuficientes ou inadequadas.

FAMILIA:

Quando os membros recebem informações e não atendem às necessidades indicadas ou por negligência e omissão não realizam os procedimentos prescritos.

SOCIAL:

É a responsabilidade coletiva de toda a comunidade ou nação, envolvendo as condições sociais, econômicas e politicas. Incluem-se os casos decorrentes da miséria, do analfabetismo, da falta de informação, da desnutrição, das epidemias etc.

Estes critérios, de acordo com os documentos consultados, foram extraídos da Associação Médica Americana (AMA). No entanto, ao elegê-los a equipe de análise, de maneira geral, tem a percepção de generalização das causas e de pouca especificidade quanto aos problemas loco-regionais. Isto dificulta a deteç̧ão exata das 'situações problemas', tendo em vista a diversidade de problemas sociais e de assistência à saúde.

Quanto aos determinantes sociais alerta-se para o caráter intrinsecamente dinâmico ao longo do tempo e das relações sociais entre a relação da evolução secular da MI com a qualidade de vida, em função da relação direta dos fatores que 
contribuem para redução ou elevação da mortalidade, segundo MONTEIRO (1982). Nessa relação, cada fator causal ou determinante assume peso relativo com a "determinação mais geral da qualidade de vida"; o autor alerta para o perigo de se estabelecer relação linear de natureza inversa entre a qualidade de vida e mortalidade infantil (MONTEIRO, 1982, p.8).

MONTEIRO (1982) em estudo do significado da evolução do CMI, no município de São Paulo, de 1950 a 1979, considera a determinação de fatores mais amplamente abrangentes para a qualidade de vida como a renda da população e a educação e como fatores de menor abrangência a assistência hospitalar $e o$ abastecimento de água. MONTEIRO $(1982, \mathrm{p} .8)$ alerta também para necessidade também de se "levar em conta o comportamento do fatores com ligação pouco objetiva à qualidade de vida, como os padrões de fertilidade e os movimentos migratórios".

Encontrou-se neste estudo que 49,83\% (4.948) e 47,25\% (4.813) dos determinantes causais eleitos para os óbitos investigados no $2^{\circ}$ e $3^{\circ}$ Triênio respectivamente, mais de $45 \%$, apresentaram como responsáveis uma área da assistência à saúde (Tabela 10). Esse fato é paradoxal ao objetivo maior da assistência à saúde, quer seja ambulatorial ou hospitalar, que é a preservação da vida com qualidade.

Nesta análise, constantemente é traçado vínculo importante com o profissional médico, pois ele é o responsável pela prescrição do tratamento e eleição da conduta implementada e avaliação da resposta à terapêutica implementada. Assim, entre o elevado percentual de consideração causal dos óbitos, quase $50 \%$, dirigido à assistência à saúde, detecta-se de maneira homogênea nos dois Triênios, cerca de $33 \%$ o foram por responsabilidade médica $\left(33,95 \%\right.$ no $2^{\circ}$ Triênio e, $33,24 \%$ no $3^{\circ}$ ). Em relação às outras áreas, ambulatorial e hospitalar observou-se que o a assistência hospitalar foi apontada como responsável em 31,27\% nas análises dos óbitos, no $2^{\circ}$ Triênio, com redução da responsabilidade para $28,34 \%$ no $3^{\circ}$ Triênio. Já a assistência ambulatorial foi mais responsabilizada no $3^{\circ}$ Triênio, em $38,41 \%$ das análises, do que no $2^{\circ}$, com $34,78 \%$ (Tabela 10 ).

A estreita e complexa relação entre as instâncias de assistência à saúde (médica, hospitalar e ambulatorial) dificulta uma análise mais precisa. Contudo, de 
maneira geral, se percebe pequena variação nos indicadores de determinantes causais, com melhoria da assistência hospitalar e da assistência ambulatorial, bem como e manutenção da mesma qualidade da assistência médica. Resultado este que pode ser considerado como sinalizador de necessidade de estudos mais aprofundados neste sentido, pois sem recursos humanos, materiais e tecnológicos adequados não se consegue uma qualidade desejável da assistência. Outro fator importante a ser considerado é a integração das instâncias de assistência à saúde. Esta deve serrealizada utilizando-se de sistemas de referência e contra-referência elaborados de acordo com as possibilidades locais, no entanto que seja eficaz e claro para o usuário e equipe de saúde.

A gestão dos serviços de saúde quer sejam públicos ou privados, não é colocada como opção de escolha nos determinantes causais. As necessidades de adequações dos recursos e de organização da rede de assistência não podem recair sobre os profissionais e instituições, há que se aprofundar nesta discussão.

Também não estão incluídos no instrumento utilizado determinantes causais relativos à assistência primária, ao acesso a esses serviços, ao acompanhamento domiciliar que deve ser realizado pelo Programa Saúde da Família (PSF) e/ou de Agentes Comunitários da Saúde (PACS). Estas instâncias aparecem nas recomendações de medidas de prevenção e intervenção e, muito enfaticamente nos discursos. Essas situações devem ser revistas pela equipe gestora estadual para adequação do instrumento.

A prevenção da mortalidade infantil tem grande parte do seu impacto na dimensão programática (Vulnerabilidade Programática), considerando que o programa faz a ligação entre o plano individual e coletivo, e pode ser aglutinador de informações, recursos materiais, suportes de diferentes ordens e um catalisador das necessidades e contradições socialmente postas, ou seja, é um caminho para o “empowerment" (AYRES et al., 2003).

A avaliação constante das propostas, estratégias e ações, pode lograr subsídios para melhoria do trabalho executado, apontando experiências exitosas ou não, dentre outros aspectos. Para esse caminho AYRES et al., (2003) afirmam que é preciso (des)construir noções tradicionais de prevenção e redução do risco, para construir estratégias que potencializem uma resposta social interligada a redes 
sociais, para tanto é preciso compreender os substratos dos discursos renovadores e agregar esforços para a discussão conceitual e filosófica das práticas de saúde.

No estudo de percepção materna da doença e do atendimento à criança doente de HADAD et al. (2002), as mães avaliaram o atendimento recebido nos serviços de saúde. As mães relataram que em $43 \%$ das situações, os problemas foram relacionados a estrutura e ao profissional do serviço de saúde; as mães relacionaram a morte da criança com falha do serviço de saúde em $46 \%$ dos casos.

No presente estudo, os determinantes causais apontados como relativos ao contexto social e à família são bastante significativos representando juntos $38 \% \mathrm{e}$ $39,37 \%$ dos determinantes para a ocorrência do óbito, nos $2^{\circ}$ e $3^{\circ}$ Triênios da pesquisa (com peso semelhante para ambas às situações) (Tabela 10).

Baseados nas orientações que fundamentam a eleição dos determinantes causais, após minuciosa análise da informações colhidas, as familias são apontadas como não aderentes às orientações, ou seja, negligentes; o social traduz a responsabilidade coletiva (comunidade + nação) sobre a determinação das condições sociais, economias e políticas (PR/SESA, 2006). Esta leitura deve ser realizada com muita cautela, com discernimento e diante de uma discussão mais aprofundada dos aspectos políticos e sócio-econômico-culturais, pois a forte tendência dos profissionais de saúde é a de culpabilizar as famílias e o 'meio' pelos problemas existentes, num movimento quase de isolamento deste 'meio social', desta cultura, desta responsabilidade como cidadão e profissional.

Em pesquisa dos condicionantes sócio-econômicos da MI no Paraná, no período de 1980 a 2001 (DEVIDÉ, 2001), utilizando-se de estudo econométrico verificou a importância da renda e das despesas sociais do governo paranaense nas categorias saúde e saneamento e educação e cultura, na redução da MI. Isto demonstrou a relevância da ação governamental no processo, simultaneamente ao desenvolvimento econômico do estado. Enfatizou que melhores condições de renda sem adequado saneamento básico, não leva à redução da MI. Alertou, também, para ação do estado sobre os segmentos mais carentes da sociedade, com o objetivo de garantir acesso a melhores serviços de saúde e infra-estrutura básica.

Outro estudo de evolução da MI em municípios rurais do Paraná, em 1980, 1991 e 1996 (CARVALHO e CARVALHO, 2002) aponta para a queda da MI. 
Indica também e que os CMI nas áreas urbanas e rurais diminuíram. Atribuiu-se o fato à expansão dos serviços de saúde, e à redução da população em municípios rurais; foram consideradas as limitações de informações para o estudo como o subregistro de óbitos e a inexistência de dados por área urbana e rural nas DOs.

Há necessidade de considerarmos a qualidade de vida no desenvolvimento de programas de saúde e no planejamento de serviços e, de levar-se em conta a qualidade de vida das populações. Neste aspecto torna-se imprescindivel identificar os fatores sociais, econômicos e ambientais que intervêm positiva ou negativamente na qualidade de vida dessas populações e que influenciam a tradução de lógicas culturais em comportamentos concretos, em face dos diversos eventos da vida e, mais particularmente, ante a saúde e a doença (HADAD et al., 2002).

Nessa perspectiva, é importante utilizar uma nova maneira de interpretar as necessidades e ações de saúde, não mais na perspectiva unicamente biológica individual, linear e uni-causal, mas numa perspectiva contextual, histórica e coletiva, elegendo metas para ação política em saúde direcionada ao coletivo (SÍCOLI e NASCIMENTO, 2003; GOLDBAUM, 1997).

Para discutir com maior assertividade as questões de desigualdades sociais e qualidade de vida, devem ser elaborados, divulgados e explorados diagnósticos geográficos, econômicos e ambientais que permitam identificar as variáveis, os fatores de riscos, locorregionais que estão determinando a manutenção da MI evitável em proporções elevadas (GOLDANI et al., 2001; DRUMOND JR e BARROS, 1999; ISSLER et al., 1996; VON RUEDEN et al., 2006; HOUWELING et al., 2006; FARLEY e LEYLAND, 2006; ALMEIDA e BARROS, 2004).

Nesta análise de determinante causal do óbito infantil, a conclusão de que o óbito realmente era inevitável aconteceu em $6,65 \%$ e $8,27 \%$, respectivamente para os dois Triênios. Essa proporção é reduzida se comparada à variável não evitável de $15,05 \%$ e 20,42\%, nos dois Triênios (Tabela 10). A equipe de análise, por meio das informações que tinha em mãos, pode ter detectado situações inadequadas que foram determinantes para o evento, 'reduzindo' o peso que se tinha dado, a priori, na eleição categórica do óbito como não evitável.

Diante dessas considerações é possível perceber que a eleição de um óbito como evitável e a determinação de seus determinantes causais exige da equipe de 
análise uma tomada de decisão e, em contra-partida, gera expectativas em relação ao encaminhamento das situações apontadas pelas pessoas responsáveis.

Quanto ao traçado das MEDIDAS DE PREVENÇÃo, atualmente essas medidas também são válidas e sugeridas para a INTERVENÇão NA MORTALIDADE INFANTIL, se deve esclarecer que, para cada óbito investigado, são eleitas mais de uma medida de prevenção e intervenção. Assim, observou-se o total de 15.618 medidas, no $1^{\circ}$ Triênio e 15.045, no $2^{\circ}$ Triênio. Considerando que foram investigados nos Triênios 5441 e 5699 óbitos, conclui-se que foram traçadas nas análises menos de 03 medidas por óbito (Tabelas 7 e 11).

Tabela 11: Caracterização do óbito infantil investigado (freqüência e \%) nos Triênios segundo as medidas de prevenção e intervenção na mortalidade infantil, estado do Paraná, 2000 a 2005.

\begin{tabular}{l|rrrrr}
\hline \multirow{2}{*}{ Medidas Gerais } & Período & \multicolumn{2}{c}{$2^{\circ}$ triênio } & \multicolumn{2}{c}{$3^{\circ}$ triênio } \\
& \multicolumn{1}{c}{ Freq } & $\%$ & \multicolumn{1}{c}{ Freq } & $\%$ \\
\hline Medidas de atenção ambulatorial & 4913 & 31,46 & 5012 & 33,31 \\
Medidas de atenção hospitalar & 3785 & 24,23 & 4186 & 27,82 \\
Medidas de suporte social & 4038 & 25,86 & 3662 & 24,34 \\
Medidas de educação em saúde & 2882 & 18,45 & 2185 & 14,53 \\
\hline Total & 15618 & 100,00 & 15045 & 100,00 \\
\hline Fonte: SESA/CIDS, Comite Estadual de Prevençăo da Mortalidade Infantil, dados brutos do SIMI.
\end{tabular}

As medidas ambulatoriais foram as mais freqüentes nos dois Triênios (31,46\% e $33,31 \%)$, seguidas por medidas hospitalares $(24,23 \%$ e $27,82 \%)$ e sociais $(25,86 \%$ e $24,34 \%)$, que assumiram significância semelhante nos dois Triênios. As medidas voltadas para a educação em saúde (18,45\% e 14,53\%) ficaram em último lugar no quadro de recomendações para prevenção e intervenção na mortalidade infantil.

Em relação às medidas ambulatoriais destacaram-se, com maior visibilidade, as medidas de atenção primária em saúde como o acesso ao pré-natal (7,35\% e $8,08 \%$ ), a qualidade do pré-natal (24,53\% e 26,30\%), e a vigilância ao risco gestacional (21,96\% e 19,73\%). Ou seja, no período de $2000 / 02$ ( $2^{\circ}$ Triênio) as questões relativas ao pré-natal (realizado em Unidades Básicas, ambulatórios ou em clínicas privadas ou não) estiveram relacionadas a $53,84 \%$ das recomendações à 
prevenção e intervenção do óbito infantil; em 2003/05 ( $3^{\circ}$ Triênio) relacionadas a $54,11 \%$ das recomendações. Estes dados mostraram piora em relação ao pré-natal no período de estudo, não condizente com a política dirigida ao pré-natal no estado (Tabela 11).

Entretanto, completando a atenção à gestante, soma-se $o$ acesso a tratamento adequado em serviços especializados em gestação de alto risco foram medidas recomendadas para $14,41 \%$ dos óbitos no $1^{\circ}$ Triênio e para $14,39 \%$ no $2^{\circ}$ Triênio, informações que mostram ainda pouca resolutividade na regionalização da atenção secundária e terciária (Tabela 12). Portanto, pode-se dizer diante destas evidências que, entre as medidas ambulatoriais e para intervenção eleitas nas análises de parte dos óbitos infantis ocorridos no estado do Paraná, no intervalo de 2000 a 2005, a assistência integral à gestante mostrou-se mais carente de providências e ações, tendo como impacto a proporção de mais de $68 \%$ das medidas. Segundo VICTORA (2001, p. 20), "uma melhoria na atenção pré-natal é medida prioritária para a redução da mortalidade de menores de cinco anos no Brasil".

A busca ativa à criança de risco, bem como, o acesso da criança a tratamento adequado das complicações em nível ambulatorial (Tabela 12) constituem-se em recomendações fundamentais para se prevenir o óbito infantil. Suas incidências nas recomendações, em $24,06 \%$ e $26,70 \%$, suscitam reflexão acerca da qualidade assistencial promovida pelo Programa Saúde da Família na rede básica de saúde, no quesito vigilância ao risco. Em relação às complicações pensa-se na necessidade da presença do pediatra para a qualidade adequada do atendimento pediátrico (público ou privado) em ambulatório e serviços de pronto-socorro. Situação que emerge com bastante realidade e ênfase nos discursos dos profissionais que realizam este atendimento. 
Tabela 12: Caracterização do óbito infantil investigado (freqüência e \%) nos Triênios segundo medidas de atenção ambulatorial, estado do Paraná, 2000 a 2005.

\begin{tabular}{l|r|rrr}
\hline \multicolumn{1}{c}{ Período } & \multicolumn{2}{c}{$\mathbf{2}^{\circ}$ triênio } & \multicolumn{2}{c}{$3^{\circ}$ triênio } \\
Especificação da Medida & \multicolumn{1}{c}{ Freq } & \multicolumn{1}{c}{ Freq } & $\%$ \\
\hline $\begin{array}{l}\text { Acesso a tratamento adequado em serviços } \\
\text { especializados em gestação de alto risco }\end{array}$ & 708 & 14,41 & 721 & 14,39 \\
$\begin{array}{l}\text { Acesso ao tratamento adequado das complicaçōes a } \\
\text { nível ambulatorial }\end{array}$ & 683 & 13,90 & 673 & 13,43 \\
Busca ativa à criança de risco (vigilância e visita & & & & \\
domiciliar) & 499 & 10,16 & 665 & 13,27 \\
Garantir acesso da gestante ao pré-natal & 361 & 7,35 & 405 & 8,08 \\
Qualidade no pré-natal & 1.205 & 24,53 & 1.318 & 26,30 \\
Realizar vigilância do risco gestacional & 1.079 & 21,96 & 989 & 19,73 \\
Outras & 378 & 7,69 & 241 & 4,81 \\
\hline Total & 4.913 & 100,00 & 5.012 & 100,00 \\
\hline Fonte: & & & &
\end{tabular}

Fonte: SESA/CIDS, Comitê Estadual de Prevenção da Mortalidade Infantil, dados brutos do SIMI.

As infecções respiratórias agudas e diarréias são, segundo VICTORA (2001), potencialmente evitáveis e dependem do manejo adequado dos casos através de antibióticos e terapia de reidratação oral (TRO). Para tanto, a ligação com o serviço básico de saúde de qualidade é essencial, pois o reconhecimento do risco em tempo oportuno evita agravamento do quadro e propicia a sobrevida de crianças menores de cinco anos.

Nesse sentido trabalhando-se com incentivo e apoio à alimentação adequada para o crescimento e desenvolvimento das crianças, com destaque ao aleitamento materno como essencial para a defesa quanto aos problemas infecciosos em menores de um ano e, com o esquema correto de imunização, será reduzida a incidência desses problemas infecciosos, bem como a morbi-mortalidade em menores de um ano (ESCUDER et al., 2003; VICTORA, 2001).

O período estudado foi de expansão e aprimoramento do Programa de Humanização do Pré-natal e Nascimento (PHPN), que integra a Rede de Proteção à Vida no estado do Paraná. Desde 2001 todos os municípios do Estado estão com o Programa implantado. Alguns indicadores de melhoria do sistema de atendimento à mulher e ao neonato podem ser conseqüentes a este processo de intervenção (PR/SESA, 2007b).

O PHPN foi instituído pelo Ministério da Saúde em 01 de junho de 2000 (Portaria / GM n 569), ano que coincide com o início dos registros do SIMI. Este 
programa instituiu a obrigação de serviços do SUS contemplarem ações à mulher em atenção básica, apoio laboratorial, atenção ambulatorial especializada e assistência obstétrica e neonatal. Também estabeleceu que sejam definidas as referências para assistência em unidades de pré-natal de alto risco e ao parto de baixo e alto risco. $\mathrm{O}$ repasse financeiro é realizado mediante cadastro no SisPreNatal e a cada fase completada e registrada no sistema o município recebe um incentivo extra-teto. No entanto, o PHPN determina que cada município deverá ser responsável pela coordenação e execução da programação física e financeira da assistência obstétrica e neonatal. Para tanto, deve alocar recursos próprios complementares (PR/SESA, 2007b). Assim, as evidências originadas da investigação do óbito infantil são úteis para subsidiar os gestores municipais e estaduais para as providências cabíveis na assistência à gestante.

Nas medidas de atenção hospitalar a especificação mais ligada à qualidade médica foi a recordista de recomendações, o melhor diagnóstico hospitalar, pode-se dizer, médico, foi sugerido em $28,14 \%$ e $25,66 \%$ das situações em que ocorreram os óbitos nos Triênios. A seguir, nos dois Triênios apareceu o acesso a tratamento adequado à mãe e criança (23,36\% e 24,51\%). Em terceiro lugar, se destaca $a$ referência para serviços de assistência secundária e terciária, ou seja, o atendimento em serviços especializados e em UTI pediátricas - Unidades de Terapia Intensiva Neonatal e/ou Infantil (18,34\% e 19, 54\%) (Tabela 13).

Outras medidas hospitalares como medicação e internamento aparecem para os dois períodos em menos de $10 \%$ dos óbitos (Tabela 13). Pode-se comentar que não há falta de leitos para internação clínica nem cirúrgica no estado, mas há falta de leitos em serviços especiais ou UTI.

Novamente, agora em relação aos Hospitais, se faz presente a assistência adequada ao parto, respondendo por $15,61 \%$ e $17,06 \%$ das recomendações, respectivamente para o $2^{\circ}$ e $3^{\circ}$ Triênios. 
Tabela 13: Caracterização do óbito infantil investigado (freqüência e \%) nos Triênios segundo medidas de atenção hospitalar, estado do Paraná, 2000 a 2005.

\begin{tabular}{|c|c|c|c|c|c|}
\hline \multirow[b]{2}{*}{ Especificação da Medida } & \multirow[t]{2}{*}{ Período } & \multicolumn{2}{|c|}{$2^{\circ}$ triênio } & \multicolumn{2}{|c|}{$3^{\circ}$ triênio } \\
\hline & & Freq & $\%$ & Freq & $\%$ \\
\hline Acesso a medicação & & 105 & 2,77 & 173 & 4,13 \\
\hline Acesso à referência secundária e ou terciária & & 694 & 18,34 & 818 & 19,54 \\
\hline Acesso a tratamento adequado à mãe e criança & & 884 & 23,36 & 1.026 & 24,51 \\
\hline Assistência adequada ao parto & & 591 & 15,61 & 714 & 17,06 \\
\hline Garantir acesso a internamento hospitalar & & 228 & 6,02 & 213 & 5,09 \\
\hline Melhor diagnóstico a nível hospitalar & & 1.065 & 28,14 & 1.074 & 25,66 \\
\hline Outras & & 218 & 5,76 & 168 & 4,01 \\
\hline Total & & 3.785 & 100,00 & 4.186 & 100,00 \\
\hline
\end{tabular}

Quando se visualiza as recomendações das medidas de prevenção e intervenção que são dirigidas à mãe, à gestante, tem-se para o $2^{\circ}$ e $3^{\circ}$ Triênios, respectivamente um impacto de $30,91 \%$ e $34,38 \%$ sobre todas as medidas de prevenção e intervenção do óbito infantil. A qualidade no pré-natal é a mais freqüente recomendação, responsável por $24,96 \%$ e $25,48 \%$ nos Triênios. Com exceção das medidas relativas a vigilância ao risco e acesso ao tratamento adequado para gestação de alto risco, as demais medidas relativas à gestação e parto foram crescentes no período (Tabela 14).

Com estas evidências pode-se dizer que a assistência materna tem se constituído um forte e importante sinalizador da necessidade de providências pelos gestores de saúde no Estado. O formato da assistência pré-natal, desde seu acesso, identificação dos riscos gestacionais, qualidade, tratamento adequado a complicações até a assistência ao parto mostrou-se deficitário e, não atendendo às necessidades regionais, à medida que foram marcadamente destacados nas medidas preventivas $\mathrm{e}$ de intervenção. Para que se avance em termos de vigilância e propostas, bem como na qualidade há que se rever desde a regionalização e hierarquização do atendimento à gestante, até o provimento de profissionais especializados para a melhoria desta qualidade. Há que se utilizar protocolos de atendimento para se ter uma melhoria do fluxo e da assistência, principalmente, e que responda às necessidades prementes de atenção à gestante. 
Tabela 14: Caracterização do óbito infantil investigado (freqüência e \%) nos Triênios segundo as medidas de prevenção direcionadas às gestantes, estado do Paraná, 2000 a 2005.

\begin{tabular}{|c|c|c|c|c|}
\hline \multirow[b]{2}{*}{ Especificação da Medida } & \multicolumn{2}{|c|}{$2^{\circ}$ triênio } & \multicolumn{2}{|c|}{$3^{\circ}$ triênio } \\
\hline & Freg & $\%^{*}$ & Freq & $\%^{*}$ \\
\hline Garantir acesso da gestante ao pré-natal & 361 & $(7,48)$ & 405 & $(7,83)$ \\
\hline Qualidade no pré-natal & 1205 & $(24,96)$ & 1318 & $(25,48)$ \\
\hline $\begin{array}{l}\text { Realizar vigilancia do risco gestacional } \\
\text { Acesso a tratamento adogudo }\end{array}$ & 1079 & $(22,35)$ & 989 & $(19,12)$ \\
\hline especializados em gestação de alto risco & 708 & $(14,67)$ & 721 & $(13,94)$ \\
\hline Assistência adequada ao parto & 591 & $(12,24)$ & 714 & $(13,80)$ \\
\hline Acesso a tratamento adequado à mãe e criança & 884 & $(18,30)$ & 1.026 & $(19,83)$ \\
\hline Total & 4828 & 30,91 & 5173 & 34,38 \\
\hline Total Geral & 15618 & 100,00 & 15045 & 100,00 \\
\hline
\end{tabular}

Investiga-se as oportunidades perdidas nos serviços para um diagnóstico acertado, maior vigilância ao risco materno e infantil e educação em saúde da mãe/responsável, as quais acontecem no trajeto do atendimento de uma criança quando se analisa as informações de seu óbito.

Em várias situações toma-se conhecimento de situações semelhantes que relatam ter sido a criança levada pela mãe / família para atendimento em vários serviços, digamos, 'paliativos'. Em muitos serviços as crianças foram atendidas por médicos que prescreveram, na maioria das vezes, 'placebo' e recomendaram que a mãe levasse seu filho para casa, muitas vezes sem falar para a mãe retornar caso a criança piorasse. Em muitas histórias investigadas, ao final de alguns dias a criança piora, chega em condições gerais irrecuperáveis nos Hospitais e sem chances terapêuticas, vai a óbito, mesmo que na instituição haja leito de UTI para acolhê-la. Situações como estas são "comuns" nas análises. Se nesta não há leito disponível de UTI neonatal ou infantil na instituição na qual a criança venha a falecer, depois de peregrinar por serviços e profissionais ineficazes, a culpa da morte acaba recaindo sobre a falta de leito de UTI e, se dão as manchetes na imprensa escrita e falada. Nesses casos se registra a indignação da equipe que investiga e analisa a ocorrência.

Segundo informações do Cadastro Nacional de Estabelecimentos de Saúde (Tabela 15) o Paraná possui atualmente 616 leitos de unidades de tratamento 
secundário e terciário para crianças, dos quais 49,67\% (306) são de UTI Neonatal; 24,19\% (149) de Unidades Intermediárias de Cuidado Neonatal (UCI) e 18,04\% (161) de UTI Infantil (ou pediátrica) (BRASIL/CNES, 2007).

Tabela 15: Distribuição ( $\mathrm{n}^{\circ}$ e \%) dos leitos de Unidades Intensivas e de Cuidados Intermediários Pediátricos (Neonatal e Infantil), segundo habilitação pelo SUS, estado do Paraná, 2007.

\begin{tabular}{|c|c|c|c|c|c|c|}
\hline \multirow[t]{2}{*}{ TIPO DE UNIDADE } & \multicolumn{2}{|c|}{ Existentes } & \multicolumn{2}{|c|}{ Cadastrados no SUS } & \multicolumn{2}{|c|}{ Não SUS } \\
\hline & $\mathbf{n}^{\circ}$ & $\%$ & $\mathbf{n}^{\circ}$ & & $\mathbf{n}^{\circ}$ & \\
\hline UTI Neonatal & 306 & 49,67 & 213 & 49,19 & 93 & 50,82 \\
\hline UTI Infantil & 161 & 26,14 & 109 & 25,17 & 52 & 28,42 \\
\hline UCI Neonatal & 149 & 24,19 & 111 & 25,64 & 28 & 20,76 \\
\hline Total Leitos Pediátricos & 616 & 100,00 & 433 & 100,00 & 183 & 100,00 \\
\hline
\end{tabular}

Fonte: Ministerio da Saude, Cadastro Nacional de Estabelecimentos de Saúde/CNES, da Secretaria de Atençlio a Saúde/SAS,

Datasus; acesso www.cnes, datasus, gov. br em julho de 2007.

Dentre essas Unidades se tomarmos os leitos de UTI Neonatal vemos que dentre os 306 leitos existentes, 213 (69,61\%) são cadastrados no SUS. Mesmo que as mesmas sejam para atender parte dos problemas que se apresentam em relação à mortalidade infantil, deve-se esperar por uma maior demanda a esses leitos por usuários do SUS, devido suas características gerais de acesso, cuidado e condições de saúde.

Tendo-se como base para os cálculos os parâmetros definidos pela Academia Americana de Pediatria (AAP), segundo relatório da Comissão Perinatal de Belo Horizonte (BRASIL, 2000), são necessários de 01 a 02 leitos de UTI e de 02 a 04 leitos de 'berçário de risco' (aqui entendidos como Unidades de Cuidados Intermediários - UCI) a cada 1000 NV. Detectamos no Paraná uma média de 174.204 NV, entre o ano de 1997 e 2004 (Apêndice 5), o que determinaria uma faixa de número de leitos de UTI Neonatal necessários entre 174 e 348 leitos.

Outra possibilidade de cálculo do número necessário de leitos intensivos é dada pela Portaria $n^{\circ} 1101 / G M$, de 12 de junho de 2002, que estabelece os parâmetros de cobertura assistencial no âmbito do SUS. O cálculo é realizado sobre o número necessário de leitos hospitalares totais para uma dada região. Para tanto, consideram-se necessários 2,5 a 3 leitos para cada 1000 habitantes. Deste total, são calculados de $4 \%$ a $10 \%$ de leitos de unidades intensivas necessários para a região. 0 documento não discrimina o percentual para cada tipo de UTI (adulto, neonatal e 
infantil), apenas instrui que o número de leitos intensivos encontrados deve ser dividido entre adultos, neonatais e pediátricos de acordo com a proporção dos leitos gerais nas especialidades, que prevê a realização de mais cálculos (BRASIL, 2002b) e, certamente a realidade loco-regional. Nesta pesquisa enfatizou-se o parâmetro da AAP.

Se apenas fossem considerados os leitos cadastrados no SUS (213) contaríamos com um número de leitos de UTI Neonatal no Estado, além do mínimo necessário, de acordo com os parâmetros da AAP. No entanto, trabalhando-se com margem de segurança, por considerar a demanda SUS e a freqüência crescente do óbito ocorrendo no período neonatal, seria necessário a implantação de mais 135 leitos, isto equivale dizer que o estado necessita de mais $63,40 \%$ de leitos de UTI Neonatal para garantir a sobrevida dos recém-nascidos que necessitam desta estrutura. Situação que exige consideração e esforço por parte de gestores estaduais e dos serviços, tendo em vista a necessidade de pessoal capacitado e recursos tecnológicos para esse fim. Há que se proceder a estudos pormenorizados que evidenciem essa necessidade de maneira regionalizada e otimizada. Nesse sentido, deve-se ter em mente que a melhoria da assistência preventiva, em nível primário e secundário, tem potencial para reduzir a necessidade de leitos terciários (ROSENBERG e MOSS, 2004; SBP, 2004; BRASIL/BH, 2000).

Em publicação pela AAP (ROSENBERG e MOSS, 2004) contendo diretrizes para a assistência pediátrica, são descritos fatores organizacionais e estruturais para uma adequada assistência intensiva. Ressaltam-se dentre eles: a estrutura física apropriada; a equipe médica e equipe multidisciplinar especializada com capacitações permanentes; disponibilidade de tecnologia e acesso aos procedimentos necessários, inclusive o de transporte e cuidados pré-hospitalares.

São importantes para subsidiar esta discussão os quesitos considerados em documento publicado pela Sociedade Brasileira de Pediatria (SBP, 2004) para a assistência ao recém-nascido, com base na integralidade e humanização da mesma: sala de parto; alojamento conjunto; unidade canguru; unidade de cuidados intermediários neonatais; unidade de cuidados intensivos neonatais; transporte neonatal intra e inter-institucional; ambulatório de acompanhamento de recém- 
nascidos de baixo peso e ambulatório de atenção integral ao desenvolvimento de recém-nascidos de risco.

Neste estudo, portanto, com base em pesquisas e documentos consultados constatam-se evidências da necessidade de adequação imediata da assistência neonatal e à gestante de risco. Considera-se importante maior aprofundamento em discussões que abordem algumas possibilidades de otimização do leito terciário neonatal: a existência de leitos de cuidados intermediários ou semi-intensivos neonatais, em instituições que já tenham ou não UTIs; o estabelecimento de protocolo para atendimento e permanência nos setores Neonatal e Infantil, de acordo com a demanda regional, para que haja ocupação inteligente e adequada dos leitos existentes; consideração da implantação adequada de todas as fases preconizadas pelo Método Canguru. Essas estratégias podem minimizar o déficit de leitos de UTI Neonatal existente no estado.

As medidas de suporte social e as de educação em saúde, como observado na Tabela 16, somam-se para determinar um processo de mudança que ocorre mais lentamente, pois é influenciado pelas condições culturais, políticas e econômicas numa sociedade de desigualdades sociais intensas. Juntas correspondem por $40 \%$ das medidas para os dois Triênios (44,31\% e 38,87\%) (Tabelas 11 e 16).

Entre as especificações das medidas de suporte social encontrou-se a renda familiar; foi recomendada sua melhoria em mais de $30 \%$ das medidas sociais, tendo havido elevação proporcional para o $3^{\circ}$ Triênio $(32,41 \%)$. Outra medida específica diz respeito à escolaridade da mãe. Para esta foi recomendada melhoria em nível de educação formal para $27,86 \%$ das situações no $1^{\circ}$ Triênio, e em $29,85 \%$ para o $2^{\circ}$ Triênio, denotando que a escolaridade se mostra cada vez mais baixa (Tabela 16).

As equipes de análise apontaram para a infra-estrutura básica para uma vida familiar como, por exemplo, a residência adequada e saneamento básico, em mais de $20 \%$ dos óbitos nos triênios, percentual em elevação, também denotando piora nas condições de vida de uma parcela das famílias paranaenses (Tabela 16).

É oportuno notar a colocação de DEMO (1994, p. 29): "falar de dignidade humana, de decência social, de compromisso público é algo estranho, embora no fundo de nossas ações sempre deparemos com tais preocupações". O autor continua 
dizendo que a preocupação com as condições materiais de vida da população não visa apenas aumentar sua renda, mas a noção de qualidade de vida. Nessa discussão "emerge a idéia de direitos da cidadania, uma qualidade tão relevante quanto incomensurável", alerta para a complexidade dessa problemática (DEMO, 1994, p.30).

Tabela 16: Caracterização do óbito infantil investigado (freqüência e \%) nos Triênios segundo medidas de suporte social, estado do Paraná, 2000 a 2005.

\begin{tabular}{|c|c|c|c|c|c|}
\hline \multirow[b]{2}{*}{ Especificação da Medida } & \multirow[t]{2}{*}{ Período } & \multicolumn{2}{|c|}{$2^{\circ}$ triênio } & \multicolumn{2}{|c|}{$3^{\circ}$ triênio } \\
\hline & & Freq. & $\%$ & Freq. & $\%$ \\
\hline $\begin{array}{l}\text { Melhores condiçð̃es de escolaridade } \\
\text { Melhores condiçðes de infra-estrutura básica } \\
\text { (saneamento, habitação, etc.) }\end{array}$ & & 1.125 & $\begin{array}{l}27,86 \\
20,16\end{array}$ & 1.093 & $\begin{array}{l}29,85 \\
22,45\end{array}$ \\
\hline Melhores condiçðes de renda familiar & & 1.215 & 30,09 & 1.187 & 32,41 \\
\hline Outras & & 884 & 21,89 & 560 & 15,29 \\
\hline Total geral & & 4.038 & 100,00 & 3.662 & 100,00 \\
\hline
\end{tabular}

$\mathrm{O}$ acesso à informação em saúde é fundamental na promoção da melhoria do cuidado das mães com seus filhos. As medidas de educação em saúde aos familiares foram apontadas como medidas de prevenção e intervenção em 18,45\% das situações no $1^{\circ}$ Triênio e $14,53 \%$, no $2^{\circ}$ Triênio (Tabela 11). Estas medidas, numa escala de prioridades, não despontaram como as mais importantes mediante a análise realizada pelas equipes multiprofissinais, assim como aparece a assistência à saúde, mediante as informações do SIMI. No entanto, são de extrema importância e impacto para a redução da MI.

Neste estudo, alerta-se para o fato de que as informações em saúde devam se iniciar precocemente, nos bancos escolares e, em qualquer situação de orientação à clientela. As estratégias utilizadas para o trabalho de educação em saúde devem favorecer abordagens diversas a partir do funcionamento fisiológico do organismo humano e suas necessidades; o que é a saúde, a doença; as particularidades de cada faixa etária; o planejamento familiar, a gravidez, o pré-natal / parto; os cuidados de higiene com o bebê, a importância da imunização, dos cuidados com acidentes domésticos, do aleitamento materno, da alimentação da criança; enfim todos os fatores de benefícios e risco que contribuem cotidianamente para a resultante saúde, doença e vida das crianças, em cada fase do seu crescimento e desenvolvimento. Os 
protocolos de puericultura atendem a esta necessidade. Entretanto, diante das histórias investigadas percebe-se que no cotidiano da atenção à saúde surgem dificuldades para o entendimento da informação, da orientação e, conseqüente educação em saúde eficaz. Os discursos contribuem para esta discussão.

A informação que motiva e sensibiliza o reconhecimento do outro como ser ativo em seu processo de cuidar, que admile aulonomia, certamente resulta na adesão da família aos cuidados adequados e necessários a seu filho. Nesta situação, sim, pode-se dizer que na saúde está se trabalhando com o processo de educação. Historicamente importante ao Brasil temos as palavras de Paulo Freire "saber ensinar não é transferir conhecimento, mas criar possibilidades para a sua própria produção ou a sua construção" (FREIRE, 2003, p.47).

Ao nosso ver, a educação em saúde banalizou-se quando se tornou medida medicalizada. Quando-não ocorre a mudança de hábitos e atitudes, tão exigida e aguardada pelos profissionais, atribui-se à negligência, à ignorância do indivíduo atendido. Em poucas ocasiões, se reflete quanto a ocorrência do não entendimento, da incompreensão, da não motivação para o valor da mudança frente à situação de vida e saúde que a família se encontra. Novamente enfatiza-se, nesta pesquisa, a valorização da integração das áreas do conhecimento para melhor leitura das situações expostas em investigações dos óbitos infantis.

Concordando com MONTEIRO (1982, p.17) a “concomitância da implementação de recursos específicos de combate à mortalidade infantil" como no caso desta pesquisa a: educação formal; moradia; saneamento básico; informações em saúde; organização e acesso à rede assistencial; melhor qualidade do atendimento médico, ambulatorial e hospitalar à mãe e criança; acesso à hospitalização; estabelecimento de referências secundárias e terciárias que atendam às necessidades locorregionais, somados a iniciativas governamentais de apoio e promoção da saúde, implementação e manutenção de políticas públicas que privilegiem o acesso universal, a integralidade do ser humano e da assistência, a eqüidade na atenção e a participação social é a situação, mesmo que complexa, que reúne o maior potencial para a redução do óbito infantil.

Este trabalho de pesquisa também privilegia a Representação Social dos vários atores que trabalham com a mortalidade infantil como portadores de 
percepções valiosas para o entendimento do valor da prevenção, da investigação, da implementação de políticas públicas por meio da expressão do que realmente existe nos serviços. Ou seja, da realidade enfrentada por profissionais e gestores das instâncias de saúde regionais e municipais. Estas representações serão apresentadas a seguir. 


\subsection{AS REPRESENTAÇÕES SOCIAIS SOBRE A PREVENÇÃO DA MORTALIDADE INFANTIL e SOBRE OS COMITÊS DE PREVENÇÃO DA MORTALIDADE INFANTIL DO ESTADO DO PARANÁ}

Nesta sessão passaremos a conhecer os sujeitos sociais entrevistados. Trataremos de sobre suas características gerais e de suas respostas quando indagados sobre a prevenção da mortalidade infantil e após serem trabalhadas com o Discurso do Sujeito Coletivo (DSC). O DSC será, portanto, o que pensam os profissionais entrevistados sobre a prevenção da mortalidade infantil em termos de programas, estratégias e ações, em termos das dificuldades que enfrentam e como elaboram as sugestões de estratégias para minimizar ou resolver as dificuldades expressadas. A esse conjunto de idéias individuais que forma um só discurso chamado de Representação Social (RS) sobre a prevenção da Mortalidade Infantil.

\subsubsection{CARACTERIZAÇÃO DOS ATORES SOCIAIS}

Os profissionais entrevistados foram categorizados em 05 grupos de acordo com a inserção profissional. Desta forma, o staff, constituído por diretores de Hospitais e Regionais de Saúde, foram categorizados como DIR. Esse grupo foi representado por 09 profissionais, foi o grupo, de mais difícil acesso e, conseqüentemente, de mais perdas. Houve uma recusa, de um Diretor por alegar que não tinha 'nada a ver com essas questões, colocadas pela entrevista, sendo o mesmo Diretor de um Hospital'.

O grupo de profissionais que trabalha com o Sistema de Informação sobre Mortalidade (SIM) e com o Sistema de Informação de Mortalidade Infantil (SIMI) foi categorizado como INF. Foram realizadas 09 entrevistas com esses profissionais. Foi um grupo no qual, além das questões gerais, foram aplicadas as específicas, respondidas com maior rapidez, mas com pouco aprofundamento. Nas respostas às questões gerais, houve dificuldade e acanhamento por parte dos INF. Permite-se concluir que este grupo de técnicos que alimenta os sistemas computacionais com as 
informações sobre os óbitos ocorridos e investigados, não possui conhecimento, de maneira geral, sobre as ações, estratégias e programas de prevenção da mortalidade infantil.

Já os profissionais responsáveis pela Coordenação dos Setores ou Serviços de Vigilância Epidemiológica nas instâncias Regionais e Municipais, os categorizados como CVE (11 entrevistados), apresentaram respostas mais consistentes, denotando conhecimento teórico-prático e leitura política em relação às instâncias preventivas do óbito infantil, bem como quanto aos programas.

Os responsáveis pelos Comitês Regionais e Municipais e Prevenção da Mortalidade Infantil foram categorizados como CPMI. Foram entrevistados 16 profissionais que expressaram suas dificuldades operacionais e sugestões para minimizá-las com muita propriedade, salvo algumas exceções de profissionais há pouco tempo na coordenação. No entanto, notou-se que alguns mostraram dificuldade no entendimento mais amplo dos Programas e ações de prevenção da mortalidade infantil.

A categoria de entrevistados de maior freqüência foram os profissionais de unidades básicas (urbanas e rurais) e de hospitais, foram os denominados SERV, com total de 35 pessoas. Esses foram médicos e enfermeiros dos serviços, ou seja, o conhecido 'pessoal da ponta' da rede de serviços de assistência à saúde. Só houve uma recusa de um profissional médico de unidade em zona rural.Este não quis esperar pela entrevista, pois primeiro foi entrevistada a enfermeira desta unidade.

Em todas as situações houve perda de pessoas por motivos diversos: falta no dia em que a pesquisadora estava no serviço; turno de trabalho diferente; reunião não programada. Houve um desdobramento possível da entrevistadora na adequação do período e dia da entrevista, desde que respeitasse o tempo de permanência no município, que foi de 03 dias no máximo em cada um deles.

Com 05 dos entrevistados (6,25\% do total) aconteceu de haver duas funções sobrepostas. Nesta situação, o entrevistado era registrado em uma delas, ganhava seu 'nome' e número para o software em uma das atividades. No entanto, a outra também era registrada, o Programa contabiliza o discurso deste sujeito para as duas categorias. As funções sobrepostas ou acumuladas, aconteceram para coordenador de 
Vigilância Epidemiológica e do Comitê (1 indivíduo) e técnico do SIMI e responsável pelos Comitês (4 indivíduos).

Tabela 17: Distribuição dos entrevistados (freqüência e \%) de acordo com as categorização e identificação no Qualiquantisoft ${ }^{\circledR}$, Paraná, 2007.

\begin{tabular}{l|crc}
\hline Categorização entrevistados & Identificação QQ & Freq. & $\%$ \\
\hline DIR - diretores & DIR 1 a DIR 9 & 9 & 11,25 \\
INF - informática & INF 1 a INF 9 & 9 & 11,25 \\
CVE - vigilância epidemiológica & CVE 1 a CVE 11 & 11 & 13,75 \\
CPMI - ligados aos Comitês & CPMI 1 a CPMI 16 & 16 & 20,00 \\
SERV - profissionais dos serviços & SERV 1 a SERV 35 & 35 & 43,75 \\
\hline TODOS & & 80 & 100,00 \\
\hline
\end{tabular}

Fonte: Qualiquantisoft ${ }^{2}, 2007$.

Desta maneira, todos os entrevistados (Tabela 17) foram registrados no QQ em ordem numérica para não perder nenhuma parte de seus discursos e não termos prejuízo na composição dos discursos.

Entre os atores sociais entrevistados sobressaíram-se as mulheres $(71,25 \%)$, a formação superior $(86,25 \%)$ e a faixa etária de 31 a 50 anos $(57,50 \%)$ como se pode observar na Tabela 18.

Tabela 18: Distribuição dos entrevistados ( $\left.\mathrm{n}^{\circ} \mathrm{e} \%\right)$ segundo sexo, faixa etária e grau de escolaridade, Paraná, 2007.

\begin{tabular}{|c|c|c|c|}
\hline Variável & Categorias & $\mathbf{N}^{\circ}$ & $\%$ \\
\hline & Masculino & 23 & 28,75 \\
\hline Sexo & Feminino & 57 & 71,25 \\
\hline \multirow{6}{*}{ Escolaridade } & $2^{\circ}$ grau completo & 7 & 8,75 \\
\hline & Superior incompleto & 4 & 5,00 \\
\hline & Superior completo & 69 & 86,25 \\
\hline & Especialização* & 25 & \\
\hline & Mestrado & 8 & \\
\hline & Doutorado & 2 & \\
\hline \multirow{5}{*}{ Faixa etária (anos) } & 20 à 30 & 13 & 16,25 \\
\hline & 31 à 40 & 15 & 18,75 \\
\hline & 41 à 50 & 31 & 38,75 \\
\hline & 51 à 60 & 17 & 21,25 \\
\hline & 61 e mais & 4 & 5,00 \\
\hline
\end{tabular}

Fonte: Qualiquantisoft ${ }^{2}, 2007$.

Nota:

*investigada no QQ apenas para os profissionais SERV, ou seja, para o total de 35 entrevistados. 
Observa-se que entre os profissionais enfermeiros e médicos que atuam em Unidades Básicas e nos Hospitais, 71,43\% fizeram algum curso de especialização (Tabela 18). O estudo é aqui entendido como demonstração de interesse que contribui para o crescimento e amadurecimento profissionais assim como favorece a 'troca' de informações e conhecimentos adquiridos.

A seguir serão abordados os discursos propriamente ditos que serão demonstrados em 03 partes, correspondentes às 03 perguntas que foram feitas, conforme relatado no Capítulo sobre Procedimentos Metodológicos desta pesquisa.

\subsubsection{CONHECIMENTO DOS PROGRAMAS, AÇÕES E ESTRATÉGLAS DE PREVENÇÃO DA MORTALIDADE INFANTIL - questão 1}

A pergunta realizada sobre o conhecimento que tinha o entrevistado de Programas, Estratégias e Açб̃es de prevenção da Mortalidade Infantil no estado do Paraná teve como primeiro objetivo, na elaboração do Instrumento de Pesquisa, saber se o pessoal que trabalha nas regionais e municípios em setores de gestão e assistência conhece, ou já ouviu falar dos Comitês. Também queríamos saber o que os Comitês representam para eles, se realmente estes aparecem como instância de incentivo e apoio à prevenção do óbito infantil.

Entre as respostas, após a seleção, com a organização e ferramentas oferecidas pelo Programa Qualiquantisoft ${ }^{\circledR}$, de expressões-chave $(\mathrm{ECH})$ e idéias centrais (IC) que apareceram nos discursos individuais foram organizadas categorias que pudessem agrupar as idéias centrais de forma mais coerente, fidedigna e que trouxessem informações à pesquisa. Assim, para a primeira pergunta foram traçadas 06 categorias (Tabela 19).

Observa-se que, para respeitar o rigor metodológico necessário na operacionalização do Método do Discurso do Sujeito Coletivo frente a grande quantidade de ECH e IC, traçou-se, logo após a identificação das categorias de análise, os critérios de inclusão. Esses critérios nortearam a categorização de cada ECH no software, para que, na seqüência, cada discurso-síntese fosse construído. Os critérios de inclusão serão mostrados à medida que discutirmos cada categoria de resposta. Os DSC foram construídos com fragmentos das falas dos entrevistados, de 
forma que alguns erros ortográficos são mantidos na edição das mesmas, respeitou-se a forma verbalizada pelo entrevistado.

\section{Pergunta 1) Quais ações, estratégias ou programas tem sido desenvolvidas para se prevenir 0 óbito infantil nesta regional $/$ município / servico?}

Tabela 19: Distribuição das categorizações construídas $(\mathrm{A} 1$ - F1) em relação à questão 1 (Quais ações, estratégias ou programas tem sido desenvolvidas para se prevenir o óbito infantil nesta regional / municipio / serviço?) segundo freqüência $\left(\mathrm{n}^{\circ}\right)$ e força de compartilhamento das idéias (\%) apresentadas nos discursos individuais e coletivo, Paraná, 2007.

\begin{tabular}{|c|c|c|c|}
\hline \multicolumn{2}{|c|}{ C'ategorias } & $N^{\prime \prime *}$ & $1 \%$ *t* \\
\hline$\overline{\mathbf{A}}$ & Organização da rede e fluxo dos serviços de saúde & 31 & 38,75 \\
\hline $\mathbf{B}$ & Estratégias governamentais (PACS, PSF, CPMMI) & 30 & 37,50 \\
\hline $\mathbf{C}$ & Desenvolvimento de programas regionais / locais & 35 & 43,75 \\
\hline D & Melhoria da qualidade de ações e dos serviços (capa & 13 & 16,25 \\
\hline $\mathbf{E}$ & Ações organizacionais do nivel regional / local & 30 & 37,50 \\
\hline $\mathbf{F}$ & Sem resposta ou resposta sem nenhuma idéia & 4 & 5,00 \\
\hline \multicolumn{2}{|c|}{ Total das entrevistas } & $80^{* *}$ & \\
\hline \multicolumn{4}{|c|}{ 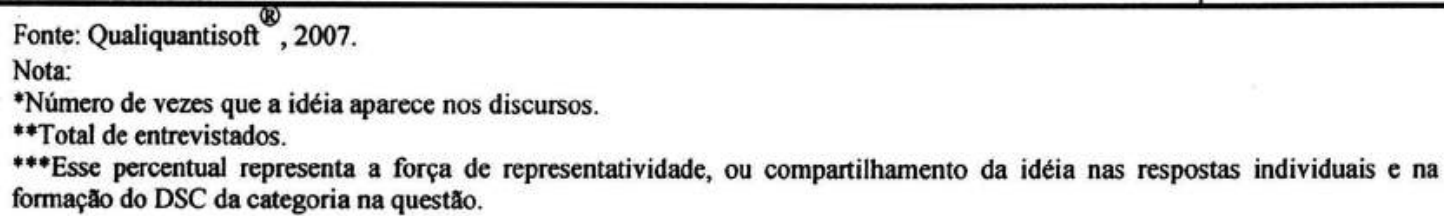 } \\
\hline
\end{tabular}

A força de compartilhamento das idéias suscitadas pela primeira pergunta foi mais intensa para o desenvolvimento de programas regionais e locais $(43,75 \%)$. Pode-se dizer que isto se deu em virtude de a prática cotidiana estar constituída em suas representações sociais sobre a prevenção da mortalidade infantil, há reconhecimento desta prática. A seguir, vieram as idéias relativas a programas / ações / estratégias que contribuem para a organização da rede e do fluxo de serviços de saúde, compartilhadas em $38,75 \%$ dos discursos relativos à pergunta. Como terceira expressão aparecem, simultaneamente, as estratégias governamentais e a ações organizacionais em nivel regional e local, ambas com $37,50 \%$ de força de compartilhamento das idéias expressas. Em último lugar, mas não menos importante, aparecem como conhecimento dos profissionais, as ações voltadas para a melhoria da qualidade dos serviços, ou seja, as medidas voltadas para a capacitação de RH. 
Infere-se que elas se mostram menos forte na Representação Social dos programas / estratégias existentes. Isso talvez porque capacitações não têm sido muito expressivas no estado ou por que mesmo acontecendo com expressão, ainda necessitam de maiores proporções de abrangência. Ou seja, os profissionais ainda sentem necessidade de mais preparo técnico.

Assim, a cada categoria foi construído um Discurso do Sujeito Coletivo com as respostas à questão sobre o conhecimento dos Programas / ações e estratégias que acontecem no Estado para se prevenir o óbito infantil. Após o trabalho de 'garimpo' das ECH e 'lapidação' das respostas para o arranjo textual harmônico, sempre respeitando o discurso original, apresentou-se os Discursos do Sujeito Coletivo na primeira pessoa do singular, de modo que as idéias de cada profissional, respeitadas e mantidas, se juntam e formam um só discurso, que são a representação que têm esses sujeitos sociais sobre o que o assunto que se abordou. Todas as categorias serão mostradas a seguir com os DSC construídos em consonância com os critérios de inclusão estabelecidos para cada uma delas.

\section{DisCURSO DO SUJEITo COLETIVO - QUESTÃo 1}

\section{DSC A1: Organizaç̃̃o da rede e fluxo dos serviços de saúde}

\section{Critérios de Inclusão:}

a) Estrutura do serviço quanto a: oferta, ao público atendido, à número de consultas, presença de profissionais especializados, estabelecimento de serviços específicos, sistema de transporte, estrutural ambulatorial, estrutura hospitalar, existência de vagas e definição das competências entre os serviços existentes.

b) Estabelecimento do fluxo entre os serviços: interno e o de referência, principalmente terciária.

o governo do Estado do Paraná tem a preocupafão grande com a prevenção da MI, lanf̧ou o ano passado algumas afōes próprias para intensificar o combate a mortalidade materno-infantil. $\mathscr{E}$ um programa estadual e existem incentivos pra Casa da Gestante, incentivo para Hospitais de referência e para os Consórcios que tem gestaf̧ão de alto risco, afém disso, a criação em alguns municípios-problema, de Centro de Atenfão Integral à Gestante e à Crianf̧a, com disponibifidade de recursos, para construfão e manutenfão.

Tá sendo feito um planejamento, já a Lgum tempo, no sentido de diminuir esses índices como a criação de hospitais de referência com uma estrutura melhor pra aceitar essas crianças, as prematuras. 
Mas, tem que haver regionalização do atendimento em atendimento primário, secundário, terciário $e$ das ações básicas de saúde. O atendimento da gestante de alto risco em unidades adequadas, a redução da mortafidade em função da diarréia, a reidratação oral, é importante e para as crianças de risco, as UTIs Neonatais e Pediátricas.

A própria melhoria das estruturas fospitalares eu vejo como um avanço, embora haja muita coisa a ser feita ainda, o trabalho é longo em nossa Regional, que é 6astante pobre, tanto em recursos fumanos, quanto em instalações físicas, de atendimento hospitalar, ambulatorial. No entanto, estão sendo desenvolvidas afões como o aumento do número de leitos hospitalares de UTI, embora ainda não suficientes.

A UTI Neonatal foi uma vitória, a gente tinfia criança prematura o problema de transporte e de vagas. Uma afão principal é o Ambulatório de Risco que tem aqui no município na tentativa de diminuir a MI, e contribui com a redução da mortafidade perinatal tardia. Trabalhamos com pacientes vindos de outros serviços, outras cidades do estado do Paraná e outros estados do Brasil também; não temos uniformidade dos pacientes em relaf̧ão a abordagem preventiva antes de chegar até a gente.

Também tem Programa de Remoções, a Central de Vagas que procura as vagas de UTIs Neonatal e Pediátrica dentro do Estado do Paraná, 6eneficia as crianças que nascem com algum tipo de problema. 0 atendimento de urgência e emergência como o SIATE (Serviço de Atendimento ao Trauma), o SAMV (Atendimento Médico de Vrgência) e Ambulâncias especiais com VTI $\mathcal{N e o , ~ c o m ~ a ~ e q u i p e ~ m u l t i d i s c i p l i n a r ~}$ acompanfiando a crianfa, diminuiu bastante o problema das crianfas chegarem em mal estado, elas vem em 6oas condiffões; todos eles estão alertas em relação à criança e gestante de risco.

Melforou muito, acho que ainda tem muito a melhorar, alguns municipios ainda enviam crianças, com más condif̧ões de transporte, crianfas em banfieirinfias, 6em envoltos em cobertores, em plástico, etc; eles fazem o que podem, ainda faltam condições para um transporte melhor. Vm serviço de Vigência Municipal é importante também.

Além disso, foi criado a Casa da Gestante, visando a centralizar todo o atendimento da gestante $e$ RN. Ela também dá acompanfamento no puerpério. Tem um Centro Infantil municipal, faz atendimento pediátrico.

A epidemiologia encaminha pras unidades todas aquelas criancas que nascem de mães adolescentes $e$ ficam intermadas em UTI porque são prematuras. As unidades fazem a 6usca e o acompanfiamento. Isso a gente depois solicita um retorno disso. Assim a gente tem como se fosse uma guia de referência e contrareferência na questão da MI.

Hoje o tipo de prevenção para o paciente de alto risco é a gestante vir pra cá, encaminfiamento da gestante para o hospital, ela ganfia o be6ê, se há uma patologia de emergência, já vai direto pra UTI. Eu tenfo certeza que a mortafidade nessa região aqui diminuiu muito, com essa nossa UTI Neonatal.

Existe também a facifidade de acesso à consulta, ao médico, a enfermeira mediante a ampliação da rede de atendimento de saúde 6ásica; a parte de saúde pú6lica esta sendo 6em feita. TNa UBS nós realizamos o acompanfamento da gestante, tem um Programa de Atenção Básica ao Recém Nascido, a gente acompanfia mensalmente essas crianfas. Nós temos o programa de Be6ê de Risco, no nível municipal e Programa que contempla todas as crianças que nascem no município.

Outras ações que são dirigidas ao bebê como os cuidados básicos de figiene fica com a atenção básica. o Centro de Saúde da Mufher acompanfia a mãe desde a gestafão. A construção de várias Unidades de Saúde da Mulher e da Criança é uma af̧ão muito importante.

Toda crianfa de baixo peso é encaminhada pro nutricionista, tem um melhor acompanfiamento médico e da equipe de enfermagem também. A gente tenta pelo menos fazer alguma coisa, colocando os enfermeiros da VBSS pra estar participando das reuniōes com a gente, colocando o 'ponto' onde ta acontecendo.

Trabalhando na organizafão do fluxo do paciente, com foco no entrosamento multidisciplinar do atendimento que envolve todo esse processo matemo-infantil. Com o encaminfiamento, o fluxo de encaminfiamento às referências dos municipios para os locais de atendimento ao parto, para o ambulatório de gestação de alto risco, desses para os fiospitais de referência para a realização do parto e com a questão complementar dos exames de apoio ao pré-natal e, mesmo com o atendimento da crianfa por pediatra, tivemos uma diminuição da MI. 
Neste DSC Al, fica clarão que há sensibilização dos profissionais ao aspecto preventivo do óbito infantil valorizando a atuação primária em saúde diante da vigilância do risco no pré-natal e após o nascimento. De maneira geral, pode-se dizer, mediante este DSC, que o Estado está caminhando com sucesso na concretização de ações para a contínua redução dos óbitos infantis e, os atores sociais têm claro que esta redução é objetivo do governo, contando com seu apoio e retaguarda.

A regionalização é enfatizada pelos profissionais de modo a que cada município / região tenha na prática seus sistemas de referência e encaminhamento do risco detectado, bem como para atendimento básico à saúde da mulher. Há a valorização urgente, principalmente do estabelecimento de Ambulatórios de acompanhamento das crianças nascidas de risco e das gestantes de alto risco. A descentralização das ações e serviços, bem como a reorganização da atenção à saúde faz parte da Agenda de Saúde da Secretaria de Estado da Saúde do Paraná (SESA). No entanto, é fato colocado pela instância de saúde do governo do estado do Paraná:

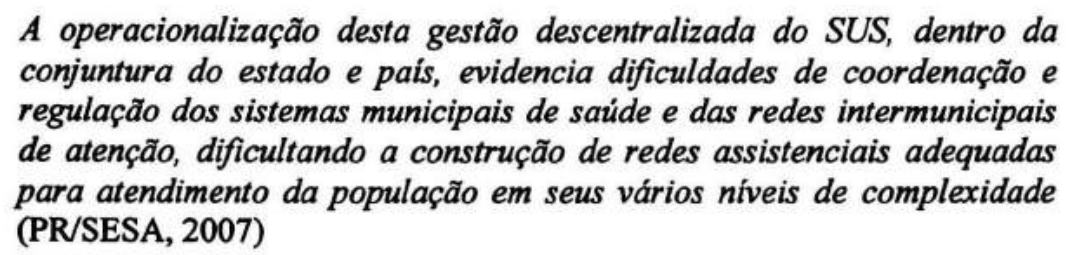

Diante da realidade e das expectativas pelas ações do governo relatadas e da dificuldade expressa pelo governo para dar conta de todas as dimensões da assistência, convivemos com paradoxos e sentimentos de frustração, em especial por parte dos profissionais que 'perdem' seus pacientes.

A referência terciária com leitos de UTI Neonatal é tida ainda como carente, confirmando o impacto na ponta da insuficiência atual dos leitos, conforme contabilizado com os dados do CNES mostrados na discussão do SIMI. Mais ainda, existe a certeza dos profissionais que se esse serviço for adequado, muitas vidas poderão ser poupadas. $\mathrm{O}$ estabelecimento da UTI Neonatal de referência para uma RegS é percebido como uma vitória no processo de combate ao óbito infantil evitável. 
Outros programas de governo que são indicados como fundamentais, no discurso, é o de Central de Vagas e a Rede de Atendimento de Urgência e Emergência. Atualmente, há no Paraná 03 instâncias dessa rede de atendimento e transporte do paciente: a Rede Paraná Urgência e Emergência com unidades de terapia intensiva móveis, o SAMU (Serviço de Atendimento Médico de Urgência) e o SIATE (Serviço de Atendimento ao Trauma). No entanto, os profissionais dizem que há muito a melhorar. Ainda se convive com transporte inadequado das crianças para as referências, a responsabilidade ainda fica por conta da criatividade e compromisso do profissional que atende, para suprir a lacuna de condições próprias que existe me várias regiões do estado.

Aparecem, nesses DSC, a importância de um sistema de referência e contrareferência com entrosamento multidisciplinar para a redução da MI. Porém, aparecem também as peculiaridades regionais em termos de recursos físicos e humanos para o estabelecimento dos serviços.

\section{DSC B1: Estratégias governamentais (PACS, PSF, CPMI)}

\section{Critérios de Inclusão:}

a) Grandes estratégias (Políticas de Saúde) definidas e emanadas do governo federal: PSF, PACS e Pactuações.

b) Comitês de Prevenção da Mortalidade Infantil (objeto desta pesquisa para o estado do Paraná).

Em virtude do afto indice de $\mathcal{M} I$ a gente orientou para redução, no ano retrasado, que tivesse um acompanfiamento, que os municipios, utifizassem a equipe de Saúde Famífia, junto com os agentes comunitários de saúde (ACSS), pra ta fazendo uma 6usca, pra ta acompanfiando mais de perto essas criancas, as equipes do PSF também visando a redução da MI. O maior programa pra prevenir o óbito infantil acho que é o PSF mesmo, e quem atua nisso são as $\mathcal{A C S s}$, que vão trazendo os problemas pra nós. As principais af̧ões trabalham-se no PSF, a parte de execucão mesmo é feito hoje pelo PSF, é a única maneira da gente chegar mais perto das famífias. São realizadas, a nivel de PSF algumas reuniōes com as gestantes, pra informafão mesmo, tipo: cuidados com a gestafãa, cuidados com o bebê, tanto na maternidade como após, com orientafão afimentar, com a amamentafãa; cuidados específicos mesmo com o bebê e com a gestafão. Fica com o PSF o acompanfiamento dessa gestante, identificafãa da gestação de risco; o trabalho de vigilância realizado pelas equipes de saúde da família, principalmente das crianças de risco, através de consultas médicas, visitas dos ACS, 6usca ativa trazendo essas crianfas, pra fazer de fato a prevenção e o tratamento.

Tem crianfas que nascem com APGAR 6om, peso 6om, são consideradas de risco devido a mãe ser menor de idade, drogada, ou alguma coisa assim... aí já vem a notificação e ela (criança) é acompanfiada durante um ano, o peso e desenvolvimento, pelo PSF. Temos o PSF, que faz a investigafão: a crianfa 
nasce com 6aixo peso, o SIJNASC diagnostica, nós já acionamos o municipio que vai fazer a investigafão e vai acompanfiar essa criança.

$O$ acompanfiamento em casa de gestante, de mãe adolescente, ou aquelas de trinta e cinco anos e dos 6ebês com peso 6aixo ao nascer, que estão na UTI, quando sair dela é realizado pelas equipes do PSF, ta muito engajado com a gente, a gente utiliza muito.

Aqui no PSF, na nossa reafidade, o médico só faz a puericultura e atende os casos clínicos. Em alguns municípios, um ou outro PSF, coloca em prática programas. INa verdade na ponta, quando você chega na reafidade, ta todo mundo a deriva, eu tenfio acompanfiado... são situações assim muito tristes... a gente vê óitos em situações que não deveriam estar acontecendo, por falha de todos segmentos, não só do médico, mas parte social, parte psicológica, econômica, um conjunto de coisas. Fu acho o PSF ainda um modelo muito novo, daqui a algum tempo é que a gente vai avaliar se a af̧ão realmente foi efetiva, é um processo em construção, do próprio modelo.

Nosso Comitê Regional (de Prevenção da Mortafidade Infantil) que inclui os municipios da nossa área de abrangência, ta sempre dedicando, oferecendo oficinas, capacitação pra ta melhorando o atendimento também dos municípios. Não temos o Comitê Municipal (CM), mas nós temos o Regional que é 6astante atuante no nosso município; embora ainda não está implantado o CM a gente participa do CR apresentando as investigações dos óbitos infantis de município. Em todos os nossos municipios tem os Comitës Municupats de Mortalidade Matema e Infantrh, onde participam os enfermeiros, virios profissionais de saúde. Cada óbito é avafiado, são feitas visitas nas casas, procura-se colter os dados, informações do paciente, investigar as maneiras que ocorreram os fatos, para se trafar diretrizes para orientar. Para tentar evitar os óbitos são implementadas afões a partir do CM que foi instituido, por decreto, em nosso município.

Essa af̧ão, esse olhar, essa exigência de prevenção da MI fica dentro da Pactuação de Gestão, que a gente vem trabalhando desde o ano de 2000. Esse ano, pontualmente, entra na questão do Pacto pela Vida, é uma questão do município e, minha percepfão é que o Estado fica num momento muito co-participativo e, em afguns momentos perdido: se ele é assessor ou se ele é parceiro. A afão hoje é direta, a cobranfa é direta, o município tem que ter essa percep̧ão no nivel local, mas é uma af̧ão muito determinada pelo Ministério da Saúde, em conjunto com os municípios através das Comissões Intergestoras (CI) a Bipartide, o Conasems, do que especificamente uma cobranfa pontual do Estado.

O foco principal quando se fala de Programas é o PSF e o PACS, é o trabalho dos ACS junto às famílias. Por um lado, o trabalho aparece no discurso como fundamental para que se firme o vínculo entre família e serviço, por outro, aparece 'perdido', 'à deriva' e, como um programa muito novo ainda a ser avaliado. A diversidade regional emerge mais uma vez no DSC. Existem os Programas, mas pôlos em prática cabe às possibilidades de cada município. Os óbitos evitáveis que ocorreram em mais de $70 \%$ dos óbitos investigados no Estado, no último Triênio de análise, são vistos como evitáveis e com pesar pelos profissionais que não dispõem de ferramentas para atender a criança. Os profissionais atribuem o evento a diversos fatores determinantes: assistência, médico, questões sociais e econômicas.

Mediante o discurso percebe-se que os sistemas de informação são utilizados com forte consideração ao SINASC, como 'diagnosticador' da situação de baixo peso para as equipes do PSF. 
O Comitê de Prevenção da Mortalidade Infantil foi selecionado para esta categoria do DSC da $1^{\text {a }}$ questão por ser a estratégia do governo do Paraná, desde 1997 e objeto deste estudo, além do fato que, para o Brasil, esta estratégia tem sido recomendada desde 2004. O relato da existência dos Comitês aparece timidamente, nas experiências da maioria dos entrevistados, principalmente entre os 'profissionais da ponta'. Ao que parece, alguns Comitês Regionais têm cumprido o seu papel de acompanhamento e de apoio aos Comitês Municipais. Os profissionais têm percebido isto. Como evidenciado anteriormente ainda faltam Comitês Municipais em 182 $(45,6 \%)$ municípios do Estado, este contexto preocupa os entrevistados. Considera-se também que existe, desde 2004, um Pacto Nacional pela Redução da Mortalidade Materna e Neonatal.

\section{DSC C1: Desenvolvimento de programas regionais / locais}

\section{Critério de Inclusão:}

Programas governamentais implantados e implementados no nível Municipal / Regional (Pré-natal, Aleitamento Materno, Programa do Leite, Promoção da Saúde, Prevenção de Doenças, Imunização, Bolsa Escola, Bolsa Família etc)

A gente teve a princípio pela Secretaria de Estado aquele Protegendo a Vida, um 6om programa, com aqueles cursos específicos para pediatras, para médicos generalistas, realizados por macrorregião. Foi um avanço da promoção da saúde e prevenfão das doenças. Era um programa espetacular também, com formafão / preparo de profissionais, na época, só que depois perdeu a continuidade, agora estão despertando para programas que tinfiam sido esquecidos, como o Programa de Assistência Integral a Saúde da Mulher/PAISM, intensificando o pré-nataL.

Temos realizado nesse aspecto de prevenção do óbito infantil várias atividades, a nivel de estado temos Programa da Mulher e da Criança, a MI fica muito no periodo neonatal, com percentual maior no periodo neonatal precoce.

Assim, temos o Pré-natal Humanizado, com o cadastro no SISPRENATAL, a obrigatoriedade pelo Ministério da Saúde de acompanfiamento de pré-natal ifimitado, inclusive é fiscalizado. A gente preza pelo pré-natah, inicialmente, porque o maior número de casos de b́bitos aqui ocorre no período perinatah A gente tem várias falhas no pré-natah, mas a gente sempre ta 6uscando orientar os nossos profissionais, tem trabalfiado muito a questão do pré-natah, isso ai é uma coisa que eu acho que é ponto positivo, e não se voltaria mais atrás que é tentar levar essa gravidez de uma forma melhor pra que essa crianfa nasça a termo.

A questão da atenção principalmente já na gestaģão pra ter um bebê sadio, visando à não mortafidade dele nos próximos meses ou dias de nascimento, trabalfiando desde o início em cima do pré-natal, com a protecão da criança, visando a não mortafidade.

Depois a gente faz o acompanfamento do recém-nascido, orientação para o 6anfo, para os primeiros cuidados, incentivando o Aleitamento Materno, a puericultura com busca ativa no caso de vacinação atrasada. Tem também o Programa de Planejamento Familiar. A prevenção acontece no pré-natal de boa qualidade, com realização das consultas, com a realização dos exames, isso é imprescindível, condịcão si ne 
qua non que se fafa adequadamente para que a MI diminua. O pré-natal deixa a desejar, principalmente, na gestafão de risco.

A gente passa em todas as crianças que nasceram de 6aixo peso, todo mês, na época do relatório do SIABB, agente confronta com as $\mathcal{D N S}$, a gente passa sempre nas crianfas de risco, faz parte do trabalho rotineiro, a vigifancia as crianfas de risco e a vigilância a gestante de risco.

No Programa de Vigifancia do Recém-nascido de Risco a gente faz um acompanfiamento dessas crianfas, antes a maternidade já manda um comunicado pra gente (embora a gente já saiba assim que ela ganha o bebê) aí quando ela chega em casa, a gente já vai fazer a visita. Com um ano completado a gente faz o fechamento do caso e manda pra Secretaria de Saúde uma notificação, relatando se crianf̧a tá 6em, se continua de Gaixo peso e, como foi a evolução dela mês a mês. Esse programa é baseado no Ministério da Saúde e adequado pra nossa realidade.

São também importantes as orientações a respeito do aleitamento materno, o incentivo com afimentaf̧̃o adequada, trabalhar com as mães incentivando a criança a estar mais perto da mãe, o aleitamento materno até os seis meses. Observa-se o retorno do aleitamento materno, com bastante campanfias em nosso Estado; estamos sempre avafiando o aleitamento materno e as af̧öes pra incentivar essa mãe a continuar.

No Posto de Saúde, é só puericultura que é feito aqui, quando chega a $\mathcal{D N}$ na Unidade, a enfermeira vai visitar as crianças, que tem maior necessidade; os enfermeiros estão fazendo o melhor de si pra acompanhar essas crianças e que evite o óbito e a prevenção de doenças como as infeç̧ões, diarréias, problemas respiratórios. O agendamento pra puericultura aqui na unidade faz-se num primeiro momento até quinzenalmente, ou mensalmente dependendo da situaf̧äo da criança.

Sobretudo a estratégia que me é mais evidente para diminuir MI é na questão da vacinação, mortalídade se reduz com imunizafão. Carteira de vacinafão das crianfas, a gente faz direitinfio tem o controle direto da justificativa dos faltosos. Outra questão é o soro reidratante oraL. Ainda tem o SISVAJ detectando crianfa desnutrida; a gente comecou a implementar esse atendimento, fazer esses Agravos $\mathcal{N}$ utricionais, o SISV AN que é o Sistema de Vigilância Nutricional, não é ainda o ideal. Tem também a Bolsa Famíla que ajuda.

O cumprimento dos programas de afimentação infantil como o Programa do Leite das crianças, que é do govermo prevê que crianfas de 6aixo peso têm direito a pegar o leite até os 3 anos de idade. Assim a gente faz o acompanhiamento do peso aqui, é uma forma de prevenção nutrindo as crianfas conseqüentemente corrige muitas desnutricōes que eram causas de mortalidade ou de debilitaçōes das crianças. O Programa do Leite das crianfas de nossa parte, agente tem observado que ajudou bastante também as famílias mais carentes.

Temos um Programa de Vigilancia a Nascidos Vivos que é o carro-chefe da Secretaria, vamos fazer 12 anos de Programa. Tem formada uma equipe multiprofissional qualificada atuando e, temos observado que vem diminuindo consideravelmente o indice de $\mathcal{M} I$ no municipio. $\mathscr{E}$ um esforço conjunto dos profissionais da área da saúde, envolvendo médicos, pediatras, neonatologistas, as UTis, os Hospitais, os Clínicos Gerais, os auxifiares de enfermagem, os enfermeiros, mediante treinamentos constantes. Somos uma cidade pólo, tem muitas mães que migram pra cá, fazemos o Programa com todas. Esse Programa também tem uma parte de monitorização das crianfas internadas de zero a um ano de idade em parceria como Setor de Controle e Avaliação, com as AIFFs...das crianças internadas de menos de um ano, fazemos relatório enviamos pra cada unidade de saúde, com todos os detalhes da intemafão; quando a criança sair da intermação já vai fazer a visita.

Aqui no Hospital a gente faz o Alojamento Conjunto pro incentivo ao Aleitamento Materno, as outras aföes fica com a Clínica da Mulher.

Acontecem as investigações quando ocorre o óbito infantil. Está tudo integrado na tentativa de um desenvolvimento mais saudável pra crianfa.

Para o cumprimento dos Pactos e Metas governamentais federais e estaduais traçados diante do diagnóstico de saúde da população, são implantadas os Programas, principalmente os voltados à saúde materno-infantil. O seu valor está em sua 
operacionalização nos municípios, mesmo na presença de suas dificuldades técnicooperacionais.

No Paraná, o movimento deflagrado pelo Protegendo a Vida na década de 90, foi revolucionário em todo o Estado. Houve mobilização de processos de sensibilização, capacitação, dotação de instrumentos tecnológicos a hospitais e redes ambulatoriais. Foi um movimento, em essência, de colocação em evidência a importância da Vigilância Epidemiológica ao risco de morte de mulheres e crianças.

Os profissionais, em suas respostas, valorizam os programas de atenção integral e vigilância ao risco materno-infantil. Nos discursos são mencionados, novamente, os Programas e os sistemas que são, por eles, utilizados como o SIAB; SISPRENATAL; o SISVAN. Além do Programa do Leite do governo do Paraná; da realização do Alojamento Conjunto; do incentivo ao Aleitamento Materno, a qualidade do pré-natal; o programa de vigilância ao recém-nascido de risco, a puericultura, a vigilância a internações de crianças menores de um ano. Enfim, os profissionais vêem à sua frente a possibilidade de desenvolvimento de programas preventivos, os conhecem e valorizam sua realização para o cerco ao óbito infantil evitável. Valorizam também a interação entre os diferentes Programas e profissionais que os operacionalizam. No entanto, priorizam a qualidade das ações e dos serviços, que será enfatizada na próxima categorização.

\section{DSC D1: Melhoria da qualidade de aşóes e dos serviços (capacitação de RH)}

\section{Critérios de Inclusão:}

a) Relacionado com a capacitação, treinamento do pessoal do serviço; melhoria dos recursos humanos da rede de assistência à saúde.

b) Relacionado à melhoria da qualidade das ações.

Estatisticamente se verifica que a maior incidência de óbitos infantis decorre justamente nos primeiros trinta dias após o nascimento. Nós temos executado trabaltio de orientaf̧ão dos municipios, através do Pólo Formador de Recursos Humanos, os pólos regionais, os PREPS (Pólo Regional de Educação Permanente em Saúde), temos feito cursos de formação, de capacitação para os gestores e profissionais de saúde a nível de município contribuindo para a melhoria da quafidade do pré-natal. Deve ser melhorado o pré-natal pra não ter tanto risco de parto prematuro, que é minfia vivência.

A primeira estratégia é um pré-natal 6em feito, o acompanfiamento da gestante, pré-natal bem realizado com o número ideah, minimo de consultas; tem sido incentivada a qualidade do pré-natah, não só 
o número como a quafidade. O acompanhamento do começo ao fim da gestafão, vendo se é uma gestante que tem ou que possa ter o risco de vir a ter um parto prematuro.

TNo Estado houve treinamento de um pessoal médico e paramédico, no sentido de um atendimento de mais quafidade no pré-natal e na sala de partos. Tem que haver orientafão, palestras mesmo sobre a qualidade do pré-natal oferecido que ta totalmente relacionado: um pré-natal mal feito com o evento de prematuro. Melhor qualidade do pré-natal significa a qualidade de saúde.

O treinamento dos ACS, sua capacitação assim eles ficaram mais envolvidos com a busca, com o controle, alertas com as criancas, para a importância do visitar. O curso serviu para motivar os ACS, em alguns casos de investigafãa do óbito só tinfa um relatório do ACS para a gente investigar, não tinfia prontuário médico, nem anotação do enfermeiro, mas tinfia o relatório do ACS!

A melforia da assistência básica e os incentivos relacionados ao cuidado com o bebê de risco, ao infante. A questão da amamentação tem que ter mais capacitafão em cima do Aleitamento Materno.

Os Comitês têm trabalhado muito em cima da qualidade no pré-natal, da assistência fospitalar pra mãe e pro bebê, para a gestaf̧ão de risco e no atendimento no geral.

O Estado tem mefhorado as condíç̄es de atendimento, vários treinamentos pra recepşão adequada, avafiafão e diagnóstico de crianças, de recém-nascido com problemas, quafificou com bastante segurança todo mundo, foi um marco bem interessante.

$\mathscr{E}$ importante continuar a capacitafão pra todas as equipes de saúde, ter profissionais capacitados, profissionais que têm alma, que gostam do que fazem, que querem trabalhar e, principalmente a sensibilização do profissional para o problema.

O pré-natal bem feito é a tônica do DSC para que seja reduzida a morte infantil evitável. Pode-se confirmar essa evidência pelas informações das investigações dos óbitos, registradas no SIMI, que realmente o atendimento à gestante no estado do Paraná necessita de uma atenção especial. Os profissionais têm clareza da importância de se prevenir a morbi-mortalidade no primeiro mês de vida da criança, com melhoria da atenção básica e da vigilância ao risco.

Há expressão discursiva de capacitações importantes por iniciativa estadual, dos Pólos Regionais de Capacitação (PREPS) em relação ao acompanhamento do pré-natal, ao parto e RN, para ACS e profissionais em geral. Em contrapartida há, também, a expressão de que a qualidade não tem melhorado na medida necessária. Concluem que há necessidade de manutenção das capacitações.

Neste sentido, emerge no discurso a valorização dos Comitês de Prevenção da Mortalidade Infantil que põe em evidência a qualidade do pré-natal normal e de risco, bem como a assistência hospitalar à mãe e à criança. Há também a expressão de que devem existir ações e iniciativas dos municípios e regionais em atendimento às suas peculiaridades.

Pode-se concluir que os profissionais consideram as ações do governo, e se sentem parte dessa responsabilidade nos programas concretizados na ponta, nos serviços. Pedem a manutenção das capacitações como apoio em suas ações. 


\section{Critérios de Inclusão:}

Ações ou iniciativas tomadas pelo município / Regional de Saúde, para o enfrentamento do problema em pauta, a prevenção do óbito infantil. São reuniões, organização de grupos técnicos (hospitalar ou não), feedback das investigações, visita domiciliar de puerpério etc.

Aqui na Regionah o ano passado, nós fizemos uma reunião com Secretários de Saúde, enfermeiros $e$ médicos da metade dos municípios da nossa Regional, pois o Coeficiente de Mortafidade Infantil tava mais alto. Nós tentamos mostrar o que é MI? Qual a prevenção? O quê o municipio poderia fazer pra isso não ocorrer? Temos em vista que a maioria desses óbitos foram evitáveis.

Temos feito ao nivel de Regional de Saúde, como resultado dessas açöes integradas entre a Regionale os municípios, uma espécie de Câmara Técnica para que nós avafiemos. Vtilizamos a Carteira da Gestante, analisamos tudo até o momento da internação da gestante até o óbito da criança, pra que a gente possa dar o feedback em relação às condições do parto e fazer uma avaliação das condições do pré-natal. Temos situaçōes 6astante differentes nos diversos municípios, temos municipios com o indice melhor, outros com indice pior. $\mathcal{N}$ a nossa regional, os indices são preocupantes, tanto de mortafidade infantil, como de mortafidade materna que é decorrente do parto.

A Secretaria de Saúde formou o Comitê com a intenf̧ão de discutir os óbitos que ocorriam, no município, um avanço! Só que parou, precisa de muito apoio técnico e disponibifídade para as investigafões.

Os Comitês de Mortafidade Materna e Infantil atuam sempre quando ocorrem óbitos, os profissionais que atenderam também recebem uma carta em caráter informativo, educativo, desta forma vai conscientizando os vários setores da área da saúde, e vai diminuindo a mortafidade matemo-infantil. Tem também englobando as RS o Programa de Estudo de Mortafidade de recém-nato, e de crianfas menor de um ano.

Nós temos o Comitê Municipal de Mortafidade Infantil, que coordena a produção das informaçōes que vão embasar as ações a serem desenvolvidas nas unidades, o comitê é composto por uma equipe que coordena as unidades, tem a participação de enfermeiras de todas as UBSS do município. A principal af̧ão é analisar todos os óbitos infantis menores de um ano, independente de ter malformafãa, de ter peso inferior a 1000 gramas, teoricamente seriam casos excluidos do estudo do Comitê pelas normas regionais, investigar $100 \%$ dos óbitos ocorridos!

Com os trabalhos dos comitês municipais temos levado as análises de óbitos de municípios da RS, mas a maioria dos óbitos ocorre no município sede; levamos para uma Câmara Técnica que vai trafar metas de mortafidade e orientar como levá-las para os municípios.

Dentre as ações que são desenvolvidas principalmente, pela equipe responsável pelo Comitê de Mortalidade Infantil da Regionah, em relafão aos municípios está a investigação dos ó6itos e a análise dos óbitos, tem também o retorno dessa análise aos profissionais que atenderam o caso.

Nós usamos muito o trabalfo do ACS, fortemente vinculados à epidemiologia. O serviço municipal de epidemiologia investiga um óbito fica sensibilizado, assim chega com força junto aos ACS e ai eles ficam com mais responsabilidade, falam assim: __ocorreu aqui na minfa área! Ai comę̧aram a cuidar um pouco mais das gestantes, dos bebês e da própria vigifância epidemiológica das doenças imunopreviníveis, que ao Congo dos anos, causou um bom impacto.

Temos indicadores todos os meses, trabafho bem focado mesmo; vê o bairro que mais morreu, as causas de óbito daquele 6airro, montamos uma planilha e enviamos para o Posto (de abrangência do óbito). Também a chefia é chamada, ou eu vou até o local da atenção básica, e a gente comefa a tratar o que fazer. Porque foi a óbito? Que ação que eles fizeram antes ou depois? $\mathcal{E}$ agora pra não acontecer mais? $\mathscr{E}$ um trabaffo centrado na 6usca ativa, é educação bem continuada mesmo, monto palestras para os ACS, com a 
epidemiologia; falo da imunização, das visitas domicifiares a todas as criancas no máximo dez dias depois do nascimento, esse é o acompanfiamento, inclusive a pesagem da criança.

São importantes os seminários sobre a MI, sobre os fatores que influenciam no ófito infantil, reafizar reuniōes nos municípios, promover oficinas com a integrafãa dos setores, intersetoriais com o PACS, PSF, Epidemiologia, Vigitância Sanitária, Pastoral da Igreja etc.

INa UBS se faz a visita a puérpera na residéncia com aproximadamente sete dias de vida da crianfa, verificando situafão habitacional e como que ta o cuidado da mãe na residência com a crianf̧a, com a figiene, com o umbigo. É a visão de como esta sendo atendida dentro de casa.

Muita orientafãa com relaşão as mães e os partos são feitas na Casa da Gestante, a gente não faz prénatal aqui,você encaminfia essa gestante pra Casa da Gestante, que é a casa da gestante, é a clinica especiafizada que faz o pré-natal pelo SUS, até a puericultura da criança até os três anos.

Existe parceria muito grande com a Pastoral da Crianfa, eu acho que é uma parceria das mais importantes que nós temos, porque elas trabalham, sem remuneração e com amor. Então eles também têm o grupo de gestantes, tem o grupo do peso, que é um elo entre a comunidade e a unidade de saúde. Tem também a missão Renascer que trabalha no tratamento da crianca desnutrida, com a pesagem. Também são importantes as palestras em escolas, sobre figiene, educação, alimentaf̧ão etc.

Outra afão é o incentivo do aleitamento materno que reduz bastante o indice de óbito, a gente tem um Comitê de Aleitamento, então a gente incentiva, como somos um Hospital de referência pela Regionah, nós orientamos todos os municipios no Aleitamento Matemo.

Mas agora existe um outro foco, em relafão aos Comitês, no sentido de incentivar a formafãa de Comitê Intra-hospitalar de Prevenfão da Mortafidade Infantil, no sentido de detectar onde estariam os problemas que aparecem dentro do hospital, a gente tem um comitê, a gente tem controle de gestante, da prevenção no hospital.

Mediante uma af̧ão multidisciplinar e multisetorial muitos óbitos puderam ser evitados.

Esta categorização se reveste de especial importância, pois neste DSC, os profissionais falaram de suas iniciativas frente às dificuldades que se apresentam no cotidiano da realização de Programas e suas ações direcionadas para a gestante e crianças. Nessas iniciativas há, concretamente, a participação de cada profissional com suas experiências, vivências, num esforço conjunto para superar as barreiras.

São explanadas iniciativas que objetivam melhorar os indicadores, evitar a morte e mostrar a qualidade de seus serviços. Assim, podemos listá-las como experiências exitosas no combate à mortalidade infantil evitável:

$\checkmark \quad$ estabelecimento efetivo dos Comitê de Prevenção de Mortalidade Infantil nos municípios com representação dos serviços municipais;

$\checkmark$ formação de Comitês Intra-hospitalares para discussão de estratégias preventivas no serviço de assistência hospitalar;

$\checkmark \quad$ produção, pelos Comitês Regionais, de informações que realmente sejam utilizadas como subsídios para as ações;

$\checkmark \quad$ investigação de $100 \%$ dos óbitos infantis ocorridos;

$\checkmark \quad$ congregação de secretários de saúde nas RegS e discutir sobre a MI e sua importância, inclusive política, nos indicadores dos municípios; 
$\checkmark \quad$ realização de câmara técnica nas RegS para discussão dos óbitos infantis em investigação, bem como para o traçado de metas e orientações para os municípios adstritos;

$\checkmark \quad$ valorização da Carteira da Gestante como portadora de informações úteis e necessárias em todo ciclo gravídico e parto;

$\checkmark \quad$ realização de feedback dos Comitês aos serviços nos quais ocorrem os óbitos mediante uma carta com caráter informativo e educativo, bem como aos profissionais que atenderam à criança;

$\checkmark \quad$ estabelecimento de Programa de Estudo sobre a mortalidade de menores de um ano;

$\checkmark \quad$ mobilização e maior incentivo aos ACS na vigilância às crianças menores de uma ano;

$\checkmark \quad$ serviços de vigilância epidemiológica municipal e regional enfatizando a todo tempo os indicadores, montando planilhas, enviando aos setores / municípios, chamando os responsáveis quando ocorre óbito, ou mesmo indo até a unidade básica; $\checkmark \quad$ incentivo contínuo à busca ativa, mediante educação continuada, principalmente aos ACS utilizando dados epidemiológicos;

$\checkmark \quad$ educação continuada, junto as equipes de saúde, contemplando todas as áreas de atenção à criança da imunização à puericultura para que seja utilizada em visitas domiciliares pelos ACS;

$\checkmark \quad$ seminários e oficinas sobre a MI que congregue o PACS, PSF, Serviços de Epidemiologia, Vigilância Sanitária, Pastoral da Criança, enfim todos os segmentos possíveis;

$\checkmark \quad$ realização efetiva de visitas domiciliares para checar condições do cuidado em casa;

$\begin{array}{ll}\checkmark & \text { realização de palestras em escolas sobre higiene, educação, alimentação etc; } \\ \checkmark & \text { estabelecimento de uma Casa da Gestante que centralize orientações com a }\end{array}$ devida qualidade;

$\checkmark$ parceira efetiva com a Pastoral da Criança no desenvolvimento dos Programas governamentais e os da própria Pastoral;

$\checkmark \quad$ estabelecimento de Comitês de Aleitamento Materno nas RegS com responsabilidade de apoiar, acompanhar e orientar os outros municípios da regional; 
$\checkmark \quad$ ações multidisciplinares e multisetoriais na prevenção do óbito infantil.

Os profissionais falam do que sabem, do que vêem, como vêem e como vivenciam os Programas, Ações e Estratégias de Prevenção da Mortalidade Infantil. Percebe-se empenho e uma riqueza de idéias desenvolvidas com esforços conjuntos e muita responsabilidade.

Os Comitês de Prevenção, principalmente os Regionais, são valorizados, apesar de pouco conhecidos pelos profissionais da ponta. No entanto, são tidos como responsáveis por boa parte da articulação entre os municípios, serviços e profissionais que atendem à criança e ao óbito. Há expectativa quanto à constituição dos Comitês Municipais e Intra-Hospitalares para o fortalecimento do processo preventivo. Como deixar de constituí-los solidamente diante dessas representações?

\subsubsection{DIFICULDADES ENCONTRADAS PARA A PREVENÇÃO DA MORTALIDADE INFANTIL E NOS COMITÊS-questão 2 $\boldsymbol{\&}$} SUGESTÕES PARA MINIMIZAR OU RESOLVER AS DIFICULDADES APONTADAS-questão 3

As respostas às $2^{\mathrm{a}}$ e $3^{\mathrm{a}}$ questões foram lidas juntas em suas categorizações, pois, para melhor recorte do discurso, optou-se utilizar para as sugestões as mesmas categorizações das dificuldades. Os próprios atores apontam as dificuldades para manter o trabalho dos Comitês ou para implantá-los. Para os profissionais que não têm ligação direta com a estratégia dos Comitês, a pergunta foi direcionada para o seu serviço cotidiano de prevenção do óbito infantil, quer em instância regional ou municipal. A essência da pergunta não se altera: são as dificuldades que os sujeitos sociais encontram para prevenir o óbito infantil. 
DISCURSO DO SUJEITO COLETIVO - QUESTÃO 2

Pergunta 2)Fale sobre as dificuldades de
implantaça do Comitê de Prevenção da
Mortalidade Infantil e/ou de execução do trabalho
preventivo do óbito infantil nesta Regional $/$
Municipio/serviço.

Tabela 20: Distribuição das categorizações construídas (A2 F2) em relação à pergunta 2 (Fale sobre as dificuldades de implantação do Comitê elou de execução do trabalho preventivo do óbito infantil nesta regional / municipio / serviço) segundo freqüência $\left(\mathrm{n}^{\circ}\right)$ e força de compartilhamento das idéias (\%) apresentadas nos discursos individuais e coletivo, Paraná, 2007.

\begin{tabular}{l|lrr}
\hline \multicolumn{2}{l}{ Categorias } & \multicolumn{1}{c}{$\mathbf{N}^{\circ *}$} & $\%^{* * *}$ \\
\hline A & Dificuldade estrutural & 18 & 22,50 \\
B & Dificuldade operacional e de recursos humanos & 27 & 33,75 \\
C & Dificuldade motivacional / sensibilização & 19 & 23,75 \\
& (profissional e clientela) & & \\
D & Dificuldade técnica ligada à qualidade da & 26 & 32,50 \\
& assistência & & \\
E & Dificuldade gerencial, política e financeira & 39 & 48,75 \\
F & Sem dificuldade / sem idéia & 10 & 12,25 \\
\hline \multicolumn{2}{l}{ Total das entrevistas } & $80^{* *}$ & \\
\hline
\end{tabular}

Fonte: Qualiquantisoft 2007 .

Nota:

"Número de vezes que a idéia aparece nos discursos.

**Total de entrevistados.

***Esse percentual representa a força de representatividade, ou compartilhamento da idéia nas respostas individuais e na formação do DSC da categoria na questão.

\section{DisCURSO do SUJEITO COLETIVO - QUESTÃo 3}

Pergunta 3)Que sugestões você faz para que as difficuldades que mencionou possam ser resolvidas ou minimizadas?

Tabela 21: Distribuição das categorizações construídas (A3 F3) em relação à pergunta 3 (Que sugestões você faz para que as dificuldades que mencionou sejam resolvidas ou minimizadas) segundo freqüência $\left(\mathrm{n}^{\circ}\right)$ e força de compartilhamento das idéias (\%) apresentadas nos discursos individuais e coletivo, Paraná, 2007.

\begin{tabular}{|c|c|c|c|}
\hline \multicolumn{2}{|c|}{ Categorias } & \multirow{2}{*}{$\frac{\mathbf{N}^{\circ *}}{12}$} & \multirow{2}{*}{$\frac{\% \text { *** }}{15,00}$} \\
\hline $\mathbf{A}$ & Sugestão estrutural & & \\
\hline $\mathbf{B}$ & Sugestão operacional e de recursos humanos & 15 & 18,75 \\
\hline C & $\begin{array}{l}\text { Sugestão motivacional / sensibilização (profissional e } \\
\text { clientela) }\end{array}$ & 23 & 28,75 \\
\hline D & Sugestão técnica ligada à qualidade da assistência & 23 & 28,75 \\
\hline $\mathbf{E}$ & Sugestão gerencial, política e financeira & 41 & 51,25 \\
\hline $\mathbf{F}$ & Sem sugestão / sem idéia & 3 & 3,75 \\
\hline \multicolumn{2}{|c|}{ Total das entrevistas } & $80^{* *}$ & \\
\hline $\begin{array}{l}\text { Fonte: Qualiquantisoft, 2007. Nota: } \\
\text { "Número de vezes que a idéia aparece nos discursos. } \\
\text { **Total de entrevistados. } \\
\text { ***Esse percentual representa a força de representatividade, ou compartilhamento da idéia nas } \\
\text { respostas individuais e na formação do DSC da categoria na questão. }\end{array}$ & \multicolumn{3}{|c|}{$\begin{array}{l}\text { A relação entre a força de compartilhamento das categorias } \\
\text { das dificuldades apontadas e as das sugestões indicadas, sinalizam } \\
\text { consistência e fidedignidade no trabalho de categorização, por } \\
\text { apresentarem perfis equivalentes (Tabela } 20 \text { e } 21 \text {, Gráficos } 4 \text { e 5). }\end{array}$} \\
\hline
\end{tabular}


Gráfico 4: Distribuição das categorizações construídas (A2 F2) em relação à pergunta 2 (Fale sobre as dificuldades de implantação do Comitê e/ou de execução do trabalho preventivo do óbito infantil nesta regional / municipio / serviço) segundo a força de compartilhamento das idéias (\%) apresentadas nos discursos coletivos, Paraná, 2007.

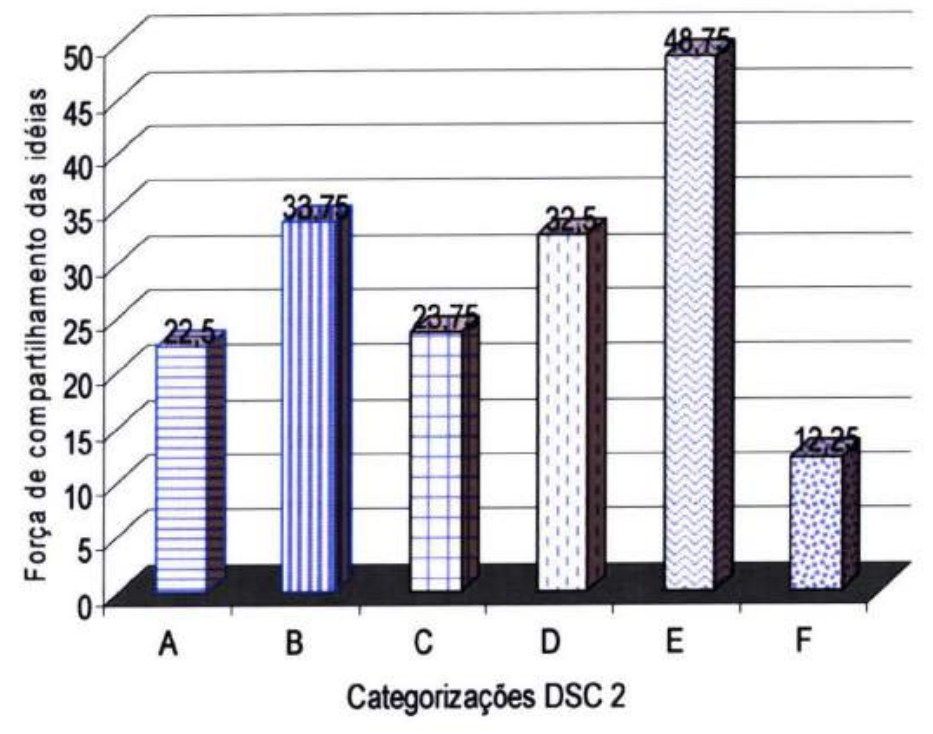

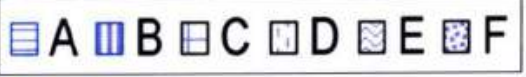

Gráfico 5: Distribuição das categorizações construídas (A3 F3) em relação à pergunta 3 (Que sugestões você faz para que as dificuldades que mencionou sejam resolvidas ou minimizadas) segundo a força de compartilhamento das idéias (\%) apresentadas nos discursos coletivos, Paraná, 2007.

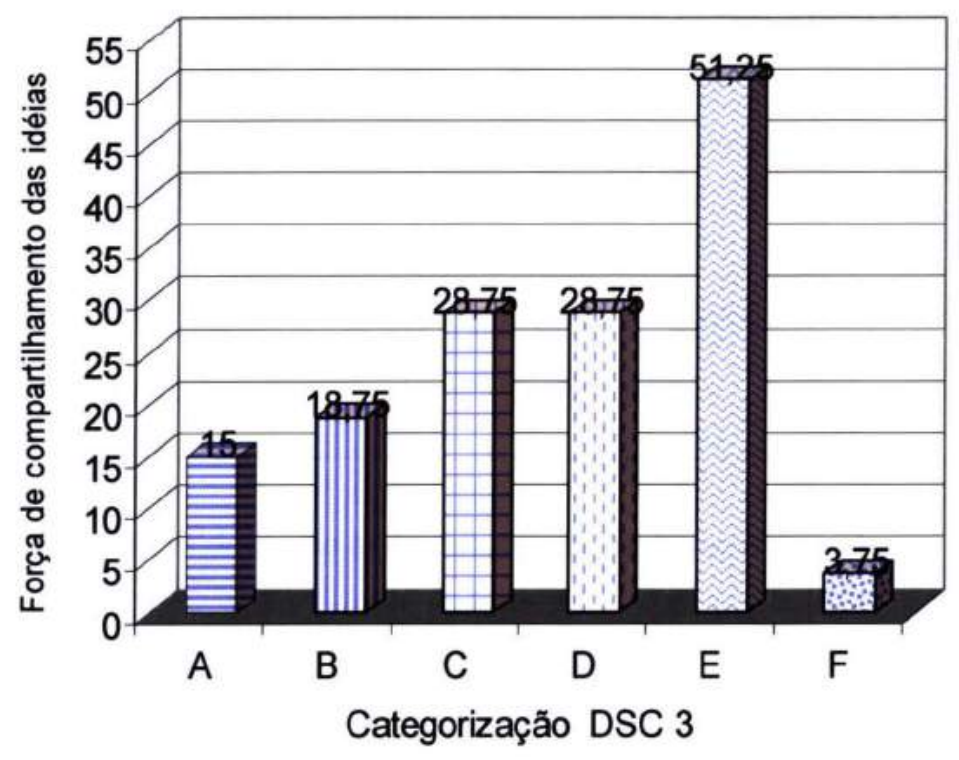

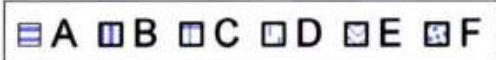


Antes de iniciarmos a discussão sobre as categorizações propriamente ditas e das sub-categorias construídas para melhor leitura e compreensão dos discursos, apresentaremos para cada categoria, ou seja, de A a F, tanto para as dificuldades apontadas como para as sugestões feitas, os critérios de inclusão estabelecidos. Estes critérios foram eleitos para que a categorização pudesse ser norteada por especificidades homogêneas e, assim, se mantivesse o rigor metodológico e de fidedignidade aos discursos trabalhados.

\section{DSC A2: DIFICULDADE ESTRUTURAL}

\section{Critérios de Inclusão:}

a) Barreira geográfica e distância;

b) Estrutura física do setor;

c) Falta ou insuficiência de: condução / transporte; rede informatizada;

d) Deficiência (falta ou insuficiência) de serviços: vagas UTI; acompanhamento de um gestante / criança; serviço de referência; sistema de transferência.

\section{DSC B2: DIFICULDADE OPERACIONAL E DE RECURSOS HUMANOS}

\section{Critérios de Inclusão:}

a) Comunicação (contate envio e recebimento de material, dados e investigaçð̃es) entre os Comitês Estadual / Municipal / Hospitalar.

b) Obtenção de documentos, informaçð̃es e dados (inexistente, incompleto, ilegível, confiável etc).

c) Quantidade e rotatividade de profissionais no Estado / Município / Serviços.

d) Realização da investigação mediante visitas e entrevistas.

e) Gerenciamento das atividades cotidianas dos serviços: da rede básica, ambulatorial e hospitalar.

DSC C2: DIFICULDADE MOTIVACIONAL / SENSIBILIZAÇÄO (PROFISSIONAL E CLIENTELA)

Critérios de Inclusão:

a) Aceitação, adesão e fide ização às orientações realizadas bem como à encaminhamentos realizadcs.

b) Querer fazer i participar: a falta de interesse, motivação pessoal; falta de compreensão da importância de; envolvimento.

c) Problemas com a ecucaçăo em saúde, desconhecimento da população.

d) Problemas sociais advindos da cultura, principalmente em zona rural.

e) Sentimentos de frustração, rejeição do óbito infantil por causas facilmente evitáveis. 
DSC D2: DIFICULDADE TÉCNICA LIGADA À QUALIDADE DA ASSISTÊNCIA

\section{Critérios de Inclusão:}

a) Questão da especialidade e da qualidade técnica: capacitação; existência ou presença do profissional especializado; conduta esperada.

b) Melhoria no desenvolvimento de ações e Programas.

c) Responsabilização por falhas em cada esfera de competência profissional.

\section{DSC E2: DIFICULDADE GERENCIAL, POLÍTICA E FINANCEIRA}

\section{Critérios de Inclusão:}

a) CPMI - o que é? objetivos? sua formação? qual o seu caráter? questão de reuniőes e participação.

b) Informaçб̃es junto à rede privada e/ou conveniada.

c) Parcerias Hospital / Município / Regional para terapia intensiva.

d) Continuidade e co-responsabilidade entre os serviços e instituiçzes.

e) Trabalho em equipe multiprofisisonal $\mathrm{e}$ intersetorial.

f) Gerenciamento das aç⿸̃es a serem tomadas frente aos problemas identificados.

\section{DSC F2: SEM DIFICULDADE/SEM IDÉIA}

\section{Critérios de Inclusão:}

Relato de não dificuldade ou de não saber dizer quais dificuldades são enfrentadas no local / serviço.

A seguir serão relatados os critérios de inclusão para todas as categorias de sugestões, os quais foram estruturados intencionalmente seguindo a linha eleita para as dificuldades. Nesse sentido buscou-se no discurso caracterizar ou 'ajuntar fragmentos' que pudessem mostrar a cada dificuldade a existência de sugestão de acordo com a percepção dos atores sociais entrevistados. Todo esse processo de 'garimpagem' exigiu concentração e atenção a cada fragmento discursivo $(\mathrm{ECH})$ e às idéias centrais que eles portavam.

\section{DSC A3: SUGESTÃO ESTRUTURAL}

\section{Critérios de Inclusão:}

a) Barreira geográfica e distância.

b) Estrutura física do setor.

c) Condiçð̃es gerais: condução / transporte; rede informatizada.

d) Serviços: vagas/leitos UTI; acompanhamento de um gestante / criança; serviço de referência; sistema de transferência; condiç̃es gerais de trabalho. 
DSC B3: SUGESTÃO OPERACIONAL E DE RECURSOS HUMANOS

\section{Critérios de Inclusão:}

a) Comunicação (contato; envio e recebimento de material, dados e investigações) entre os Comitês Estadual / Municipal / Hospitalar.

b) Obtenção de documentos, informações e dados (inexistente, incompleto, ilegível, confiável etc).

c) Quantidade e rotatividade de profissionais no Estado / Município / Serviços.

d) Realização da investigação mediante visitas e entrevistas.

e) Gerenciamento das atividades cotidianas dos serviços: da rede básica, ambulatorial e hospitalar.

\section{DSC C3: SUGESTÄO MOTIVACIONAL/SENSIBILIZAÇÃO (PROFISSIONAL E CLIENTELA)}

\section{Critérios de Inclusão:}

a) Aceitação, adesão e fidelização às orientações realizadas bem como à encaminhamentos realizados.

b) Querer fazer / participar: a falta de interesse, motivação pessoal; falta de compreensão da importância de; envolvimento; solidariedade.

c) Problemas com a educação em saúde, desconhecimento da população.

d) Problemas sociais advindos da cultura, principalmente em zona rural.

e) Sentimentos de frustração, rejeição do óbito infantil por causas facilmente evitáveis.

f) Humanização do atendimento.
DSC D3: SUGESTÃO TÉCNICA LIGADA À QUALIDADE DA ASSISTÊNCIA

Critérios de Inclusão:

a) Questão da especialidade e da qualidade técnica: capacitação; existência ou presença do profissional especializado; conduta esperada; preenchimento da DO.

b) Melhoria no desenvolvimento de ações e Programas.

c) Responsabilização por falhas em cada esfera de competência profissional.

DSC E3: SUGESTÃO GERENCIAL, POLÍTICA E FINANCEIRA

\section{Critérios de Inclusão:}

a) CPMI - implantação o que é? Presidência? objetivos? sua formação? qual o seu caráter? questão de reuniões e participação.

b) Informações junto à rede privada e/ou conveniada.

c) Parcerias Hospital / Municipio / Regional para terapia intensiva e outras açðes.

d) Integração e co-responsabilidade entre os serviços e instituições: feedback das informações, foliowup.

e) Trabalho em equipe multiprofisisonal e intersetorial.

f) Gerenciamento das ações a serem tomadas frente aos problemas identificados na investigação.

g) Divulgação do Comitê e de Programas.

\section{DSC F3: SEM SUGESTÄO/SEM IDÉLA}

\section{Critérios de Inclusão:}

Relato de não dificuldade ou de não saber dizer quais dificuldades são enfrentadas no local/serviço 
$\mathrm{Na}$ seqüência relacionam-se as categorizações e subcategorizações designadas param cada discurso coletivo das dificuldades apontadas e sugestões relatadas para que se possa visualizar a coerência entre as mesmas.

Para relato das dificuldades, os discursos, de maneira geral, foram mais longos, como se pode notar diante das sub-categorizações, com citação de exemplos. À medida que uma dificuldade era verbalizada, a outra emergia instantaneamente, como se houvesse uma expressão de situações guardadas, que precisavam ser ouvidas. A intensidade de compartilhamento das dificuldades estruturais foi maior $(22,50 \%)$ do que a intensidade das sugestões estruturais $(15,00 \%)$ (Tabela 20 e 21, Gráficos 9 e 10).

DSC A2: Dificuldade estrutural

* INFORMACÃO

* ACESSO

* estrutura física

* referência / contra-Referêncta e leitos de UTI NEONATAL E PEDIATTRICA

* transporte especialtzado
Notou-se que as sugestões foram mais enxutas, mais específicas, ou seja, mais diretas na expressão-discursiva. A percepção é a de que as sugestões foram mais elaboradas e refletidas pelos profissionais que sentem a responsabilidade em seu cotidiano de trabalho. Assim, como as respostas contendo sugestões foram mais precisas, as sub-categorizações foram também mais ampliadas, mais generalizadas, com discursos mais enxutos. As condições gerais e trabalho podem contemplar as dificuldades de informação, acesso e de estrutura física assim temos uma grande ênfase conjuntural à assistência terciária (Tabela 20 e 21 , Gráficos 9 e 10).

DSC A3: Sugestão estrutural

* condicóes gerais de trabalHo

* serviço especializado

* leitos de uti neonatal / pedítrica 
DSC B2: Dificuldade operacional e de recursos humanos

- atividades do servico

* normas de tRABalHo

* iNFoRMAÇÃo

* RH

DSC C2: Dificuldade motivacional / sensibilização (profissional e clientela)

* cOMPREENSÃO / ADEsÃO (dos profissionais)

* compreEnsão / adesão (da população)

* senstbilIzação / motivacão

- enVolvimento

* sentimento de frustração / angústia

* social

* conhectmento da populacão

* educacáo em saúde

Entre as categorizações sobre as dificuldades e sugestões operacionais e de RH houve equilibrio entre os DSC B2 e DSC B3, no entanto, a força de representação das dificuldades foi $33,75 \%$, mais intensa do que as sugestões (18,75\%) (Tabela 20 e 21, Gráficos 9 e 10). Sugerindo o reconhecimento da dificuldade de se operar um Programa e, em especial, as dificuldades intensas com os recursos humanos que ocorrem em certos municípios do estado do Paraná.

DSC B3: Sugestão operacional e de recursos humanos

* atividaades do servico

* informacão

* normas de trabalHo

* $\mathrm{RH}$

DSC C3: Sugestão motivacional/sensibilização (profissional e clientela)

* compREENSÃO / ADEsÃO (dos profissionais).

- compreEnsão / aDEsÃo (da população)

* senstbillzação / motivaç̃o

- educacáo em saúde

* RECONHECIMENTO / VALORIzACÃo pRofisstonal 
No tocante à motivação e sensibilização, estas foram mais expressivas no compartilhamento das sugestões $(28,75 \%)$ do que na evidenciação das dificuldades $(23,75 \%)$. Talvez porque seja difícil elaborar verbalmente um relato de desmotivação, ou falta de reconhecimento, ou pelo 'medo' de serem reconhecidos pelo que falaram nas várias entrevistas (Tabela 20 e 21, Gráficos 9 e 10).

DSC D2: Dificuldade técnica ligada à qualidade da assistência * capacttaça

* especialtoade

* REsPONSABILIDADE PROFIsSional

* melhoria de programa

DSC E2: Dificuldade gerencial, política e financeira

* comitês

* participacão

* parcerias

* integração e co-responsabilidadoe entre os SERVICOS

* eqUiPE mULTIPROFISSIONAL E INTERSETORIALIDADE

* mecanismos de ação para os sevicos

* modelo de atencão / gestão

- fiNANCEIRo
DSC D3: Sugestão técnica ligada à qualidade da assistência

* capacttacáo

* RESPONSABILIDADE PROFISSIONAL

* melhoria de programa

As dificuldades ligadas à qualidade da assistência relatadas pelos atores foram compartilhadas com maior expressão $(32,50 \%)$ do que as sugestões $(28,75 \%)$ feitas para resolver ou minimizar problemas dessa ordem. Talvez isso tenha ocorrido pelo grau de complexidade para encaminhamentos que visem a melhoria da qualidade e capacitações (Tabela 20 e 21, Gráficos 9 e 10).

DSC E3: Sugestão gerencial, política e financeira

* COMITÉs

- participaçáo

- parcerias

* integração e co-responsabilidoade entre os SERVICOS

* EQUIPE MULTIPROFISSIONAL E INTERSETORIALIDADE

* mecanismos de acão para os serviços

* modelo de atenção / gestão

- financeiro 
As dificuldades gerenciais, políticas e financeiras recordistas $(48,75 \%)$ e paralelamente as sugestões gerenciais , políticas e financeiras, também recordistas $(51,25 \%)$, referemse à gerência geral do sistema de saúde no estado do Paraná; aos programas e estratégias, seus posicionamentos políticos e dificuldades financeiras. Houve homogeneidade na prevalência das dificuldades e das sugestões relatadas. Entretanto, as sugestões apresentaram uma expressão muito mais forte entre todas as categorias (de A3 a F3), foram responsáveis por mais de $50 \%$ das expressões discursivas dentre as demais sugestões (Tabela 20 e 21, Gráficos 9 e 10).

Foram proferidas idéias para que se melhore o sistema de saúde como um todo. Esses dados traduzem a esperança dos atores sociais, a visão de perspectivas possíveis para melhoria das dificuldades apontadas, além de atitude pró-ativa de compromisso com a vida, pelos gestores e profissionais da área da saúde.

As categorias $\mathrm{F}$, tanto para as dificuldades como para as sugestões, foram as categorias que surgiram nos discursos de profissionais que não sabiam relatar dificuldades e tampouco sugestões. A única coisa interessante para se comentar nessa situação de 'sem idéia' é que mesmo sem idéias, esses profissionais falaram mais de suas 'ausência de dificuldades' (12,25\%) do que da 'ausência de sugestões' (3,75\%) (Tabela 20 e 21, Gráficos 9 e 10).

Na seqüência estão os DSC construídos com as respostas às estas duas questões que caracterizamos nesta parte deste capítulo. 


\section{DISCURSO DO SuJEITo Coletivo - questões 2 E 3}

\section{DSC A2: Dificuldade estrutural}

\section{INFORMACÄO}

As dificuldades giram em torno da questão da informação, a rede ainda está para ser informatizada, isso é um problema sério, ainda são várias instâncias de saberes dentro Secretaria de Saúde, ainda fica muito truncado o serviço de Informação.

ACESSO

Aqui nós temos a dificuldade da mãe ta vindo até a unidade, em virtude da distância, o acesso, a questão geográfica interfere também. Também é muito dificil chegar até o local de residência de muitas pessoas, para trazer a informaf̧ão. Com a dificuldade da distância, a gente acompanfia só os casos extremos mestmo. Para essa Vnidade o acesso é muito difficil dat tem também o problema das mães trazerem as crianças elas lêm que atravessar linfia đo trem com carrinfiv... é impossível, algumus mäes até cuem ita linfia! 'A nossa 'UBS' é muito longe vamos até a residência e näo encontramos as pessoas em casa às vezes,

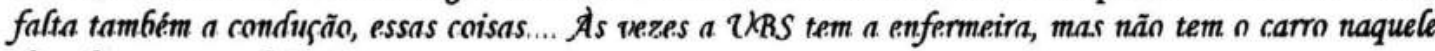
dia, ela programa dai não consegue.

Muitas vezes, como estamos sem carro a gente tem que ir fazer puericultura a pé, é longe e, às vezes deixando alguns trabalhos a serem feitos aqui na unidade. Tinfia um problema com o carro para realizar as entrevistas, melhorou com a compra do nosso carro da vigilância.

ESTRUTURA FISICA

Temos um problema de estrutura aqui pra chegar na VTI JNeonatal agente passa por outras unidades intensivas.

Além disso, também se tem um problema maior: é espaço para a UTi Neonatal. $\mathcal{A}$ gente cresceu em aparelfiagem, a gente ta numa situação, não digo adequada, mas 6em 6oa; mas, a questão de espafo, ta bem limitado, vivemos superlotados.

\section{REFEREAVCIA / CONTRA-REFEREAVCIR e LEITOS DE UTI NEONATRL E PEDIRTRICA}

Falta também um serviço de referência, pra que essa gestante de risco seja acompanfiada. Um Hospital de referência para gestantes de alto risco e sem VTI JNeonatal, esse problema é grave, não tão aceitando a situafão. Muitas pacientes chegam aqui com 6olsa rota, com 26 a 28 semanas, são fetos quase que inviáveis, mas em alguns lugares que tem UTI Neonatal podem perfeitamente sobreviver. A gente encontra dificuldade em mandar a crianca ainda dentro da barriga da mãe para se fazer a cesária lá e, já ter uma assistência imediata do especialista e do serviço de neonatologia de UTH, só aceitam a criança. Ai a gente é obrigada a fazer a cesariana, porque não dá pra esperar mais, e depois transporta a crianfa. $A$ transferência para a UTh é um problema grave; a Central de Leitos é outro problema. Acho que isso ai também pode acarretar em prejuizo ao recém-nascido prematuro que já está debilitado. Embora a gente tenfa UTI Neonatal a gente tem uma demanda reprimida, muitos municipios encaminfam ainda pacientes pra cá, a dificuldade da VTi é a superlotação que é constante.

Agora, sobre a volta a instituifão de origem e de que maneira ele vai ser acompanfiado, qual é a distância da residência...não sabemos. Se existem alguns ambulatórios de followup para esses pacientes, eu acfio que ele é pouco divulgado. Eles deviam ser incrementados, inclusive com a participação dos afunos do Curso de Medicina, porque demonstraria pra eles que o paciente que ficou internado numa UTI precisa ser acompanfiado depois, porque as taxas de MI estão diretamente relacionadas ao periodo perinatah TRANSPORTE ESPECIALIZADO

O transporte antigamente era extremamente deficiente, mesmo com a vaga na UTH para oferecer, nós tínhamos um transporte inadequado. A criança chegava pra gente já sem condições, ou ela estava extremamente seqüelada e ia a óbito imediatamente, ou não agüentava nem o transporte. Com o Suporte Avanfado de Vida melhorou sensivelmente a questão do transporte, a gente recebe as crianças, com o transporte adequado e nós conseguimos fazer a nossa parte que é o atendimento aqui na UTT. 


\section{DSC A3: Sugestâo estrutural}

\section{CONDDIÇÕES GERAIS DE TRRABALFO}

Se a gente não tem o apoio e a estrutura, não adianta só se sensibilizar, tem que ter uma estrutura pra isso, principalmente na rede básica de saúde. Deveria ser feita uma re-divisão das equipes do PSF, pensando mais geograficamente, os postos deveriam ser mais próximos das casas. Devemos ter um carro para o serviģo de investigafão do óbito. Pra suprimir essa etapa de transporte de ambulância, se possivel a criança deve ser transportada intra-útero. Deveria estar com uma rede toda informatizada, na qual você conseguisse vários níveis de agregação dessa informafão com viabifidade de rapidez da mesma. Para haver serviço deve-se ter organização nesse sentido, quanto ao CIH a gente não tinfia um lugar para por prontuário, não tinfia um armário pra guardar uma pasta, para guardar os impressos de investigafão, enfim nenfuma estrutura.

SERVIÇO ESPECIALIZADO

Também deve ter um ambulatório, pra gestante de alto risco, e a gente não dispõe disto. Elas ficam trocando de unidades básicas, isso não se faz, precisa de ambulatório médico de referência certa para a gestante de alto risco.

\section{LEITOS DE UTI NEONGTAL / PEDIATTRICA}

Distribuir methor o número de leitos pelas cidades que realmente precisam ter pólos de atendimento pra VTI J Neonatal, UTI Pediátrica, mas com estrutura pra atender. '́ uma coisa bem política, eu acredito que não é só aumentar leitos terciários nos servifos de referência. Porque aumentar leito até que não é tão dificil, e a quafidade? Devem se aumentar esses leitos com quafidade: de número de funcionários (o que falta é mais enfermeiro), de estrutura fisica, de equipamentos. Pois a falta de uma estrutura fisica adequada impede que haja um ambiente adequado pro serviço, isso prejudica demais o trabalho.

A VTI Neonatal deve ser fechada, para evitar contaminação. A disponibilidade de leitos desse tipo no estado do Paraná alcançará uma ação efetiva na prevenção, mas a distribuição desses leitos tem que ser norteada por uma necessidade regional. Deve ser considerada uma pequena distância geográfica do local onde pode haver a necessidade do leito, pois quando a crianfa precisa de atendimento imediato, ela não pode esperar um dia, dois dias ou até três dias pra que esse atendimento ocorra no mais tardar duas foras de viajem, você deve ter condição de colocar essa crianfa no serviço especializado.

Entre as dificuldades dos profissionais na realização de seu trabalho de prevenção da mortalidade infantil está o problema da informatização do serviço o que dificulta a própria integração dos serviços internos. Também é indicado o acesso ao serviço. Neste caso, o acesso é ligado à distância longa e / ou presença de barreiras físicas como linhas de trem que oferecem perigo à clientela. Também há dificuldade de deslocamento da equipe devido às barreiras físicas e à ausência de carros ou similar para o serviço.

$\mathrm{O}$ reduzido espaço físico emerge na fala relativa às UTIs. Em relação ao número de leitos terciários, há muita ênfase nos discursos quanto a insuficiência dos mesmos; e conseqüentemente a superlotação dos serviços que existem no estado. Representação que confirma as conclusões do processo de investigação que apontam a necessidade de acesso terciário. 
Cabe à Central de Leitos do estado melhorar seu serviço, na voz dos atores sociais. Ficam claras: a falta de serviços regionalizados de referência, à ausência de ambulatório de folow up para essas crianças, e que o transporte para essas crianças que necessitam de leito terciário melhorou, propiciando a manutenção da vida.

Os profissionais dizem, claramente, que é impossível manter um serviço seja na rede básica ou hospitalar para cuidados terciários, se não houver uma logística mínima para que as ações aconteçam, para que as informações cheguem e sejam vistas. Para implantar serviços de saúde é exigido o adequamento da estrutura física, bem como, a qualidade do pessoal técnico. Os atores sociais têm se preocupado com isso.

A história de adequação de leitos para UTIs Neonatal e Pediátrica mostra a acomodação de uma situação de necessidade pela improvisação de cantinhos nas unidades hospitalares que, geralmente, deixam a desejar tanto quanto ao desempenho de trabalho com qualidade como aos padrões exigidos, pelas resoluções governamentais federais. Poucos são os serviços, públicos como particulares, com construção recentes e adequadas.

Os registros no SIMI também apontam para a situação deficitária da referência para gestantes de risco, da assistência hospitalar e de leitos terciários, nas recomendações de medidas de prevenção e responsabilização pelos óbitos. Contexto que tende a piorar tendo em vista os dados do SIM que apontam por proporções cada vez maiores de baixo peso ao nascer e duração não adequada das gestações.

\section{DSC B2: Dificuldade operacional e de recursos humanos}

\section{ATVIDADES DO SERVIÇO}

Outro fator é o grande volume de consultas, aqui na VBSS, são muitas consultas, o recorde foram 42 consultas de manfiã, estamos tentando limitar em 30 consultas. Mas, se você atende 30, amanfia a demanda vai pra 40, você cria essa própria demanda; desta maneira tá dificicil de sair pra fazer visita, que é muito importante. Vejo claramente que a gente ta "tampando o sol com a peneira", nós estamos ainda atendendo a demanda, praticamente a livre demanda, não estamos indo fazer a prevenção que é muito mais importante, não estamos indo lá ensinar. Eu tinfia que ta lá conversando, explicando uma série de coisas na casa das famílias.

\section{NORM TS DE TRABALFO}

As normas de trabalfo são diferentes em cada Hospital em que a paciente foi atendida, aí quando a gente precisa do prontuário encontra alguns que não fazem o prontuário. A gente precisa daquela fistória, dai não tem aonde 6uscar. Existem municípios que tem atendimento básico e fospitalar, mas não tem prontuário do recém-nascido, isso gera dificuldade pra investigaşão Muitas vezes não se consegue os 
prontuários dos Hospitais pra poder finalizar, essa é uma dificuldade grande! Muito grande! Tem melhorado porque foram adotadas estratégias, até de intervenção da $R S$.

Aqui nós não temos problema em relação ao acesso ao prontuário nos $\mathcal{H}$ ospitais, só um pouquinfio de demora, pede um prontuário demora 15, 20 dias. A gente tem notado também é a demora de vir de outras regionais, sem isso às vezes a gente não pode fechar o caso investigado. A gente encaminha as DOs para os municípios e eles têm dificuldades, com prontuário e com as visitas, eles não conseguem fazer as visitas, porque as vezes não encontra a mãe em casa.

INFOROACTO

Tem hospital que ta com prontuário informatizado, cada dia de internação gera assim... dez folhas ou mais, pra tirar cópia se toma impossivel, o jeito é ir lá no hospital e tentar resumir esse prontuário. $\mathcal{A}$ investigaf̧ão do óbito infantil tem uma conotafão que não é só você chegar e pegar um prontuário; tem que ir atrás, desde o pré-natal, às vezes desde o planejamento famifiar, das causas dos problemas.

Muitas dificuldades giram em torno da questão da informação, os próprios Programas do Ministério da Saúde, não deixam nós fazermos a desagregaf̧ão por Vnidade de A6rangência de VBSS, então isso uma dificuldade para o nivel locah, assim o serviço se torna precánio, moroso. Esse é um fator que emperra, ainda a gente tem muita deficiência na produção de dados, que são deficitánios, são sem quafidade, você tem que questionar a quafidade dos dados, a questão da informaşão ainda fica num sentido inatingiveh porque ainda você trabalfa com um dado que você tem que desenvolver para o nivel local, arrumar esses dados. NNo preenchimento dos relatónios pelos hospitais, pelos médicos, há informafões insuficientes e, também nas evolucões desde o momento da intermação, no momento do parto; na verdade desde o pré-natal. Dados médicos insuficientes no prontuário e nas $D$ D s pra que a gente possa formar uma investigação consistente, dados que são importantes pra ficar bem claras as peças do quebra-cabeças, pra juntar e a gente poder cuidar da assistência. Além disso, existem informações que às vezes você questiona se são verdadeiras ou não, a gente se preocupa com a veracidade dessas informaçōes, se são realmente aquilo mesmo que está anotado. Coletar as informações anotadas também fica dificil, pois a gente não consegue ler o que está escrito, é quase que ilegivel. Em municipios pequenos o problema é maior vc não consegue o prontuário, vai buscar no hospital os prontuários, muitos não têm informaf̧ão, é dificil! Temos um problema interno de dificuldade com computador. RHF

O grande problema do Estado é falta de Recursos Humanos. Aqui na RS, há uma falta de enfermeiras que poderiam ta colaborando. Fão há RH suficiente pra fazer uma ação que poderia ta methorando muito mais esse indice que nós temos $e$ isso precisa pra comitê funcionar redondinfio; além de pouquíssimos funcionários, ainda estão se aposentando. Mefhoraria se a pessoa tra6afhasse apenas com os Comitês, pelo menos um período totalmente dedicado a isso; isso hoje se toma impossivel, assim a gente trabalha com o PSF. Às vezes a gente não tem a equipe pra ta auxifiando o município, nossa estrutura aqui é pequena, chega ser composta por 'não técnicos na área! A gente não tem como acompanfiar toda a micro-área; assim aquela mãe de 17 anos, é de risco, mas gente não acompanfia tanto se vê que o nenê ta bem, daí a gente deixa. Agora, se a mãe já tem dificuldades, tem alguma doença e, tem o bebê com risco, a gente acompanfia mais.

Com a dificuldade de RH a gente fica brigando muito com as questões de investigafão nos municípios, - município não tem a equipe lá que possa desenvolver, esse é um dos 'nós' que enfrentamos. Para você formar equipe e ter os profissionais que podem participar, que tenfam tempo para isso, é dificil. Temos alguns profissionais daqui e de outras áreas, que estão em outras atividades também, pois são tantas as tarefas... $\mathcal{N a}$ atual conjuntura administrativa não vejo como melhorar isso a não ser com tra6altio voluntário. Veja a gente, na UBS, ta envolvido com muita coisa, às vezes falta tempo da gente ir fazer a investigafão, nenfium deixou de ser investigado, mas falta tempo pra gente se dedicar mais para esse tra6alho, tempo necessário para uma investigação completa, com mais detalhes.

Outra dificuldade normalmente é carga forária de tra6afho, principalmente em região mais distante de grandes centros, tem uma certa dificuldade de profissionais médicos pra dar cobertura no Hospital, em VTI Neo. A gente tem que dar um jeito e fazer, então há sobrecarga de horas de trabalho. Também a superlotação constante, na UTI Neo, dificulta o número ideal de funcionários atuando e aca6a elevando o stress no trabalho. Nesse sentido a rotatividade de profissionais dos municípios dificulta, a gente sofre muito. Está mudando todo o ano, principalmente o profissional de enfermagem, ele é mais rotativo. $\mathfrak{N a}$ 
verdade a enfermeira do município faz várias atividades: ela ta na epidemiologia, no PSF, atendendo no hospital e, afém disso, fica na contribuição da investigação, na análise dos óbitos no nivel do municipio.

\section{DSC B3: Sugestão operacional e de recursos humanos}

\section{ATVIDADES DO SERVIÇO}

Deveria ser feito um 6om planejamento das afões, assim tipo semanal, definifão de quem vai fazer a investigação $e$ as outras pessoas dos setores, estariam cobrindo aquele horário: assim outra realizando as outras tarefas. Acho que ta faltando um 6om planejamento. A única forma de ser melhorado o trabalto dos Comitês é que a pessoa trabalhe apenas com os Comitês, ter pelo menos um periodo do día dedicado a isso. Mesmo sabendo que isso é impossivel na atual conjuntura administrativa dentro da Secretaria de Estado de Saúde do Paraná.

Diminuiria alguns problemas se quando a paciente for internada pra acontecer "o imprevisto" então já orientar ela sobre isso, tudo isso depois "do acontecido", explica do Comitê e avisa pra ela que vai ter que explicar o atendimento que recebeu e que vai haver essa entrevista; assim eles talvez estejam mais receptivos, porque muitos não aceitam. Também, a gente respeita muito a questão de tempo, porque se falecer uma crianfa hoje, amanfia já sai fazendo investigą̧ão fica complicado, a gente costuma dá um tempo também pra mãe.

Os médicos precisam se reunir pra discutir, fizemos um curso com 140 colegas. Havia a idéia, mas não desenvolveu, de fazermos Vnidade de Discussão (nome que a gente deu para as reuniōes), a gente ia continuar a discutir, houve um começo, um esbofo. Eu me sinto isolado, distanciado, "tapando o sol com a peneira".

\section{INFORMAÇO}

Ter uma efetividade mediante as informaçöes em tempo hábih, em tempo real, de uma morte infantí. Hoje com o programa SIM/SIJNASC isto é facilitado. Assim o Comitê teria $100 \%$ de investigafão dos óbitos ocomidos.

O médico tem que prescrever mais no prontuário, ter mais detalhes, ser mais claros, principalmente quando a crianfa vai fazer a primeira consulta. Nesse momento tem que escrever mais se ta alterado também escrever mais sobre os achados normais. Quanto as DOs, tem que ser methor preenchida, fazer direitinfio, toda a fistória do bebezinfo. Quanto ao acesso aos prontuánios há necessidadé mesmo da gente ta fazendo cobrança e, eu não sei qual é a dificuldade que existe lá no hospital de formecer essa documentafão!

NORMAS ФE TRABALFO

$\mathcal{A}$ questão de gerenciamento técnico tem que ter comę̧o, meio e fim. Assim você vai primeiramente identificar a ocorrência do óbito infantih, aí vai identificar as causas desse problema e, por fim você vai ta enfrentando a causa de uma maneira muito mais efetiva.

Não somente ficar uma pessoa aqui e outra lá fazendo o trabafho. Tem que se reformular o processo de investigafão com critérios técnicos bem específicos. Acho que tem que resolver de forma profissional, quem faz o pré-natal deveria anotar todas as observaföes na Carteirinfia de Pré-natal; a gente vê que a gestante consultou várias vezes, mas no campo das observações, do resultado de exames não consta nada! Fica falha essa investigafão por falta de informafão.

\section{RHS}

Nós da RS precisamos de mais RH pra ta atuando nas áreas, pra diminuir essa demanda que temos hoje, em cima de todos os programas. Näo vou falar que falta de envolvimento dos profissionais que atuam no hospitah, eles tão envolvidos, eles têm vontade de fazer. Aqui a equipe da gente no municipio é a mesma coisa o pessoal ta envolvido, tanto é que houve uma queda extraordinária nos indices de mortafidade infantir, mas o problema é falta de pessoas mesmo, profissionais destinados para as afões, tendo em vista que os Programas tomam muito tempo. Assim a gente ta envolvido em muita coisa, então teria que ter mais tempo pra Comitê. Outra coisa é se manter essas equipes o máximo possivel nos municípios, não só pela questão da prevenfão da MI, mas também para outras funçöes: na epidemiologia, no planejamento saúde da famífia, hospital etc. Se os municipios tivessem esses profissionais concursados daria pra minimizar essa questão. No Estado mesmo, acontece essa rotatividade e essa politica, esse Comitê é novo, tem alguns 
médícos que tão recentes lá, mas a coordenafão mudou também. Assim mesmo o Paraná tendo uma politica, não tem $R \mathcal{F} \mathcal{H}$ pra fazer, pra desempenfiar.

As dificuldades operacionais dizem respeito aos sistemas de trabalho da rede básica e hospitalar. Mostram a dificuldade que existem na prática para deixar de ser envolvido pelo paradigma curativo e passar a realizar açñes de prevenção. Mudar a práxis revela-se difícil para os atores que falaram nesta pesquisa, demosntrando a complexidade do sistema de saúde.

Por outro lado, quando falam da demanda que está sendo criada, temos aí, uma expressão de que o serviço local tem uma boa capacidade de alcançar a população-objetivo, pois sua demanda potencial está crescendo. De acordo com COHEN e FRANCO $(1993$, p. 95) a demanda potencial é "função tanto da oferta adequada em quantidade e qualidade em relação ao tamanho e às carências do grupo a servir (disponibilidade dos recursos), como da acessibilidade em suas distintas dimensões (econômica, social, espacial e cultural)". Portanto, esses serviços estão sendo bem sucedidos por um lado e mal sucedidos por outro. $O$ insucesso, de acordo com os profissionais, refere-se à não saída da unidade para trabalhar a prevenção junto às famílias, em domicílio.

Em pesquisa realizada na rede básica de saúde, no município de São José dos Campos, ASSIS (2005, p.21) enfatiza a necessidade de considerar variáveis sociais individuais e culturais da comunidade quando se analisa a relação oferta-demanda nos serviços de saúde. Ressalta que "há um comportamento racional de exagerar no cuidado com a saúde quando o usuário não tem o peso do custo". Assim, alerta para que as inadequações devem ser analisadas, identificadas as causas e definidas ações para correções necessárias da utilização. Para essa abordagem sugere a inclusão na equipe de saúde de um profissional comunicador social, que com a utilização de instrumentos específicos para análise de demanda, poderá inclusive subsidiar a alocação de recursos humanos no SUS (ASSIS, 2005).

CARVALHO (2004, p.114) afirma em pesquisa do uso de serviços de saúde materno-infantil enfatiza que a "municipalização dos serviços, implantação de novos serviços ambulatoriais e hospitalares e aumento no número de unidades ambulatoriais por habitante e de leitos SUS por habitante" causaram importantes 
alterações na utilização dos serviços. A pesquisadora recomenda contínuo estudo da demanda de serviço, com organização de informações em bancos de dados.

Dizem os nossos entrevistados que é preciso desenvolver mais programas de investimento em capital humano, para que o preparo de mão de obra seja incorporado pelos programas de saúde.

Para prevenir precisa-se de evidências, essas evidências devem estar registradas por completo em documentos do cliente (não do médico), que são seus prontuários de atendimento ambulatorial e hospitalar, se não há documentos, não há informações, não há como rastrear as evidências.

Como dar continuidade entre o acompanhamento de saúde básico e 0 hospitalar, ou seja, integrá-los num objetivo único: a saúde e vida do cliente? Como contar com um contingente profissional maior e melhor preparado no setor saúde do Estado? Como investigar os óbitos infantis ocorridos sem anotações de atendimento à criança? Alguns serviços com tantos recursos e outros sem nenhum, como torná-los eqüitativo ${ }^{1}$, para melhor atender à população? Como acreditar no que está registrado nos prontuários, ao se analisar os documentos e se comparar as informações com o desfecho? Como manter os Comitês Regionais sem pessoal capacitado e preparado para gerenciá-lo? Como ter equipe de profissionais com 'tempo' para investigar? Como manter profissionais especializados em pequenos e médios municípios?

São muitas incertezas e indagações para serviços que, enfim, estão funcionando, mas não a contento!

Antes de relatar as sugestões construídas pelos próprios sujeitos que expressaram as dificuldades, citamos COHEN e FRANCO (1993, p.22):

A politica social cumpre o objetivo de investir em recursos humanos (que pode ser interpretado como "ensinar a pescar"), mas necessita que o sistema produtivo (o económico) esteja em condições de demandar esse pessoal. É preciso, continuando com a metáfora', que exista um rio que tenha peixes, onde possa ser aplicada essa habilidade adquirida" (COHEN e FRANCO, 1993, p.22).

\footnotetext{
'Equidade é aqui entendida de acordo com o conceito de COHEN e FRANCO (1993, p.27) de que "a equidade implica na satisfaçlo das necessidades básicas da populą̧lio, priorizando-as segundo seus graus de urgencia relativa". Os autores enfatizam que o critério a ser considerado na priorizaçło deve ser geral a problema em foco e năo a dramaticidade, alertam tambem para o respeito a uma hierarquia de necessidades.

2 'Ensinar a pescar em vez de dar o peixe a quem tem fome', foi a metáfora utilizada por COHEN e FRANCO (1993, p. 22) ao discorrer sobre a distinça entre politica económica e politica social. Os autores advertem que o 'dar o peixe' é outra grande vertente da politica social, referente ao subsídio aos setores carentes; não sendo assim é provável que nåo cheguem ao momento de terem condiģoes de pescar.
} 
Os profissionais entrevistados respondem à suas dificuldades com as seguintes sugestões:

Realização de um bom planejamento, para curto, médio e longo prazo em nível estadual, regional, municipal e nos serviços da rede de assistência à saúde é o primeiro passo.

Mesmo que pareça impossível, atualmente, para os serviços públicos, os profissionais reconhecem, que nas RegS, deve-se aumentar o contingente de recursos humanos, com ênfase ao trabalho dos Comitês de Prevenção, Regional e Municipal.

Melhor gerenciamento técnico das questões ligadas à prevenção; a ação deve ter começo, meio e fim: manifesta-se problema sentinela (o óbito infantil; não existência de prontuários; equipes que não investigam; informação que não chega etc), identificam-se as causas e planejam-se estratégias para combatê-las. Enfim, deve haver compromisso quando se trata de saúde pública, $100 \%$ de efetividade é o esperado e critérios técnicos cada vez melhor definidos.

Estratégias de troca de experiências entre os serviços regionais são extremamente importantes para que cada profissional não se sinta isolado em seu trabalho. Cada um precisa de estímulos para sentir-se realmente ativo e resolutivo, dentro de seus limites profissionais.

Estado implementando uma política de saúde deve também suprir as condições mínimas necessárias de recursos humanos para realizá-las.

Existe o reconhecimento de que a organização do sistema de saúde não é simples, nem tampouco as coisas são fáceis de serem planejadas e cumpridas; há o reconhecimento da complexidade que permeia a saúde. Porém, a despeito das dificuldades apresentadas existe a intenção e o compromisso dos profissionais para ajudar no desenvolvimento dos programas eficazes; essa posição é de extrema importância para a continuidade e melhoria do sistema e da assistência.

\section{DSC 02. Dificulahde motivacional / sensibilizacăo (profissional e clientela)}

\section{COMCPREEASTO / ADESAO (dos profissionais)}

É uma questão da politica da saúde, por mais que se estude, por mais que se fique em cima, eu creio que ela não tem atingido a atenfão das cabefas pensantes, dos organizadores, dos gerentes do sistema, dessas pessoas que estão montando os Programas. A partir do momento que elas compreendam fica fácil de se executar. J⿹äo adianta mandar pessoal pra fazer reuniōes, se aperfeiçoar, voltar cheio de novas idéias e na 
hora de implantar não consegue. No comeģo houve uma certa rejeição a tudo que vinfa para se estudar, investigar, tinfia assim um certo medo como se fosse uma af̧ão policialesca. A implantação foi complicada até que os profissionais entendessem a importância, custou pra entender todo o processo, e toda a seriedade que tem a informação que ele coloca quando ele atesta a causa do óbito, no preenchimento das DOs. Assim, essa compreensão por parte dos profissionais foi um trabalfo muito árduo, muito complicado, dos nossos profissionais que atuam aqui na epidemiologia, que foi a origem de tudo.

Quanto ao cuidado para a prevenfão é mais das mães os problemas, acho que não é tanto da equipe, a gente tenta passar, mas elas não compreendem, não seguem.

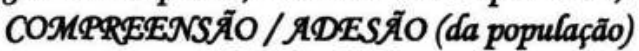

Existe grande dificuldade na aceitação das gestantes pra ta fazendo o pré-natal, a gente tem que ficar em cima para que façam os exames de rotina, elas não fazem, não é por falta da gente orientar e falar, a gente já tirou elas da fila elas não precisam mais ficar em fila, pra marcar consulta, pra marcarem exame, pra colher o exame, mesmo assim a gente tem uma resistenciazinfia' delas. Em relafão ao aleitamento materno também são resistentes, a gente acaba não conseguindo, mesmo explicando tudo o que vai acarretar de 6om pro bebê. A vacinafão, que é uma prevenção também da morte infantil, a gente coloca os ACSs em cima, e mesmo assim, a gente vê que as mães deixam e taL... a gente tem toda uma forma de ta indo atrás, a gente vê também que a populafão ta meio... A gente tenta trabalfar várias coisas pra chamar $a$ atenfão deles.

Hoje as pessoas saem da escola com um pouquinho mais de informação, aqui na unidade você pode falar alguma coisa da parte clinica, mais médica: riscos de uma gravidez indesejada, riscos dessa mãe ter problemas por causa do aumento de peso, com a idade, fipertensão arterial, o que você pode transcorrer durante essa primeira fase da gestafão etc. Jós temos um acesso bom dos paciente, a gente pode conversar aqui no Posto de Saúde sem problemas. Existe uma aceitabilidade muito grande dos pacientes, mas percebemos que eles podem ouvir o que você fala, mas se eles vão fazer? JNão vão fazer! Porque ta aí a explosão da gravidez indesejada, o problema maior é os jovens estar escutando esse tipo de coisa, você fala, você orienta, você mostra através do planejamento familiar, ao contrário é díficí.

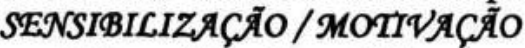

Existe a falta de sensibilização, não só do gestor, mas também dos próprios profissionais que atuam, principalmente dos médicos. Tem que haver é a sensibilização das pessoas pra participar do Comitê,é um processo muito dificil nas cidades da RegS, você conseguir sensibilizar alguém pra que comande o Comitê, o médico não é motivado pra esse tipo de trabalho. O funcionário da Secretaria de Saúde como os enfermeiros, as vacinadoras são mais sensiveis a esse tipo de tra6alfo do que o médico.

ENV OLVIMEENTO

No caso de investigasãa, nós não temos regulamentado, no municipio, o Comitê Municipal até por comodismo, pelo município ser o município sede da Regionah, assim participa do Comitê Regionah́ é por isso que acho que ficou meio que acomodado, mas não assim por dificuldade mesmo. A dificuldade sempre se encontra em você incluir as pessoas que se estimulem a trabafhar com isso, nos municípios acontece isso, a falta de envolvimento dos próprios profissionais de saúde. Eu noto dificuldade é na ponta a falta de médico engajado, mais o médico, porque outro profissional do serviço 'se dobra em dois' pra fazer, ai ele consegue até fazer, mas o médico, ele é meio relapso, a gente sente muito isso.

SENTIMENTO DE FRUSTRAC TO / ANGUSTIA

$V_{m}$ sofrimento grande da gente é verificar que são causas evitáveis às vezes por uma ação simples de confiecimento científico e de responsabilidade. Isso causa uma certa angústia pro grupo que investiga. Outra coisa é a dificuldade de obter resultados que a gente deseja, a gente se frustra porque os resultados obtidos, com o trabafho dos Comitês é meio a conta-gotas, a uma velocidade muito mais lenta do que a gente deseja, pensar isso leva a uma frustraçäo que a gente segura pra não esmorecer.

SOCLAL

Isso abre uma questão cultural, mais até na área rural, a gente pode ver que é por falta de orientafão, é questão de moradia, é questão social. $\mathcal{A}$ gente vai lá, faz o trabalho, fala...fala...é complicado, sabe? As mães são muito irresponsáveis, muito novas, ou tem muito filho, e carentes. A maior dificuldade que a gente em é o relaxo da mãe mesmo; não levam as crianfas pra acompanhar, tem oito filhos, que vivem tudo juntinho, num cômodo só, comem mah, sem alimentação, tem mais problemas por não ter educaf̧ão, ter 
higiene. A gente já entra em contato com a assistente social até com o Conselho Tutelar quando a gente vê que a mãe não ta fazendo o papel dela: de mãe.

\section{CONHECIMENTO D POPULACATO}

$\mathcal{A}$ gente observa a falta de confiecimento da populafão em relação aos seus próprios filhos. São mães que não procuram o serviço antes, não procura o médico... Teve um caso da criança ser cianótica (problema cardíaco) a gente perguntou pra mãe_ Porque você não procurou o médico antes? Af! Mas é porque eu pensei que fosse assim. Mãe pensando que aquilo lá era normal, porque ela é Granca, mas o marido escurinhio, então pensou que era da cor do pai. Desse jeito quando procura o médico às vezes já passou do tempo, então a criança já está em situafão grave. Às vezes fica dificil salvar aquela criança. $V_{m}$ dos principais problemas que a gente vê é que ainda falta de esclarecimento da populafãa em relafão às complicaf̧ões do parto, da gestaf̧ão, pois o pessoal não confece, ou ta ignorando isso.

\section{EDUCAC TO EM SAVDE}

Agora vamos supor um prematuro extremo que fica na UTH três meses, investe-se muito nele, ai recebe alta da UTI e vai pra casa, ai o óbito acontece devido a broncoaspirafãa, pois a mãe colocou a criança junto no leito, uma morte perfeitamente evitáveh, falta de educaf̧ão de saúde! Essa questão das mães quanto aos 6e6ês: questão de figiene, aleitamento materno; inclusive se a gente não ficar em cima da vacinaf̧ão elas esquecem. A higiene desses bebês, então é muito sério esse problema! Por exemplo, tem um bebezinfo que estava internado e que voltou para casa, ele tomou banho no hospital e, se você demorar 10, 15 dias pra chegar lá, vezes o bebê nem tomou banfio ainda. A questão de pediculose em crianças, bichos de pé... tudo é um problema muito sério! A semana passada, uma menininha de sete meses chegou lá na escolinfia, ela estava com uma barata morta nas costas e ela tava com uns bichinhos no corpo; ai então foi recolhido esses bichinfios e, as meninas levaram pra gente ver. Sabe o que o bebezinfo tinfia no corpo? Percevejo! A mãe só traz a crianfa quando tá mais doentinha, aí encontra dificuldade nas orientafōes, a gente orienta, principalmente sobre medida de figiene, mas não parece surtir tanto efeito quanto a gente esperava.

\section{DSC C3: Sugestão motivacional /sensibilização (profissional e clientela)}

\section{COMPREEDSÃ / ADESAO (dos profissionais)}

$\mathcal{A}$ questão de continuar essas afỗes que a gente implementou são dificultadas com mudanfas de gestões, de prefeitos, de secretários e da própria equipe. Assim o próprio gestor de saúde tem que ser também orientado nesse sentido, pois às vezes eles não dão a devida importância para prevenir o óbito. Acho que a gente esta errando em sempre ficar apontando os problemas, a gente acaba afastando estes profissionais; eles não querem vir porque a gente acaba puxando a orelfa, tem que mudar a tática.

$\mathcal{A}$ conscientizafão dos profissionais da saúde, principalmente, na questão humana, se todo mundo trabalhar unido, se todo mundo enxergar com o mesmo objetivo, a assistência, a partir dai as coisas mudam. É a humanizafão, a partir do momento que cada pessoa se colocar no lugar do outro, o médico, o enfermeiro, o auxifiar de enfermagem, o ACS, pensando que poderia ser um membro dele que poderia ta naquela situafão! Aqui temos um compromisso pra nós mesmos de analisar todos os óbitos, até mesmo aqueles que a Secretaria Estadual dispensa, não é uma coisa protocolar, é uma coisa de compromisso do grupo. Às vezes, acho que falta um pouco de interesse, de vontade, de ter mais profissional engajado com a prevenfão da morte infantil.

$\mathcal{E} m$ relafão aos prontuários, documentos hospitalares, aí cabe sim um trabalho junto d̀s diref̧ões clinicas dos fospitais, aos gestores municipais e aos profissionais co6rando, orientando, instruindo sobre 0 porquê da necessidade de uma correta anotaf̧ão, isso para que fiaja uma maior participação.

o profissional médico é realmente atribulado de af̧ões no município assim acaba ficando mais na questão de consultas, de tratamento, do que na parte preventiva. Precisa aderir a uma orientafão melhor sobre os fatores de risco na gestafão, na observância desses fatores de risco, que normalmente passam em branco; por exemplo, a paciente faz lá oito consultas, mas ai morre ela e o neném, ou morre só o neném por prematuridade, que é o nosso problema aquil $\mathfrak{N a}$ realização de entrevista para o médico é mais dificih, mas dependendo do local do óbito, a gente tem mais contato com o médico, porque ele também atendé aqui no 
Centro com a gente, aí fica mais fácil. Assim quanto mais informação tiver para o pessoal da saúde, a gente mesmo fica perdido ds vezes... pra onde encaminfiar, onde procurar? Tipo no caso da amamentação, todo mundo ta sendo capacitado pra orientar para amamentar a crianca.

COMPREEENSATO/ADESÃo (da populasãa)

$\mathcal{A}$ gente tenta ta reunindo as gestante, já fazendo a palestra sobre o que é o parto, o que a mãe deve saber praos cuidados que ela tem que ter, preparando ela pro aleitamento materno, a importância do aleitamento. O ideal mesmo é fazer palestras, de conscientização. Dividir em grupos, mães com filhos muito pequenos, mäes com filhos maiorzinfios e orientar.

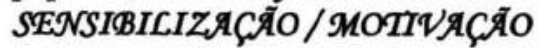

A gente tem aproveitado as reuniöes dos Secretários, pra falar, pra mostrar os dados, pra ver se ele se sensibiliza que esse é um indice importantíssimo que avafia a Ação Básica deles, que eles estão prestando a comunidade, isso é mundial! Tem que existir a constante sensibilização, o envolvimento da equipe como um todo, não só enfermeira, sensibilizar médico; acho que é mais a sensibilizafãa mesmo desses profissionais que atuam afi com aquela gestante em entender, saber que também pode ir a óbito com o 6 e $6 \hat{e}$.

Se a gente conseguisse trabafhar muito bem a sensibifizafão e, as pessoas tivessem consciênucia do quanto ela poderia contribuir, não seria dificil da gente conseguir indices positivos a partir do momento que você investe nesse trabalho.

SNo caso da gestante é a primeira pessoa a ser de alguma maneira trabalhada, com todas as gestantes. Porque muitas coisas dependem dela: se é fumante, se ela bebe, se tem uma infinidade de outras situaçöes que acabam ocorrendo. Ai depois a conscientizafão das mães, acho que seria importante realizar algum projeto, alguma coisa em relação a educação das mães que têm suas crianças desnutridas, com o 6aixo peso, situafões que podem levar a morte, na verdade são mães realmente que não tem muito interesse em prestar os cuidados. Vejo que trabalfiar com amor! Ai o que a gente tenta fazer é gratificante; apesar de todo o trabafho, de toda desestrutura, a correria, é gratificante. Além de estudar, estudar... Vejo mesmo que é uma coisa, mais de solidariedade, a gente tem o intuito de ajudar, o objetivo é o bem estar dessa criança, é mais um trabalho sofidário mesmo, a gente vê que os colegas estão muito envolvidos, e eles ajudam.

EDVCACTO EM SЯVDE

Temos que preparar essa comunidade, principalmente as mães, os pais, em relafão aos cuidados com uma criança sadia, com uma criança doente, também em relaf̧ão a vacinafão e prevenções das moléstias. Esse trabalho tem que ser feito na comunidade, com palestras porque a gente tem que trabalhar com a cultura das pessoas, com a 6ase, a educafão. Na verdade teria que trabalhar muitos assuntos já na escola, ver se a gente informa essas crianfas mais cedo.

Ai tem as mães adolescentes, que não tem confiecimento nenfium quase, sai do hospital e não sabe nem da 6anfo direito na crianfa, ai vem aqueles afogamento, essas coisas, tem que orientar 6astante também. $\mathcal{A}$ gente visitava as escolas, tínfiamos lá o trabalho de uma vez por mês, ministrava aula, conversava com os jovens, mostrava as conseqüências de uma gravidez, deu uma diminuída lá esse tipo dé coisa. Mas não fazer isso dentro do consultório só, você tem que ir no colégio, lá ondé eles se aglomeram, assim acho que você vai ter maior aceitabilidade. Sabe, dentro do consultório todos os jovens são acompanfiados por um maior, o maior é o pai ou a mãe, então você não tem mais aquela líerdade pra orientar e conversar. Tem que ser feito também um trabalho de base realmente a nível de educafão em casa, com os pais, com a família.

\section{RECONFECIOMENTO / VALORIZACÃO PROFISSIONAL}

o Comitê tem que ter uma forma reconfiecimento do profissional que trabalha nele, talvez uma remunerafão, um papel que chamasse mais a atenf̧ão, para as pessoas se interessarem. Porque é desinteresse mesmo, ninguém tem interesse numa coisa que ninguém paga e ninguém recebe por aquilo e que é que falta também o reconfiecimento. 
Como todas as categorizações realizadas, esta também, o foi em função da intensidade com que se apresentou na fala dos profissionais de saúde que trabalham com a prevenção da morte infantil.

Como já comentado em outro capítulo deste trabalho nada se realiza sem que alguém tenha compreendido, apreendido os por quês. $O$ por quê deve participar? $O$ quê deve fazer? Para que objetivo está participando? Isso vale para os gestores, para os profissionais e para a população.

Todos têm num dado momento de vida, um 'modo de fazer', seus hábitos (ruins ou bons...) adquiridos em sua formação enquanto ser social, de acordo com 0 contexto de vida, de família, de valores, de crenças etc; adequá-los elaborando novos modus faciendi e vivendi que privilegie hábitos considerados positivos para a saúde, não é fácil, nem simples e, muito menos rápido. Nessa ótica, seria atitude de bom senso que o indivíduo com maior escolarização e melhores condições de vida, ou seja, os profissionais, entendessem a clientela que passou e passa por tantas privações. 'Puxar as orelhas' dos gestores e da população a todo o momento de contato pode ser um caminho mais curto para distanciá-los do mais adequado e oportuno para a saúde, falam os profissionais. A união, a parceira, a troca de experiências, problemas e sugestões pode ser uma melhor opção de caminho a trilhar quando se acredita em algo do tipo 'humanizar' as relações, a assistência, a saúde, os programas, as políticas. Humanizar, pôr-se no lugar do outro e num insight imaginar sua (re)ação naquele momento, gera entendimento, gera perseverança no fazer cotidiano.

O compromisso, antes de qualquer coisa, se estabelece para cada profissional que realiza sua tarefa na área da saúde. $\mathrm{O}$ compromisso parte do ser individual para o social e dependerá do interesse da cada membro do grupo, com a contribuição social que acredita ser factível. Mas, para isso, deve haver envolvimento dos profissionais das RegS, dos municípios, dos serviços e também da população; é um processo coletivo. Os médicos também devem envolvido, não são eximidos da responsabilidade de prevenir, melhorar, educar e investigar.

Mas, ainda fica uma resposta um tanto incerta dos profisisonais em suas falas: como valorizar as pessoas 'voluntárias' que se dedicam aos Comitês e ao processo de investigação? Há que serem valorizados, isso está claro! Será que é acertada a ênfase 
de poucos atores de que: o trabalho com amor realiza o profissional e torna tudo gratificante, que a 'coisa é mais de solidariedade', que o interesse para o estudo supera tudo e o que importa é o bem-estar dessa criança? Ou será que: ninguém trabalha sem receber, em termos financeiros ou em statu quo profissional? Vamos continuar ouvindo os atores para verificar que se esta questão se torna mais clara.

A evidência, no discurso coletivo, de que a pobreza, a baixa escolaridade, 0 distanciamento dos serviços complicam todo o processo de educação em saúde é forte. Como conciliar a vigilância ao risco com a insuficiência de profissional e com a falta de compreensão por parte das mães, e muitas delas adolescentes? Uma estratégia é expressa como oportuna e certa: é a saída dos muros da unidade básica, é ir até a população, não importando onde ela esteja. Se os profissionais vão até a população rotineiramente, 'o risco' é previsto, é prevenido ou é impedido de se desenvolver.

Alguns profissionais, podemos inferir até que por motivo de responsabilidade, culpam as mães pelas más condições de vida que têm. Esquecem-se da cultura, das tradições, das agruras que impostas às famílias mais pobres em seu cotidiano. Mas, existe entre os profissionais entrevistados, o comprometimento com a educação em saúde para a prevenção da morbi-mortalidade infantil, embora esse processo não seja fácil e, nem aconteça em curto prazo como se deseja.

Percebe-se, por outro lado, o sofrimento dos profissionais na luta pela preservação da vida, em situações que poderiam ter sido evitado o evento sentinela. Mesmo entre os profissionais envolvidos com os Comitês há desânimo no processo, pois não vêem a realidade social e política, nem as situações locorregionais dos serviços mudanças acontecendo de modo mais rápido.

Nesta situação lembra-se dos determinantes distais para a ocorrência do óbito infantil citados por VICTORA (2001), os quais são os fatores sociais, econômicos e culturais. Estes apesar de serem considerados como de maior impacto para a redução da MI, são os mais difíceis de serem trabalhados. Novamente, se faz presente a complexidade, permeando as representações sociais sobre a prevenção do óbito infantil. 


\section{DSC D2: Dificuldade técnica ligada à qualidade da assistência}

\section{CAPACITRCAO}

Em primeiro lugar é o preparo de funcionário, principalmente, dos profissionais que ditam a conduta que definem a vida. Quando eu entrei para tra6alhar, eu não tinha treinamento nenfum, então eu tive que aprender sozinfia e, até encontrar os caminhos, se passaram quase dois anos. $\mathcal{N}$ em sempre as equipes do PSF são bem preparadas para fazer o pré-natah, fazer a busca ativa. Tem que haver treinamento melhor das equipes e dos ACSs; tem muita gestante que comega tardiamente o pré-natal que pode acarretar risco para o bebê. Há falta de confiecimento dos funcionários, da equipe de enfermagem e, principalmente auxifiares e técnicos, em relafão às afões preventivas, como são funcionários mais antigos são mais voltados para o modelo assistencial. Da epidemiologia houve essa proposta de estar capacitando melhor os técnicos, formando uma equipe mesmo pra trabalhar a questão do óbito infantih nós ainda temos dificuldade. Capacitar para que os profissionais encarem o óbito infantil como uma atividade primordial na atenção 6ásica.

\section{ESPECIALIDADE}

Todos os comitês foram formados a dificuldade veio depois, na maioria dos municipios, não tem médico pediatra nem ginecologista e obstetra, são clinicos gerais, então tem dificuldades nas investigafões de coisas mais complexas, pois o pediatra tem mais facifidade em conduzir a investigação do óbito infantil. Eu diria que tem muitos casos de óbito devido não ter as especialidades; a ausência do profissional limita a nossa participação na prevenfão, porque a gente tem algumas crianfas que morrem pela falta deles. SNäo é o especialista que atende! Falta de funcionários pode prejudicar a quafidade do trabalho, pode desencadear um trabatho não ideah, pode levar sim ao óbito. O PSF ainda não esta atuando de acordo, como deveria atuar no esclarecimento dessa populafão, onde cada equipe atua, falta é profissional especializado, gabaritado pra isso. $\mathcal{N}$ em sempre a cesariana é a causa de prematuridade por tirar muito antes, a gente tem feito cesariana aqui porque precisa fazer, é impressionante, e o indice é alto mesmo, porque nós atendemos gestaf̧ão de afto risco. Mas. a questão es6arra com a mortafidade afta no período neonatal ou pela prematuridade, o que falta é estabelecer uma politica de pessoal, você não consegue montar equipe de médicos e enfermagem especializadas. O hospital até ta retardando, inaugurar uma UTI Neonatal justamente por questão do pessoah, não é nem equipamentos, mas para você manter uma equipe de especialistas tem que ter subsidios, isso ai prejudica muito. Tem também a situação dos bebês que ficam na UTI e são referenciados de novo pro município e, este não tem o pediatra ou tem um que vai duas vezes por semana, então não há como acompanfiar esses bebês. Essa dificuldade também deve ser levantada, faz parte aqui do nosso problema regional.

\section{RESPOONSABILIDADE PROFISSIONAL}

No município sede a investigafão dos óbitos infantis funciona que é uma maravifha, tem uma pessoa que se empenfia em fazer, até ela mexe com toda mortalidade, quando chega nessa fase de investigação ela está em cima, ela faz tudo certinfio, então a gente não ta tendo problema. O problema ta com os outros municípios, não sede. Existe uma dificuldade clara que é a de trazer na prática, de fato, todos os profissionais. A gente chama o pediatra para discussão, às vezes ele não pode ir; quando ele não pode, quem vai? Jão tem esse profissional! Precisa conseguir trazer os médicos, pra definir, discutir ou até responsabifizar, de repente e isso não é fácif; com a enfermagem e o ACS a gente consegue. Há também afto indice de cesária marcada, agendada, existem erros na ultra-sonografia, na idade gestacionale muitas vezes eles aca6am tirando a crianfa antes do tempo por cesária marcada, e a gente está vendo isto todos os dias. A principal dificuldade aqui no Hospital é o plantão à distância dos pediatras, uma U'TI não deveria funcionar sem pediatra 24 horas, pois acontecem emergências, situaçôes que você se apura realmente, porque não tem o pediatra presente.

Ai em relação ao Hospital é dificil de compreender se eles têm responsabifídade ou não! Como é que pode um óbito por incompatibilidade sanguinea? Quando tinfia uma vacina! Você vê que foi por isso. E a gente não vê do lado do Hospital eles assumindo eventualmente o erro. Há municípios da nossa região que ainda têm grandes problemas de atendimento na sala de parto. Essa falta de Pediatra na safa de parto eu considero tafvez como o problema mais importante. Então não é que o Governo não tenfla treinado esse profissional, não tenfia orientado; é que o profissional não tem aparecido na sala de parto. Assim esse ou 
aquele caso que dependia do pediatra para diminuir o problema, diminuir a lesão, não tem ocorrido, a crianfa nasce sem atendimento e termina tendo um problema sério.

Nossa UTI Neonatal tem vários casos de crianças anoxiadas graves que vão a óbito ou vão ficar com seqüelas definitivas gravissimas, porque como é um hospital de referência, nós recebemos essa crianfa já em situafão extremamente dificil. $\mathcal{A}$ gente tem muita faffa do ponto de vista preventivo, no diagnóstico da potencialidade de evolufão de uma patologia banal, como uma diarréia, ou uma pneumonia. A gente vê muita falha médica antes dos pacientes serem transferidos para gente em tempo fábil pra que tenfia melhora da morbi-mortafidade. Falta muita conscientizacão dos profissionais, mais especificamente dos pediatras quanto a deteç̧ão precoce, na qual uma conduta aparentemente simples como a expansão de volume poderia evitar que a evolufão tomasse proporçōes graves. O problema de cardiopatia congênita não diagnosticada em tempo passa 1-2 meses, aquela mãe procurando novos serviços, então a criança já está em situação grave, com muitas dificuldades. São as péssimas condições da crianfa, quando é encaminfiada já pra nós por falta de um 6om diagnóstico médico; o profissional médico deveria ter a consciência de não enviar pra nós crianças com problema de cardiopatia congênita, cinurgico, pois nós não conseguiremos resolver. É perda de tempo pra crianfa, perda de tempo pra equipe que vem na UTI móveh, de longe, traz a crianfa aqui e essa crianfa tem que ser levada novamente pra um centro maior pra cirurgia. Eu acho que falta um preparo desses profissionais médicos. Porque se esta acontecendo o óbito infantil, é porque alguma coisa está muito ruim lá na questão básica, na unidade, no acompanhamento da ponta.

MELFORUA DE PROGRAMA

Tem o PSF que tão implantando, mas com ele houve uma queda na quafidade do pré-natal no início e, ainda existe. A gente sabe que não vem todo mundo fazer o pré-natal na Escola da Gestante precisava methorar. Nos municipios, em termos de Saúde Pública, é preciso monitorizar essas gestantes intensificar essa parte para que elas sejam acompanfiadas pelo médico. Além do que o número de consultas que a mãe deveria receber não é o adequado e, não tem a busca ativa da mãe problemática. Agora o hospital passou a ser materno-infantil assim a gente verifica que se a mãe já tem uma infecção teria que tratar, quando chega aqui já ta no auge da infeção urinária, o neném já nasce infectado, ai tem todo um trabafho em cima desse neném, que nasce ou prematuro ou muito 6aixo peso, pode até perder o neném. Com a melhoria do pré-natal a gente pode ver mais adiante a redução desses indices, deve ser feita a deteç̧ão dessa gestante de risco.

\section{DSC D3: Sugestão técnica ligada à qualidade da assistência}

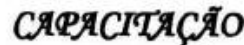

Apesar da compreensão que os nossos gestores têm hoje e de confiecer a importancia do trabalho existem dificuldades de ordem operacionah, de conseguir mais profissionais pra trabalharem com a investigação do óbito. No entanto esse profissional tem que ser treinado, tem que saber como codificar o óbito, ter todo esse raciocínio lógico da investigaf̧ão; é todo um processo de formação que leva um tempo pra ele poder raciocinar da forma mais correta. Mas devem-se colocar pessoas capacitad́as para gerenciar o serviço de saúde! O que eles fazem por indicaf̧ão politica, essas coisas, pessoas que não tem formação nenfuma na área da saúde, não tem graduafão nenhuma e sempre ta atrasando o processo; essas pessoas não entendem a trama da área da saúde. Acfio até que pode ter como parâmetro os cursos de pós-graduação, colocar pessoas que realmente estão interessadas. O Estado ta mudando isso agora de indicação politica, assim $80 \%$ tem que ser do quadro próprio do funcionalismo. É importante a questão do gerenciamento da coisa, a questão do treinamento do pessoal, valorizar os profissionais que realmente demonstram confiecimento na área da saúde.

A gente tem até pensado em fazer um treinamento com os gestores da rede, pra ta melhorando a quafidade do pré-natal dessas mäes. Vrgente é preparar a equipe multiprofissional: médicos, enfermeiros, técnicos, auxifiares que trabalfiam com essas crianfas na UTI, em relação ao seu confiecimento profissionah. Esses profissionais deveriam estar melhor preparados, com uma visão mais ampla para o problema. Considerando que nem sempre tem interesse de investir, uma sugestão que eu tenfio é comegar pela capacitafãa das equipes, principalmente a equipe de enfermagem, comeşar pelos enfermeiros e investir em capacitafão do pré-natah, saúde da mulher e na saúde da criança também. Também a reciclagem dos 
médicos de suas condutas, não é a enfermagem que toma conduta, ela pode só sugerit, aí essa diferenfa de conduta, de um dia pra outro dia, eu acho que interfere muito na evolufão da crianfa, principalmente chegando ao óbito, eu já tive essa experiência. Eu acho que o profissionah, o funcionário, tem que ser preparado, primeiro psicologicamente, e ser formado pra investigar.

A grande massa da população médica, que atua sobre essas crianfas, faz atuação a nivel de atenção primária e secundária, somos um número muito pequeno de profissionais de nivel terciário, onde essas crianfas chegam num estágio, muitas vezes, de uma gravidade muito avanfada. SÓs teríamos que atuar no nivvel de atencào secundária e primánia, através da reeducafäo, de programas de atuafizafäo profissional nos moldes, por exemplo, dos PAVS, programas voltados 6astante pra atuafão precoce do ponto de vista clinico. A gente faz a abordagem de criancas, inclusive de recém-natos com patologias específicas. Penso que a capacitafão profissional deve ser mais direcionada pra esse cuidado, do RJ, do lactente e deve ser feita por profissionais dessa área mesmo.

RESPONSABILIDADE PROFISSIONGL

Atualmente, na área de saúde, no Brasil, tem que se investir muito nos gestores. Deveria ser obrigatório a todos os vereadores, todos os secretários, receberem informações, se preciso criando tafvez novas leis para serem obrigados a receber informafoes por pessoal quafificado para gerir, senäo o municipio não vai pra frente, um comesa, o outro interrompe, diz nunca teve informafão. Quando ta todo mundo organizado, todo mundo mobilizado, desde a pessoa que faz o acollimento até aquela que vai se despedir do paciente, ai eu acredito que a coisa comega a funcionar. A sugestäo que eu tenfio é que o 'Estado contribua com a contratafão, o servico púbfico acaba por implementar o serviço e vai se adequando. $\mathcal{A}$ gente tem conseguido, através dos ACS realizar o servico na ponta. As gestantes mais faltosas a gente consegue buscar, monitorar mesmo desde a questão da carteira de vacina das crianças, ta totalmente relacionada a isso no primeiro ano, e tudo isso a gente consegue com a equipe do PSF que tem os ACS; às vezes até é vizinfio, é tudo, moram próximo, então a gente não tem muita dificuldade numa cidade pequena.

De minha responsabilidade e, da responsabilifade do Comitê de Aleitamento Materno, é manter encontros e treinamentos com os funcionários a gente orienta todos os passos de aleitamento materno, sobre os cuidados de recém-nascidos ou mesmo de criancas de pediatria, isso a gente tem constantemente.

$\mathcal{E} u$ acho que a equipe responsável pelo preparo do pessoal para investigação é principalmente os $R \mathcal{R} \mathcal{H}$ da Regionah. Devemos atingir a massa maior de pediatras que atuam com essas crianfas, de modo que se conscientizem da sua responsabifidade de atuação. Como primeiro profissional que vai fazer o diagnóstico, eles devem ter consciência da má evolução que as patologias já citadas podem atingir, e as condutas iniciais a serem tomadas para que a crianfa deixe de evoluir pra situaf̧ões mais graves e, muitas vezes não necessitando mais de uma UTI, por exemplo. $\mathscr{E}$ claro que o Pediatra deve permanecer 24 horas dentro da UTi Neonatal.

\section{MELFORIA DE PROGRAMA}

O PSF já foi capacitado, já foi feito curso, seminário assim eu acho que tem que levar mais a sério! $\mathcal{A}$ SMS tem que atuar mais em cima desse pessoah, pra realizar uma 6usca mais ativa, mas ta dificil! Eu diria que seria um trabaffo mesmo de Saúde Pública, eu acho que as equipes de PSF deveriam ser mais intensas, mais diretas no contato com o paciente. Muita coisa fica a desejar. Existe o projeto, a pessoa sabe das funcôes: que tem que ir até a casa... tem que vê... Näo sei aondé que fica essa falha, se todo mundo se empenfiasse e falasse a mesma lingua e 6uscasse um objetivo, daria pra ser feito.

O principal é a prevenfão, mas o nosso pré-natal esta muito aquém. Saão ta tendo um pré-natal de qualidade, assim quando a mulher chega até nós ainda não fizeram exames o atendimento também é precário. Mediante as investigafões e com as análises dos óbitos infantis a gente tem observado que existe muita prematuridade em funfão de alguma coisa que é decorrente da mãe, pode ser infeç̧ão urinária... que é uma das coisas que a gente tem observado muito nas declarafóes de óbito. Existe problema, de acompanfiamento da gestante na rede pública e até particular isso complica no nascimento da crianfa. Se você buscar uma melhor quafidade no pré-natal, com certeza você vai dar uma melhor quafidade de vida pra esse bebê, que de repente pode ficar na UTI um mês, dois meses e, acaba sobrevivendo mesmo em função dessa melhor qualidade do pré-natal. Foi feito um 6om trabalho no sentido de melhorar a qualidade do prénatal, mas a busca ativa da gestante de alto risco não tem ocorrido. Penso que nós estamos numa fase muito mais de policiar do que até de educar. 
É o que nós estamos fazendo nessa Câmara Técnica, anexa, suplementar ao CMI. A gente prepara para fazer a análise das Carteiras das Gestantes, para que a gente possa estar analisando a qualidadé e a quantidade das informaf̧ões aqui colfidas. Ai a gente vai chamar o SMS ou até mesmo ir até o municipio com os prestadores de serviço responsáveis e, colocar pra eles o porquê que precisa ser preenchido, fazer orientafão e, solicitar colaborafãa, ou mesmo cobrar uma responsabilidade funcional. Assim a Carteira da Gestante deve ser usada também pra subsídio de informações, de outros profissionais que atendam no ambulatório de gestafão de afto risco, nos ambulatórios dos fospitais. Eles devem saber que as informaf̧ōes não são apenas pra ele ali que atende e, que as outras instâncias constantes do fluxo organizado para o atendimento da gestante de alto risco têm que ter essa informação.

As dificuldades com recursos humanos não são apenas devido ao número insuficiente de pessoas, mas também com a qualidade de seus serviços. Estes serviços oferecidos é que determinam a qualidade da assistência que os serviços oferecem. É colocada uma situação mais preocupante ainda que é: o despreparo profissional. Os entrevistados abordam-no desde o nível básico passando pelo técnico e chegando à classe médica, eles dizem: em primeiro lugar é o preparo dos profissionais que ditam as condutas que definem a vida; falta de qualidade pode levar ao óbito sim!

Dizem os nossos entrevistados que é preciso desenvolver mais e mais programas de investimento em capital humano, para o preparo de mão de obra que seja incorporada pelos programas de saúde.

Quando avaliamos o SIMI, mais especificamente os determinantes causais eleitos após o processo de investigação, notou-se que a situação profissional do médico, em especial, não está adequada à necessidade de atendimento à mulher e à criança. Isso acontece mais acentuadamente com a gestante, tanto na rede básica como na hospitalar.

Há falta de médicos especialistas nos municípios do interior do Paraná, principalmente de médicos pediatras, dizem os sujeitos sociais. Há dificuldade médica na vigilância ao risco materno-infantil. Há deficiências de conhecimento da gravidez normal e, com maior impacto na mortalidade infantil, no entendimento e reconhecimento de riscos que possam determinar uma 'gestação de alto risco'. Os médicos do PSF não se encontram preparados para esse atendimento, são generalistas, na maioria. Se somarmos essas dificuldades, expressas pelos próprios profissionais, com a dificuldade estrutural, ou seja, de não se ter serviços de 
referência para encaminhar gestantes de risco, tem-se o aumento do risco em proporções absurdas, determinando a intensidade da morbi-mortalidade maternoinfantil no Estado. Inclusive sem médicos ginecologistas e pediatras em sala de parto, como fica a assistência ao binômio, perguntam os entrevistados?

Emerge no discurso a responsabilidade profissional de cada um, que quando compartilhada vira coletiva e trazendo todos (até os médicos) pra discutir, reponsabilizar... não é fácil....mas, a gente consegue. Os próprios profissionais dizem: cada qual deve ser responsabilizado, mediante a ocorrência de falha, pela assistência que assumiu. Como UTI Infantil, sem Pediatra 24h? Inconcebível, pois existe a equipe e cada um com as suas responsabilidades profissionais.

Será que é o governo que não capacita, ou o profissional, em especial o médico, que não demonstra responsabilidade e competência, perguntam os sujeitos. Diagnósticos médicos inadequados, encaminhamentos em péssimas condições, como um último recurso, depois de tanto tempo perdido, gerando sobrecarga e conflito na organização dos leitos intensivos, dizem os entrevistados.

$\mathrm{O}$ pré-natal precisa melhorar em capacidade técnica e qualidade. Os profissionais dizem que estão acontecendo situações de perda de criança devido ao despreparo da maioria dos profissionais que acompanham a gestante. É necessário um acompanhamento eficaz dos problemas da gestante de suas infecções, dos seus riscos, busca ativa como rotina, não deixar que a gestante opte por não realizar o prénatal, se preciso fazê-lo em domicílio. As gestantes de risco estão 'soltas', sem monitoramento, no entender dos profissionais, em parte das realidades de saúde local.

Neste discurso, como em outros, aparece a figura do profissional herói competente, que sozinho, comprometido com o social e com o serviço que executa, ultrapassa as dificuldades e consegue realizar 'milagres' em termos assistenciais e no estabelecimento de estratégias com êxitos.

$\mathrm{O}$ que sugerem os atores sociais entrevistados para resolver ou minimizar os sérios problemas de qualidade da assistência preventiva à gestante e criança para que óbitos possam ser evitados? 
A informação sobre a saúde e seus indicadores deve circular nos meios políticos para que seja formada uma corrente de sensibilização em função das adequações necessárias nos serviços municipais.

$>\quad$ Deve ser gestor na área da saúde quem tem capacidade para o cargo e que seja da área da saúde. Indicações políticas não dão certas, deve-se valorizar o profissional de saúde que tem conhecimento para gerenciar as questões da área.

$>\quad$ Os gestores regionais devem ser responsáveis pelo pessoal que investiga e deve aumentar o contingente humano capacitado (inclusive psicologicamente) nos serviços de investigação do óbito, ou seja, nos Comitês.

$>\quad$ Urgente preparo da equipe de saúde para atender o pré-natal, o parto e para os cuidados intensivos; ênfase é dada aos médicos tanto da rede pública quanto particular.

$>\quad$ Estabelecimento e utilização de protocolos de atendimento nos níveis primários, secundário e terciário da saúde para direcionar a melhoria da qualidade em todos os serviços.

$>\quad$ O foco central é a prevenção, mas a prevenção está aquém do desejável. Os serviços têm que estar preparados para prevenir. As capacitações devem continuar.

$>\quad$ Os gestores municipais devem gerenciar as equipes de PSF, estar mais atentos e procurar saber onde ocorrem os problemas para solucioná-los.

$>\quad$ Realizar câmara técnica nas RegS para avaliar a qualidade dos documentos utilizados no processo de investigação do óbito. Por exemplo, verificar se existe a utilização da Carteira da Gestante, se esta contém as informações necessárias. As falhas devem ser, de fato, rastreadas e levadas ao conhecimento do Secretário de Saúde e, aos prestadores de serviços de saúde dos municípios.

\section{DSC E2: Dificuldade gerencial, política e financeira}

\section{COMITtÊS}

Para implantar o CR até que a gente não teve dificuldade foi montado pelo próprio diretor da Regional com a sua equipe da parte administrativa, mas as reuniōes não estão acontecendo como deveriam acontecer. Deixa muito a desejar, pela dificuldade de reunir, por envolver pessoas não ligadas direto à RegS. Existe dificuldade de ter as reuniões, em conciliar que todo mundo venfia, em saber que às vezes o médico não participa. Não dá pra acontecer uma vez no mês, ela tem que acontecer mais vezes, periodicamente, é um comitê que tem que ser dinâmico. Vai ocorrendo os óbitos a gente tem que ta sentando e discutindo com os dados frescos, bem recentes. A gente vê que está meio solto surgem as dificuldades dai a gente vai 
discutindo. Vemos a importância do gestor estimular estes profissionais a virem, porque o que a gente tem percebido é que são sempre as mesmas pessoas que vem, aquelas que deveriam vir acabam não vindo. Acho que isso tem que ser revisto pelos Comitês, não basta simplesmente dizer nós temos um CE, CRe um CM se inexiste trabalho a meia, em todos eles, essa é a verdade, tem que se dar mecanismos pra isso.

$\mathcal{A}$ comunicafão com os CM é 6oa, mas a maior dificuldade que a gente enfrenta nos municípios, é a formagão do Comitê. Tem-se um número limitado de servidores que trabalham no município, que geralmente não são técnicos com formação na área de saúde, são indicados pelo prefeito; eu não sei realmente qual o município que está com uma equipe plena formada.

Outra dificuldade é de ta entendendo o papel do CIH e transmitir isso dentro do Hospital, por quê a maioria das pessoas não sabe. A gente fica sem muitos caminhos dentro do hospital é só investigação mesmo. O trabalho do Comitê na verdade é de voluntariado, assim existe a dificuldade de agregar os membros, acabaram ficando três membros no CHCPMI, que reafmente discutiam e conseguiam fechar algumas análises pra mandar pra Secretaria. A Regional passou a adotar a questão do xérox dos prontuários, então ela na verdade não tinfia pressa da análise intra-hospitalar, ela tinfia pressa do xérox do prontuário, assim a gente xerocava e já encaminfiva pra Secretaria, muitas vezes sem fazer a análise. $\mathcal{A}$ gente sente que o objetivo principal do Comitê ta sendo atingido em parte. Um problema bastante importante é o retormo por parte do $C R$ no sentido de apontar o que tem que melhorar e tal; esse não existe. Nem o próprio CIH não trabalha com o retorno ao profissional que atendeu esse óbito discutindo o que aconteceu realmente, não tem esse feedback, esse vai e volta de informaf̧ões.

Ai você tem a questão da gestão, de você ter uma política, de você estar promovendo a questão da informação dessa avaliafão, tudo perpassa pela avafiação, de modo que as pessoas do nível local se sintam responsáveis por essa informação e, não esperar do nível central a informafãa pronta, a construcão tem que ser em conjunto. A comunicafão tem problema, os gestores teriam que ter uma quantidade de informaföes maior para sentir o problema. Neles está o ponto de partida, tem que mudar de cima pra 6aixo, porque sem essa conscientização não se consegue nada. A conscientização dos colegas é uma conseqüência, que se consegue facilmente, através de reuniôes, através de debates, oficinas, que funciona muito 6em, mas nem ta tendo.

PARAICIPAÇ̃̃

Em todas as questões de saúde você precisa de participação de profissionais da área de saúde principalmente na prevenção. Conseguir colegas médicos, pediatras, que participassem do Comitê por ser uma coisa sem remunerafão e que prevê reuniōes quinzenais, é dificil, pois alguns acham que o tempo deles é o mais especial de todos. A gente sabe que a participação externa é sempre muito dificich isso não especificamente no CMI, mas a gente vê em todas as coisas que tem participação de autônomos da área de saúde ou até profissionais da área de saúde relacionada aos poderes municipais. Vamos focar a Prefeitura, existe nela uma grande dificuldade de você fazer com que haja participação, até pode haver a participação mais não há a efetivação do trabalho realmente que precisa ser feito.

PARCERLAS

Na verdade temos pessoas voluntárias que estão investigando e analisando estes óbitos que não têm o papel da Secretaria do Estado de estar implementando estes Programas. Tra6alhar com voluntários é dificil! Uma grande dificuldade é o Comitê funcionar com pessoas não vinculadas a área da saúde, como por exemplo, a Pastoral da Crianfa. Eles pararam de ir nas reuniões, penso que leigo não se sente muito sensibilizado; é que na verdade as pessoas não higadas a área da saúde ficam cansadas, não dizem mas parece que pensam: __Isso não vai ter função nenfuma! Pois a discussão dos casos e da causa do óbito também é uma discussão muito técnica, médica, muito da área de saúde.

INTEGRAC TO T CO-RESPONSABILIDADE ENTREE OS SERVIÇOS

$\mathcal{N a}$ Atenfão Básica, a nível estaduah, a gente não tem alguém que esteja exatamente puxando a prevenfão da MI, fica por conta do Comitê Municipal de Mortalidade Materna e InfantiL. Dentro da SIPAS, por exemplo, a gente não tem a figura de um pediatra ou de um gineco-obstetra que esteja envolvendo o Programa Saúde da Mulher e Saúde da Crianfa, acho que isso também tem dificultado muito este trabalho. Eu tenho acompanhado esse processo e notei que não existe uma figaf̧ão entre as várias sessões, por exemplo, entre a epidemiologia, o pessoal do Comitê e o pessoal do PSF, pra poder fazer um trabalho em equipe. No município nós temos uma "euquipe" também que vai, faz a investigafão e, nos manda. 
Quanto à obtenfão de dados de pré-natal particular, ou de acompanfamento da crianfa no particular ou convênio, a gente não tem tido acesso a esses dados; tem também a recusa da mãe em ta fazendo a entrevista, assim não temos muitas informaf̧ões para a investigafão e conclusão.

$\mathcal{N a a ̃ o ~ t e m o s ~ r e t o r n o ~ a q u i ~ p a r a ~ o ~ H o s p i t a l ~ d a ~ a n a ́ l i s e ; ~ c o m e c ̧ o u ~ a ~ e x i s t i r ~ u m ~ r e t o r n o ~ p e l o ~ C R ~ n a ~ v e r d a d e , ~}$ quando o óbito era gritante e tinfia informações sérias pra ser passadas.

Quando você identifica of fator de risco em uma gestante e manda para a referência sabe que ela vai voltar pra sua casa, vai retormar ao seu domicífio. Quando a gente recebe para fazer esse acompanfiamento na casa, a gente não sabe o que fazer, o que a gente. sahe é o fásico. Se tițper alguma outra coisa para fazer?

Sahê, nã̃ existe esssa contra-referência. Eu acho isso é um déficit que podía ta até melhorando nosso relacionamento na saúde. Também no extra-fiospitalar, a partir do momento que ele recefe alta da UTH, eu fico na dúvida se a gente consegue fazer o melhor. '́ ai exatamente em que incide o maior problema da reincidência das doenças, do aumento da mortafidade abrupta desses pacientes. Aqui dentro do hospital a gente tem preocupafão com o tratamento, a gente vê as necessidades e quando devolvê-la ao ambiente doméstico, ao lar? Como saber pra onde a gente ta devolvendo essa crianfa? Eu não sei realmente qual o município que está com uma equipe plena formada, como a gente não tem muito problema com MI, eu acredito que eles devam estar fazendo um trabatho adequado.

EQVIPE MULTIPROFISSIONAL E INTERSETORIALIDADE

F.u trahaffio num hospitaf-escola pribfico, a gente vê aqui situaçoes com o pröprio residente médico e de enfernagem que nos coloca numa situafão delicada. Você sabe o que tem que ser feito, no entanto, você vê que aqui não é feito e isso leva a uma situagão mais crítica, de risco de vida mesmo. Isso porque há dificuldade devido a condutas diferentes, devido a habifidades de cada equipe, de entendimento mesmo da nossa percepsão em relą̧ão à evolução da situação da criança. Existem diversas equipes profissionais, uns mais recentes, outros mais antigos, esses último "dão pouca 6ola" naquilo que eu to falando, outros se atentam mais. Sei que até é antiético eu ta verbalizando isso, mas é uma dificuldade que eu vivo freqüentemente!

Encontramos muito é o desencontro de informaf̧ões, assim a mãe chega com uma criança, pra enfermagem e fala que o médico não orientou isso, não orientou aquilo; ela também acha que a orientação do enfermeiro não é tão importante que nem a do médico. Tem alguns funcionários ainda que limita essas coisas, não trabalfia em conjunto.

Eu acho que o certo não é a saúde ta fazendo cadastros e, sim um outro profissionah, tipo uma afão social. Nossa parte seria a parte de avaliafão, de pesagem, de acompanfiamento. Assim, tem um acompanfiamento de cadastro para programas (tipo Bolsa Família) que tem que ser feito nas casas; dai o ACS faz, se acontece de cortar eles vão achar que foi porque a gente foi lá fazer o cadastro, pois a gente que fica responsáveh, eles vão pensar que é culpa nossa. Então já quebra aquele vinculo, entendeu? Daí, a famífia ds vezes, já não aceita mais a equipe na casa.

\section{MECAIISMOS DE AÇ TO ФARA OS SEVIÇOS}

Ai toda vez que é feita a avafiafão na RS, em algumas eu tenfio a oportunidade de participar, sempre vejo que os questionamentos são feitos aos servicos por parte da regional. Mas, o que é primordial? É saber como nós vamos colocar isso em prática lá na ponta; houve uma falha lá por isso que essa criança morreu. Sim, morreu. $\mathcal{E}$ agora como nós vamos fazer pra resolver isso? Tem que se dar mecanismos pra você conseguir chegar nos profissionais que estão envolvidos.

São verificadas falfias na assistência ambulatorial e hospitalar, por parte médica ou social e a gente tem pouca maneira de atuar, não existem meios que sejam realmente efetivos para combate as causas da situafão problema.

A gente sabe que existe locais em que a assistência é inadequada, isso é repassado em nível de discussão local na regionah, os gestores tem esse diagnóstico e tem levado pra SESA, isso tem que ser discutido! Quando ocorre óbito na fase de assistência, aí você vai de encontro com quem? Quem é a assistência? A assistência é toda saúde em sil Faz-se a investigação, e aî? Detecta-se o problema, e aí? Como é que fica? E ainda se tratando duma morte que seria evitáve! $\mathcal{N a}$ reafidade a vigifância epidemiológica se defrontando às vezes com outros órgãos da própria instituicão, ou do próprio sistema, dai ser essa a grande dificuldade.

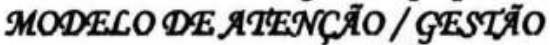

Eu me sinto muito isolado para fazer um tra6alio 6om, para fazer uma Medicina Preventiva. Tara fazer um Programa de Saúde você tem estar sempre estudando, tem que ter um espaf̧o pra discutir, tem que 
ter um estado de espirito, que é diferente do estado de espirito de vir aqui e "apagar o fogo". Eu pelo menos tenfio dificuldade pra limitar as consultas, na verdade limitar essa 'aflicão por consultas!. Mas, a possibifidade de dizer 'não' pra demanda é um enfrentamento que esbarra no politico, então eu não sou um comandante... Quanto às cidades vizinhias atendidas pela Regional a dificuldade maior é que não tem um modelo de rede púbfica, de rede básica, de posto de saúde tão voltada para a prevençäo (não têm atendimento completo à gestante, pré-natal adequado, exames adequados), ai como nós somos referência recebemos esses $R \mathcal{N}$ e crianfas e a gente não sabe o que tem? O que aconteceu realmente? O fistórico da crianfa vem em fragmentos.

FINGINCEIRO

Geralmente o gestor estadual leva o problema pro gestor da união, o recurso pra saúde é um grande obstáculo porque ele é a menor do que deveria ser destinado a área da saúde, na verdade no país inteiro tem dificuldade orģamentária na área da saúde.

Nosso Hospital tem interesse em montar UTI Neonatal, montou uma UTI pra adultos, mas existe uma enorme dificuldade em manter essa UTI, porque o custo é altíssimo, o pagamento pelo consentimento de funcionamento muitas vezes não cobre nem um terf̧o do que se gasta. Fala-se na questão do investimento, mas para que seja bem colocado de modo a resolver o problema da região. Aqui atendemos gestafäa de alto risco, mas deixamos de receber o que dá, por não termos VTI Neonatah, nós recebemos $25 \%$, então é um desestímulo ao profissional que está fazendo gestafão de alto risco.

Estamos sobrevivendo, antes éramos uma entidade privada, nós mudamos nossa identidade jurídica, pra gente poder fugir de alguns encargos, nós fomos pra Curitiba dispostos a fechar as portas para o SUS, com toda assistência de UTI $\mathcal{N}$ eo, Adulto... $\mathscr{E}$ muito dificil manter plantonistas, quando você se refere a VTI hoje, com o que o SUS paga. Ainda com respeito ao econômico as parcerias também são dificeis, a parceria com a Prefeitura deixa muito a desejar; a gente já até pediu pra Regionah, mas não nos deram nem resposta.

\section{DSC E3: Sugestâo gerencial, política e financeira}

\section{COMITtEs}

Minha sugestão é que o Comitê fosse oficializado, que fosse mais forte no sentido de ser uma Politica de Saúde, 6aseada na evidência, apesar da gente saber que a Politica de Saúde esta sendo baseada na informafão dos Comitês. Assim foje a gente tem taxa de mortalidade muito mais segura, do que a gente tinfia antes. A minfia sugestão é que o Comitê fosse muito forte! Há necessidade de ter um deslocamento da Regionah, não fazer só reuniōes aqui, deixar os munićtpios tomar as decisões, eles se reunirem, a Regional teria que se deslocar. Para isso ter um cronograma, uma politica para ir aos municípios, fazer as reuniōes, juntamente com os municipios; estabelecimento de cronograma de tarefas, de reuniōes nos municípios.

Regional entraria também como mediador, como orientador, que é a função mesmo da RegS, daí a gente teria um resultado melhor, minimizaria todos os problemas. Este ano passado nós comegamos a fazer visitas nos municipios, conversar com os secretários, com a enfermeira, mostrar o que é o Comitê. Nós também mostramos em reunião da bipartide, mas nem todos compareceram. Os municípios que não vieram nós estamos visitando, de alguns municípios já tá tendo retormo. 'É trabalho de divulgafão das atividades do Comitê, dizendo pra que esses dados vão ser usados. Deve-se tomar mais abrangente os mecanismos de feedback dessas informaçōes. A gente tem um jormalzinfio, mas acho que é de circulação restrita, aí a gente tem que aumentar. Precisa também trabalfiar melhor esse feedback das informaçöes, porque as pessoas tem tido muito 6oa vontade em formecer as informafōes, estão todos de portas abertas, mas achio que falta ainda um pouquinfio a gente trabalhar melhor a discussão das informações que a gente consegue organizar, a partir das investigaf̧ôes que são feitas.

Quanto ao sistema de avaliafão dos óbitos pelos Comitê precisa urgentemente de uma reformulação. $\mathcal{N a}$ verdade eles foram criados, esquecidos pelas próprias pessoas que faziam parte deles e, ficou por isso mesmo. Vai ter uma reunião de câmara técnica em Curitiba e, nossa proposta é que essa Câmara Técnica comece a ser reafizada por macrorregião, é muito bom que o pessoal do nivvel central venfia também para o interior, para gente ta discutindo as dificuldades. 
$\mathcal{E} u$ acho que a questão de organização mesmo, ter as CIH, que iria ajudar 6astante seria porque a gente já taria trabalfando mais diretamente com a patologia, já dentro dos hospitais, onde os óbitos ocorrem. A CIF precisa ter condifōes de trabalho como uma equipe amarrada, com vários membros dos setores envolvidos na área materno-infantil e que eles fossem atuantes. Se tivéssemos um pediatra como Presidente do Comitê, dai fica bem mais fácil a investigaf̧ão, então algumas informaf̧ões médicohospitalares. Acho também que deveria haver um espaço, uma forma de remunerar esses profissionais, no horário extra-expediente, todas as pessoas estão cansadas, não produz muito, além disso, nenfium médico deixa de atender o seu consultório pra fazer um trabalho voluntário. Assim.teria uma possibilidade maior pra se conseguir reunir. Mas, na medida do possiveh, a gente tem feito um revezamento, um remanejamento, não existe um horário único pra gente se reunir, devido a essa dificuldade, nem todos podem se reunir naquele horário, a gente se reúne até em horário extra do horário de expediente, pra poder ter essa reunião. $\mathcal{N}$ o nosso CM as pessoas que participam são funcionários dai nós conversamos com o Secretário de Saúde e ficou decidido que no dia da reunião nós somos dispensados, pra gente poder fazer a reunião. Dessa maneira eu tenho certeza que naquele dia vai ta o obstetra, vai ta o pediatra, posso contar com a enfermeira, então existe dispensa no tra6alho pra reunião, dai melhorou mesmo.

PARACIPACÃ

Sabe a gente contava no caso dessa paciente com ajuda da vizinfi, como uma "vigia", uma pessoa que ficava de ofho e em qualquer situafão de risco, ela acionava a Unidade de Saúde. Assim a gente deve orientar os vizinfios, as pessoas mais próximas, os parentes, assim deve envolver as pessoas da comunidade também nesse sentido de ta alertando para os riscos de morte.

\section{PARCERLAS}

É importante termos parcerias com programas não especificos da saúde, o Rotary, por exemplo. A igreja também é bem envolvida, eu falo assim da que eu conheço, dentro da Igreja que eu participo tem uma instituição, uma oficina que faz esse acompanfamento: a mãe precisa ter alguma alimentação especial, a mãe que não amamenta, se precisa de um reforço. Melhorar a prevenção da morte infantil com o trabalho se tiver tudo sincronizado, vai conseguir diminuir.

\section{IJTEGRACATO E CO-RESPOSSABILIDADE ENTTRE OS SERVICYOS}

$\mathcal{A}$ união tem que ser a base, a união de todo o município, o governo, dando estrutura, todos juntos os postos de saúde também.

Eu vejo que o Setor de Epidemiologia tem que manter uma cobrança, mas também trabafhar no sentido de efucidar pro municipio o que ta acontecendo em cada um deles, pra gente poder analisar não só regionalmente. $\mathcal{A}$ gente deve analisar a dificuldade de cada municipio, porque cada um tem sua peculiaridade. Tem alguns que permanecem numa 6aixa incidência, já outros uma ano tem um alto indice, no outro a gente tem algumas idéia e faz algumas açōes junto, tudo programado entre a equipe e o Secretário deve aceitar. Desta maneira a equipe ta lá, tra6alfa, se incentiva, e normalmente esse município melhora.

A gente deve tá trabalhando mais próximo dos Hospitais, dos médicos que tra6alham com as crianças, até pra que não ocorram erros, as próprias orientações não serem equivocadas, assim acho que nós teriamos um trabafho melhor do que temos hoje... não sei se a médio ou longo prazo.

Se existisse um diálogo intemo no Hospital, pode facifitar. Tem que ter o ambulatório de followup do paciente internado na UTI e na Enfermaria de Pediatria; acho que isso depende basicamente dé um diálogo entre o ambulatório e os setores fechados de dentro do hospital, culpa nossa. O mesmo seria se os servifos de referência nos darem uma contrapartida (como contra-referência) pra gente saber como conduzir os casos, principalmente de gestantes de risco.

Estamos pensando daqui pra frente comefar ir in loco, queremos levar estudo de caso pra essas equipes e comegar a discutir, tanto nos outros municípios como no município sede. A gente programou um Seminário Regional e a gente quer discutir então a questão das causas da prematuridade, a falta de leito de VTI Neonatal, a incompetência istmo-cervical, coisas que a gente detecta na investigą̧ão, trazendo um pouquinfo eles mais pra pratica.

Estamos tentando trabalhar com PSF, nesse sentido o que a gente fez aqui eu achei que por um tempo foi 6astante 6om, foi um resumo do todos os óbitos do ano de determinados municipios. Dai a gente ia fazia reunião no municipio com o pessoal do atendimento hospitalar, do atendimento básico, da vigilancia epidemiológica e do PSF. A gente expunfia os óbitos que ocorreram, as principais causas, a evitabifidade. 
Só que esse trabalho também requer tempo, exige viajem e ele não pode ser feito sistematicamente por falta de tempo, então quando da pra fazer é um trabalho que realmente é 6om, e surte efeito. Mas a gente acha que a questão dos cadastros (tipo Bolsa Família) poderia deixar de ser nossa funfão e, passar pra algum outro departamento de educafão, por exemplo, desvincular essa responsabilidade da gente, deixar a gente mesmo, só com o acompanfiamento e a avafiafão.

$V_{\text {ma }}$ preocupafão aqui dentro do ambiente hospitalar é a gente procura saber pra onde vai devofver a crianfa, saber a fistória dessa criança, aí a gente encaminfia pro Ambulatório de Risco, se acha que vai precisar de continuidade no tratamento Se vai precisar de outra especialidade a gente liga, consegue as consultas, a gente se desdo6ra mesmo em funfão desse atendimento à crianfa.

Tem que ter comunicação troca de informaçōes entre os profissionais, psicólogas, assistente social, médico, enfermeiro, até os dentistas afi, pra poder numa açäo conjunta resolve melhor os problemas das pessoas. Uma maior integração mesmo entre os membros do Comitê, e as enfermeiras da ponta. $\mathcal{N a}$ verdade eles passam informações pra gente, e a gente já sabe! Por exemplo, eles mandam um relatónio de bebês que deveriam estar no programa de $R \mathcal{V}$ de risco, programa de vigifância, eles mandam essa listagem 10, 15 días depois que o bebê nasceu, e a gente já sabe quando a mãe foi gantiar, pelo trabalho dos ACS. Noo outro dia, ou quando tem final de semana, na segunda-feira, a gente já sabe que deu problema no parto, que essa crianfa ta internada, sabe muito antes! Está tendo uma lacuna sabe? O pessoal lá de cima, não ta conseguindo acompanfiar nosso trabalfo aqui, com os agentes, a gente ta mais na frente. Eu acho que essa integrafão ia tanto ajudar eles, quanto a gente melhorar o trabalho.

EQUIRE MULTIPROFISSIONAL E INTERSETORIALIDADE

Fazer esse trabalho com a secretaria de Af̧ão Social e com a Assistência Social pra ver como é que vivem mesmo essas pessoas, confecer o ambiente, ver se tem comida ... ter esse vinculo de ta fazendo encaminhamento com as assistentes sociais dos Hospitais. Ninguém dá esse apoio para a questão social pra gente, tem coisa aí que não é da nossa alfada, assim a gente consegue ir até um ponto aí depois nós temos que ter um respaldo. Deve ter alguém pra apoiar essas famílias, pra ta acompanfiando, não ta havendo uma parceria legal. Sei que é complicado trabafhar com a questão social Ter uma visão multiprofissional para detectar os problemas e conseguir fazer que haja um direcionamento melhor para a prevenção do óbito infantil. Tem que ter a união e a colaboraf̧ão de todos os setores, inclusive comegando do hospitah, também do posto de saúde, quer dizer de todos... se unir com o mesmo objetivo, que é a prevencão da morte infanti.

Mesmo tendo problemas sociais graves, com municípios pequenos, fiá que ter uma equipe multidisciplinar: psicólogos, assistente sociah, enfermeiras, médicos, fonoaudiólogas etc é o trabaltio em conjunto que vai minimizar, tem que ser uma equipe, não pode deixar de ser uma equipe. Existe a importância dos médicos pediatras pra poder ajudar na anátise dos óbitos, 6em como de um obstetra, porque de repente só ele confiece.

Aqui na gestão temos um obstetra, ele é responsável pela gravidez de risco, então assim quando a gente tem dúvida, a gente chama ele, ele participa sim, mas como um apoio. Assim quando chega um óbito ta mais tranqüilo fechar dentro de um prazo até bem rápido.

MECANISMOS DE AC TO PARA OS SERVIÇOS

Quando se constata que houve falha deveria se estabelecer um mecanismo punitivo, porque se nós não tivernos isso, nunca vamos conseguir com que as pessoas se conscientizem, porque por mais que você fale, converse, entra naquela velha questão: nem todo mundo aceita como algo positivo. Porque colher dados, depois encaminfiar e não ter aquilo como uma ação concreta, fica muito vazio.

Com a intervenção da Regional melhorou 6astante, alguns fiospitais encaminfiam, eles xerocam todo o prontuário e mandam pra gente.

$\mathcal{E} u$ acho que tem que vir de uma pessoa com muito mais forç do que eu, ou do que das colegas que estão envolvidas, uma força assim, nem digo tanto de Secretário da Saúdé, mas de alguém que pudesse ter essa facilidade de conversacão dentro do hospital, esse acesso, essa facilidade para chamar os médicos e certos pediatras. Acho mesmo que eu seria até mais drástica: tá na hora de se fazer até uma politica de punição pra essas falfias!

O Governo até que tem feito a parte dele o treinamento do pessoal, o que falta é uma atitude mais 'policialesca' dos hospitais, no sentido de cobrar realmente a participação do médico pediatra na sala de parto. O mecanismo, por exemplo, de só pagar se o pediatra realmente estiver na sala, ele deve fazer um relatório comprovando o horário de atendimento. Essa seria uma atitude mais coerente, pois o Governo 
como ele fez a parte educativa terá que fazer uma cobranfa 'poficialesca' daquilo que ele ofereceu. Precisa também uma dîvulgafão dos programas que a gente tem, do aleitamento materno, da avafiação nutricionah eu acho que o acompanfiamento é muito 6om.

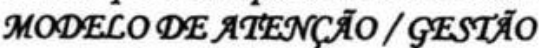

Também é dificil para o Ministério, porque tem uma questão de você estar fazendo um pactuação, um modelo que seja implantado nas várias regiōes, para os vários Brasis' existentes. Então você tem recursos, gestões diferentes, pactuações cobradas de maneira diferente, então eu acho que é um conjunto de açöes. Nós que somos um munićpio de média complexidade, a gente já tem uma exigência maior do que outro que tenfia 2 mil habitante, e na verdade ele unifica essa informação e essa tecnologia para todos da mesma forma.

Eu acho que é uma regionafização e hierarquização, mas com envolvimento de todo mundo, isso já existe no papeh, mas a execufão na pratica é que não anda na mesma velocidade do planejamento. Acho que o planejamento estratégico esta até satisfatónio, mas o que falta é envolvimento dos diversos setores envolvidos no atendimento da mãe. $\mathscr{E}$ bem o modelo de organização, eu acho que as prefeituras, os municípios, eles deveriam organizar e melhorar o atendimento da rede básica, dos postos de saúde, assim uma reestruturafão pra rede básica. Precisamos contar com vários níveis de agregafãa dessa informafão, viabilídade de rapidez dessa informação, de um feedback muito mais rápido, é assim a questão no município é mais rápida do que no continente territorial, no Brasil. $A$ gente deve sempre procurar trabalhar em rede.

\section{FINCTNCEIRO}

$\mathcal{A}$ questão do investimento também é importante! Se por aqui tem um Hospital Regionah pra que montar outro que faz a mesma coisa que faz aqui, não investe nem direito lá nem direito aqui, então não tem VTI JNeonatal aqui, nem VTI JNeonatal lá! Deve-se então direcionar o investimento pra aqueles

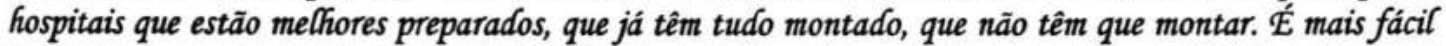
implantar o serviço, onde tem possibilidade de ampliar, pois tem toda uma equipe montada, não se vai gastar muito mais do que já ta gastando, e eles querem montar uma com tudo lá! É uma questão de gerenciamento do que já existe. Deve haver um maior entendimento, um maior compromisso da Prefeitura com o que realmente vem pra $U$ TI Jeonatal. $A$ gente sabe que a gente tem um recurso, mas a gente não sabe se esse recurso foi realmente repassado! Existe UTIs, em outros municípios maiores, que a prefeitura ajuda a pagar os plantonistas, nós não temos ajuda nenfiuma, pelo contrário acho que nós é que pagamos para eles. Eles mandam casos e nunca há recusa.

Acho também que se existisse uma maneira de ser remunerado o trabalho que realmente é feito, pois às vezes são pessoas extermas ao quadro, que não são funcionários, nem do Estado, nem do Município. Existe a dificuldade, principalmente, dos colegas médicos participarem como voluntários.

Nesta categorização encontramos com mais especificidade as questões que cercam a organização e trabalho dos Comitês de Prevenção de Mortalidade Infantil. Assim, uma das dificuldades apresentadas pelos próprios atores que trabalham com os Comitês fica por conta da sua constituição, por profissionais competentes e comprometidos, que tenham 'tempo' para participar de reuniões freqüentes. Reclama-se por apoio dos gestores regionais e municipais para estimular a participação multiprofissional e intersetorial. Algumas estratégias são sugeridas para conseguir maior participação: remuneração; dispensa do trabalho no dia da reunião; revezamento de períodos de reunião. 
Existe muita dificuldade na constituição dos Comitês Municipais como equipe com caráter multiprofissional e intersetorial. Há muitas 'euquipes' e, eventualmente, equipes formadas por não técnicos na área da saúde. Enfatizada, mais uma vez, a necessidade de participação com contribuição, de fato, por parte dos municípios. Um dos aspectos apontados é a necessidade de se ter a participação da Secretaria de Ação Social nas ações de saúde nos municípios. Isso devido à magnitude dos problemas sociais apresentados no cotidiano do trabalho dos profissionais de saúde. Os profissionais pedem ajuda e retaguarda no atendimento às famílias.

A qualidade política dos entrevistados é manifestada nesta categorizaçào. Essa expressão é conceituada por DEMO (1994, p. 30) como “[...] a arte da comunidade se autogerir, a criatividade cultural que demonstra em sua história e espera para o futuro, a capacidade de inventar seu espaço próprio, forjando sua autodeterminação, sua autopromoção, dentro dos condicionantes objetivos".

É afirmado que os Comitês devem ser mais fortemente instituídos como Política de Saúde baseada em evidências, pois suas informações se constituem em evidências para muitas ações e estratégias na saúde. Por outro lado, é dito também que é urgente a reformulação do sistema de análise dos óbitos, pois desde que foram criados os Comitês, pouco se (re)adequou tecnicamente, parecem esquecidos pelo Estado, dizem os entrevistados. Ao mesmo tempo, admite-se a dificuldade para se instituir as políticas públicas federais, bem como as pactuações; dificuldades para serem objetivadas em realidades tão díspares. Os profissionais apontam, realmente, para a regionalização e hierarquização do atendimento com envolvimento dos diversos setores da sociedade. Contudo, não esquecem dos problemas de ordem financeira para a manutenção da qualidade dos serviços e implantação de mais leitos terciários.

As parcerias com organizações não governamentais (Pastoral da Criança, em especial; Rotary; Igrejas) são valorizadas, mas por outro lado, as dificuldades dos leigos em participar de uma reunião técnica. Há que se (re)pensar em como incluir definitivamente os parceiros. Até os vizinhos de residência podem ser parceiros na vigilância ao risco e nas informações necessárias na investigação, dizem os sujeitos sociais entrevistados. 
Os profissionais afirmam que deve haver uma ligação de intercâmbio de informações entre os Comitês Estadual, Regionais, Municipais e Intra-hospitalar. Estes não devem trabalhar isolados na investigação de óbitos comuns. No entanto, as RegS devem ser sempre mediadoras e orientadoras do trabalho; as RegS devem sair de seus municípios-sede e fazer agenda de visitas aos municípios; devem orientar ações mas, favorecer oportunidades para os municípios agirem por sua conta. Os municípios devem ir até os serviços discutir a ocorrência e os fatores determinantes dos óbitos. As câmaras técnicas devem ser descentralizadas, não acontecerem sempre na Capital e, sim ser itinerante, para que os técnicos responsáveis, em nível estadual, conheçam as dificuldades locais. Assim, uma real ajuda pode acontecer tanto na discussão como na eleição das possibilidades de ação.

Outro aspecto que é indicado pelos profissionais é o de feed back, pelo Comitê Regional, das informações obtidas nas investigações. Este deve ser dar de maneira específica e adequada para a população, gestores, serviços e profissionais. Querem o retorno como uma forma de esclarecimento aos que ajudaram na investigação, desde a família, vizinhos, serviços e profissionais. Porém, os profissionais observam que essa ação não é fácil de ser concretizada. Há que se trabalhar mais no formato das informações.

O papel dos $\mathrm{CIH}$ ainda é obscuro para os profissionais do nível hospitalar; não sabem ainda como devem se posicionar perante os colegas do Hospital e o que é exatamente esperado deles, há necessidade de maior atenção para esta situação.

Olhar especial é lançado à necessidade de mecanismos para o acompanhamento da criança de forma integrada e co-responsável entre os serviços da rede básica, ambulatórios de risco, hospitais e setor terciário da saúde, e também da rede privada. É necessário, para o bom andamento das ações e para a prevenção do óbito infantil, que haja um diálogo instituído entre estas instâncias. É preciso existir a referência e a contra-referência. É necessária a preocupação no encaminhamento da criança de um serviço a outro e com a sua devolução para a família, segundo a expressão dos próprios profissionais.

Os profissionais reclamam a falta de apoio para a definição de mecanismos de ações para serem acionados quando se detectam situações de falha técnica assistencial ou institucional. Dizem que investigar apenas por investigar e, não se ter 
meios para agir de modo a tentar a correção da falha, não faz sentido, parece que fica sem ação, um 'vazio'. Afirmam que o governo treina o pessoal para vigilância e atendimento materno-infantil, mas falta uma atuação mais 'policialesca' nos serviços, por exemplo: 'o parto só será pago se houver a presença do pediatra em sala de parto, com relatório de horário devidamente assinado'. Conclui-se que os próprios profissionais dizem que a própria atuação têm que ser 'vigiada' pelo governo.

\section{DSC F2: Sem dificuldade / sem idéia}

O Comitê tem vários anos de implantação, mas eu não acompanhei essa implantação. Prefiro deixar essa parte com o responsável pelo Comitê efa ta com tudo isso catalogado. No último evento que houve efa fez até um levantamento das dificuldades junto a cada municipio. Teve algumas dificuldades, mas agora ta 6em melhor.

Essa área é uma coisa mais dos Comitês mesmo. Eu, enquanto funcionária da epidemiologia e membro desse comitê, posso dizer que não tenho muita díficuldade pra conseguir essas informaf̧ōes não, nem em consultório particular. Eu acho que eu tenfio tido facilidade mesmo em busca, abordar essa mãe, não tenfio dificuldade nenfiuma pelo menos até hoje. A vigilância epidemiológica é pra gente ter uma estatística da mortafidade e tentar mefhorar, pra que esses bebês futuramente não acabem indo ao óbito. Nãa, não encontro nenhuma dificuldade, nem por parte da instituifão, nem por parte da família. O PSF nesse ponto, ele é uma função básica da enfermeira programa saúde da familia. Normalmente esse trabalho é feito pelo pessoal da docência, eu to aqui como técnica.

\section{DSC F3: Sem sugestão / sem idéia}

Não sei dizer nada, essa parte eu prefiro deixar com o responsável pelo Comitê.

\subsubsection{DSC e PREVENÇÃO DA MORTALIDADE INFANTIL: considerações}

Por mais que o pesquisador que trabalhe com pesquisa empírica e com o método DSC de análise discursiva é pretensioso intentar comentar plenamente as riquezas de idéias discursivas que emergem das palavras dos atores sociais. Faz-se necessário realizar aqui um esforço de síntese, já que as expressões mostram divergência e conflito de opiniões, que, de certa forma, são viabilizadores de mudanças. Mostram, também, a complexidade do tema prevenção em saúde pública, reconhecendo que as solicitações feitas pelos atores sociais, muitas vezes são conscientemente tidas como acima das reais possibilidades de ação, por parte do Estado (TARRIDE, 1998). 
Sintetiza-se esta seção do Capítulo 6 com as palavras de Mario Ivan Tarride: "De qualquer modo, enquanto não se produzir um ajuste entre as expectativas dos atores, a missão declarada nos discursos e os reais resultados obtidos, a crise da saúde pública se manifestará (TARRIDE, 1998, p.22)".

Os comentários que se empreendam não alcançam a magnitude e a transcendência dos discursos coletivos. Pois esses foram construídos com a expressão verbal de cada um dos entrevistados; são todos falando em uma só pessoa, todos tendo seu espaço democrático no saber-pensar, no saber-fazer, falando sobre sua práxis. O DSC constitui-se a expressão de vivências singulares e impactantes nos serviços, para os que a ouvem, mesmo considerando a questão dos atores serem refratários a avaliar o que realizam e o eventual reflexo dessa situação nos DSC.

Desse modo, acreditamos que o objetivo central desta pesquisa foi alcançado. Ouvir os atores sociais que agem na prevenção da $\mathrm{MI}$, conhecer o que pensam da prevenção, quais são suas dificuldades, como efetuam a avaliação dos Comitês, permitiu-nos compreender uma nova realidade daqueles que vivenciam o cotidiano da MI no Estado. A cada releitura dos DSC, novas visões e leituras aparecem em uma dinamicidade reflexiva complexa.

Importante constatação foi obtida nesta pesquisa: a representação social, em todos os DSC construídos, evidência a importância de mecanismos estruturais e organizacionais preventivos adequados no estado do Paraná. As falas de gestores, bem como de profissionais corroboram com as evidências obtidas com a discussão dos dados do SIM e, sobretudo com os dados veiculados pelo SIMI, como consequência do trabalho dos Comitês no estado do Paraná.

Nos DSC dos sujeitos sociais aparecem preocupações com a melhoria da qualidade dos Programas na área da saúde, principalmente com o atendimento da mulher na gestação. Os atores atentam para a necessidade urgente de se ter, para os municípios, um fluxo regionalizado e hierarquizado de atendimento materno-infantil, com médicos habilitados para Centros Materno-infantis, dentre outras iniciativas. Descrevem a atuação do PSF na vigilância e busca ativa de gestantes de risco; falam da qualidade do pré-natal, com muita ênfase, para a prevenção da prematuridade, que contribui para a ocorrência dos óbitos infantis. Expressam que a Central de Regulação de Leitos do Estado precisa melhorar suas atividades. Evidenciam os 
problemas com os transportes de urgência-emergência das mães e recém-nascidos. Os leitos de UTI Neonatal também são apontados como a extrema urgência para a ampliação no Estado. No entanto, o aumento no número de leitos deve ser acompanhado do provimento de recursos humanos especializados e competentes. Um consenso entre os atores sociais é a ausência de médicos pediatras nos municípios, a grande rotatividade de profissionais enfermeiros, dimensões que dificultam o estabelecimento e continuidade das ações.

Os profissionais falam da manutenção da capacitação dos profissionais pelo Estado, mas, por outro lado, afirmam a necessidade de maior 'vigilância' do cumprimento das atividades em cada função e cargo. Ênfase é dada à qualidade dos serviços e dos profissionais que os operacionalizam, verbaliza-se a falta de especialistas para a o cuidado materno-infantil, principalmente em municípios menores, o que dificulta também a análise e encerramento das investigações.

Neste sentido recorda-se que os elementos básicos do conceito de qualidade dos serviços de DOANBEDIAN (1980) se encontram em dois domínios: o técnico e o interpessoal. A parte técnica expressa a aplicação da ciência e tecnologia médica e das outras áreas da saúde, para o monitoramento dos problemas de saúde, de modo a maximizar os benefícios à saúde sem que os riscos se elevem. Aliado a este benefício científico e tecnológico há o relacionamento interpessoal que vai interferir na intensidade do benefício (DONABEDIAN, 1980).

Em todos os discursos aparece a importância do trabalho interdisciplinar e multiprofissional, com união dos esforços, do conhecimento, das idéias com objetivo único de salvar vidas de crianças. As parcerias com instituições não governamentais são muito valorizadas nos serviços. Destaque é feito para a Pastoral da Criança, embora expressem certa dificuldade nessa interação.

Especificamente quanto aos Comitês de Prevenção da Mortalidade Infantil, a pesquisadora percebeu que, de maneira geral, estes não são muito bem conhecidos por profissionais da rede básica de saúde e hospitais; alguns desses profissionais já ouviram falar, mas não sabem bem como funcionam os Comitês. A Representação Social é de que o Comitê investiga o óbito infantil ocorrido evidenciando falhas, principalmente, no pré-natal, impacto considerado de extrema importância para os serviços. Entretanto, não sabem como é organizada a investigação, quais atitudes são 
tomadas, e quais são os mecanismos de divulgação ou não do trabalho, é necessário que os gestores de todas as instâncias de governo atentem para este fato para facilitar a continuidade das ações dos Comitês.

No entanto, podemos dizer que os profissionais que conhecem os Comitês e, nele trabalham, de maneira geral:

$>$ Pensam pro-ativamente nas questões dos Comitês Regionais, Municipais e Hospitalares de Prevenção da Mortalidade Infantil.

$>\mathrm{O}$ discurso dos atores sociais apontou pela necessidade de fortalecimento da estratégia diante dos serviços e profissionais de instituições públicas e privadas.

$>$ Os profissionais recomendam que a estratégia dos Comitês seja forte como uma política pública, tenham maior visibilidade, para que, de fato, seja implantado e implementado respeitando sua constituição multiprofissional e interinstitucional com caráter ético e educativo.

$>$ Os sujeitos sociais dizem, também, que o modus operandi do processo de investigação deve ser revisto, pois desde sua implantação pouca coisa mudou.

$>$ Uma das estratégias mais sugeridas foi a de descentralização das reuniões de Câmara Técnica, com a vinda de membros do Comitê Estadual para o interior do Estado.

$>$ O compartilhando das situações-problemas e apoio presencial para os encaminhamentos necessários são relatados como capazes de otimizar a efetivação do trabalho dos Comitês, segundo os sujeitos entrevistados.

$>$ Reclamam pelo estabelecimento, com apoio do nível estadual, de mecanismos de ação nos municípios e serviços, frente à deteç̧ão de falhas assistenciais, técnicas e sociais.

$>$ Os profissionais que trabalham diretamente com os Comitês Regionais e Municipais sentem-se desvalorizados, frustrados mediante tantas situações diagnosticadas, perante as quais são impotentes.

Entre as situações consideradas intangiveis, pelos atores sociais entrevistados, está a cultura das mães no cuidado a seus filhos e a situação das mães adolescentes. Os profissionais confessam que não conseguem realizar um 
processo satisfatório de educação em saúde, sugerem a integração, em especial, de ações do serviço social público.

$>$ Os entrevistados se deparam com situações de muita pobreza, ignorância e condições desfavoráveis de vida. Essas condições deixam os profissionais de saúde abatidos, pois não vêm perspectivas para melhoria das condições em curto prazo e acabam culpabilizando as mães, como se quisessem 'proteger' as equipes de saúde da responsabilidade pelas situações sociais encontradas.

Existe a expressão de que os profissionais de saúde, em especial os enfermeiros, geralmente assumem as situações contextuais e dos serviços além de suas possibilidades de resolução e de competência.

$>$ Com o DSC pode-se perceber que a estabilidade estrutural não colabora para o bom desenvolvimento de suas atividades, a ênfase aconteceu para: estrutura dos Comitês Regionais; da rede de atendimento regional à saúde, com definição do fluxo; e, principalmente, às especialidades, que são essenciais para a vigilância ao risco materno-infantil.

Lembra-se que a noção de estrutura enfatizada por COHEN e FRANCO (1993, p.94) refere-se a "uma organização relativamente estável dos recursos para atingir os fins" do que se empreende, e na estrutura são distinguidos os recursos e a organização.

Diante dos conflitos e dilemas gerenciais, políticos e financeiros expostos e diante da unicidade de pareceres na orientação para a prevenção do óbito infantil evitável, alguns princípios de consenso indicados por COHEN e FRANCO (1993, p.30-37) são desenvolvidos para que haja a reorientação das políticas sociais de eqüidade. São eles:

a) Praticar uma politica compensatória: atender primeiro aos mais necessitados aplicando uma "discriminação positiva mediante a seletividade" no estabelecimento de prioridades. Contudo, não se deve deixar de lado a valorização de ações universalistas, como por exemplo a imunização, dentre outras. COHEN e FRANCO (1993) alertam para o fato de as prioridades serem estabelecidas por decisão política e serem inviáveis sem os conhecimentos técnicos adequados. 
b) Aumentar e eficiência do gasto social: nesse sentido é aconselhado que se tenha controle adequado dos gastos e, que se disponha de metodologias de avaliação que poderiam ajudar na opção de alternativas mais econômicas para se alcançar aos objetivos procurados e a re-orientação do programa.

c) Conseguir que se usem os serviços: para isto é necessário que se analise o modo como os serviços são ofertados, e quais são os problemas de demanda que afetam seus potenciais destinatários. Neste sentido, pode haver indicações para:

- redefinição de oferta - serviços oferecidos de acordo com a necessidade considerando a realidade de cada local e suas peculiaridades culturais; serviços abertos em horários de necessidade da população e, com pessoal para atender, evitando a peregrinação, sofrimento e gastos desnecessários; oferta de serviços e medicamentos de acordo com a demanda conhecida; instalação de unidades de saúde em local que favoreça o acesso.

- Promoção da demanda - o oferecimento de informações do que realmente é feito e oferecido pelos serviços e Programas, pois se houver ignorância da existência dos mesmos como a população / profissionais poderão aderir? Oferecer apoio aos usuários (aqui tidos como profissionais e população) para "movimentarem-se no labirinto burocrático" (p. 32), pois nele as múltiplas organizações seguem procedimentos heterogêneos. Neste sentido, entende-se que cada município, regional e serviços neles inseridos e oferecidos têm seus caminhos. Dos gestores, profissionais até a população, todos ficam 'perdidos' em questões burocráticas e acabam não tendo acesso ao que lhes é proporcionado.

- Avançar no conhecimento técnico: a política social precisa de orientação técnica competente aliada a seu componente político. Ao componente técnico cabe: realizar diagnósticos adequados (análise objetiva da situação a ser modificada mediante informações consistentes e reais); melhorar os sistemas de informação (descobrir e 
quantificar os problemas existentes); avaliar os programas sociais (estabelecer uma cultura avaliativa, avaliação como rotina de trabalho técnico).

- Construir uma nova institucionalidade: diz respeito à administração dos programas e suas dificuldades que tornam necessária a postulação de avanços parciais para a "persistência e continuidade das ações" ( $p$. 34). Os quesitos postos por COHEN e FRANCO (1993) para a construção de uma nova institucionalidade nos levam a pensá-los como bastante cabíveis e factíveis à reorganização dos CPMI nas RegS. Eles dizem respeito à necessidade de:

$\checkmark$ Coordenar as instituições evitando a duplicação de direção, traçando planos e realizando ações compartilhadas, coordenadas e cooperadas na rede pública da saúde. Os Programas governamentais têm uma interface agora precisam ter uma interlocução nos serviços de saúde e nas instâncias gerenciais, com ênfase ao PFS / PACS / Comitês de Prevenção da Mortalidade Infantil e todas as outras ações e estratégias relatadas no DSC.

$\checkmark$ Estabelecer uma autoridade ou executivo social com poderes suficientes para fixar prioridades válidas para toda ou parte da sua área de abrangência, "coordenar suas instituições, alocar recursos e efetuar controle, monitoramento e avaliação da execução realizada por outros órgãos” (p.35). Para tanto, essa autoridade executiva deve ser estruturada com capacidade de recursos humanos e outros instrumentos necessários para realizar adequadamente a tarefa.

$\checkmark$ Criar uma rede descentralizada de serviços sociais com a incorporação de novos atores. Isto significa, em nosso contexto, avançar nas condições dos Comitês Regionais, principalmente, e poder contar com maior integração de instituições privadas, de organizações habilitadas pelo SUS, 
ONGs e com profissionais de áreas complementares para às questões sociais, dentre outras apontadas. Deve-se trazê-las próxima da realidade de MI e compartilhar a responsabilidade que lhes cabe no processo de atendimento à saúde e doença da população infantil. Obviamente, essa situação apresenta conteúdo político a ser bem definido e discutido.

$\checkmark$ Obter a participação dos usuários, ou seja, faz parte de um processo democrático o apoio, a colaboração e a aceitação da população e, também, propicia a adesão de ações implementadas para vigilância e investigação dos óbitos infantis.

O processo de desenvolvimento de Programas e de suas ações concretas é mediado por diferentes coletivos de atores. Aqui, podemos falar de nossos entrevistados, segundo comentado por COHEN e FRANCO (1993), compondo o grupo de burocratas. Ou seja, são os diretores de hospitais e regionais de saúde, são profissionais cuja racionalidade é baseada nos procedimentos, na aplicação de normas e na competência legal. Temos, também, o grupo de técnicos, coordenadores de vigilância epidemiológica, dos Comitês e os profissionais dos serviços que são orientados pela racionalidade de fins. Uma outra instância de racionalidade relatada por Ernesto Cohen e Rolando Franco com base em algumas idéias de Medina Echavarría (1972 apud COHEN e FRANCO, 1993, p.64) é a dos "políticos, que são responsáveis por tomar as decisões e fixar os grandes objetivos da política". Essas três racionalidades devem ser complementares e em certas circunstâncias podem ser conflitivas; normalmente se apresentam com limites imprecisos que podem ser interpretados como desnecessário. Assim, é conveniente que se reconheça a existência dessas instâncias de ponderação e que sejam fixados critérios para 0 esclarecimento de posições. A discussão de COHEN e FRANCO (1993) quanto à esses coletivos de racionalidade é extensa e não é objetivo desta pesquisa aprofundar-se nela. 
Desta maneira, por meio dos DSC detecta-se que não há a efetiva fixação de critérios entre as racionalidades dos grupos de políticos, burocratas e técnicos. Este é um fato que, pelas próprias palavras dos atores, tem gerado insatisfação de uns para com os outros, desmotivação na execução do trabalho preventivo, em especial dos Comitês, além de cobranças não direcionadas para instâncias de competência.

É importante ressaltar novamente que são várias as situações que não têm permitido a investigação de todos os óbitos infantis de residentes no Estado. Estas situações vão desde a orientação, momentânea, por partc do próprio CEPMI de usar o peso da criança que foi a óbito para limitar as investigações, na impossibilidade de realizá-la em $100 \%$ dos óbitos ocorridos, até o estabelecimento de estrutura técnica e organizacional para fazê-lo. Os problemas crescem com a insuficiência de profissionais aptos e disponíveis para a investigação, pois ficam por conta de estrutura básica de saúde municipal em cada local. Uma situação ainda bastante dificil, em algumas RegS, é a participação interinstitucional e multiprofissional, um problema relativo a essa participação é a inserção, de fato, de pessoas voluntárias. Esses participantes voluntários são representantes de instituições e, normalmente, não têm tempo necessário ou suficiente para esse tipo de trabalho. Outro problema advindo para o trabalho investigativo na área de saúde é a designação de pessoas voluntárias com indicações políticas locais.

A avaliação dos serviços e dos programas na área da saúde é um instrumento relevante e deve ser permanente. Ele viabiliza escolhas de planejamento e possibilita um controle técnico e social das estratégias implantadas para servir à sociedade. Como enfatiza DESLANDES (1997, p.104), o conhecimento construído por pesquisas avaliativas "têm a peculiaridade de ser estratégico e viabilizador de uma práxis social".

Como evento sentinela da qualidade da assistência e acesso à saúde, os óbitos infantis devem ganhar visibilidade e ter um significado para os sujeitos sociais que o vivenciam, quer sejam gestor, profissionais da ponta ou comunidade. Com os dados até aqui discutidos aliados à nossa experiência afirmamos ser indubitável a contribuição da estratégia de vigilância e investigação do óbito infantil orientada pela formação dos Comitês de Prevenção da Mortalidade Infantil para essa formação de significados. 
Esta pesquisa valorizou a dimensão compreensiva e dialética da mortalidade infantil, mais especificamente a sua prevenção, pois o Pacto Nacional da Mortalidade Materna e Neonatal (BRASIL, 2004) é voltado para a REDUÇÃo dos indicadores de mortalidade infantil e de mulheres. Isto se consegue preservando a vida com ações e direcionamentos que valorizem a integridade da assistência com consciência político-adimistrativa, cultural, social e técnica num contexto de complexidade comprovada para que óbitos evitáveis não ocorram. 


\section{CONCLUSÕES}

Com o objetivo de contextualizar a mortalidade infantil no estado do Paraná trabalhou-se com as Taxas de Mortalidade Infantil (\%o NV) e caracterização dos óbitos infantis ocorridos no estado, no período de 1997 a 2005, dividido em 03 Triênios ( $1^{\circ}$ - 1997/1999; $2^{\circ}$ - 2000/02 e $3^{\circ}$ - 2003/05). Foram utilizados dados secundários do Sistema de Informação sobre Mortalidade e o de Nascidos Vivos (SIM e SINASC) do Ministério da Saúde. Neste sentido, obtiveram-se parâmetros para o trabalho que foi realizado com o SIMI (Sistema de Informação de Mortalidade Infantil) do estado do Paraná, que fornece informações sobre os óbitos que foram investigados pelos Comitês de Prevenção da Mortalidade Infantil..

Obteve-se na etapa quantitativa de análise contextual os seguintes resultados:

$\checkmark$ A TMI decresceu para todo o estado do Paraná mostrou-se com os seguintes valores $1^{\circ}$ Triênio - 19,91, $2^{\circ}$ Triênio - 18,01 e $3^{\circ}$ Triênio - 15,48 óbitos de menores de um ano por \%o NV; esse decréscimo ocorreu de maneira distinta nas 22 Regionais de Saúde do Estado.

$\checkmark$ A grande parte das Regionais de Saúde, 19 delas, apresentou TMI considerada baixa (menos do que 20\% NV), no último Triênio, com exceção de Guarapuava $\left(5^{a}\right)$, Pato Branco $\left(7^{a}\right)$ e Telêmaco Borba $\left(21^{a}\right)$.

$\checkmark$ Apresentaram TMI crescentes, entre os primeiro e último Triênios pesquisados, quatro Regionais: a de Pato Branco $\left(7^{\mathrm{a}}\right)$ teve acréscimo de 4,93\%, Francisco Beltrão $\left(8^{\mathrm{a}}\right)$, com 19,23\% de acréscimo de óbitos infantis, ambas constituem a Macrorregional Sudoeste; além de Telêmaco Borba (21 $\left.{ }^{a}\right)$ com $8,33 \%$ de acréscimo e Ivaiporã $\left(22^{a}\right)$ com elevação na ordem de $2,96 \%$ no contingente de óbitos infantis.

$\checkmark$ Houve melhoria das informações registradas nas Declarações de Óbitos em relação a todas as variáveis estudadas, percebidas pela grande redução das categorias ignoradas.

$\checkmark$ Houve predomínio de óbitos infantis no sexo masculino em todo o período com proporção variando entre $57,57 \%, 56,98 \%$ e $56,27 \%$, respectivamente para os Triênios. 
$\checkmark$ Os óbitos neonatais precoces ocorreram em maioria, 50,76\%, 52,97\% e $51,89 \%$ do total das crianças que faleceram nos Triênios.

$\checkmark$ Entre as crianças que foram a óbito no último Triênio $54,17 \%$ haviam nascido com idade gestacional abaixo de 36 semanas.

$\checkmark$ Quanto ao peso ao nascer das crianças que foram a óbito no último Triênio observou-se que mais de $55,5 \%$ apresentaram baixo peso ao nascer (abaixo de $2500 \mathrm{~g}$ ); cerca de $20 \%$ com menos de $1000 \mathrm{~g}$.

$\checkmark$ Mais da metade $(56,79 \%)$ das mães de crianças que foram a óbito no $3^{\circ}$ Triênio tinha entre 20 a 34 anos; as mães adolescentes (até 19 anos) corresponderam a percentual de $25,81 \%$.

$\checkmark$ ensino fundamental quer completo ou não, considerando-o como escolaridade de 1 a 7 anos, é o que predominou nas mães das crianças que foram a óbito no $3^{\circ}$ Triênio, com proporcionalidade $46,14 \%$.

A proposta organizada pelo Comitê Estadual de Prevenção da Mortalidade Infantil da Secretaria de Estado da Saúde do Paraná preconiza que os óbitos infantis ocorridos em todos os municípios sejam identificados e investigados para o reconhecimento de fatores causais e determinantes. Desde 1997 existe a organização de instâncias Regionais, os chamados Comitês Regionais, que são responsáveis por gerenciar, apoiar e incentivar esse sistema de investigação. Por recomendação, os Comitês devem ser interinstitucionais e multiprofissionais e ter caráter técnico, científico, educativo e de assessoria, visando à prevenção do óbito infantil. Diante da detecção de falhas que favoreceram o óbito os Comitês Regionais coadunados com o Estadual, devem propiciar sua correção de modo a garantir o funcionamento adequado do sistema de saúde no estado.

Assim, pela organização dos Comitês Regionais, é estimulada a criação dos Comitês Municipais que ficam responsáveis pela investigação em unidades de saúde locais e visita domiciliar, bem como a criação de Comitês Intra-Hospitalares, para discussão técnica aprofundada do óbito, que geralmente acontece em ambientes hospitalares. O roteiro da investigação é dado pela Ficha Confidencial de Investigação, há o modelo para óbito neonatal e outro para óbito pós-neonatal, com algumas diferenças. No entanto, os blocos que compõem as Fichas de Investigação 
são: identificação, dados do óbito, dados do pré-natal, dados do parto, dados do prontuário hospitalar e informações da visita domiciliar.

Após o término da busca pelas informações e documentos de atendimentos hospitalares e ambulatoriais à criança, de maneira geral, os municípios encaminham o que conseguiram para o Comitê Regional. Neste Comitê uma equipe deve proceder à Análise Final do Óbito subsidiada pelas informações escritas e documentos anexados. $\mathrm{Na}$ análise final o óbito é tido como evitável ou não, são traçados os determinantes causais, os critérios de redutibilidade e as medidas de prevenção e intervenção. Nesta instância também se discute, diante das evidências e documentos, a adequação da causa básica do óbito e, se necessário, troca-se a causa básica após o processo de investigação.

A Ficha de Análise Final do Óbito é composta por um resumo do óbito; pela identificação da criança; pela causa básica da DO e pela causa básica pósinvestigação; pela definição de morte evitável ou não; por critérios de redutibilidade; pelos determinantes causais; pelas medidas de prevenção e intervenção; pela qualidade dos dados da ficha de investigação; bem como pelos nomes dos integrantes da equipe de análise final. Toda essa categorização segue a uma normativa de preenchimento e esclarecimento quanto às variáveis fornecida por um Manual. São essas as informações que alimentam o Sistema de Informação da Mortalidade Infantil (SIMI) da SESA/PR desde o ano 2000.

Nesta pesquisa, portanto, também se trabalhou com informações advindas do SIMI com as seguintes variáveis: óbito investigado; sexo; faixa etária; evitabilidade; qualidade dos dados da ficha de investigação; determinantes causais; critérios e redutibilidade e intervenção na mortalidade infantil. Adverte-se para o fato de serem essas informações parciais, ou seja, não abrangem todos os óbitos ocorridos. As variáveis do SIMI foram trabalhadas para os dois últimos Triênios do estudo e mostraram que:

No $2^{\circ}$ Triênio foram investigados $59,03 \%$ dos óbitos infantis ocorridos no Estado (média de 68,14\% entre as RegS), no $3^{\circ}$ Triênio ocorreu investigação de $77,21 \%$ dos óbitos (média de $81,73 \%$ entre as RegS); elevação de aproximadamente $31 \%$ na investigação em 6 anos, cerca de $5 \%$ ao ano. Em relação à mediana dos óbitos investigados no $2^{\circ}$ Triênio verificou-se que foi 
de $66,50 \%$ e no $3^{\circ}$ Triênio de $81,00 \%$ (ressalta-se erro no registro do sistema, nesse Triênio, com percentuais de investigação até de 103\%).

$\checkmark$ A única RegS que reduziu o percentual de investigação no período foi a de Telêmaco Borba, passou de $65 \%$ para $55 \%$ de óbitos investigados.

$\checkmark$ As RegS que não atingiram a meta pactuada no estado em 2003 , de $70 \%$ de investigação foram: 'lelêmaco Borba $\left(21^{a}\right)-54 \%$; Foz do Iguaçu $\left(9^{a}\right)-57 \%$; Ponta Grossa ( $\left.3^{a}\right)$ - 58\%; Paranaguá $\left(1^{a}\right)-65 \%$; Ivaiporã $\left(22^{a}\right)-67 \%$ e Metropolitana $\left(2^{a}\right)-68 \%$.

$\checkmark$ O sexo das crianças menores de um ano que tiveram seus óbitos investigados acompanhou o percentual da ocorrência dos óbitos no SIM, isto é, o sexo masculino predominou, $57,95 \%$ e $56,87 \%$, nos Triênios.

$\checkmark$ Quanto à faixa etária das crianças notou-se que mais de $50 \%$ das investigações são de óbitos neonatais precoces, seguindo o mesmo padrão da ocorrência; a seguir teve-se a pós-neonatal com $34,75 \%$ e $31,29 \%$ no $1^{\circ}$ e $2^{\circ}$ Triênios e com menor proporcionalidade os óbitos de crianças no período do $7^{\circ}$ ao $27^{\circ}$ dia de vida (neonatal tardio), com 12,96\% e 15,49\%, nos Triênios.

$\checkmark$ No tocante à qualidade das anotações em fichas de investigação o grau de satisfação foi apontado como "satisfatórios" para 53,24\% e 64,31\%; a "insatisfação" pelas anotações foi expressa ao redor de $10 \%$ das investigações.

Entre os óbitos investigados a proporção de óbitos considerados evitáveis pela investigação e análise, no $2^{\circ}$ Triênio foi de $73,70 \%$ e no $3^{\circ}$ Triênio de $71,71 \%$. Se comparados ao total de óbitos ocorridos (dados do SIM), conclui-se que dos óbitos ocorridos em 2000/02, no mínimo $43,50 \%$ deles tiveram chances para ser evitados, e no período de 2003/05 cerca de, no mínimo, $55 \%$ dos óbitos também poderiam ter sido evitados, segundo parecer da equipe de análise. Os óbitos concluídos como inevitáveis representaram $15,05 \%$ e $20,42 \%$.

$\checkmark$ Em relação aos determinantes causais, podendo ter mais de um determinante para cada óbito investigado, encontrou-se que $49,83 \%$ e $47,25 \%$ tiveram responsabilidade atribuída a uma das áreas da assistencia d̀ sunude; em cerca de $33 \%$ dos óbitos foi determinada a responsabilidade médica; a assistência 
hospitalar foi apontada como responsável por $31,27 \%$ dos óbitos, no $2^{\circ}$ Triênio, com redução da responsabilidade para $28,34 \%$ no $3^{\circ}$ Triênio; assistência ambulatorial foi mais responsabilizada no $3^{\circ}$ Triênio, em $38,41 \%$ dos óbitos, do que no $2^{\circ}$, com $34,78 \%$. Já a responsabilidade social e a responsabilidade pela familia alternaram-se como determinantes causais no segundo lugar, ou seja, no $2^{\circ}$ Triênio a responsabilidade social foi apontada para $19,19 \%$ dos óbitos, e a da família para 18,81 ; no $3^{\circ}$ Triênio a família assume $19,24 \%$ e o social $20,13 \%$.

Quanto às medidas de prevenção $e$ intervenção na mortalidade infantil chama-se a atenção para que para cada óbito ocorreu em média o estabelecimento de 03 medidas. Assim, as medidas de atenção ambulatorial foram as mais freqüentes nos dois Triênios (31,46\% e 33,31\%), a seguir estiveram as medidas de atenção hospitalar no mesmo nível de importância que as medidas de suporte social, ambas variando entre $24 \%$ e $27 \%$ nos dois Triênios, notando que as medidas de atenção hospitalar mostraram-se crescentes, de $24,23 \%$ para $27,82 \%$. As medidas recomendadas para educação em saúde apareceram em $18,45 \%$ do total de medidas no $2^{\circ}$ Triênio e $14,53 \%$ no $3^{\circ}$ Triênio.

$\checkmark$ Em relação específica às medidas de atenção ambulatorial o acesso ao prénatal e a sua qualidade como medidas para mais de $30 \%$ dos óbitos investigados (31,88\% e 34,38\%), com ênfase à qualidade $(24,63 \%$ e $26,30 \%$ nos Triênios). Observou-se redução na recomendação de medidas de atenção à gestação de alto risco, incluindo sua vigilância, passando de $36,37 \%$ para $\mathbf{3 4 , 1 2 \%}$ (as duas especificações estiveram em descenso). A busca ativa d̀ criança de risco, bem como, o acesso da criança a tratamento adequado das complicações em nivel ambulatorial mostrou-se com $24,06 \%$ e $26,70 \%$, respectivamente nos Triênios, indicativo de piora na atenção infantil.

Em especial quanto às medidas de atenção hospitalar nos dois Triênios aparecem, como causas recordistas, o acesso a tratamento adequado à mãe $e$ criança incluindo também o acesso adequado ao parto (38,97\% e 41,57\%). A qualidade médica ficou em segundo lugar dentre as recomendações, 0 melhor diagnóstico a nível hospitalar, pode-se falar em diagnóstico médico, 
foi sugerido em $28,14 \%$ e $25,66 \%$ das situações em que ocorreram os óbitos nos Triênios. A seguir, no terceiro lugar, se destaca a referência para serviços de assistência secundária e terciária, ou seja, o atendimento em serviços especializados e em UTI pediátricas - Unidades de Terapia Intensiva Neonatal e/ou Infantil (18,34\% e 19,54\%).

$\checkmark$ Somadas as medidas de suporte social $e$ as de educação em saúde determinaram $44,31 \%$ e $38,87 \%$ das medidas de prevenção e intervenção eleitas para os dois Triênios, com ênfase na renda familiar, escolaridade, infra-estrutura de moradia e educação em saúde.

Às informações relatadas anteriormente, advindas de dados de fontes secundárias, devem ser consideradas as limitações existentes para cada banco de dados quanto à qualidade dos dados informados e registrados, no Sistema de Informação de Mortalidade (SIM), bem como à limitação por falta de investigação da totalidade de óbitos infantis e eventuais incoerências no Sistema de Informação de Mortalidade Infantil (SIMI).

No SIMI a primeira ressalva é não conter informações de todos os óbitos ocorridos. As outras ressalvas se referem às inconsistências das informações como idade negativa, investigação de mais de $100 \%$ dos óbitos ocorridos em algumas Regionais de Saúde. No entanto, acredita-se que essas incoerências na alimentação do sistema não tenham impedido a pesquisa de ter uma qualidade, até porque puderam ser apontadas para eventuais adequações.

Quanto ao trabalho das Representações Sociais, as respostas à primeira pergunta que indagava sobre o conhecimento do ator profissional de programas, ações ou estratégias de prevenção do óbito infantil no estado do Paraná, foram categorizadas em 6 grupos, estes são compostos por Expressões Chaves e Idéias Centrais semelhantes. As categorizações foram utilizadas em todo o trabalho do DSC, inclusive com estabelecimento de critérios de inclusão para se manter o rigor metodológico no trabalho das expressões-discursivas. Assim, para a primeira pergunta emergiram as categorias de expressões de conhecimento de programas pelos atores sociais com sua força de compartilhamento das idéias, a saber: 
A1 - Organização da rede e fluxo dos serviços de saúde (38,75\%)
B1 - Estratégias Governamentais (37,50\%),
C1 - Desenvolvimento de programas regionais / locais $(43,75 \%)$,
D1 - Melhoria da qualidade das ações e dos serviços $(16,25 \%)$,
E1 - Ações organizacionais do nivel regional / local $(37,50 \%)$ e
F1 - Sem resposta ou resposta se nenhuma idéia central $(5,00 \%)$

Em linhas gerais, pode-se perceber que a Representação Social dos Programas Federais ou locorregionais, de ações e estratégias que previnem o óbito infantil no estado do Paraná: a) enfatiza a importância do PSF e PACS; b) aponta por necessidade de melhor organização dos Programas em nível local; c) expressa a necessidade de capacitação dos profissionais que os integram, principalmente dos médicos, para atendimento à gestante e crianças.

Os profissionais citam a imunização, o aleitamento materno, a puericultura, 0 sistema de vigilância ao agravo nutricional, o soro de reidratação oral, o programa do leite do estado, bem como os programas de vigilância ao recém-nascido de risco e à gestante de risco, e o pré-natal humanizado, segundo preconizado pelo PHPN, ressalvando importância da qualidade do que se faz e a competência de quem faz; ou seja, não basta implantar o programa em cumprimento às determinações de estado.

A regionalização e hierarquização dos serviços são vistas como necessárias e, com urgência, precisam ser mais bem definidas no Estado do Paraná. Há necessidade premente de estabelecimento de serviços de urgência e emergência para a população materno-infantil, inclusive com a disponibilização de maior número de leitos secundários e terciários. Serviços como o da Central de Vagas, dos transportes de urgência e emergência e de atendimento ao trauma, melhoraram bastante a situação de vida das crianças. No entanto, esses serviços ainda necessitam de adequações, segundo os entrevistados.

Quanto aos Comitês, não se percebeu uma forte representação social, principalmente entre os profissionais dos serviços. As falas em relação aos Comitês, geralmente foram dadas pelos profissionais que os coordenam e pelos Diretores de Regionais de Saúde e técnicos do SIM e SIMI. Assim, os profissionais reconhecemno como importante, principalmente porque põem em evidência situações inadequadas de pré-natal e atendimento à criança. Expressam a necessidade de tê-los 
nos municípios que ainda não o constituíram. São valorizadas as parcerias na constituição dos Comitês e expressas as dificuldades para o seu estabelecimento.

Em todas as categorias, os discursos apresentam-se preocupados com a qualidade dos serviços prestados à população materno-infantil e com a vigilância dos riscos e do óbito. Expressão principalmente de profissionais que atendem à gestante $\mathrm{e}$ ao parto, que reconhecem que a incidência do óbito neonatal tem forte ligação com o pré-natal. Para a melhoria da qualidade reconhecem a importância das especialidades e ações de capacitação para profissionais médicos e para-médicos. Existe a manifestação de que o governo tem feito sua parte, mas em contra-partida não é sentida a disposição dos colegas profissionais em mudar suas ações.

As Representações Sociais conhecidas corroboram com as informações obtidas dos bancos secundários, com evidencia de pré-natal deficiente no Estado, quanto ao: acesso, vigilância ao risco, atendimento a complicações em ambulatório e referência para alto risco, como também ao atendimento deficiente a menores de um ano. Houve ênfase na necessidade do estabelecimento de hierarquia na referência aos serviços; a contra-referência também aparece com preocupação tanto na rede básica, como hospitalar.

Os resultados das investigações, registrados no SIMI, apontaram: a) o grande contingente de óbitos evitáveis; b) para os determinantes causais e para c) as medidas de prevenção e intervenção na mortalidade. Estas validam as expressões de dificuldades de acesso ao pré-natal, da qualidade do pré-natal, a dificuldades no setor médico, a necessidade de melhor definição e provimento de serviços de referência e, situações mais complexas como as sociais de moradia, renda e escolaridade; situações também com forte representação social nos discursos construídos.

Foram relatadas, sobretudo, ações organizacionais exitosas para vigilância e investigação do óbito infantil que valorizam e clamam por trabalho intersetorial e multidisciplinar. As mesmas se mostraram direcionadas às áreas de maior deficiência e problemas sentidos pelos entrevistados em seus cotidianos de trabalho como: a de estabelecimento de Comitês Municipais, Hospitalares e seus modos de operar, com a importância ressaltada ao feed back das investigações aos serviços e instituições que colaboram; também em relação ao trabalho com o PACS e PSF e de parceria com a Pastoral da Criança, entre outras organizações. 
A segunda e terceira questões foram analisadas em paralelo, pois ao categorizá-las, como diziam respeito a evidenciação de problemas no processo de trabalho de prevenção do óbito infantil e na seqüência às sugestões para minimizar ou resolver os problemas, optou-se por lê-las integradamente. Assim, as categorias, juntamente com o percentual que expressam a sua força de compartilhamento das idéias ficaram assim distribuídas para o segundo e terceiro questionamentos:

A2 - Dificuldade estrutural (22,50\%),

B2 - Dificuldade operacional e de recursos humanos (33,75\%),

C2 - Dificuldade motivacional / sensibilização (profissional e clientela) $(23,75 \%)$,

D2 - Dificuldade técnica ligada à qualidade da assistência (32,50\%),

E2 - Dificuldade gerencial, política e financeira $(48,75 \%) \mathrm{e}$

F2 - Sem dificuldade / sem idéia (12,25\%)

A3 - Sugestão cstrutural $(15,00 \%)$

B3 - Sugestão operacional e de recursos humanos (18,75\%),

C3 - Sugestão motivacional / sensibilização (profissional e clientela) $(28,75 \%$ ),

D3 - Sugestão técnica ligada à qualidade da assistência $(28,75 \%)$,

E3 - Sugestão gerencial, política e financeira $(51,25 \%) \mathrm{e}$

F3 - Sem sugestões / sem idéias (3,75\%)

A categoria que apresentou maior força de compartilhamento tanto das dificuldades como das sugestões para minimizá-las foi a denominada gerencial, política e financeira. A seguir apareceram as dificuldades e sugestões acerca da área técnica e ligadas à qualidade da assistência. É interessante notar que a área estrutural aparece com uma força maior de compartilhamento das dificuldades e menor de sugestões, talvez devido ao reconhecimento pelos atores da dificuldade em resolver os problemas apontados. $\mathrm{O}$ mesmo acontece com a categoria de dificuldades e sugestões operacionais $e$ de recursos humanos que não têm forças de compartilhamento equiparadas. A última categoria, a $F$, para ambas as perguntas, mostrou também que, provavelmente é mais fácil expressar as dificuldades do que elaborar as sugestões.

Os discursos apresentaram contradições que foram entendidas como sadias e necessárias para a compreensão de questões que cercam a prevenção da mortalidade infantil, entre aos profissionais e gestores, como também pontuam reflexos da atual situação de saúde pública, não só no Paraná, como em todo o Brasil. Situação na qual se busca sua identidade diante do progresso populacional, tecnológico e profissional, 
e diante de diferentes e dinâmicas situações que provocam adoecimento e morte. São também situações de (re)definição da estrutura de saúde do Estado (regionalização e hierarquização), de mudanças ideológicas na saúde (prevenção, promoção, medicalização), de (re)pensar em valores, afeto e amor na saúde (humanização), de atender ao contexto regional e à sua complexidade, de melhorar a capacitação dos trabalhadores, entre outras questões.

Quanto aos Comitês fica claro o impacto positivo de sua proposta de dar maior visibilidade à vigilância de riscos ao óbito infantil e a sensibilização que existe dos profissionais que por eles respondem nas Regionais de Saúde

Há, entretanto, uma advertência bastante séria, nas falas dos sujeitos sociais desta pesquisa. É a indicação de que os Comitês de Prevenção de Mortalidade Infantil necessitam de redirecionamento estrutural, no que diz respeito: a organização do trabalho; ao feedback às instituições hospitalares e da rede básica; à operacionalização nas instâncias Estadual, Regional, Municipal e Hospitalar; ao contingente humano responsável nas regionais e municípios; à gestão estadual mais participante e aos mecanismos de ação diante das inadequações encontradas nos processos de investigação dos óbitos.

Conclui-se esta investigação avaliativa com a certeza do expressivo impacto dos trabalhos de vigilância e investigação dos óbitos infantis: na situação de registro das informações nas Declarações de Óbitos; na visibilidade do evento sentinela para gestores e profissionais; na motivação profissional para melhor desempenho de suas ações e na expectativa dos mesmos em relação à melhoria da estrutura dos serviços e de condições de vida da população para que o óbito infantil possa ser evitado. Além disso, este trabalho proporciona o conhecimento da história da implantação e das atividades dos Comitês de Prevenção da Mortalidade Infantil no estado do Paraná e no Brasil, e conseqüentemente favorece a abertura para o avanço na visibilidade, vigilância e redução dos óbitos infantis. 


\section{CONSIDERAÇÕES FINAIS}

Vivemos numa época marcada pelo rápido avanço do progresso científico e tecnológico. Na saúde este avanço pode ser visto, entre outras instâncias, pela implantação de Políticas Públicas na área da saúde, formatadas por Programas, Estratégias de Ação que deverão ser concretizadas por Estados e Municípios. Para o êxito destes Programas nos estados e municípios, os gestores devem efetivá-los em ações concretas aliando o conhecimento regional dos diversos fatores locais com os indicadores já universalmente consagrados na saúde, como os econômicos, sociais e culturais.

Com essa orientação, este trabalho de tese percorreu um caminho teórico e metodológico, num esforço dialético e compreensivo. Desse modo, utilizou-se da triangulação de métodos de avaliação dos serviços de saúde, pesquisou-se a dimensão dos indicadores de mortalidade infantil (fornecidos por Bancos de Dados Nacionais), a prevenção do óbito infantil evitável (frutos da vigilância ao óbito infantil, dados pelo trabalho dos Comitês no estado do Paraná) e a dimensão do impacto social (com enfoque qualitativo) ocorrido junto aos sujeitos sociais envolvidos numa instância de formulação ou execução de políticas de saúde, em particular a de Prevenção e de Redução da Mortalidade Infantil no estado do Paraná e, conseqüentemente no Brasil.

Diante de toda complexidade que cerca a prevenção em saúde e os discursos dos sujeitos sociais, e mesmo em nível de "ressignificação interpretativa" de suas representações sociais, compartilha-se com certeza da idéia de que sem o compartilhamento e interação entre os sistemas as possibilidades potenciais de sucesso organizacional e operativo se perdem com o tempo (LEFÈVRE et al., 2007, p. 7; TARRIDE, 1998; COHEN e FRANCO, 1993; MINAYO, 2004).

Posto isto, os dados revelaram grande problema em relação à mortalidade infantil no estado, tendo-se em vista seu percentual de evitabilidade nos óbitos investigados. Também emergiram questões em relação ao atendimento das gestantes, normais e de risco, somam mais de $80 \%$ das recomendações ambulatoriais, dados 
esses, entre outros que não são condizentes com a política dirigida ao pré-natal no estado do Paraná, mediante o Programa de Humanização do Parto e Nascimento PHPN, bem como não são plenamente condizentes com o incentivo à redução de óbitos maternos e infantis no estado. Muito embora as Taxas de Mortalidade Infantil mostrem-se em redução contínua, esse fenômeno não ocorre em todo o estado conforme constatação nas entrevistas e nas informações dos óbitos investigados. De acordo com os atores sociais investigados há muitas falhas nesse processo assistencial preventivo, mais seriamente relacionadas ao contingente de profissionais especializados.

Em relação à atenção a criança na rede básica e a tratamentos ambulatoriais adequados tem-se a constituição das recomendações fundamentais para se prevenir o óbito infantil. A sua ocorrência nas recomendações realizadas por equipes de análise final do óbito leva-nos a questionar a qualidade assistencial promovida pelo Programa Saúde da Família, na rede básica de saúde, principalmente em relação à vigilância ao risco. As medidas de atenção hospitalar a especificação mais direta à qualidade médica é a recordista entre as recomendações, o melhor diagnóstico médico. Novamente, o fenômeno chama a atenção a necessidade de melhorar o atendimento as mães e crianças também em nível secundário e terciário de assistência.

Pela perspectiva compreensiva utilizada nessa investigação, buscou-se perceber as representações articuladas sobre a atuação dos serviços de prevenção da mortalidade infantil, na sua base profissional e relacional com a proposta de vigilância e investigação. Os DSC, devido à riqueza de idéias centrais, acabaram por se constituir em longos discursos que nos trouxeram ao conhecimento uma realidade que não poderia ter sido explorada senão por método de valorização da "consciência histórica" (DESLANDES, 1997, p. 105) de seus agentes e de suas representações sociais, que por sua vez estarão objetivadas na prática. Confirmando a opção pela pesquisadora de reconhecer os atores sociais como portadores de experiências racionais que não devem ser ignoradas quando se intenta avaliar um Programa, Estratégia ou Ação em saúde.

Pode-se dizer também que durante todas as fases do presente trabalho de tese, na consulta à documentos e à memória da pesquisadora e, principalmente, em relação 
ao trabalho com o DSC esteve-se alerta para os grandes obstáculos à esse tipo de pesquisa conceituados por MINAYO (2004, p.197), quais sejam: "a ilusão da transparência", "fidedignidade das informações", e às "dificuldades de se juntarem teorias e conceitos muito abstratos com dados os dados colhidos no campo", todos apresentando-se como problemas potenciais para o distanciamento entre as descrições e a elaboração teórica. Bem como, no trabalho como Discurso do Sujeito Coletivo (DSC), buscou-se mediante exercício permanente "não atomizar" as falas, não somá-las apenas como parte de um todo de idéias, valores, comportamentos, mas tratá-las respeitando sua integridade, e zelando para assegurar a redução da arbritariedade e da artificialidade na construção do Discurso Coletivo, segundo orientações e conceituação de LEFÈVRE e LEFÈFRE (1998, p.5, 2007) .

Constatou-se sob uma análise dialética, que há contradições quando se examina as estratégias de prevenção da mortalidade infantil. Isto se deve ao seu caráter histórico fortemente associado às condições de vida da população. Como enfatiza DESLANDES (1997, p. 105) não é que essas contradições emergentes "se tratem de oposições excludentes entre o sim e ou não", elas apenas evidenciam situações que se negam, devido a diferentes racionalidades entre os sujeitos, mas que, no entanto, se coadunam para formar novas formas, maneiras e opções de ações e atitudes de superação e estabelecimento do que se acredita ser possível naquele dado momento histórico, político e social (COHEN e FRANCO, 1993).

As contradições, conforme afirmou DESLANDES (1997), correspondem ao hiato que há entre a o projetos institucionais e sua prática. Assim, há o entendimento, nesta pesquisa, de que se está analisando conflitos para que se consiga superá-los e ensaiar entender a prática, no estado do Paraná, dos agentes sociais no movimento da prevenção da mortalidade infantil envolve.

Desta forma, trabalhou-se como um interlocutor desses sujeitos sociais para oferecer subsídios avaliativos dialéticos, que pretenderam ir além das Taxas de Mortalidade Infantil e do componente político. Embora o percurso metodológico quantitativo e qualitativo - realizado para este trabalho tenha apresentado dificuldades inerentes ao processo de investigação avaliativa pelo uso dos dois métodos complementares de pesquisa, o quantitativo e o qualitativo, há muito ainda 
o que se (des)velar e conhecer desta totalidade complexa que é a saúde e sua abordagem preventiva.

Esta avaliação pretendeu, mesmo que tomada com restrições por formuladores e gestores, conhecer e apresentar a representação social que concorre para o êxito do processo de investigação e prevenção do óbito infantil, acreditando na otimização do benefício e do impacto sobre a população-objetivo e operadores desta Estratégia preventiva. Sobretudo, tendo em vista a contribuição à política nacional expressa mediante a adoção, em 2004, do Pacto Nacional pela Redução da Morte Materna e Neonatal, bem como para o estado do Paraná o cumprimento das metas relatadas na Agenda de Saúde do Estado, do ano de 2003, com ênfase aos eixos-programas voltados para a saúde materno-infantil. 


\section{REFERÊNCIAS}

ALBERMAN, E. Prospects for better perinatal health. Lancet, London, v.2, p.189-192, 1980.

ALMEIDA, S. D. M.; BARROS, M. B. A. Atenção à saúde e mortalidade neonatal: estudo caso-controle realizado em Campinas, SP. Revista Brasileira de Epidemiologia, São Paulo, v. 7, n. 1, p. 22-35, 2004.

ALMEIDA, M.F. Utilização do peso ao nascer como critério de evitabilidade para óbitos infantis. Brasília, DF, 2006. (Produto 3, Contrato Br/CNT/0600251.001)

ALMEIDA, M. F. de et al. Sistemas de informação e mortalidade perinatal: conceitos e condições de uso em estudos epidemiológicos. Revista Brasileira de Epidemiologia, São Paulo, v. 9, n. 1, p. 56-68, 2006.

ALMEIDA, M. F. de et al. Mortalidade neonatal no município de São Paulo: Influência do peso ao nascer e de fatores sócio-demográficos e assistenciais. Revista Brasileira de Epidemiologia, São Paulo, v. 5, n. 1, p. 93-107, 2002.

ALMEIDA, M. F.; MELLO JORGE, M. H. P.de. Pequenos para a idade gestacional: fator de risco para mortalidade neonatal. Revista de Saúde Pública, v. 32, n. 3, p. 217-224, 1998.

APM- ASSOCIAÇÃO PAULISTA DE MEDICINA. SUS: O que você precisa saber sobre o Sistema Único de Saúde. São Paulo: Atheneu, 2002.

ARAÚJO, B. F. et al. Estudo da mortalidade de recém nascidos internados na UTI neonatal do Hospital Geral de Caxias do Sul, Rio Grande do Sul. Revista Brasileira de Saúde Materno Infantil, Recife, v. 4, n.5, p. 465-469, 2005.

ARAÚJO, B. F.; BOZZETTI, M. C.; TANAKA, A. C. A. Mortalidade neonatal precoce em Caxias do Sul: um estudo de coorte. Jornal de Pediatria, Rio de Janeiro, v. 76, 200-206, 2000.

ARAÚJO, J. D. Polarização epidemiológica no Brasil. Informe Epidemiológico do SUS, Brasília, DF, v.1, n. 2, p. 5-16, 1992.

ARRUDA, A. Teoria das representações sociais e teorias de gênero. Cadernos de Pesquisa, Rio de Janeiro, n. 117, p. 127-147, 2002.

ASSIS, S. F. M. de. Um olhar mercadológico sobre a estratégia do sistema único de saúde SUS. 2005. Tese (Doutorado em Saúde Materno Infantil) - Faculdade de Saúde Pública, Universidade de São Paulo, 2005.

AYRES, J. R. C. M. et al. Vulnerabilidade e prevenção em tempos de AIDS. In: BARBOSA, R.M.; PARKER, R.G. Sexualidade pelo avesso: direitos, identidade e poder. 34. ed., Rio de Janeiro: UERJ, IMS, 1999. p. 49-72.

BARBOSA, N. B. Estudo de um caso de implantação de projeto de redução da mortalidade infantil e seu papel. 2000. Dissertação (Mestrado em Política, Planejamento e Administração em Saúde)- Instituto de Medicina Social, Universidade Estadual do Rio de Janeiro, Rio de Janeiro, 2000. 
BARROS, M. B. A. Epidemiologia e superação das iniqüidades em saúde. In: BARATA, R. B. et al. (Org.). Equidade e Saúde: contribuições da epidemiologia. Rio de Janeiro: Fiocruz: Abrasco, 1997. p. 219. Serie Epidemiológica 1.

BARROS, M. B. A.; VICTORA, C. G.; VAUGHAN, J. P. Causas de mortalidade perinatal em Pelotas, RS (Brasil). Utilização de uma classificação simplificada. Revista de Saúde Pública, São Paulo, v. 21, n. 4, p. 310-316, 2002.

BARROS, M. B. A.; XIMENES, R.; LIMA, M. L. C. Validação de variáveis de declaração de óbito por causas externas, Recife, PE, Brasil. Revista de Saúde Pública, São Paulo, v. 36, n. 3, p. 301-306, 2002.

BODSTEIN, R. C. A. Cidadania e modernidade: emergência da questão social na agenda pública. Cadernos de Saúde Pública, Rio de Janeiro, v. 13, n. 2, abr./jun. 1997.

BRANDÃO, D. B.; SILVA, R. R.; PALOS, C. M. C. Da construção de capacidade avaliatória em iniciativas sociais: algumas reflexões. Ensaio: avaliação de políticas públicas e educação, Rio de Janeiro, v. 13, n. 48, p. 361-374, 2005.

BRASIL. Constituição da República Federativa do Brasil. Brasília, DF: Senado, 1988.

BRASIL/BH. Secretaria Municipal de Saúde de Belo Horizonte. Comissão Perinatal. Relatório da Comissão Perinatal 1999-2000. Belo Horizonte, 2000. Disponível em:

<www.pbh.gov.br/smsa> Acesso em: 16 ago. 2007.

BRASIL. Ministério da Saúde. Secretaria de Políticas de Saúde. Atenção humanizada ao recém nascido de baixo peso: método mãe canguru: manual do curso. Brasília, DF, 2002a

BRASIL. Ministério da Saúde. Gabinete do Ministro. Portaria $\mathrm{n}^{\circ} 1101$, de 12 de junho de 2002b. Regulamenta os parâmetros de cobertura assistencial no âmbito do Sistema Único de Saúde - SUS, considerando o disposto no Capítulo III, artigo 26 da Lei $n^{\circ} 8.080 / 90$ e dá providências. Disponível em: <http://atr2001.saude.gov.br/sas/PORTARIAS/Gm/GM1101.htm>. Acesso em: 4 jun. 2007.

BRASIL. Ministério da Saúde. Matriz de indicadores básicos: Indicadores básicos para a saúde no Brasil: conceitos e aplicações, Brasília, DF, 2002c.

BRASIL. Ministério da Saúde. Secretaria de Atenção à Saúde Programa nacional de avaliação de serviços de saúde: PNASS. Brasília, DF, 2004a.

BRASIL. Ministério da Saúde. Manual dos comitês de prevenção do óbito infantil e fetal. Brasília, DF, 2004b.

BRASIL. Ministério da Saúde. Balanço de dois anos do pacto nacional pela redução da mortalidade materna e neonatal. 17. ed., Brasília, DF, Dez. 2006. Disponível em: $<$ http://drt2002.saude.gov.br/proesf/Site/Arquivos-pdf-word/pdf/Balan347\%2028\%2021\%2006.pdf>. Acesso em: 4 jun. 2007.

BRASIL. Ministério da Saúde. Balanço de três anos do pacto nacional pela redução da mortalidade materna e neonatal, 19. ed., Brasília, DF, 2007a. Disponível em: <http://dtr2002.saude.gov.br/proesf/site/paginas/pacto.htm>. Acesso em: 04 fev. 2007. 
BRASIL. Ministério da Saúde. Informações de saúde: dados demográficos e econômicos. Brasilia, DF, 2007b. Disponível em:

<http://tabnet.datasus.gov.br/cgi/deftohtm.exe?ibge/cnv/poppr.def>. Acesso em: 21 jan. 2007.

BRASIL/CNES- CADASTRO NACIONAL DE ESTABELECIMENTOS DE SAÚDE. Disponível em: $<$ http://cnes.datasus.gov.br/>Acesso em: jul. 2007.

BUSS, P. M. Uma introdução ao conceito de promoção da saúde. In: CZERESNIA, D.; FREITAS, C.M.de. Promoção da Saúde: conceito, reflexões e tendências, Rio de Janeiro: Fiocruz, 2003, p. 15-38.

CALDEIRA, A. P.; FRANÇA, E.; GOULART, E. M. A. Mortalidade infantil pós-neonatal e qualidade da assistência médica: um estudo caso-controle. Jornal de Pediatria, Rio de Janeiro, v.77, n. 6, p. 461-468, 2001.

CALDEIRA, A. P.; FRANÇA, E.; GOULART, E. M. A. Mortalidade infantil pós-neonatal evitável: o que revelam os óbitos em domicílio. Revista Brasileira de Saúde Materno Infantil, Recife, v.2, n. 3, p. 263-274, set./dez. 2002.

CAMARANO, A. A. et. al. Fecundidade e anticoncepção da população jovem. In: BEQUÓ, E. et al. Jovens acontecendo na trilha das políticas públicas. Brasília, DF: CNPD - Comissão Nacional de População e Desenvolvimento. 1998, v. 1, p. 109-133.

CANO, I. Introdução à avaliação de programas sociais. 2. ed. Rio de Janeiro: FGV, 2004.

CARVALHO, G.; ROSEMBURG, C. P.; BURALLI, K. O. Avaliação de ações e serviços de saúde. Revista 0 Mundo da Saúde, São Paulo, v. 24, n. 1, p. 72-88, jan./fev. 2000.

CARVALHO, M.L.; SILVER, L.D. Confiabilidade da declaração de causa básica de óbitos neonatais: implicações para o estudo da mortalidade prevenível. Revista de Saúde Pública, São Paulo, v.29, n. 5, p. 342-348, 1995.

CARVALHO, W. O. de Uso de serviços de saúde materno-infantis na região sudoeste da grande São Paulo em dois períodos: 1990-2000. Inquéritos de saúde como fonte de dados para estudos de utilização de serviços de saúde. 2004. Tese (Doutorado em Saúde Pública) Faculdade de Saúde Pública, Universidade de São Paulo, São Paulo, 2004.

CARVALHO, S. C.; CARVALHO, W. O. Evolução da mortalidade infantil em pequenos e médios municípios rurais do Paraná. In: CONGRESSO MUNDIAL DE SOCIOLOGIA RURAL, 10., 2000, Rio de Janeiro. Anais... Rio de Janeiro: Sober, IRSA, 2000.

CASTELLANOS, L. P. Perfis de mortalidade, nível de desenvolvimento e iniqüidades sociais na região das Américas. In: BARATA, R. B. et al (Org.). Equidade e Saúde: contribuições da epidemiologia. Rio de Janeiro: Fiocruz, abrasco, 1997, p. 137-160. (Serie Epidemiológica, 1).

CESAR, C. L. G. Fatores de risco associados à mortalidade infantil em duas áreas da região metropolitana de São Paulo (Brasil), 1984-1985: proposta de instrumentos preditivos. Revista de Saúde Pública, São Paulo, v. 24, n. 4, p.300-310, ago. 1990.

COHEN, E.; FRANCO, R. Avaliação de projetos sociais. 6. ed. Petrópolis: Vozes, 2004. 
COHN, A. O estudo das políticas de saúde: implicações e fatos. In: CAMPOS, G.W.S. et al. (Org.). Tratado de saúde coletiva. São Paulo, Rio de Janeiro: Hucitec: Fiocruz, 2006. p. 231258.

CONTANDRIOPOULOS, A. P. et al. A avaliação na área de saúde: conceitos e métodos. In: HARTZ, Z.M.de A. (Org.). Avaliação em saúde. Rio de Janeiro: Fiocruz, 2000. p.29-47.

CUNHA, E. M. G. P.da. Raça: aspecto esquecido na iniqüidade em saúde no Brasil. In: BARATA, R.B. et al. (Org.). Equidade e Saúde: contribuições da epidemiologia. Rio de Janeiro: Fiocruz: Abrasco, 1997, p. 219. (Serie Epidemiológica, 1).

DARLAN, C. (Org.). Estatuto da Criança e do Adolescente: lei 8069/90. Rio de Janeiro: DP\&A, 1998. $v 2$.

DESLANDES, S. F. Concepções em pesquisa social: articulações com o campo da avaliação em serviços de saúde. Cadernos de Saúde Pública, Rio de Janeiro, v.13, n.1, p. 103 - 107, 1997.

DEMO, P. Metodologia da avaliação de como ignorar em vez de enfrentar problemas. Campinas: Autores Associados, 1999. (Coleção polêmicas do nosso tempo, 68)

DEMO, P. Avaliação qualitativa. Campinas: Autores Associados, 1994. (Coleção polêmicas do nosso tempo, 25).

DESLANDES, S.F. $O$ atendimento às vítimas de violência na emergência: prevenção numa hora dessas?. Ciência \& Saúde Coletiva, São Paulo, v.4, n.1, p. 81- 94, 1999.

DEVIDÉ, A. J. Os condicionantes socioeconômicos da mortalidade infantil no Paraná 1980-2001. 2001. Monografia de Conclusão de Curso (Graduação em Economia) Universidade Estadual de Londrina, Londrina, 2001.

DONABEDIAN, A. The quality of care. How can it be assessed? JAMA, Michigan, v. 260, n. 12, p. 1743-1748, set.1988.

DONABEDIAN, A. Explorations in quality assessment and monitoring: The definition of quality and approaches to its assessment. Michigan: Board, 1980.

DRUMOND JÚNIOR, M.; BARROS, M. B. A. Desigualdades socioespaciais na mortalidade do adulto no Município de São Paulo. Revista Brasileira de Epidemiologia, São Paulo, v.2, n. 1/2, p. 34-48, 1999.

ESCUDER, M. M. L.; VENANCIO, S. I.; PEREIRA, J. C. R. Estimativa de impacto da amamentação sobre a mortalidade infantil. Revista de Saúde Pública, São Paulo, v. 37, n. 3, p. 319-325, 2003.

FAIRLEY, L.; LEYLAND, A. H. Social class inequalities in perinatal autcomes: Scotland 1980-2000. Journal of Epidemiology and Community Health, London, v. 60, p. 31-36, 2006.

FERREIRA, C. E. C. Mortalidade infantil e desigualdade social em São Paulo. 1990. Tese (Doutorado em Saúde Pública) - Faculdade de Saúde Pública, Universidade de São Paulo, São Paulo, 1990. 
FREIRE, P. Pedagogia da autonomia: saberes necessários à prática educativa. 28 ed. São Paulo: Paz e Terra, 2003.

FRIAS, P. G. et al. Avaliação da notificação de óbitos infantis ao Sistema de Informações sobre Mortalidade: um estudo de caso. Revista Brasileira de Saúde Materno Infantil, Recife, v. 5, p. 543-551, dez. 2005. Suplemento 1 .

GOLDANI, M. Z. et al. Mortalidade infantil e nível socioeconômico em uma cidade brasileira. Revista de Saúde Pública, v. 35, n. 3, p. 256-261, 2001.

GOLDBAUM, M. A. A epidemiologia em busca da eqüidade em saúde. In: BARATA, R.B. et al. (Org.). Equidade e Saúde: contribuições da epidemiologia. Rio de Janeiro: Fiocruz: Abrasco, 1997. p. 63-80. (Série Epidemiológica 1).

GOLDENBERG, M. A arte de pesquisar: Como fazer pesquisa qualitativa em Ciências Sociais. 7. ed. Rio de Janeiro: Record, 2003.

GORDIS, L. Medidas da ocorrência de doenças.In: Epidemiologia. Rio de Janeiro: Revinter, 2004. p.31-62.

HADAD, S.; FRANÇA, E.; UCHÔA, E. Mortes infantis por causas evitáveis e qualidade dos serviços de saúde: um estudo da percepção materna da doença e do atendimento à criança doente. Cadernos de Saúde Pública, Rio de Janeiro, v. 18, n. 6., p. 1519-1527, nov./dez. 2002.

HARTZ, Z. M. A. et al. Mortalidade infantil "evitável" em duas cidades do nordeste do Brasil: Indicador de qualidade do sistema local de saúde. Revista de Saúde Pública. São Paulo, v. 30, n. 4, p. 310-318, 1996.

HARTZ, Z.M.de A. (Org.). Avaliação em saúde: dos modelos conceituais à prática na análise da implantação de programas. Rio de Janeiro: Fiocruz, 1997.

HOROCHOVSKI, M. T. H. Representações sociais: delineamentos de uma categoria analítica. Em tese: Revista Eletrônica dos Pós-Graduandos em Sociologia Política da UFSC.

Florianópolis. v.2, n.1, p.92-106, jan./jun. 2004. Disponível em: <http:// www.emtese.ufsc.br>. Acesso em: 21 jan. 2007.

HOUWELING, T. A. J. et al. Mortality inequalities in times of economic growth: time trends in socioeconomic and regional inequalities in under 5 mortality in Indonesia, 1982-1997. Journal of Epidemiology and Community Health, London, v. 60, p. 60-68, 2006.

IBGE- INSTITUTO BRASILEIRO DE GEOGRAFIA E ESTATÍSTICA. 2007. Disponível em: < http://www.ibge.gov.br/estadossat/perfil.php?sigla=pr>. Acesso em: 15 jan. 2007.

ISSLER, R. M. S. et al. Nível de pobreza e estado de saúde das crianças: um estudo de fatores de risco em população urbana de baixo nível socioeconômico. Revista de Saúde Pública, São Paulo, v. 30, n. 6, p. 506-511, 1996.

JODELET, D. (Org.). As representações sociais. Rio de Janeiro: EdUERJ. 2001.

JODELET, D. Loucuras e representações sociais. Petrópolis: Editora Vozes; 2005. Resenha de PAREDES, E.C. Cadernos de Saúde Pública, Rio de Janeiro, v. 22, n. 12, p. 2722-2727, dez. 2006. 
LANSKY, S.; FRANÇA, E.; LEAL, M. C. Mortalidade perinatal e evitabilidade: revisão da literatura. Revista de Saúde Pública, São Paulo, v. 36, n. 6, p. 759-772, 2002a.

LANSKY, S.; FRANÇA, E.; LEAL, M. C. Mortes perinatais evitáveis em Belo Horizonte, Minas Gerais, Brasil, 1999. Revista de Saúde Pública, São Paulo, v. 18, n. 5, p. 1389-1400, set./out. 2002b.

LAURENTI, R. Fatores de erros na mensuração da mortalidade infantil. Revista de Saúde Pública, São Paulo, v.9, p. 529-537, 1975.

LAURENTI, R. Mortalidade infantil nos Estados Unidos, Suécia e Estado de São Paulo.

Revista de Saúde Pública, São Paulo, v. 21, n. 3, p.268-273. jun. 1987.

LAURENTI, R.; BUCHALLA, C. M. Estudo da morbidade e da mortalidade perinatal em maternidades. Revista de Saúde Pública, São Paulo, v.19, p. 225-232, 1985.

LAURENTI, R.; MELLO JORGE, M. H. P.; GOTLIEB, S. L. D. O Sistema de informações sobre mortalidade: passado, presente e futuro. São Paulo: CBCD, 2006 (Série Divulgação, 11).

LAURENTI, R; MELLO JORGE, M.H.; GOTLIEB, S. L. D. Estatísticas de saúde. São Paulo: EPU, 1985.

LEAL, M. C.; SZWARCWALD, C. L. Características da mortalidade neonatal no Estado do Rio de Janeiro na década de 80: uma visão espaço-temporal. Revista de Saúde Pública, São Paulo, v.31, n. 5, p. 457-465, 1997.

LEAL, M. C.; SZWARCWALD, C. L. Evolução da mortalidade neonatal no Estado do Rio de Janeiro, Brasil (1979-1993): análise por causa segundo grupo de idade e região de residência. Cadernos de Saúde Pública, Rio de Janeiro, v.12, p. 243-252, 1996.

LEFÈVRE, F.; LEFÈVRE, A. M. C.; MARQUES, M. C. C. Discurso do sujeito coletivo, complexidade e auto organização. Ciência \& Saúde Coletiva, Rio de Janeiro, 2007a.

Disponivel em:

$<$ http//www.abrasco.org.br/cienciaesaudecoletiva/artigos_int.php?id_pdr.shtml>. Acesso em: 7 fev. 2007.

LEFÈVRE, F. et al. Acessando o discurso do sujeito coletivo e o software qualiquantisoft. São Paulo: IPDSC, 2007b.

LEFÈVRE, F.; LEFÈVRE, A. M. C. Discurso do sujeito coletivo como expressão narrativa da quantidade. São Paulo: IPDSC, 2007. Instituto de Pesquisa do Discurso do Sujeito Coletivo, São Paulo, 2007. Disponível em: $<$ http//www.ipdsc.com.br/scp/showcat.php?id=8>. Acesso em: 5 mar. 2007.

LEFÈVRE, F.; LEFÈVRE, A. M. C. O discurso do sujeito coletivo: um novo enfoque em pesquisa (desdobramentos). Caxias do Sul: EDUCS, 2003.

LEFÈVRE, F.; LEFÈVRE, A. M. C. O sujeito coletivo que fala. Interface, São Paulo, v.10, n.20, p. 517-24, jul./dez. 2006.

LEFÈVRE, F.; LEFÈVRE, A.M.C. Recuperando a fala do social. São Paulo: FSP,USP, HSP, 1998. (Série Monográfica, 9). 
LEITE, A. J. M. et al. Mortes perinatais no município de Fortaleza, Ceará: o quanto é possível evitar? Jornal de Pediatria, Rio de Janeiro, v. 73, n.6 p. 388-394, 1997.

LEITE, A. J. M. Óbitos infantis: como melhor estudá-los (ou de como devemos evitá-los) Jornal de Pediatria, Rio de Janeiro, v. 73, n.6 p. 362-363, 1997.

LEVCOVITZ, E.; LIMA, L.D.; MACHADO, C. V. Política de saúde nos anos 90: relações intergovernamentais e o papel das Normas Operacionais Básicas. Ciência \& Saúde Coletiva, Rio de Janeiro, v. 6, n. 2, p. 269-291, 2001.

LILJESTRAND, J. Commentary: reducing perinatal and maternal mortality in the World: the major challenges." British Journal of Obstetrics and Gynaecology. v.106 n.9, p.877-880, 1999.

MALTA, D. C.; DUARTE, E. C. Causas de mortes evitáveis por ações efetivas dos serviços de saúde: uma revisão de literatura. Ciência \& Saúde Coletiva, Rio de Janeiro, 2007. Disponível em: <http://www.abrasco.org.br/cienciaesaudecoletiva/artigos/artigo_int.php?id_artigo=336>. Acesso em: 16 jun. 2007

MALTA, D. C.et al. Lista de causas de mortes evitáveis por intervenções do Sistema Único de Saúde. Aceito para publicação, 2007.

MANN, J.; TARANTOLA, D. J. M.; NETTER, T. W. Aids in the world. Cambridge: Havard University Press, 1992.

MANSANO, N. H. et al. Comitês de prevenção da mortalidade infantil no Paraná, Brasil: Implantação e operacionalização. Cadernos de Saúde Pública, Rio de Janeiro, v. 20, n.1, jan./fev. 2004.

MARANHÃO, A. G. K.; JOAQUIM, M. M. C.; SIU, C. Mortalidade perinatal e neonatal no Brasil. Tema Radis, Rio de Janeiro, v. 2, p.6-17, 1999.

MEDRONHO, R. A. et al. Epidemiologia. São Paulo: Atheneu, 2004.

MELLO JORGE, M. H. P.de. Mortalidade de adolescentes: um risco para o almejado aumento da esperança de vida no país. Jornal de Pediatria, Rio de Janeiro, n. 75, p. 309-310, 1999. Editorial.

MELLO JORGE, M. H.; GOTLIEB, S. L. D.; OLIVEIRA, H. O sistema de informação sobre Nascidos Vivos: primeira avaliação dos dados brasileiros. Informe Epidemiológico do SUS, Brasília, DF, v.2, p.15-48, 1996.

MELLO JORGE, M. H. P.de.; GOTLIEB, S. L. D. As condições de saúde no Brasil: retrospecto de 1979 a 1995. Rio de Janeiro: Fiocruz, 2000.

MELLO JORGE, M. H. P.de.; GOTLIEB, S. L. D.; LAURENTI, R. A saúde no Brasil: Análise do período de 1996 a 1999. Brasília, DF: OPAS: OMS, 2001.

MENDONÇA E. F.; GOULART, E. M. A.; MACHADO, J. A. D. Confiabilidade da declaração de causa básica de mortes infantis em região metropolitana do sudeste do Brasil. Revista de Saúde Pública, São Paulo, v. 28, n. 5, p. 385-391, 1994. 
MENEZES, A. M. B. et al. Estudos populacionais de investigação de óbitos perinatais e infantis: Metodologia, validade do diagnóstico e sub-registro. Jornal de Pediatria, Rio de Janeiro, v. 73, n.6, p. 383-387, 1997.

MINAYO, M.C.S. O desafio do conhecimento: pesquisa qualitativa em saúde. 8. ed. São Paulo: Hucitec, 2004.

MINAYO, M. C. S. Conceito de avaliação por triangulação de métodos. In: MINAYO, M.C.S.; ASSIS, S.G.; SOUZA, E.R. (Org.). Avaliação por triangulação de métodos. Rio de Janeiro: Fiocruz, 2005a. p. 19-51.

MINAYO, M.C.S. Mudança: conceito-chave para intervenções sociais e para avaliação de programas. In: MINAYO, M.C.S.; ASSIS, S.G.; SOUZA, E.R. (Org.). Avaliação por triangulação de métodos. Rio de Janeiro: Fiocruz, 2005b. p. 53-70.

MINAYO, M. C. S.; ASSIS, S. G.; SOUZA, E. R. (Org.). Avaliação por triangulação de métodos: abordagem de proramas sociais. Rio de Janeiro: Fiocruz, 2005.

MINAYO, M. C. S.; SOUZA, E .R.de. É possível prevenir a violência?: reflexões a partir do campo da saúde pública. Ciência \& Saúde Coletiva, São Paulo, v.4, n.1, p. 7-21, 1999.

MS- MINISTÉRIO DA SAÚDE. Datasus - Departamento de Informática do SUS. Informações de Saúde. Estatísticas Vitais. Óbitos Infantis. Nascidos Vivos, Brasília, DF. Disponível em: $<\mathrm{http}: / / \mathrm{w} 3$. datasus.gov.br/datasus/datasus.php?area=359A1B378C5D0E0F359G22HDd5L25M 0N\&Vinclude=../site/infsaude.php> . Acesso em: 2005, 2006 e 2007).

MONTEIRO, C.A. Contribuição para o estudo do significado da evolução do coeficiente de mortalidade infantil no Município de São Paulo, SP (Brasil), nas três últimas décadas (19501979). Revista de Saúde Pública, São Paulo, v. 16, p. 7-18, 1982.

MONTEIRO, C. A.; NAZÁRIO, C. de L. Declínio da mortalidade infantil e eqüidade social: o caso da cidade de São Paulo entre 1973 e 1993. In: MONTEIRO, C.A. (Org.). Velhos e novos males da saúde no Brasil: a evolução do país e de suas doenças. São Paulo: Hucitec, NUPENS/USP, 1995. p. 173-185.

MOREL, C. M. A pesquisa em saúde e os objetivos do milênio: desafios e oportunidades globais, soluções e políticas nacionais. Ciência \& Saúde Coletiva, São Paulo, v.9, n.2, p.261270, abr./jun. 2004.

NETO, O. C.; MOREIRA, M. R. A concretização de políticas públicas em direção à prevenção da violência estrutural. Ciência \& Saúde Coletiva, São Paulo, v. 4, n.1, p. 33-49, 1999.

NEVES, F. A. M. et al. Assistência humanizada ao neonato prematuro e/ou de baixo peso: Implantação do método mãe canguru em hospital universitário. Acta Paulista de Enfermagem, São Paulo, v. 19, n. 3, p. 349=353, 2006.

NIOBEY, F. M. L. et al. Fatores de risco para morte por pneumonia em menores de um ano de uma região metropolitana do sudeste do Brasil. Um estudo tipo controle. Revista de Saúde Pública, São Paulo, v. 26, n. 4, p. 229-238, dez. 1992.

OLIVEIRA, M. S. B.de. Representações sociais e sociedades: a contribuição de Serge Moscovici. Revista Brasileira de Ciências Sociais, São Paulo, v. 19, n. 55, p. 180-186, jun. 2004. 
OMS- ORGANIZAÇÃO MUNDIAL DA SAÚDE. Classificação estatística internacional de doenças e problemas relacionados à saúde/CID- 10. Tradução do Centro Colaborador da OMS para Classificação de Doenças em Português. São Paulo: EDUSP, 1994. v. 2.

OMS- ORGANIZAÇ̃̃O MUNDIAL DA SAÚDE. Classificação estatística internacional de doenças e problemas relacionados à saúde/CID-10. Tradução do Centro Colaborador da OMS para Classificação de Doenças em Português. 9 ed. rev. São Paulo: EDUSP, 2003. v. 1.

OPAS- ORGANIZAÇÃO PANAMERICANA DE SAÚDE. La salud em las Américas. Washington, DC, 1999. (OPS - Publicação Científica, 569).

ORLANDI, M. H. F. Mortalidade de adolescentes e jovens no município de Maringá/PR: magnitude e tendências. 2000. Dissertação (Mestrado em Saúde Materno-Infantil) - Faculdade de Saúde Pública, Universidade de São Paulo, São Paulo, 2000.

ORLANDI, M. H. F.; CARVALHO, W. O.de. Óbitos infantis de extremo baixo peso ao nascer: a importância da investigação. Revista da Sociedade Brasileira de Enfermagem Pediátrica, São Paulo, v.1, p. 33-40, 2001.

PEDROSA, L. D. C. O.; SARINHO, S. W.; ORDONHA, M. A. R. Óbitos neonatais: por que e como informar? Revista Brasileira de Saúde Materno Infantil, Recife, v. 5, n. 4, p. 411-418, 2005 .

PEREIRA, M. G. Epidemiologia: teoria e prática. Rio de Janeiro: Guanabara Koogan, 1995.

POST, C. L. A. et al. Fatores prognósticos de letalidade hospitalar por diarréia ou pneumonia em menores de um ano de idade. estudo de caso controle. Revista de Saúde Pública, São Paulo, v. 26, n. 6, p. 369-378, dez. 1992.

PR/SESA- SECRETARIA DE ESTADO DA SAÚDE, PARANÁ. Proposta de reorganização dos comitês de prevenção da mortalidade infantil. Curitiba, 1997.

PR/SESA- SECRETARIA DE ESTADO DA SAÚDE, PARANÁ. Diretoria de Vigilância e Pesquisa. Comitê Estadual de Prevenção da Mortalidade Infantil. Resolução nº. 0262/98.

Regimento Interno do Comitê Estadual de Prevenção da Mortalidade Infantil, Curitiba, 1998.

PR/SESA- SECRETARIA DE ESTADO DA SAÚDE, PARANÁ. Manual para preenchimento ficha de Investigação. Curitiba, 2006

PR/SESA-SECRETARIA DE ESTADO DA SAÚDE, PARANÁ. Programação pactuada integrada-2003. Curitiba, 2003. < Disponível em:

$<$ http://saude.pr.gov.br/instrumentos/ppi.shtml> Acesso em: 4 jun. 2007.

PR/SESA-SECRETARIA DE ESTADO DA SAÚDE, PARANÁ. Plano diretor de regionalização- 2001, Curitiba, 2001. Disponível em:

$<$ http://www.saude,pr.gov.br/instrumentos/>. Acesso em: 04 jun. 2007.

PR/SESA - SECRETARIA DE ESTADO DA SAÚDE, PARANÁ. Resolução nº 0229/99 de 23 de junho de 1999. Disponibilização de prontuários por hospitais/maternidades, Curitiba, 1999.

PR/SESA-SECRETARIA DE ESTADO DA SAÚDE, PARANÁ. Regionais de Saúde e Municípios. Curitiba. Disponível em: $<\mathrm{http}: / / w w w . s a u ́ d e . p r . g o v . b r / R S / i n d e x . h t m l>$. Acesso em: 2006, 2007. 
PR/SESA- SECRETARIA DE ESTADO DA SAÚdE DO PARANÁ. Programa de humanização no pré-natal e nascimento: o que é o programa? Disponível em: $<$ http://www.saude.pr.gov.br/phpn/ $>$. Acesso em: 15 ago. $2007 \mathrm{~b}$.

REICHENHEIM, M. E.; HASSELMANN, M. H.; MORAES, C. L. Conseqüências da violência familiar na saúde da criança e do adolescente: contribuições para a elaboração de propostas de ação. Ciência \& Saúde Coletiva, São Paulo, v.4, n.1, p. 109-121, 1999.

RONCHEZEL, V. S. C.; YUNES J. Evolução da mortalidade geral, infantil e proporcional no Brasil. Revista de Saúde Pública, São Paulo, v.8, p. 3-48, 1974. Suplemento.

ROSENBERG, D. I.; MOSS, M. M. Guidelines and levels of care for pediatric intensive care units. Pediatrics, Washington: AAP, Section on Critical Care and Committee on Hospital Care, v. 114, p. 1114-1125, 2004. Disponível em $<$ http://aappolicy.aappublications.org/cgi/content/full/pediatrics;114/1/274>. Acesso em: 15 ago. 2007.

RUTSTEIN, D. D. et al. Measuring the quality of medical care: a clinical method. The New England Journal of Medicine, Boston, v. 294, n. 11, p. 582-588, mar.1976.

SANTA HELENA, E. T.; ROSA, M. B. Avaliação da qualidade das informações relativas aos óbitos em menores de um ano em Blumenau, 1998. Revista Brasileira de Saúde Materno Infantil, Recife, v. 3, n.1, p. 75-83, jan./mar. 2003.

SANTOS JÚNIOR, J. D.dos. Fatores etiológicos relacionados à gravidez na adolescência: vulnerabilidade à Maternidade. Cadernos Juventude Saúde e Desenvolvimento, Brasília, DF, v. 1, p.223-229, ago.1999.

SARINHO, S. W. Mortalidade de pós-neonatal: novas abordagens. Jornal de Pediatria, Rio de Janeiro, v. 77, n.6, p.437-438, 2001.

SBP- SOCIEDADE BRASILEIRA DE PEDIATRIA. Infra-estrutura para atendimento integral ao recém-nascido. Documento Científico do Departamento de Neonatologia da SBP, Rio de Janeiro, 2004. Disponível em:

$<\mathrm{http}: / / \mathrm{www}$. sbp.com.br/show_item2.cfm?id_categoria=21\&id_detalhe=1636\&tipo_detalhe=s $>$ Acesso em: 16 ago. 2007.

SCHRAIBER, L. B. Pesquisa qualitativa em saúde: reflexões metodológicas do relato oral e produção de narrativas em estudo sobre a profissão médica. Revista de Saúde Pública, São Paulo, v. 29, n. 1, p. 63-74, 1995.

SCHRAMM, J. M. A.; SZWARCWALD, C. L. Sistema hospitalar como fonte de informações para estimar mortalidade neonatal e a natimortalidade. Revista de Saúde Pública, São Paulo, v. 34, n. 3. p. 272-279, 2000.

SEADE-FUNDAÇÃO SISTEMA ESTADUAL DE ANÁLISE DE DADOS. Conjuntura Demográfica. 1991. São Paulo, 1991.

SERAFIM, D. Mortalidade neonatal em Maringá - PR, 1997 - 2000. 2002. Tese (Doutorado em Saúde Pública) - Faculdade de Saúde Pública, Universidade de São Paulo, São Paulo, 2002. 
SÍCOLI, J. L.; NASCIMENTO, P. R.do. Promoção de saúde: concepções, princípios e operacionalização. Interface: Comunicação, Saúde, Educação, Botucatu, v. 7, n. 12, p. 101122, fev. 2003.

SILVA, L. T.; COSTA, A. J. S. T.; ROCHA, R. Representações sociais e práticas docentes: trilhas e caminhos de professores(a)s de Geografia na educação ambiental. In: SIMPÓSIO BRASILEIRO DE GEOGRAFIA FISICA APLICADA, 10., 2003, Rio de Janeiro. Geo UKKJ. Rio de Janeiro: Universidade do Estado do Rio de Janeiro, 2003. p. 236-248. Edição especial.

SILVA, R. R.; BRANDÃO, D. Os quatro elementos da avaliação. São Paulo: Instituto Fonte para o desenvolvimento da sociedade, 2003. Disponível em:

$<\mathrm{http} / / / \mathrm{www}$.fonte.org.br/documentos/artigo\%209.pdf>. Acesso em:15 ago. 2007.

SILVA, L. M. V. da; FORMIGLI, V. L. A. Avaliação em saúde: limites e perspectivas. Caderno de Saúde Pública, vol.10, n.1, p.80-91, 1994.

SIMÕES, C.C (Org.). Perfil estatístico de crianças e mães no Brasil: murtalidade infantil e saúde na década de 80. Rio de Janeiro, IBGE, 1989.

SIMÕES, C.C.; OLIVEIRA, L.A.P. Evolução da mortalidade infantil. In: IBGE. Perfil estatístico de crianças e mães no Brasil: aspectos socioeconômicos da mortalidade infantil em áreas urbanas. Rio de Janeiro, 1986. p. 29-48.

SIMÕES, C.C.S. Perfis de saúde e de mortalidade no Brasil: Uma análise de seus condicionantes em grupos populacionais específicos. Brasília, DF: OPA, 2002.

SOUZA, R. K.T. Mortalidade infantil e sub-registro de nascidos vivos no município de Maringá-PR, EM 1989. 1992. Dissertação(Mestrado em Saúde Pública) - Faculdade de Saúde Pública, Universidade de São Paulo, São Paulo, 1992.

SOUZA R. K.T.; GOTLIEB S. L. D. Probabilidade de morrer no primeiro ano de vida em área urbana da região sul, Brasil. Revista de Saúde Pública, São Paulo, v. 27, n. 6, p. 445-454, dez. 1993.

STROZZI, G. M. et al. Estudo de causa básica de óbitos de menores de 15 anos, ocorridos em hospital de Florianópolis, SC (Brasil), em 1982. Revista de Saúde Pública, São Paulo, v.19, n. 2, p.123-132, abr.1985.

SZWARCWALD, C. L. et al. Mortalidade infantil no Brasil: Belíndia ou Bulgária? Cadernos de Saúde Pública. Rio de Janeiro, v. 13, n. 3, p. 503-516, jul./set.1997.

SZWARCWALD, C. L. et al. Estimação da mortalidade infantil no Brasil: o que dizem as informações sobre óbitos e nascimentos do Ministério da Saúde? Cadernos de Saúde Pública, Rio de Janeiro, v. 18, n. 6, p. 1725-1736, nov.-dez. 2002.

TANAKA, O.; MELO C. Avaliação de programas de saúde do adolescente: um modo de fazer. São Paulo: EDUSP, 2001.

TARRIDE, M. I. Saúde pública: uma complexidade anunciada. Rio de Janeiro: Fiocruz, 1998. 
TREURNIET, H. F.; BOSHUIZEN, H. C.; HARTELOH, P. P. M. Avoidable mortality in Europe (1980-1997): a comparison of trends. J. Epidemiol. Community Health, London, v. 58, p. 290-295, 2004.

VICTORA, C. G. Intervenções para reduzir a mortalidade infantil pré-escolar e materna no Brasil. Revista Brasileira de Epidemiologia, São Paulo, v. 4, n. 1, p. 3-55, 2001.

VIDAL, S. A. et al. Óbitos infantis evitáveis em hospital de referencia estadual do Nordeste brasileiro. Revista Brasileira de Saúde Materno Infantil, Recife, v. 3, n.3, p. 281-289, jul./set. 2003.

VIEIRA, L. A. S. A mortalidade infantil como reflexo da desigualdade social e a atenção à saúde. Divulgação em Saúde para Debate, Londrina, n. 24, p. 90-97, dez. 2001.

VON RUEDEN, U. et al. Socioeconomic determinants of health related quality of life in childhood and adolescence: results from a European study. Journal of Epidemiology and Community Health, London, v. 60, p. 130-135, 2006.

WALDMAN, E. A.; MELLO JORGE, M. H.de. Vigilância para acidentes e violência: instrumento para estratégias de prevenção e controle. Ciência \& Saúde Coletiva, São Paulo, v.4, n.1, p.71-79, 1999.

WALDMAN, E. A. Vigilância como prática de Saúde Pública. In: CAMPOS, G.W.S. et al. (Org). Tratado de Saúde Coletiva. São Paulo: Hucitec; Rio de Janeiro: Fiocruz, 2006. p. 487527.

WEN, S.W. et al. Epidemiology of preterm birth and neonatal outcome. Seminars in Neonatology. Ottawa, 2004.

WESTPHAL, M. F. Promoção da saúde e prevenção de doenças. In: CAMPOS, G.W.S. et al. (Org). Tratado de Saúde Coletiva. São Paulo: Hucitec, Rio de Janeiro: Fiocruz, 2006, p. 635667.

WHO- WORLD HEALTH ORGANIZATION. Recent WHO publications on maternal and child health and useful websites. Eastern Mediterranean Health Journal, Geneva, v. 11, n. 4, p. 837-846, 2005a.

WHO- WORLD HEALTH ORGANIZATION. the millennium development goals report. 16 Sept. 2005b. Disponível em: <http:/ /www.millenniumcampaign.org> Acesso em: 2007.

WHO- WORLD OF HEALTH ORGANIZATION. Carta de Ottawa. Ottawa, 1986. Disponível em: < http://www.opas.org.br/promocao/uploadArq/Ottawa.pdf>. Acesso em: 20 jun. 2007.

YUNES, J.; RONCHENZEL, V.S.C. Evolução da mortalidade geral, infantil e proporcional no Brasil. Revista de Saúde Pública, São Paulo, v. 8, p. 3-48, 1974. Suplemento. 


\section{SECRETARIA DE ESTADO DA SAÚDE COMITÊ ESTADUAL DE PREVENÇÃO DA MORTALIDADE INFANTIL}

\section{FICHA CONFIDENCIAL \\ DE INVESTIGAÇÃO OBITO INFANTIL NEONATAL $L_{(A T E ́ \text { 27 dias })}$}

I. Identificação: (Dados da D.O. e D.N.)
Anexar cópia :

$$
\text { D.O.+D.N.V.( ) }
$$

Carteirinha de pré-natal ( )

Pront. da Unidade de Saúde (Cça) ( ) Pront. da Unidade de Saúde (mãe,pré-natal) ( )

Pront. Hospitalar Cça (todas internações) ( )

Pront. Hospitalar mãe (parto, se necessário) ( )

Receitas e exames de ambos, se houver ( )

Relatório do Sis-pré-natal ( )

Análise do Comitê Municipal ( )

\begin{tabular}{|c|c|c|c|c|}
\hline Nome da criança & & & & \\
\hline Nome da mãe & & & \multicolumn{2}{|c|}{ Idade da Mãe: } \\
\hline \multicolumn{5}{|l|}{ Endereço } \\
\hline \multicolumn{5}{|l|}{ Ponto de referência: } \\
\hline Bairro & Distrito & & Mur & \\
\hline Data de nascimento & 1 & Sexo & masculino & 2 feminino \\
\hline
\end{tabular}

II. Dados do Óbito: (Dados da D.O.)

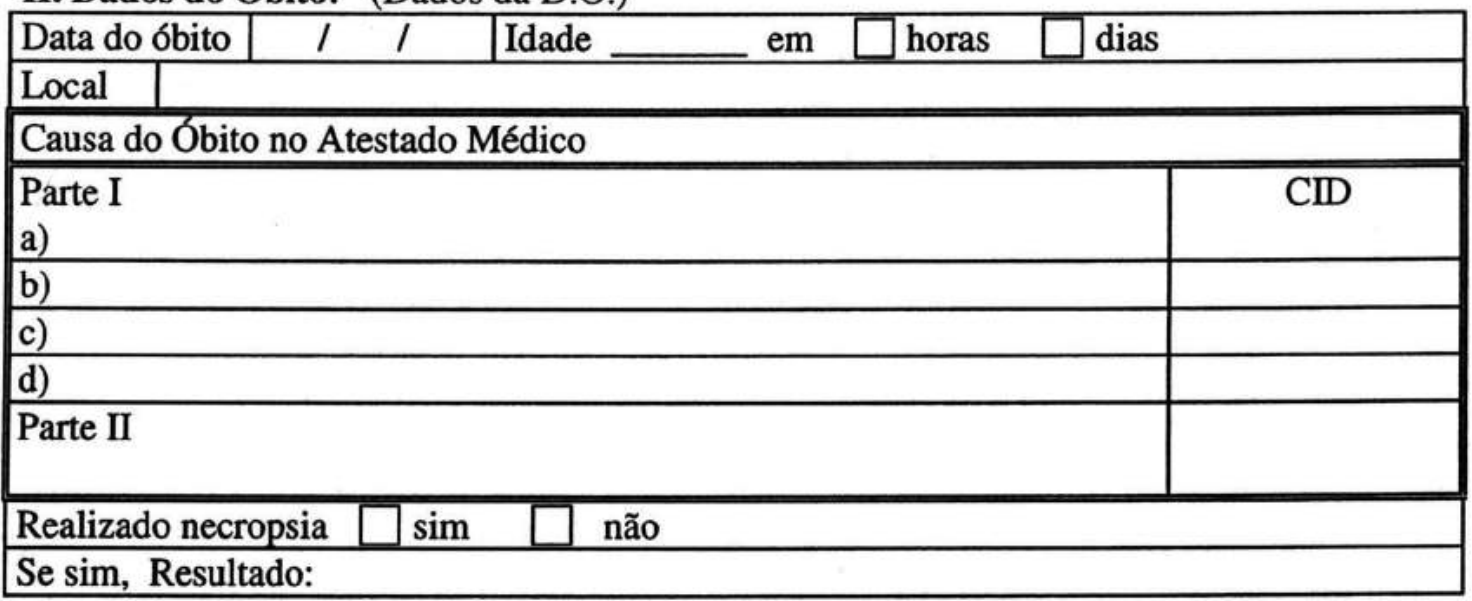

\section{Dados do Pré-natal}

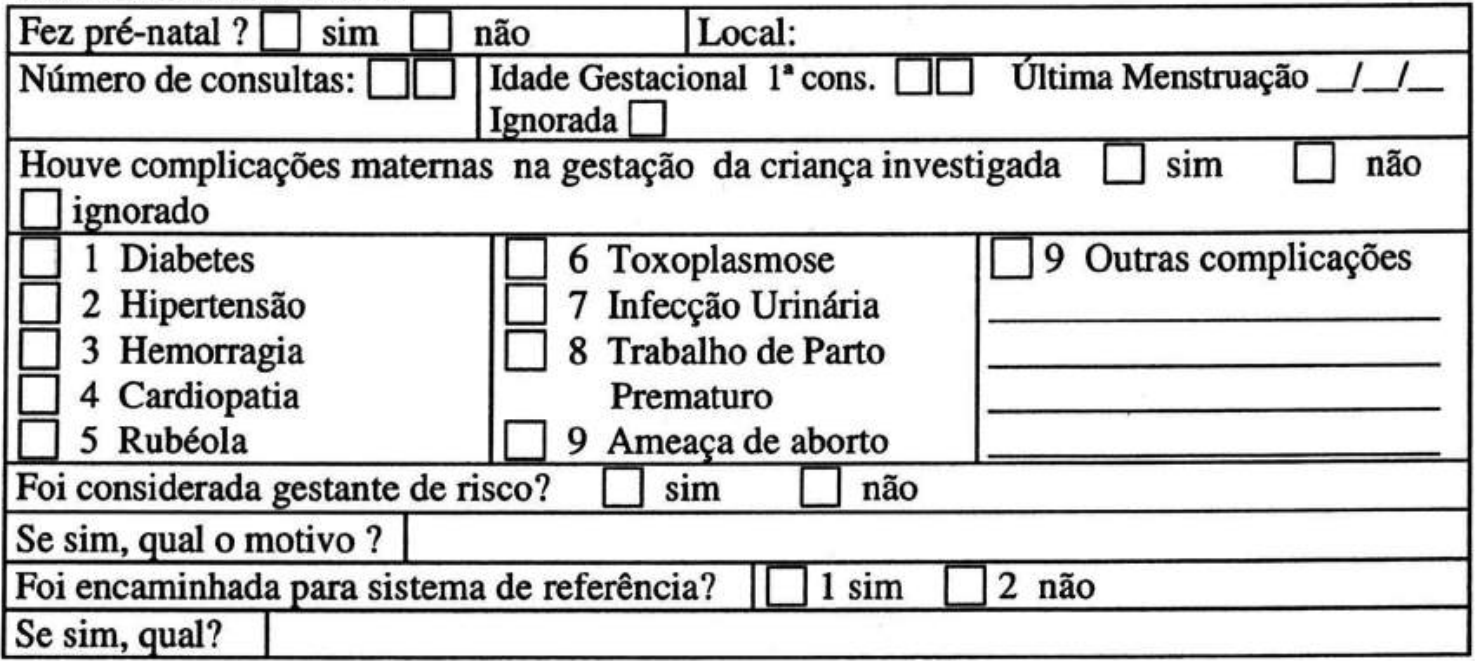


Exames laboratoriais no pré-natal

\begin{tabular}{|c|c|c|c|}
\hline Exame & Datas / Resultados & Exame & Datas/Resultados \\
\hline Tipo Sangüíneo & & Glicemia & \\
\hline Hemoglobina & & Toxoplasmose & \\
\hline V.D.R.L. & & HBSAg & \\
\hline Urina I & & HIV & \\
\hline Outros & & & \\
\hline Vacinação Antitetânica completa: & $\square$ 1 sim $\square$ 2 não & Número de doses: \\
\hline
\end{tabular}

Dados da : C ARTEIRA OU FICHA DE PRÉ-NATAL

\begin{tabular}{|c|c|l|l|l|l|l|l|}
\hline Data & $\begin{array}{c}\text { Sem. } \\
\text { Gest. }\end{array}$ & Peso & P.A. & A.U. & B.C.F. & Edema & $\begin{array}{c}\text { Intercorrências / } \\
\text { terapêutica }\end{array}$ \\
\hline & & & & & & & \\
\hline & & & & & & & \\
\hline & & & & & & & \\
\hline & & & & & & & \\
\hline & & & & & & & \\
\hline & & & & & & & \\
\hline & & & & & & & \\
\hline & & & & & & & \\
\hline
\end{tabular}

IV. Dados do parto: ( a serem extraídos do prontuário hospitalar materno e D.N.)

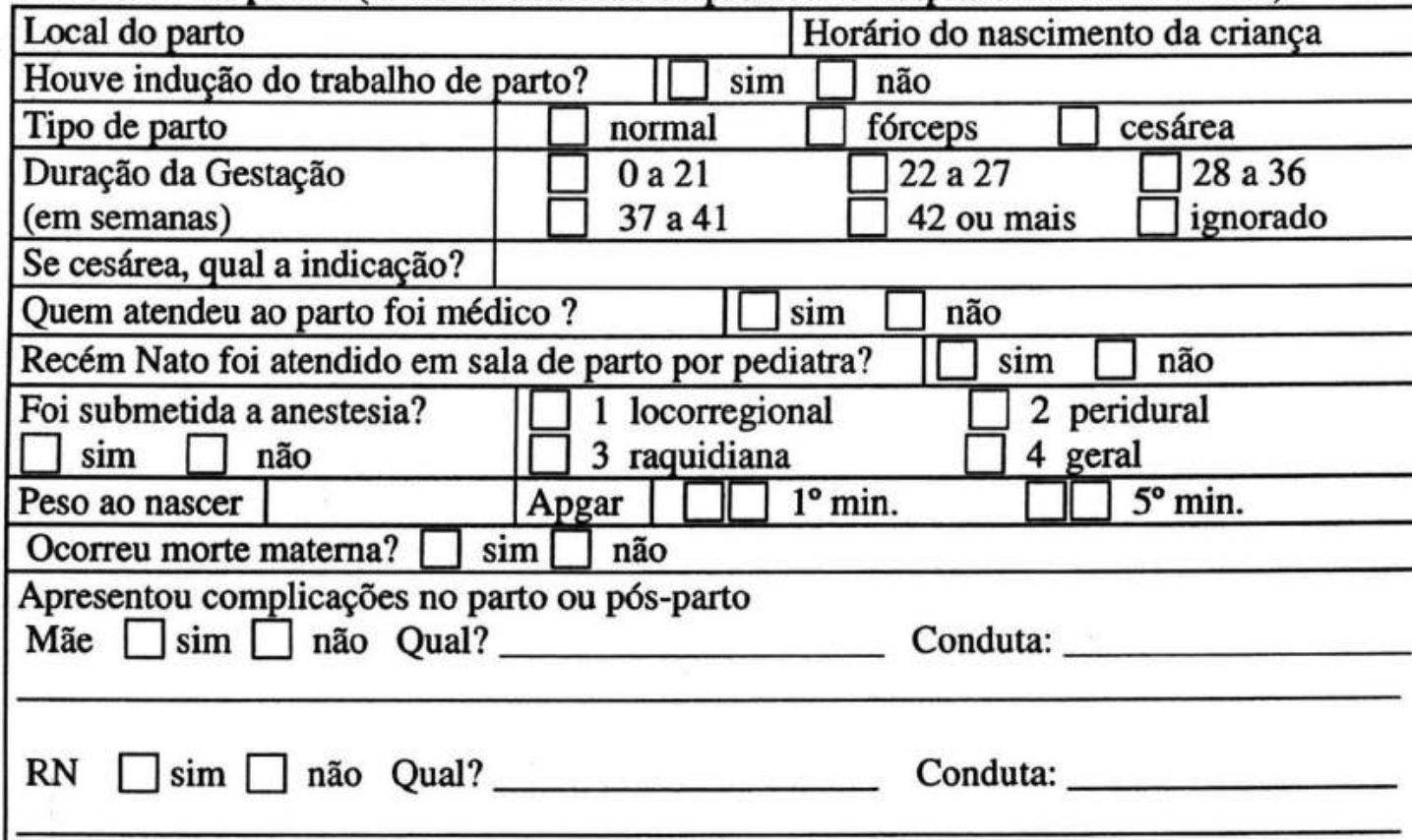


V. Dados do prontuário hospitalar da criança:

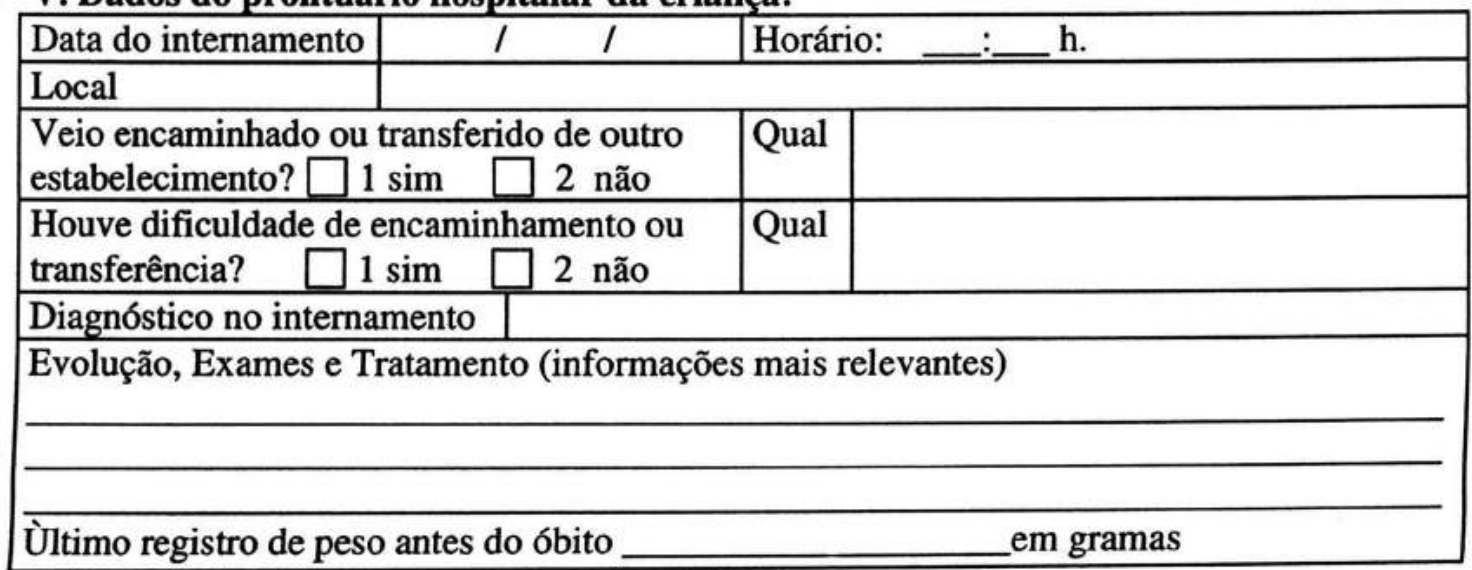

VI. Visita Domiciliar:

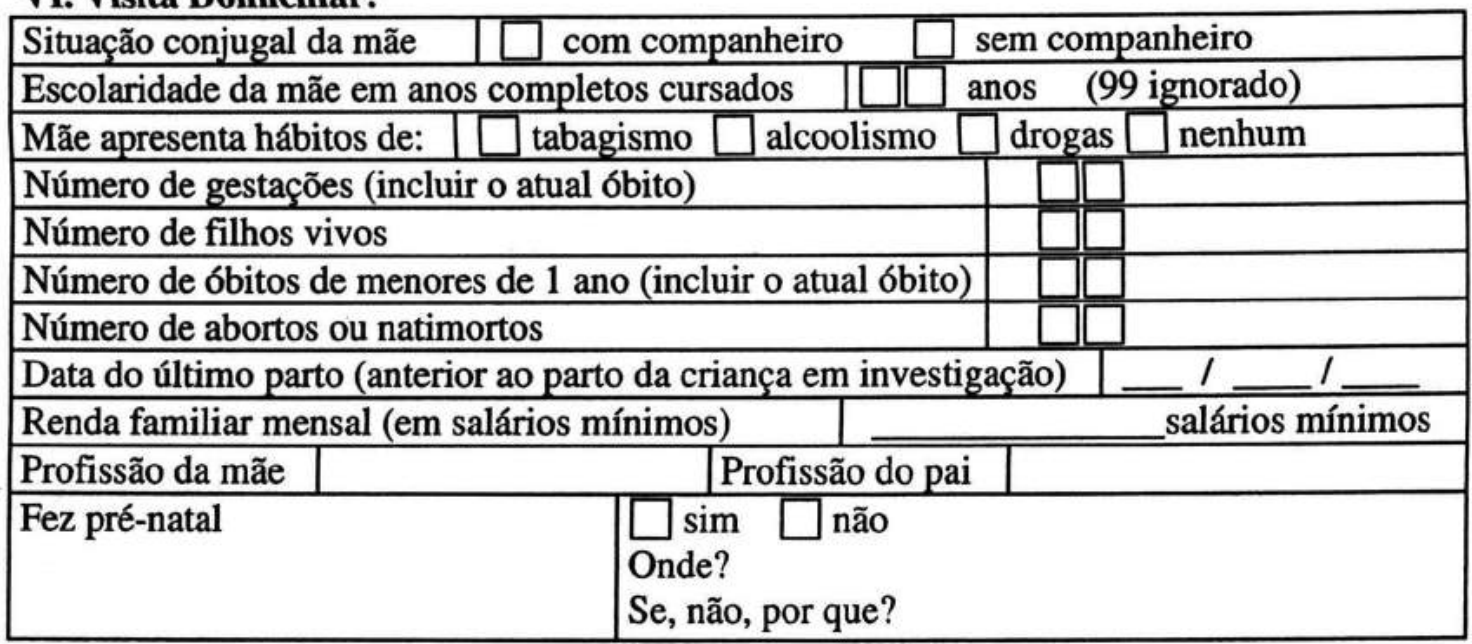

Informações sobre o parto da criança em investigação:

\begin{tabular}{|l|l|l|}
\hline Quanto tempo durou o trabalho de parto? & $\square \square$ horas \\
\hline
\end{tabular}

Quantos serviços procurou até ser atendida para o parto? $\square \square$ serviços

Como foi o atendimento do parto e quem fez o parto?

Tempo decorrido do início do trabalho de parto até o atendimento: $\square \square$ (horas)

Sobre internações anteriores da criança:

\begin{tabular}{|l|l|}
\hline Houve internações anteriores? $\square \operatorname{sim} \square$ não $\quad$ Quantas? $\square \square$ \\
\hline Motivo:
\end{tabular}


Sobre a doença que levou a criança à morte:

\begin{tabular}{|l|c|l|l|}
\hline $\begin{array}{l}\text { Data dos primeiros } \\
\text { sintomas }\end{array}$ & $/ \quad /$ & Quais? & \\
\hline & \\
\hline Onde foi atendido: \\
\hline Teve fácil atendimento? \\
\hline O que foi feito? $\square$ sim $\square$ não \\
\hline Qual a sua opinião sobre o atendimento: \\
\hline Na sua opinião do que seu filho morreu:_ \\
\hline
\end{tabular}

Data da Conclusão da Investigação:

Quem investigou:

Função: 


\section{ANEXO 2}

FICHA CONFIDENCIAL DE INVESTIGAÇÃO DE ÓBITO INFANTIL TARDIO 
SECRETARIA DE ESTADO DA SAÚDE

COMITÊ ESTADUAL DE PREVENÇÃO DA MORTALIDADE INFANTIL

FICHA CONFIDENCIAL DE

INVESTIGAÇÃO DE ÓBITO

INFANTIL

Tardio ( 28 dias até 1 ano)
Para enviar ao Comitê Regional, anexar cópia :

D.O.+ D.N.( )

Carteirinha de pré-natal ( )

Pront. da Unidade de Saúde (Cça) ( )

Pront. da Unidade de Saúde (mãe,pré-natal) ( )

Pront. Hospitalar Cça (todas internações) ()

Pront. Hospitalar mãe (parto, se necessário) ( )

Receitas e exames de ambos, se houver ( )

Relatório do SIS-Pré-Natal ()

Análise do Comitê Municipal ( )

I. Identificação:

D.O. $\mathrm{n}^{\circ}$

D.N. $\mathrm{n}^{\circ}$

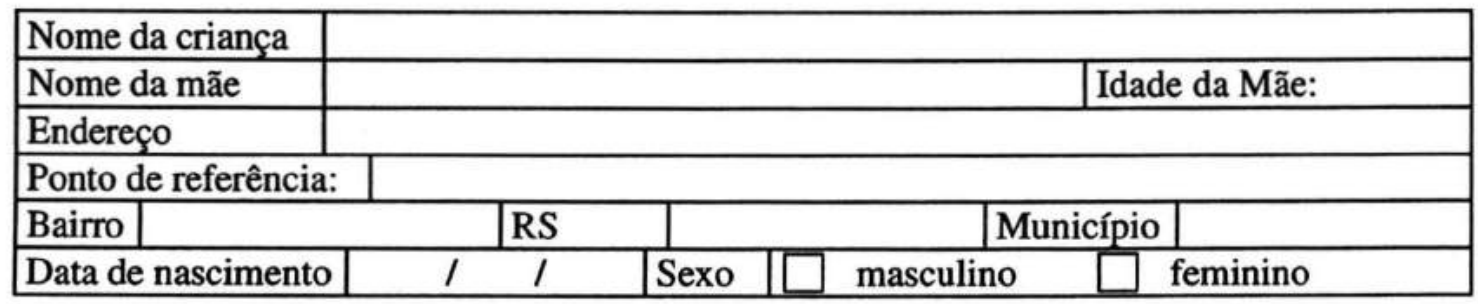

II. Dados do Óbito: (Dados da D.O.)

\begin{tabular}{|l|l|l|}
\hline Data do óbito $1 / \quad$ Idade _ em $\square$ dias & meses \\
\hline Local $\quad$ CID & \\
\hline Causa do Obito no Atestado Médico & \\
\hline $\begin{array}{l}\text { Parte I } \\
\text { a) }\end{array}$ & \\
\hline b) & \\
\hline c) & \\
\hline Parte II & \\
\hline & \\
\hline Realizado necropsia $\square$ 1 sim $\square$ 2 não \\
\hline Se sim, Resultado: \\
\hline
\end{tabular}

III. Dados do parto da criança em investigação: (prontuário e D.N.)

\begin{tabular}{|l|l|l|l|}
\hline Tipo de parto & $\square$ normal $\square$ fórceps $\square$ cesárea \\
\hline Peso ao nascer & Apgar \\
\hline Duração da gestação $\square \square$ Semanas \\
\hline $\begin{array}{l}\text { Foi incluído em programa de } \\
\text { busca ativa ao RN de risco? }\end{array}$ \\
\hline
\end{tabular}




\section{Dados do prontuário ambulatorial / puericultura (Unidade de Saúde):}

\begin{tabular}{|l|l|l|}
\hline Local & Data da $1^{\text {a }}$ consulta \\
\hline Número de atendimentos entre o nascimento e o óbito & $\square \square$ médico \\
\hline Evolução: Idade/peso/Doenças que apresentou/Tratamentos \\
\hline
\end{tabular}

\section{Dados do prontuário hospitalar da criança na ocasião do óbito:}

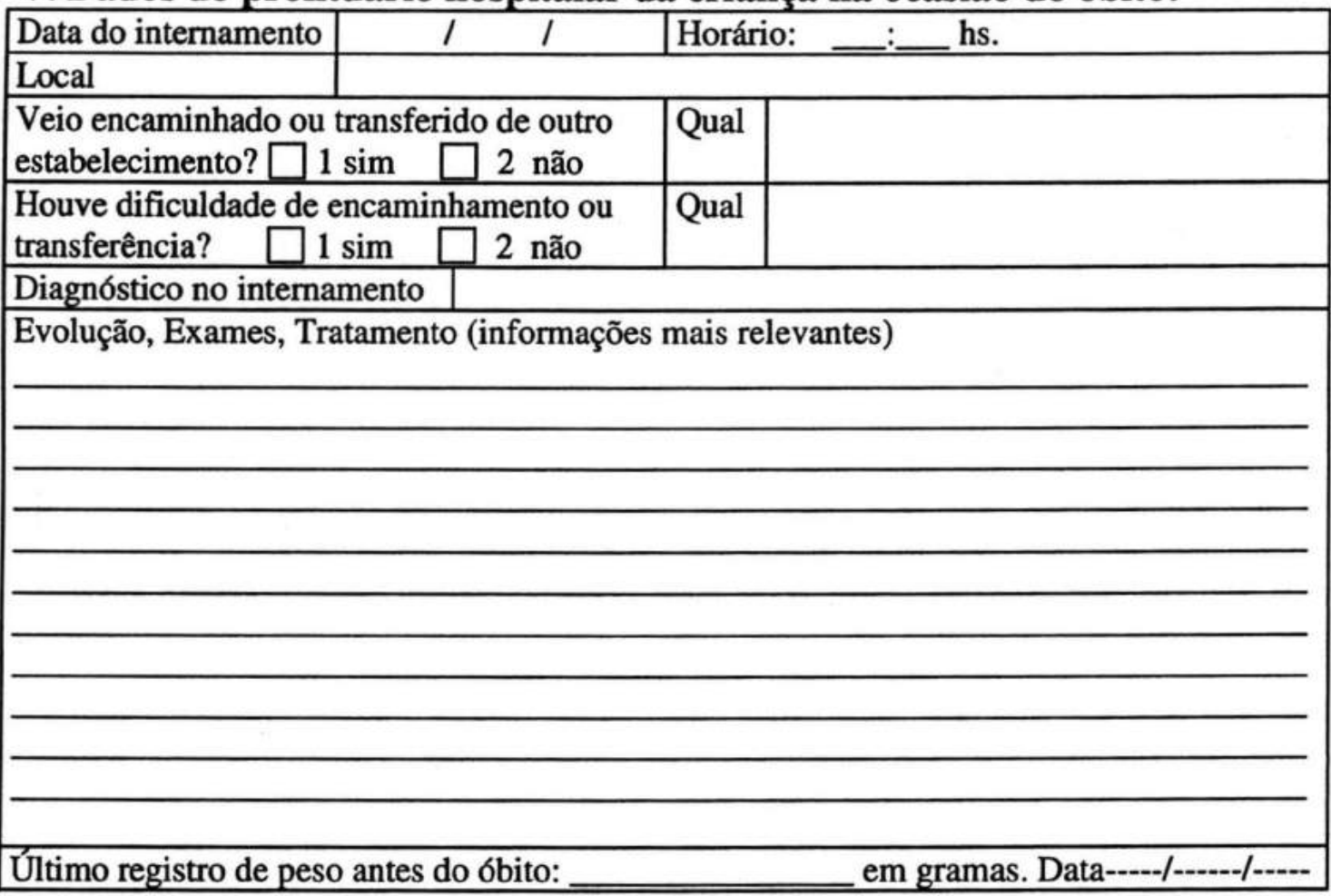




\section{Visita Domiciliar:}

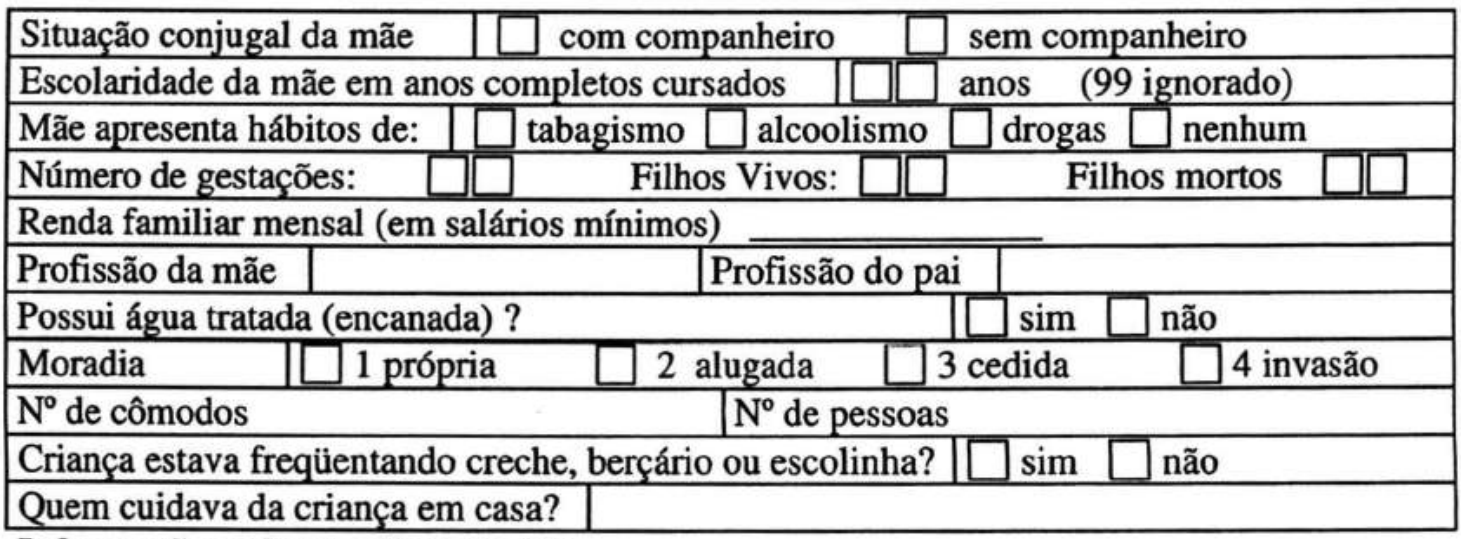

Informações sobre a alimentação:

\begin{tabular}{|c|c|c|}
\hline Tempo de aleitamento materno: & meses & \\
\hline Idade de início da mamadeira: & meses & nunca \\
\hline Idade de início de outros alimentos: & meses & nunca \\
\hline
\end{tabular}

\section{Sobre internações anteriores da criança:}

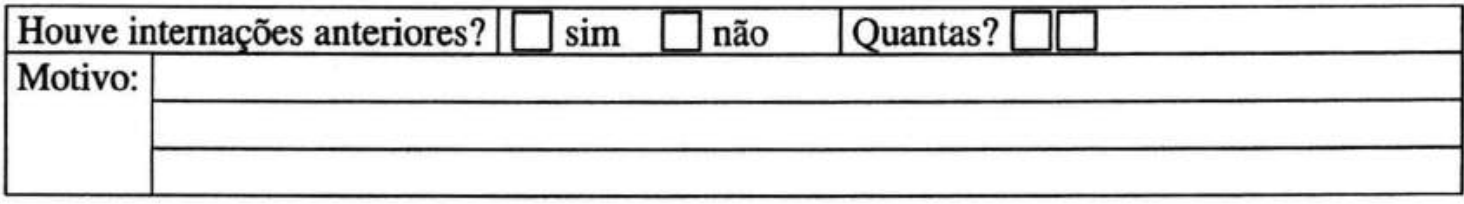

\section{Sobre a doença que levou a criança à morte:}

\begin{tabular}{|l|ll|l|l|}
\hline $\begin{array}{l}\text { Data dos primeiros } \\
\text { sintomas }\end{array}$ & $/ \quad /$ & Quais? & \\
\hline Onde foi atendido: \\
\hline Teve fácil atendimento $\square$ sim $\square$ não \\
\hline O que foi feito: \\
\hline
\end{tabular}

Qual sua opinião sobre o atendimento?

Na sua opinião do que seu filho morreu?

Data da conclusão da investigação:

Quem investigou:

Função: 


\section{ANEXO 3}

FICHA DE ANÁLISE FINAL DO ÓBITO 


\section{COMITÊ ESTADUAL DE PREVENÇÃO DA MORTALIDADE INFANTIL}

Análise do Óbito Infantil - Comitê ( ) Municipal

( ) Regional

( ) Estadual Data da Análise:

Regional de Saúde de Residência

Município de Residência:

\begin{tabular}{|l|l|l|l|l|}
\hline $\mathrm{N}^{\circ}$ DO: & Data de nasc. & Hora do nasc.: & Data do óbito: & Hora do óbito: \\
\hline $\mathrm{N}^{\circ}$ da D. N: & Sexo: & \multicolumn{2}{|l}{} \\
\cline { 1 - 2 } & &
\end{tabular}

I-Análise do Óbito:

\begin{tabular}{l}
\hline I-Análise do Obito: \\
\hline \\
\hline \\
\hline \\
\hline \\
\hline \\
\hline \\
\hline
\end{tabular}

\begin{tabular}{|l|l|}
\hline III - CID & Causa básica do óbito após investigado \\
\hline
\end{tabular}

V - Morte evitável:

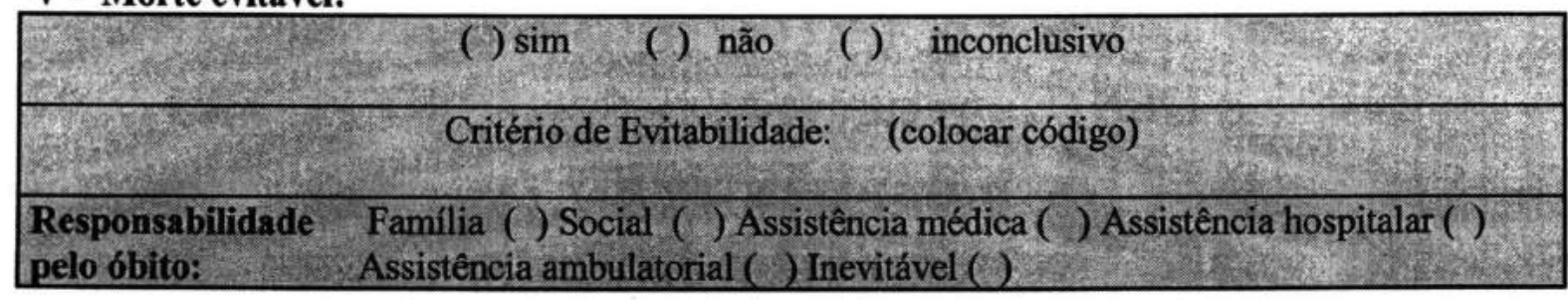

V I - Medidas de prevenção: (colocar código)

VII - Qualidade dos dados da ficha de investigação

( ) Satisfatória

( ) Pouco satisfatória

( ) Insatisfatória

VII - Membros Presentes:

Profissão

\begin{tabular}{|l|l|}
\hline & \\
\hline & \\
\hline & \\
\hline & \\
\hline & \\
\hline
\end{tabular}


ANEXO 4 CRITÉRIOS DE REDUTIBILIDADE PARA O ÓBITO INFANTIL 


\section{CRITÉRIOS DE REDUTIBILIDADE - Óbito Infantil - (antes critérios de evitabilidade)}

\begin{tabular}{|l|l|}
\hline GRUPO A: óbitos reduzíveis por imunoprevenção \\
\hline $01-\mathrm{A} 15$ a A19 & Tuberculose \\
\hline $02-\mathrm{A} 35$ & Tétano \\
\hline $03-\mathrm{A} 33$ & Tétano Neonatal \\
\hline $04-\mathrm{A} 36$ & Difteria \\
\hline $05-\mathrm{A} 37$ & Coqueluche \\
\hline $06-\mathrm{A} 80$ & Poliomielite Aguda \\
\hline $07-\mathrm{B} 01$ & Varicela \\
\hline $08-\mathrm{B} 05$ & Sarampo \\
\hline $09-\mathrm{B} 16$ & Hepatite B \\
\hline $10-\mathrm{G} 00.0$ e G00.1 & Meningite por Haemophilus influenzae / pneumocócica \\
\hline $11-\mathrm{P} 35.0$ & Rubéola Congênita \\
\hline $12-\mathrm{A} 08.0$ & Enterite por Rotavírus \\
\hline
\end{tabular}

\begin{tabular}{|l|l|}
\hline GRUPO B: Óbitos reduzíveis por adequada atenç̃̃o à gestação \\
\hline $01-\mathrm{A} 50$ & Sífilis congênita \\
\hline $02-\mathrm{P} 00$ e P04 & Afecções maternas que afetam feto e RN \\
\hline $03-\mathrm{P} 01$ & Complicações maternas que afetam feto e RN \\
\hline $04-\mathrm{P} 02.0$ & Feto e RN afetados por placenta prévia \\
\hline $05-\mathrm{P} 02.1$ & Feto e RN afetados por descolamento da placenta \\
\hline $06-\mathrm{P} 02.2$ & Feto e RN afetados por anormalidades da placenta \\
\hline $07-\mathrm{P} 02.3$ & Feto e RN afetados por síndromes de transfusão placentária \\
\hline $08-\mathrm{P} 02.4$ a P02.9 & $\begin{array}{l}\text { Complicações do cordão umbilical e das membranas que afetam feto e } \\
\text { RN }\end{array}$ \\
\hline $09-\mathrm{P} 05$ & Crescimento fetal retardado e desnutricão fetal \\
\hline $10-\mathrm{P} 07$ & $\begin{array}{l}\text { Transtornos. Relacionados com a gestação de curta duração e baixo } \\
\text { peso ao nascer }\end{array}$ \\
\hline $11-\mathrm{P} 37.1$ & Toxoplasmose congênita \\
\hline $12-\mathrm{P} 55$ e P56 & Isoimunização do feto e RN \\
\hline $13-\mathrm{P} 70$ & $\begin{array}{l}\text { Transtornos transitórios do metabolismo dos carboidratos específicos } \\
\text { do feto e RN }\end{array}$ \\
\hline $14-\mathrm{P} 00.0$ & Feto e recém-nascido afetados por transtornos maternos hipertensivos \\
\hline $15-\mathrm{P} 00.1$ & $\begin{array}{l}\text { Feto e recém-nascido afetados por doenças maternas renais e das vias } \\
\text { urinárias }\end{array}$ \\
\hline $16-\mathrm{P} 01.1$ & Feto e recém-nascido afetados por ruptura prematura das membranas \\
\hline
\end{tabular}

\begin{tabular}{|l|l|}
\hline Grupo C: Óbitos reduzíveis por adequada atenção ao parto \\
\hline $01-\mathrm{P} 03$ & Complicações do trabalho de parto que afetam feto e RN \\
\hline $02-\mathrm{P} 08$ & $\begin{array}{l}\text { Transtornos relacionados com a gestação prolongada e peso elevado } \\
\text { ao nascer }\end{array}$ \\
\hline $03-\mathrm{P} 10$ a P15 & Traumatismo de parto \\
\hline $04-\mathrm{P} 20$ e P21 & Hipóxia intra-uterina/ Sofrimento fetal / Asfixia ao nascer \\
\hline
\end{tabular}




\begin{tabular}{|l|l|}
\hline Grupo D: Óbitos reduzíveis por adequada atenção ao recém nato \\
\hline 01 - P22 a P29 (exceto P24.0) & $\begin{array}{l}\text { Transtornos respiratórios e cardiovasculares específicos do } \\
\text { período perinatal }\end{array}$ \\
\hline $\begin{array}{l}\text { 02 - P35 a P39 (exceto P35.0 e } \\
\text { P37.1) }\end{array}$ & Infecções específicas do período perinatal \\
\hline $\begin{array}{l}\text { 03 - P50 a P61 (exceto P55 e } \\
\text { P56) }\end{array}$ & Transtornos hemorrágicos e hematológicos do feto e RN \\
\hline $04-$ P71 a P74 & Transtornos endócrinos e metabólicos transitórios do feto e RN \\
\hline $05-$ P75 a P78 & Transtornos do aparelho digestivo do feto e RN \\
\hline 06 - P80 a P83 & $\begin{array}{l}\text { Afecções que comprometem o tegumento e a regulação térmica } \\
\text { do RN }\end{array}$ \\
\hline $07-$ P96.0 & Insuficiência renal no RN \\
\hline
\end{tabular}

\begin{tabular}{|c|c|}
\hline \multicolumn{2}{|c|}{ Grupo E: Óbitos reduzíveis por diagnóstico e tratamento precoce } \\
\hline \multicolumn{2}{|c|}{\begin{tabular}{|c|c|} 
E I. DOENÇAS INFECCIOSAS E PARASITÁRIAS \\
\end{tabular}} \\
\hline $01-\mathrm{A} 00$ a A09 & Doenças infecciosas intestinais \\
\hline 02 - A20 a A49 (exceto A35, A36 e A37) & Doenças bacterianas \\
\hline $03-\mathrm{A} 81$ a $\mathrm{A} 89$ & Viroses do SNC (meningite viral) \\
\hline $04-\mathrm{A} 90$ a A99 & Arboviroses e febres hemorrágicas virais \\
\hline $05-\mathrm{B} 00$ a B09 (exceto B05 e B06) & Infecções virais \\
\hline $06-\mathrm{B} 15$ a B17 e B19 & Hepatite aguda $\mathrm{A}$ e outras \\
\hline $07-\mathrm{B} 20$ a B24 & Doença pelo HIV \\
\hline $08-\mathrm{B} 25$ a B34 & Outras doenças por vírus \\
\hline \multicolumn{2}{|c|}{ E II. DOENÇAS DAS GLÂNDULAS ENDÓCRINAS E METABÓLICAS } \\
\hline $09-\mathrm{E} 00$ a E07 & Transtornos da glândula tireóide \\
\hline $10-\mathrm{E} 10$ a E14 & Diabetes mellitus \\
\hline $11-\mathrm{E} 20$ a E35 & Transtornos de outras glândulas endócrinas \\
\hline $12-\mathrm{E} 40$ a $\mathrm{E} 46$ & Desnutrição \\
\hline $13-\mathrm{E} 63$ & Outras deficiências nutricionais \\
\hline $14-\mathrm{E} 70$ a E90 & Distúrbios metabólicos \\
\hline \multicolumn{2}{|c|}{ E III. DOENÇAS DO SISTEMA NERVOSO CENTRAL } \\
\hline $15-\mathrm{G} 00$ e G03 (exceto G00.0) & Meningite \\
\hline $16-\mathrm{G} 04$ & Encefalite, mielite e encefalomielite \\
\hline $17-\mathrm{G} 09$ & Seqüelas de doenças inflamatórias do SNC \\
\hline $18-\mathrm{G} 80$ & Paralisia cerebral infantil \\
\hline $19-\mathrm{G} 91$ & Hidrocefalia \\
\hline \multicolumn{2}{|c|}{ E IV. DOENÇAS DO APARELHO CIRCULATÓRIO } \\
\hline $20-\mathrm{I} 00$ a I99 & Doenças do aparelho circulatório \\
\hline \multicolumn{2}{|c|}{ E V. DOENÇAS DO APARELHO RESPIRATÓRIO } \\
\hline $21-\mathrm{J} 00$ a J06 & Infecções agudas nas vias aéreas superiores \\
\hline $22-\mathrm{J} 12$ a J21 & Pneumonia \\
\hline 23 - J80 a J99 & Outras doenças do aparelho respiratório \\
\hline
\end{tabular}




\begin{tabular}{|c|c|c|c|}
\hline \multicolumn{4}{|c|}{ E VI. DOENÇAS DE OUTROS ÓRGÃOS OU APARELHOS } \\
\hline \multicolumn{3}{|c|}{$\begin{array}{l}24-\text { D } 50 \text { a D77 (exceto D50.9, D52.9, D53.0 e } \\
\text { D53.2) D80 a D } 89\end{array}$} & Doenças do sangue e órgãos hematopoiéticos \\
\hline \multicolumn{3}{|l|}{$25-\mathrm{K} 00$ a K93 } & Doenças do aparelho digestivo \\
\hline \multicolumn{3}{|l|}{$26-\mathrm{N} 00$ a N99 } & Doenças do aparelho genitourinário \\
\hline \multicolumn{3}{|l|}{27 - L00 a L99 } & Doenças da pele e tecido subcutâneo \\
\hline \multicolumn{4}{|c|}{ Grupo F: Óbitos reduzíveis por adequada atenção, orientação e cuidado com a criança } \\
\hline $01-\mathrm{W} 65$ a W74 & \multirow{2}{*}{\multicolumn{3}{|c|}{ Afogamento }} \\
\hline $02-$ W85 a W99 & & \\
\hline $03-\mathrm{W} 00$ a W19 & \multicolumn{3}{|l|}{ Quedas } \\
\hline $04-\mathrm{V} 01$ a V99 & \multicolumn{3}{|c|}{ Acidentes de transporte (inclui atropelamentos) } \\
\hline $\begin{array}{r}05-\mathrm{X} 00 \text { a Y98,W00 a } \\
\text { W77 }\end{array}$ & \multicolumn{3}{|c|}{ Outras mortes violentas } \\
\hline $06-\mathrm{W} 75, \mathrm{~W} 78$ a W84 & \multicolumn{3}{|c|}{ Sufocação, Broncoaspiração de conteúdo gástrico, corpo estranho, etc. } \\
\hline \multicolumn{4}{|c|}{ Grupo G: Óbito vinculado ao risco pela malformação congênita (viável) } \\
\hline $01-\mathrm{Q} 90$ & \multicolumn{3}{|c|}{ Síndrome de Down } \\
\hline $02-\mathrm{Q} 20$ a Q28 & \multicolumn{3}{|c|}{ Cardiopatias congênitas } \\
\hline $03-\mathrm{Q} 05$ e Q03 & \multicolumn{3}{|c|}{ Mielomeningoceles } \\
\hline $04-\mathrm{Q} 03$ & \multicolumn{3}{|c|}{ Hidrocefalia congênita } \\
\hline \multicolumn{4}{|c|}{ Grupo H: Óbitos por malformações congênitas não viáveis } \\
\hline \multicolumn{2}{|c|}{$01-\mathrm{Q} 00 \mathrm{a} Q 07$ (exceto Q03 e Q05) } & \multicolumn{2}{|c|}{ Malformações do SNC } \\
\hline \multicolumn{2}{|l|}{$\begin{array}{l}02-Q-\text { não mencionadas nas } \\
\text { classificaçóes anteriores }\end{array}$} & \multicolumn{2}{|c|}{ Outras malformações congênitas } \\
\hline \multicolumn{4}{|c|}{ Grupo I: Óbitos por outras causas mal definidas } \\
\hline $\begin{array}{l}01-\mathrm{P} 90 \text { a P96 (exceto } \\
\text { P96.0) }\end{array}$ & \multicolumn{3}{|c|}{ Outros transtornos do período perinatal } \\
\hline 02 - R00 a R99(exceto R95) & \multicolumn{3}{|c|}{ Sinais, sintomas e achados anormais não classificados em outra parte } \\
\hline $03-\mathrm{R} 95$ & \multicolumn{3}{|c|}{ Síndrome da morte súbita na infância } \\
\hline \multicolumn{4}{|c|}{ Grupo J: Óbitos dificilmente reduzíveis } \\
\hline $11-\mathrm{C} 00$ a C97 & \multicolumn{3}{|c|}{ Neoplasias } \\
\hline
\end{tabular}




\section{CRITÉRIOS DE REDUTIBILIDADE - Óbito Fetal-}

\begin{tabular}{|l|l|}
\hline GRUPO A: óbitos reduzíveis por imunoprevenção \\
\hline $01-\mathrm{P} 35.0$ & Rubéola Congênita \\
\hline
\end{tabular}

\begin{tabular}{|c|c|}
\hline \multicolumn{2}{|c|}{ GRUPO B: Óbitos reduzíveis por adequada atenção à gestação } \\
\hline $01-\mathrm{A} 50$ & Sífilis congênita \\
\hline $02-\mathrm{P} 00$ e P04 & Afecções maternas que afetam o feto e RN \\
\hline $03-\mathrm{P} 01$ & Complic. Maternas que afetam o feto e RN \\
\hline $04-\mathrm{P} 02.0$ & Feto e RN afetado por placenta prévia \\
\hline $05-\mathrm{P} 02.1$ & Feto e RN afetado por descolamento da placenta \\
\hline $06-\mathrm{P} 02.2$ & Feto e RN afetado por anormal. da placenta \\
\hline $07-\mathrm{P} 02.3$ & Feto e $\mathrm{RN}$ afetados por síndromes de transferência placentária \\
\hline 08 - P02.4 a P02.9 & $\begin{array}{l}\text { Complicações do cordão umbilical e das membranas que afetam o feto } \\
\text { e RN }\end{array}$ \\
\hline $09-\mathrm{P} 05$ & Crescimento fetal retardado e desnutrição fetal \\
\hline $10-\mathrm{P} 55$ e P56 & Isoimunização do RN \\
\hline $11-\mathrm{P} 35$ a P39 & $\begin{array}{l}\text { (exceto P35.0, P36, P38, P39.0, P39.1, P39.3, P39.4) Infecções } \\
\text { específicas do período perinatal }\end{array}$ \\
\hline 12 - P50a P61 & $\begin{array}{l}\text { (exceto P51, P54, P57, P58, P59, P61) Transtornos hemorrágicos e } \\
\text { hematológicos do feto e RN }\end{array}$ \\
\hline 13 - P70 a P74 & $\begin{array}{l}\text { ( exceto P70.2, P70.3, P70.4, P71, P72, P74 ) Transtornos endócrinos } \\
\text { e metabólicos transitórios do feto e RN }\end{array}$ \\
\hline 14 - P75 a P78 & $\begin{array}{l}\text { ( exceto P76, P78.1, P78.2, P78.3 ) Transtornos do aparelho digestivo } \\
\text { do feto e RN }\end{array}$ \\
\hline $15-\mathrm{P} 80$ a P83 & $\begin{array}{l}\text { (exceto P80, P81, P83.0, P83.1, P83.4) Afecções que comprometem } \\
\text { o tegumento e a regulação térmica do feto e RN }\end{array}$ \\
\hline
\end{tabular}

Grupo C: Óbitos reduzíveis por adequada atenção ao parto

\begin{tabular}{|l|l|}
\hline $01-$ P03 & Complicações do trabalho de parto que afetam o feto e RN \\
\hline $02-$ P08 & $\begin{array}{l}\text { Transtornos relacionados com a gestação prolongada e peso elevado } \\
\text { ao nascer }\end{array}$ \\
\hline $03-$ P10 a P15 & Traumatismo de parto \\
\hline $04-$ P20 & Hipóxia intra uterina / Sofrimento fetal \\
\hline
\end{tabular}

\begin{tabular}{|l|l|}
\hline Grupo D: Óbito vinculado ao risco pela malformação congênita (viável) \\
\hline $01-$ Q90 & Síndrome de Down \\
\hline $02-$ Q20 a Q28 & Cardiopatias congênitas \\
\hline $03-$ Q05 e Q03 & Mielomeningoceles \\
\hline
\end{tabular}

\section{Grupo E: Óbitos por malformações congênitas não viáveis}
\begin{tabular}{l|l}
\hline $01-\mathrm{Q} 00$ a Q07 & (exceto Q03 e Q05) Malformações do SNC
\end{tabular}
$02-\mathrm{Q}-$ não mencionadas nas Outras malformações congênitas
classificações anteriores

Grupo F: Óbitos por outras causas mal definidas

\begin{tabular}{l|l}
\hline $01-$ P90 a P96 & Outros transtornos do periodo perinatal \\
\hline
\end{tabular} 
ANEXO 5

MEDIDAS DE PREVENÇÃO E INTERVENÇÃO NA MORTALIDADE INFANTIL 


\section{MEDIDAS DE PREVENCCÃO E INTERVENCCÃO}

\begin{tabular}{|l|l|}
\hline \multicolumn{2}{|l|}{ 1. Medidas de promoção de saúde e prevenção primária } \\
\hline 1.A & Educação em saúde \\
\hline 1.B & Cobertura vacinal adequada \\
\hline 1.C & Planejamento familiar \\
\hline 1.D & Avaliação de risco gestacional \\
\hline 1.E & Acesso ao pré-natal \\
\hline 1.F & Busca ativa à criança de risco \\
\hline
\end{tabular}

\begin{tabular}{|l|l|}
\hline \multicolumn{2}{|l|}{ 2. Medidas para o pré-natal } \\
\hline 2.A & Disponibilidade de consultas \\
\hline 2.B & Qualidade da consulta \\
\hline 2.C & Disponibilidade/realização de exames laboratoriais \\
\hline 2.D & Disponibilidade de medicamentos \\
\hline 2.E & Orientações básicas (hábitos, sinais de trabalho de parto, cuidados com o RN, etc.) \\
\hline 2.F & Vigilância do risco gestacional \\
\hline
\end{tabular}

\begin{tabular}{|c|c|}
\hline 3. Mec & las para atenção ambulatorial infantil \\
\hline 3.A & Acesso ao tratamento \\
\hline 3.B & Adequada assistência (diagnóstico e tratamento) \\
\hline 3.C & Disponibilidade de medicamentos \\
\hline 3.D & Adequado encaminhamento hospitalar (disponibilidade e rapidez) \\
\hline 3.E & Qualidade nas orientações (quanto ao tratamento, quanto a gravidade do caso, retornos) \\
\hline
\end{tabular}

\begin{tabular}{|l|l|}
\hline 4. Medidas para atenção ambulatorial materna \\
\hline 4.A & Acesso ao tratamento \\
\hline 4.B & Adequada assistência (diagnóstico e tratamento) \\
\hline 4.C & Disponibilidade de medicamentos \\
\hline 4.D & Adequado encaminhamento hospitalar (disponibilidade e rapidez) \\
\hline 4.E & Qualidade nas orientações (quanto ao tratamento, quanto a gravidade do caso, retornos) \\
\hline 4.F & Adequado acesso ao tratamento da gestante de alto risco \\
\hline
\end{tabular}

\begin{tabular}{|c|c|}
\hline 5. $\mathrm{Mec}$ & das para atenção hospitalar infantil \\
\hline $5 . \mathrm{A}$ & Garantir acesso ao internamento \\
\hline $5 . \mathrm{B}$ & Presteza e qualidade no atendimento \\
\hline 5.C & Recursos adequados ao atendimento (UTI) \\
\hline 5.D & Disponibilidade terapêutica \\
\hline 5.E & Garantir transporte adequado da criança \\
\hline
\end{tabular}

\begin{tabular}{|l|l|}
\hline 6. Medidas para atenção hospitalar materna \\
\hline $6 . \mathrm{A}$ & Garantir acesso ao internamento \\
\hline 6.B & Presteza e qualidade no atendimento \\
\hline 6.C & Recursos adequados ao atendimento (UTI) \\
\hline
\end{tabular}




\begin{tabular}{|l|l|}
\hline 6.D & Disponibilidade terapêutica \\
\hline 6.E & Garantir transporte adequado da gestante \\
\hline
\end{tabular}

\begin{tabular}{|c|l|}
\hline 7. Medidas de suporte social \\
\hline 7.A & Suplementação alimentar \\
\hline 7.B & Melhoria de infra-estruturas básicas (saneamento, habitação) \\
\hline 7.C & Visita domiciliar \\
\hline 7.D & Apoio ao tratamento de drogadição / alcoolismo \\
\hline 7.E & Outras medidas de apoio à melhoria das condições sociais (escolaridade, renda) \\
\hline 7.F & $\begin{array}{l}\text { Acolhimento familiar, comunitário e institucional à criança, adolescente e gestante de } \\
\text { risco social. }\end{array}$ \\
\hline
\end{tabular}




\section{ANEXO 6}

INSTRUMENTO DE PESQUISA 


\section{INSTRUMENTO DE PESQUISA}

ulo da Pesquisa: Comitês de Prevenção da Mortalidade Infantil no Paraná: uma pesquisa avaliativa

squisadora responsável: Márcia Helena Freire Orlandi

ntificação:

Macrorregional:

Entrevistador: Maicue Heléanci

A pesquisa tem por objetivo realizar uma avaliação das estratégias de Prevenção do Óbito Infantil e do trabalho de alguns mitês Regionais e Muncicipais de Prevenção da Mortalidade Infantil, no estado do Paraná. Quanto ao trabalho dos Comiês serão colhidas umações (facilidades e dificuldades encontradas) de suas diversas fases: de implantação, constituição das equipes, implementação de jes, organização do trabalho de investigação. Buscaremos também conhecer ações exitosas implementadas na regional ou municipioe, que possam servir como exemplo, junto a outros gestores regionais e municipais.

Além disso, temos como objetivo de verificar o impacto social das ações e o perfil de redução dos óbitos de menores de um ano, estigando para isso as caracteristicas de Regionais, no que tange à oferta de serviços de rotina, urgência e emergência a este segmento xlacional.

Com os depoimentos e consultas aos Bancos de Dados sobre Mortalidade Infantil (SIM e SIMI) pretende-se levantar informações abalhá-las de modo a revertê-las em maior reconhecimento sobre o trabalho de Prevenção e dos Comitês, e assim contribuir para a tinuidade do trabalho preventivo.

Informamos que a técnica utilizada para a entrevista não oferece risco de constrangimento e desconforto e, fica assegurada a ada de sua participação na pesquisa a qualquer momento, sem que haja prejuizo.

As entrevistas serão gravadas e transcritas para posterior análise; será mantida cópia para eventual consulta do entrevistado. Será tido sigilo das informaçōes obtidas nas entrevistas que serão lidas e trabalhadas mediante codificação dos entrevistados.

Qualquer dúvida que possa existir sobre esta pesquisa, será respondida pelo pesquisador responsável, durante o trabalho ou pelo ereço no rodapé.

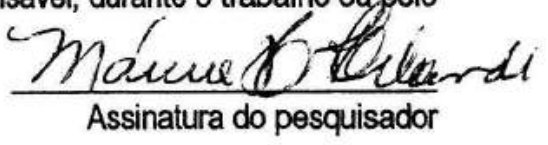

Eu, declaro que recebi informaçōes por - do pesquisador, li sobre a intenção dessa pesquisa, sanei todas as minhas dúvidas e, estou disposto a colaborar com a ma. Não faço objeção à utilização de meu discurso para análise e obtenção de resultados dessa pesquisa, desde que m mantidos os principios éticos.

de de 2007 .

Assinatura do entrevistado

Jentrevistado!

ideve lêr e responder à essas perguntas. Essas informações deverão complementar a pesquisa que será realizada mediante nossa vista.

Regional de Saúde: RS

2. Municipio:

3. Instância de Gestão:

Instituição:

4. Setor:

Profissão:

5. Cargo ou função que ocupa atualmente:

iquanto tempo ocupa esse cargo ou função?

Sexo: ( ) masculino ( ) feminino

8. Idade: anos

Escolaridade e formação superior:

ndamental incompleto edio incompleto perior incompleto. Qual?

( ) fundamental completo

( ) médio completo

( ) técnico. Em?

s-graduação. Em que niveis e área(s)?

( ) superior completo. Qual?

ricipaçăo contribuirá com o aprimoramento da Pesquisa e Avaliaçăo em Saúde, bem como com o Programa de Prevençáo da Mortalidade Infantil, em sua regiāo e iso Paraná. Muito obrigada! 


\section{ENTREVISTA}

As respostas serão gravadas, transcritas e trabalhadas segundo o Método do Discurso do Sujeito Coletivo, no Qualiquantisoft.

\section{PERGUNTAS GENÉRICAS}

1. Você pode me dizer algumas ações, estratégias ou Programas que têm sido desenvolvidos nesse municipio / Regional de Saúde, até por recomendação e incentivo da Secretaria de Saúde do Estado do Paraná, para prevenir-se a morle de uma criança antes de completar seu primeiro ano, ou seja o óbito infantil?

2. (Caso o Programa de Prevenção da Mortalidade Infantil não tenha aparecido na resposta anterior....)

2a Você conhece o Programa de Prevenção da Mortalidade Infantil, mediante o trabalho dos Comitês nos moldes preconizados pelo Estado do Paraná?
( ) Sim
$2 b$ Fale-me um pouco sobre êle. Vai para a pergunta 3a
( ) Não
Não faço nenhuma pergunta. Vai para a pergunta $3 b$.

3. Participação:

3a Aqui nessa Instituição (estadual ou municipal) existe alguma forma de participação nesse Programa? Qual?

OU

3b Aqui se faz alguma coisa que contribua com a prevenção do óbito infantil?

\section{Dificuldades:}

4a Fale-me um pouco sobre as dificuldades passadas para implantação e, no momento, para execução do trabalho dos Comitês / ou de participação nele.

4b Que sugestõs você tem a fazer para que essas dificuldades citadas sejam minimizadas ou sanadas?

\section{Intersetorialidade e Multiprofissionalidade}

5.a. Para se prevenir o óbito infantil é necessário um trabalho intersetorial e multiprofissional, não é mesmo? Fale-me um pouco sobre isso.

6. Rede assistencial.

A prevenção do óbito infantil depende de vários fatores sociais, politicos e organizacionais, não só do setor saúde, mas também de outros setores da sociedade, nao é mesmo?

6a Como você ve a prevenção do óbito infantil em seu municipio / em sua RS?

6b Como está a articulação com os outros municipios dessa Regional de Saúde / com os outros serviços que o muncipio oferece? está a articulação com os outros serviços que o municipio oferece?

6c Em relação ao atendimento Infantil existe sistema de referência e contra-referência eficaz à serviços de urgência $e$ emergência nessa regional / nesse municipio e entre os outros dessa regional de saúde?

\section{PERGUNTAS ESPECÍFICAS}

Para o responsável pelo Comitês de Prevenção da Mortalidade Infantil, na Regional de Saúde, do Município e do Hospital:

7. Como está organizada a estrutura técnica desse Comitê?

8. Desde quando essa estrutura está formada?

9. Existem Comitês Municipais nessa Regional de Saúde? Em quais?

10. Existem Comitês Hospitalares? Em que municipios?

11. Você tem algumas sugestōes que possam ajudar na estrutura e trabalho do Comitê?

Para o técnico responsável pelo Sistema de Informação sobre Mortalidade - SIM e SIMI, na Regional de Saúde e da Secretaria Municipal de Saúde

12. Fale-me um pouco sobre a qualidade do preenchimento das Declarações de Óbito (DOs) a partir do trabalho dos Comitês तo Drovannãn to Mnrtalidarto Infontil 
ANEXO 7

APROVAÇÃO DO COMITÊ DE ÉTICA 


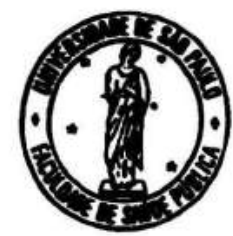

\section{Universidade de São Paulo}

Faculdade de Saúde Pública

COMITÉ DE ÉTICA-COEP

Av. Dr. Arnaldo, 715 - CEP 01246-904 - São Paulo - Brasil

Telefones: (55-11) 3066-7779/7742 - 0-e-mail: coep@fsp.usp.br

\section{Of.COEP/31/05}

16 de fevereiro de 2005

Pelo presente, informo que o Comitê de Ética em Pesquisa da Faculdade de Saúde Pública da Universidade de São Paulo-COEP. analisou e aprovou, em sua 1."\%/05 Sessão Ordinária, realizada em 15.02.05, de acordo com os requisitos da Resolução CNS/196/96, o Protocolo de Pesquisa n. 1207, intitulado: "COMITÊS DE PREVENÇÃO DA MORTALIDADE INFANTIL DO PARANÁ: UMA PESQUISA AVALIATIVA.", apresentado pela pesquisadora Márcia Helena Freire Orlandi.

Atenciosamente.

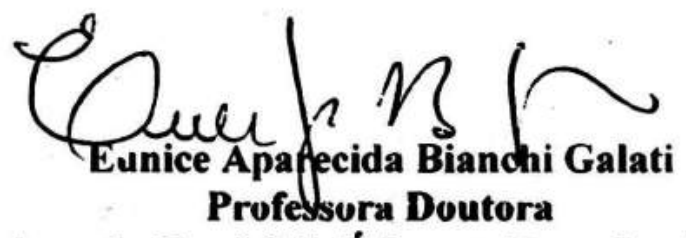

Coordenadora do Comitê de Ética em Pesquisa da FSP-COEP 


\section{ANEXO 8}

\section{REGIONAIS DE SAÚDE DO ESTADO DO PARANÁ}


Regionais de Saúde do estado do Paraná.

\begin{tabular}{|l|l|}
\hline $1^{\mathrm{a}}$ & Paranaguá \\
\hline $2^{\mathrm{a}}$ & Metropolitana \\
\hline $3^{\mathrm{a}}$ & Ponta Grossa \\
\hline $4^{\mathrm{a}}$ & Irati \\
\hline $5^{\mathrm{a}}$ & Guarapuava \\
\hline $6^{\mathrm{a}}$ & União da Vitória \\
\hline $7^{\mathrm{a}}$ & Pato Branco \\
\hline $8^{\mathrm{a}}$ & Francisco Beltrão \\
\hline $9^{\mathrm{a}}$ & Foz do Iguaçu \\
\hline $10^{\mathrm{a}}$ & Cascavel \\
\hline $11^{\mathrm{a}}$ & Campo Mourão \\
\hline $12^{\mathrm{a}}$ & Umuarama \\
\hline $13^{\mathrm{a}}$ & Cianorte \\
\hline $14^{\mathrm{a}}$ & Paranavaí \\
\hline $15^{\mathrm{a}}$ & Maringá \\
\hline $16^{\mathrm{a}}$ & Apucarana \\
\hline $17^{\mathrm{a}}$ & Londrina \\
\hline $18^{\mathrm{a}}$ & Cornélio Procópio \\
\hline $19^{\mathrm{a}}$ & Jacarezinho \\
\hline $20^{\mathrm{a}}$ & Toledo \\
\hline $21^{\mathrm{a}}$ & Telêmaco Borba \\
\hline $22^{\mathrm{a}}$ & Ivaiporã \\
\hline & \\
\hline
\end{tabular}




\section{APÊNDICES}


Ap-1: Distribuição da população residente no Brasil segundo ano e Região Federativa, 1997 a 2005.

\begin{tabular}{l|rrrrrr}
\hline Ano & Norte & Nordeste & Sudeste & Sul & C.Oeste & Total \\
\hline 1997 & 11604203 & 45334474 & 68065809 & 23862627 & 10769184 & 159636297 \\
1998 & 11868731 & 45811262 & 68961230 & 24154142 & 10994817 & 161790182 \\
1999 & 12133636 & 46288935 & 69858187 & 24445843 & 11220835 & 163947436 \\
2000 & 12900704 & 47741711 & 72412411 & 25107616 & 11636728 & 169799170 \\
2001 & 13245016 & 48331118 & 73470738 & 25453492 & 11885412 & 172385776 \\
2002 & 13504612 & 48845219 & 74447443 & 25734111 & 12101547 & 174632932 \\
2003 & 13784895 & 49357119 & 75392023 & 26024981 & 12317233 & 176876251 \\
2004 & 14064278 & 49862741 & 76333625 & 26315184 & 12532306 & 179108134 \\
2005 & 14698834 & 51018983 & 78472036 & 26973432 & 13020789 & 184184074 \\
\hline
\end{tabular}

Fonte: DATASUS / MS. Informaçōes de Saúde. Dados Demográficos, 2007; dados brutos.

Ap-2: Distribuição da população de menor de um ano residente no Brasil segundo ano e Região Federativa, 1997 a 2005.

\begin{tabular}{l|rrrrrr}
\hline Ano & Norte & Nordeste & Sudeste & Sul & C.Oeste & Total \\
\hline 1997 & 300814 & 989324 & 1202300 & 445260 & 223334 & 3161032 \\
1998 & 307912 & 999733 & 1219064 & 450938 & 228433 & 3206080 \\
1999 & 315034 & 1010176 & 1235892 & 456625 & 233552 & 3251279 \\
2000 & 320875 & 996497 & 1236967 & 436747 & 222224 & 3213310 \\
2001 & 329666 & 1008940 & 1255971 & 443091 & 227462 & 3265130 \\
2002 & 336235 & 1019963 & 1273346 & 448274 & 231957 & 3309775 \\
2003 & 343371 & 1030877 & 1290247 & 453643 & 236483 & 3354621 \\
2004 & 350466 & 1041707 & 1307066 & 459028 & 240984 & 3399251 \\
2005 & 366522 & 1066320 & 1345300 & 471196 & 251216 & 3500554 \\
\hline
\end{tabular}

Fonte: DATASUS / MS. Informaçðes de Saúde. Dados Demográficos, 2007; dados brutos.

Ap-3: Distribuição dos óbitos infantis (freq. e \%) com idade ignorada, Brasil, Regiões e estado do Paraná, 1997 a 2004.

\begin{tabular}{|c|c|c|c|c|c|c|c|c|c|c|c|c|c|c|c|c|}
\hline \multirow{2}{*}{$\begin{array}{c}\text { Regiăol } \\
\text { UF }\end{array}$} & \multicolumn{2}{|c|}{1997} & \multicolumn{2}{|c|}{1998} & \multicolumn{2}{|c|}{1999} & \multicolumn{2}{|c|}{2000} & \multicolumn{2}{|c|}{2001} & \multicolumn{2}{|c|}{2002} & \multicolumn{2}{|l|}{2003} & \multicolumn{2}{|c|}{2004} \\
\hline & Freq & $\%$ & Freq & $\%$ & Freg & $\%$ & Freq & $\%$ & Freq & $\%$ & Freq & $\%$ & Freq & $\%$ & Freg & $\%$ \\
\hline Norte & 22 & 0,35 & 8 & 0,12 & 0 & 0,00 & 0 & 0,00 & 3 & 0,04 & 1 & 0,02 & 15 & 0,22 & 16 & 0,25 \\
\hline Nordeste & 221 & 1,00 & 159 & 0,66 & 107 & 0,45 & 28 & 0,11 & 16 & 0,07 & 129 & 0,58 & 122 & 0,56 & 56 & 0,29 \\
\hline Sudeste & 48 & 0,16 & 37 & 0,13 & 40 & 0,15 & 8 & 0,03 & 11 & 0,05 & 84 & 0,43 & 55 & 0,29 & 53 & 0,29 \\
\hline Sul & 0 & 0,00 & 0 & 0,00 & 2 & 0,02 & 3 & 0,04 & 2 & 0,03 & 2 & 0,03 & 1 & 0,02 & 1 & 0,02 \\
\hline $\begin{array}{l}\text {..Paraná } \\
\text { Centro- }\end{array}$ & 0 & 0,00 & 0 & 0,00 & 0 & 0,00 & 3 & 0,09 & 1 & 0,03 & 2 & 0,07 & 1 & 0,04 & 0 & 0,00 \\
\hline Deste & 18 & 0,38 & 28 & 0,60 & 3 & 0,07 & 8 & 0,19 & 9 & 0,22 & 10 & 0,25 & 15 & 0,40 & 13 & 0,33 \\
\hline Brasil & 309 & 0,43 & 232 & 0,32 & 152 & 0,22 & 47 & 0,07 & 41 & 0,07 & 226 & 0,38 & 208 & 0,36 & 139 & 0,26 \\
\hline
\end{tabular}


Ap-4: Taxa de Mortalidade Infantil (\%o NV) segundo Regional de Saúde e Triênios, estado do Paraná, 1997 a 2005.

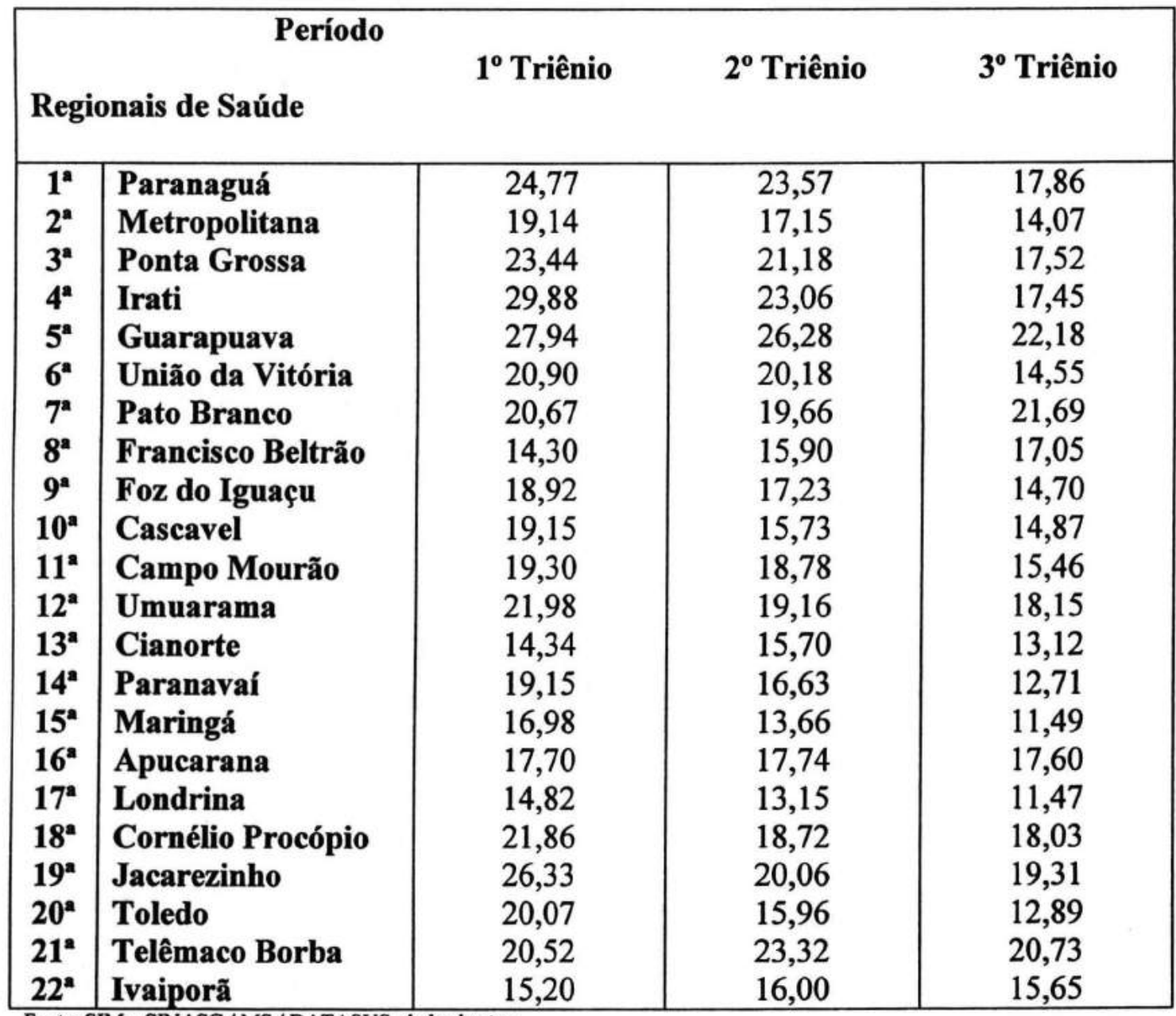

Fonte: SIM e SINASC / MS / DATASUS, dados brutos 
Ap-5: Distribuição dos Nascidos Vivos $\left(n^{\circ}\right)$ segundo Regional de Saúde e ano de ocorrência, estado do Paraná, 1997 a 2005.

\begin{tabular}{l|rrrrrrrr}
\hline Regional de Saúde & 1997 & $\mathbf{1 9 9 8}$ & $\mathbf{1 9 9 9}$ & $\mathbf{2 0 0 0}$ & $\mathbf{2 0 0 1}$ & $\mathbf{2 0 0 2}$ & $\mathbf{2 0 0 3}$ & $\mathbf{2 0 0 4}$ \\
\hline 1 Paranaguá & 5228 & 5005 & 5111 & 4907 & 4653 & 4758 & 4674 & 4714 \\
2 Metropolitana & 55626 & 55455 & 56804 & 53955 & 52202 & 51555 & 48669 & 49029 \\
3 Ponta Grossa & 11616 & 11124 & 11610 & 11011 & 10265 & 10445 & 9902 & 10139 \\
4 Irati & 3154 & 2986 & 3096 & 2996 & 2790 & 2802 & 2635 & 2703 \\
5 Guarapuava & 10129 & 10284 & 10224 & 9960 & 9473 & 8950 & 8603 & 8577 \\
6 União da Vitória & 3486 & 3438 & 3553 & 3627 & 3194 & 3237 & 2957 & 2892 \\
7 Pato Branco & 5135 & 4891 & 4922 & 4810 & 4442 & 4431 & 4393 & 4236 \\
8 Francisco Beltrão & 6572 & 5835 & 5912 & 5705 & 5095 & 5109 & 4849 & 4800 \\
9 Foz do Iguaçu & 9640 & 9303 & 9171 & 8524 & 7707 & 7510 & 6939 & 7076 \\
10 Cascavel & 10088 & 9585 & 9310 & 8682 & 7894 & 7641 & 7414 & 7515 \\
11 Campo Mourão & 6927 & 6327 & 6121 & 5905 & 5463 & 5196 & 4985 & 5010 \\
12 Umuarama & 4618 & 4365 & 4302 & 4165 & 3689 & 3786 & 3461 & 3656 \\
13 Cianorte & 2279 & 2197 & 2151 & 2060 & 1804 & 1806 & 1815 & 1831 \\
14 Paranavaí & 4565 & 4070 & 4213 & 4004 & 3716 & 3706 & 3584 & 3715 \\
15 Maringá & 10836 & 10307 & 10308 & 9963 & 9105 & 9113 & 8824 & 9210 \\
16 Apucarana & 5922 & 5562 & 5406 & 5180 & 4837 & 4807 & 4741 & 4762 \\
17 Londrina & 14335 & 13485 & 13347 & 13612 & 12151 & 12022 & 11501 & 11854 \\
18 Cornélio Procópio & 4984 & 4682 & 4471 & 4274 & 3698 & 3728 & 3418 & 3645 \\
19 Jacarezinho & 5182 & 4833 & 4949 & 4706 & 4475 & 4177 & 4070 & 4112 \\
20 Toledo & 6116 & 5584 & 5391 & 5366 & 5006 & 4915 & 4754 & 4879 \\
21 Telêmaco Borba & 3353 & 3375 & 3557 & 3380 & 3190 & 2992 & 2895 & 3028 \\
22 Ivaiporã & 2921 & 2676 & 2627 & 2581 & 2417 & 2438 & 2250 & 2252 \\
Município ignorado - PR & 45 & 9 & 119 & 89 & 4 & 1 & 0 & 1 \\
\hline Total & 192757 & 185378 & 186675 & 179462 & 167270 & 165125 & $\mathbf{1 5 7 3 3 3}$ & $\mathbf{1 5 9 6 3 6}$ \\
\hline & $506,2007)$ & & & & & & & \\
\hline
\end{tabular}

Fonte: SINASC (MS/BRASIL, 2005, 2006, 2007). 